
$\checkmark$

$\therefore$

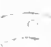









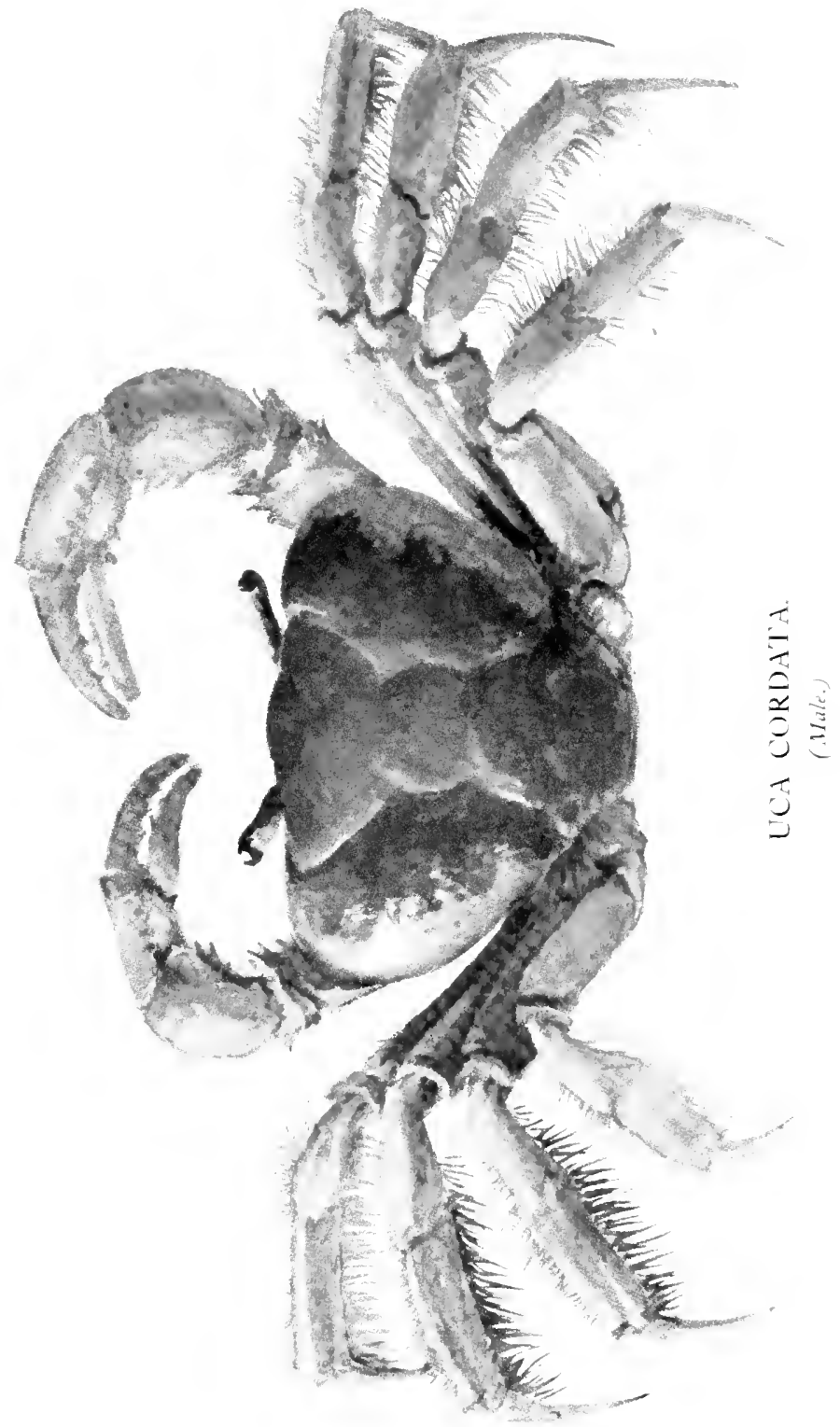


'THE

\title{
STALK-EYED CRUSTACEA
}

$\mathrm{OF}$

\author{
BRITISH GUIANA, WEST INDIES, \\ ANI BERMUDA
}

BY

CHARLES G. YOUNG, M.A., M.D., DUDLIN MEMBER OF THE ROYAL IKISH ACADEMW

IAAELY OF THE BKITISH GUIANA MEDICAI SEKWCF

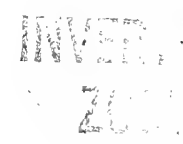

\section{LONDON}

JOHN M. WATKINS

$53 \mathrm{St}$. Martin's Lane 1900 


\section{INTRODUCTION.}

THIs hand-list of the Stalk-Eyed Crustacea of the western tropical and subtropical Atlantic about the West Indian Islands, of these Islands, of the muddy shore and fresh water of British Guiana, and of the fresh water of tropical America, is the result of an attempt to bring together, for the use of collectors, the description, already published in many monographs and periodicals by such naturalists as H. Milne Edwards, Dana, Stimpson, Bell, Sidney Smith, A. Milne Edwards, Kingsley, Miers, Henderson, Spence Bate, Rathbun, Brooks, and many others whose names are mentioned in the text, of these interesting animals. The name of the naturalist is placed opposite the name under which the crustacean has been described by him.

The classification followed is that of $\mathrm{H}$. Milne Edwards for the larger divisions of the two Orders and for the tribes of the Brachyura, otherwise the classification of the latter is that of Mr. E. J. Miers and Mr. J. S. Kingsley; excluding the fresh-water crabs properly so called, the arrangement followed being that of Miss M. J. Rathbun, who has thrown much light on the family, and to whom I take this opportunity of expressing my thanks for the assistance given me; of the Anomoura, that of Professor Henderson and A. Milne Edwards; and of the Macroura, that of Mr. Spence Bate. A list of all the works consulted is given on p. ix, and to them the student is referred for a more full 
description of any specimen mentioned. In these works a number of names unfamiliar to the general public will be met with which I have tried to do without by substituting, where possible, more familiar terms, or numbers.

The following are the various parts to which the reader's attention is drawn.

The carapace, shell, "crab-back." The part that covers the head and chest (cephalo-thorax) in one piece. It is usually marked above with lines indicating the various organs of the body lying beneath. Two lines passing backwards and inwards, starting from the external angles of the orbits, divide it into three portions; one on each lateral margin, one central. Of the regions on the lateral margins, in front, is, on each side, the hepatic region, covering the liver; behind it the branchial region, covering the gills. The central division is divided, from before backwards, into, behind the orbits, the gastric region, covering the stomach; the genital region, covering the organs of generation; then a transverse line; behind the transverse line the cardiac region, covering the heart; and behind this the intestinal region. On the front margin are situated the eyes when present, usually protected by carities, orbits, and placed on movable stalks. The part between the bases of the eye-stalks is the frontal region or front. The margin of the carapace is bounded by an antero-lateral, a postero-lateral, and a posterior border between the bases of the last pair of legs, where the abdomen is attached.

The abdomen may be large or small, covered with a hard substance or with a soft membrane, divided into segments or enclosed in a uniform sack, folded under the body or extended backwards, and may be provided with a terminal fan made up of expansions from the last segment but one and the last segment (the telson), used 
as a swimming organ. The segments may or may not be provided with false feet on their under surface.

The internal antenna, antennules, are thread-like limbs or "feelers," either folded under the front into pits, antennulary fossa, or free and prominent; they are composed of basal joints, and terminate in one or more terminal threads, flagella.

The external antennæ, antennæ, are usually situated near the internal antenne and outside them, nearer to the eyes. They do not rest in pits, are composed of basal joints, and terminate in a long thread, flagellum, usually. They may be very small or very long and strong; sometimes they are in the form of flat plates. The part of the front where these two pairs of organs spring is called the antennary region; below this region, above the mouth, is the epistomian region.

The mouth, buccal cavity, is situated below the epistomian region; and is bounded on the sides by the pterygostomian region, which is the front part of the infero-lateral wall of the carapace.

The external maxillipedes. In crabs these close the mouth like two doors, the fourth and fifth joints being flat. They are sometimes pediform, like feet, and usually have an external appendage (exognath); the internal part is sometimes called the endognath. On the summit of the fourth joint in crabs is seen three very small terminal joints, the fifth, sixth, and seventh joints.

The legs are composed of five pairs, the first pair used as hands usually, anterior legs, pincers, chilipedes, and the four posterior pairs, or walking legs. The first pair only may have pincers or all the legs may have them ; sometimes some of the pairs are modified for various duties, holding, walking, or for swimming : sometimes the last pair is very small and atrophied. 
viii

\section{INTRODUCTION}

In counting the joints of a limb the first joint is counted as two joints, being two small joints soldered together. The first joint is that nearest the body, and the first pair is the two legs nearest the eyes. The eyes, antenna, antennules, and external maxilipedes are considered as legs altered to discharge other duties from that of walking or feeding. Of the legs of the first pair, or of other pairs armed with pincers like them, the fourth and fifth joint may be called arm and forearm; the sixth joint, the hand; the serenth joint, the movable finger, which works against a projection of the sixth joint, called the fixed finger. Among some crustacea the legs have only six joints, and then there is no pincer.

The verges are the organs of generation, and may be seen on the under surface of the animal.

The outline drawings are more or less diagramatic; the plates are from living specimens. About 42 I species are described. 


\section{GENERAL WORKS.}

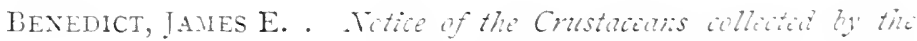
Lis. Sicintitic Expitition to It ist Africt. Smithsonian Institution. United States National Musem. Nashington. 1893.

Beli, Thousas. . A History of the British Stalk-Eyed Crustucer. London, I $8 ; 3$.

DANA, JAIIES 1). . "On the Geographical Distribution of Crustacea," Americun Jommal of Sicnic and $A$ t. and series, vol. xriil. Nor. I $5 ; 4$.

Kingsley. J. S. . . " Notes on North American Decapoda," Proceidings B.S.M.H., vol. xx., May 1879 .

Kingsles, J. S. . . . "On a Collection of Crustacea from Virginia, North Carolina, and Florida." Proceedings of the Academy of Natural Sicnces of Philadelphia, part iii., Nor. and Dec. I8 79 .

MILNe Edwards, H. Histoire Naturelle des Crustaces. Three vols., with plates. Paris, $18_{4}$.

MinRs, EDWARD J. . Catalogue of the Stalk-and Sessile-Ejyed Crustacea of $N_{e i}$ Zicaland. London, $18-6$.

Miers, EDWARD J. . "On a Collection of Crustacea, Decapoda, and Isopoda, chiefly from South America, with Descriptions of New Genera and Species," Proc. Zool. Soc. London, i 877 , No. xliii.

Saussure, Henri de Mimoires pour seritr a l'histoire Naturelle du Merique, des Antilles, et des États-Luis. Genève et Paris, I 858. 
Stimpson, Willian. The Crustace and Echinodomete of the Pacific Shores of North America. Riverside, Cambridge, U.S.A., I857.

Stmipson, Wiltian . "Notes on North American Crustacea, New York," reprinted from the Annals of the Lyceum of Natural History. N. Y., Harch is 59 , April i 860 .

Sidney Suith, I. . " Notice of the Crustacea collected by Professor C. F. Hartt on the Coast of Brazil in I 867," Transactions of the Connecticut Acadinny of Arts and Scicnces. New Haven, I 870.

Sidney Sirti, I. . Report on the Decapod Crustacel of the "Alhatross" Dredgings off the Eust Coast of the United States in $\mathrm{I} 88_{3}$. New Haven, 1884 .

Sidney Salth, I. . . "Result of the Dredgings of the U.S. Ship Blake in 1877, 1878, 1879," Bull. Muc. Comp. Zool. at Haratal College, Cambritge, U.S.A., vol. x., I $882-83$.

WhITE, ADAM Catalogue of British Crustacea in the British Museum. London, I850.

\section{BRACHYURA.}

DaNa, James 1). . "Un the Classification of the Crustacea Grapsoidea," Amcrican Joumal of Sicince and Arts, vol. xii., and series, September I85i.

Kingsley, J. S. . . "Carcinological Notes, No. ii. Revision of the Gelasimi," Proccelings of the Academy of Natural Sciences of Philadelphia, isso.

Kingsley, J. S. . " "Carcinological Notes, No. iii. Revision of the (ienus Ocypoda."

"Garcinological Notes, No. ir. Synopsis of the Grapsidre," Prociedings of the Acadimy of Natural Sciences of Phitadelphiar, April to September isso.

Miers, Edwari J. . "On the Classification of the Maioid Crustacea or Oxyrlyncha, with a Synopsis of the Families, Subfamilies, and Genera, Limn. Soi.Joum. Zool., vol. xiv. London, March I879. 
MIERs, EDWARI J. . Refort on the Brachyzracollated by H.MIS. "Challenger" duringthe I'cars i $873-74$. London, is 86.

MIL.Ne Edwards, A. Mission Sciontifique an Mirique ct dens L'Ancrique Centrali: Paris, 1873. This work has never been published beyond the 8 th part.

Rathbun, Mary J. . "Descriptions of New Species of American Fresh-water Crabs," Prowedings of the United States Netional Museum, vol. xvi. Washington, I893.

R.ithbun, MARY J. . "Descriptions of two New Species of Freshwater Crabs from Costa Rica," Preceedinss of the United Stutis National Museum, vol. xvi. Washington, I893.

R.ithbun, Mary J. . Cirtulogue of the Crabs of the Family Marida in the United States National Museum. Washington, 1893 .

R.sthbun, Mary J. . Votes on the Crahs of the Fomily Inachida in the United States National Museum. Washington, I894.

Rathioun, Mary J. . "The Genus Callinectes," Procedings of the United States National Miuseum, vol. xviii. Washington, I $\$ 96$.

Rathbun, Maky J. "A Contribution to a Kinowledge of the Fresh-water Crabs of America - the Pseudothelphusinie," Procedings of the United States Notional Muscum. Washington, 1898 .

Sidney Suith, I. . "Notes on American Crustacea, No. i. Ocypodoidea," Transuctions of the Connecticut Acadeny of Arts and Sciences. New Haven, I870.

\section{ANOMOURA.}

Benedict, JAMES E. . "Preliminary Descriptions of Thirty-seven New Species of Hermit Crabs of the Genus Eupagurus in the United States National Museum," I'rucecdings of the Muscum. Washington, I892.

Hexderson, I. R. . . Report on the Anomoura collected by H.M.S. "Challenger" during the Iears I $873-76$ London, I 888. 
Milne Edwards, A., Reports on the Result of Dredging by the and Bouvier, E. L. U.S. Coast Survey Steamer "Blake" in the Gulf of Mexico (1977-78), in the Caribbean Sea (1578-79), and along the Atlantic Coast of the United States (1880).

Description des crustacées de la Famille des Paguriens. Cambridge, U.S.A., 1893. Description des Crustacées dé la Famille des Galuthéidés. Cambridge, U.S.A., 1897.

\section{MACROURA.}

Kingsiex, J. S. . . " "A Synopsis of the North American Species of the Genus Alpheus," Bulletin L..S. Geological Suray, 1877 .

Milne Euwards, A. . "Macroures from the West Indies," An. Si: Nit. Zool. Paris, ISSI.

SPENCE B.tTe, C. . . Report on the Macroura collicted by H.M.S. "Challenger" during the Years $1873-76$ London, i88s.

\section{STOMAPODA.}

BRooks, W. K. . . . Refort on the Stomatopoda collected by H.M.S. "Challenger" during the lears 1 $\$ 73-76$. London, i $\$ 86$. 


\section{SYSTEMATIC INDEX.}

Order Decapoda.

Suborder Brachyura.

Tribe I. Oxyrhyncha.

Legion I. Nainea.

Family Inachidae.

Subfamily I. Leptopodina:

I. Leptopodia. 1. sagittaria.

2. Netoporaphis. 1. for ficulatus.

3. Podochela.

I. grossipes.

2. macrodera.

3. gracilipen.

4. reisei.

5. spatulifrons.

Sulbamily II. Inachine.

I. Anisonotus.

I. curvirostric.

2. Inachoides.

I. obtusus.

2. forceps.

3. Anasimus.

I. fujax.

4. Arachnopsis.

1. filipes.

5. Euprognatha.

I. rastellifra.

2. gracilipes,

3. inermis.

6. Trachymaia.

I. cornuta.

7. Lispognathus.

I. furcillatul..

8. Anamathia.

I. hystrix.

2. crassa.

9. Nilsilia.

3. morlesta.

I. armata.

2. erinacea.

Io. Chorinus.

I. heros.
Sulfamily III. Acanthonychine.

I. Anomalothir,

I. furcillatus.

2. frontalis.

2. Epialtus.

I. bituberculatus.

2. dilatatus.

3. longirostris.

3. Acanthonyx.

I. petiverii.

Subfamily IV. Microrhynchine.

I. Esopus,

I. crassun.

Sulfamily V. Stenocionopine.

I. Tyche.

I. emarginata.

Family Maiide.

Subfamily I. Mainas.

I. Iferbstia.

2. Pisa.

I. depressa.

I. antilocapra.

2. prelonga.

3. erinacea.

3. Sisyphus.

I. compressus.

Subfamily II. Schizophrysinx.

I. Temnonotus.

1. granulosus.

2. simplex.

Family I'ericerictit.

subfamily I. Pericerince.

1. Libinia.

I. dubia.

2. thomboidea.

2. Scyra.

I. umbonata.

3. Lissat.

I. chilagra. 
4. Sphenocarcinus.

I. corrosus.

5. Pericera.

I. cornuta.

2. spinosissima.

3. crelata.

6. Microphrys.

1. weddellii.

2. bicornutus.

7. Macrocceloma.

I. trispinosa.

2. subparallela.

3. diplacantha.

4. lievigata.

Sulfamily II. Othoniine.

I. Othonia.

I. aculeata.

2. Iherminieri.

3. levigata.

Sulfamily III. Nithracine.

I. Thoe.

I. puella.

2. Mithrax.

I. rostrata.

2. spinosissimus.

3. cornutus.

4. aculeatus.

5. hispidus.

6. depressus.

7. pleuracanthus.

S. levimanus.

9. verrucosus.

Io. leucomelas.

I I. sculptus.

I2. cinctimanus.

I3. forceps.

I4. nudus.

I5. ruber.

16. coronatus.

Legion II. I'arthenopinea. Family Parthenopide. sulffamily Parthenopine.

I. Lambrus.

J. pourtalesii.

2. agonus.

3. serratus.

4. nitidus.

2. Paithenope.

I. horrida.

3. Solenolambrus.

I. typicus.

4. Mesorhiea.

I. cristatipes.

5. Heterocrypta.

I. granulata.
Tribe II. Cyclometopa.

Leegion Cancrinea.

Family Cancridze.

I. Carpilius.

I. corallinus.

2. Lophactrea.

I. loluata.

3. Medien.

I. spinimanus.

4. Actrea.

I. setigera.

2. acantha.

3. noclosa.

5. Xantho.

I. denticulatus.

6. Xanthodes.

I. bidentatus.

7. Panopers.

I. herbstii.

2. xanthiformis.

8. Eurypanopeus.

I. abbreviatus.

2. parvulus.

9. Nicropanope.

I. sculptipes.

2. pugilatur.

3. lobifrons.

IO. Carpilodes.

I. longimanus.

I I. Chlorodius.

I. longinanus.

12. Leptodius.

1. floridanits.

2. caribens.

3. americanus.

I3. Phymodius.

I. maculatus.

14. Eurytium.

I. limosum.

15. Ozius.

I. reticulatus.

16. Menippe.

I. mercinaria.

17. Pilumnus.

I. aculeatus.

2 . vinacens.

3. caribeus.

4. gracilipes.

5. lactens.

6. 'puoyi.

7. miersii.

8. gemmatus.

9. nudifrons.

Io. reticulatus.

II. fragosus.

IS. Lobopilumnus.

I. agassizii. 
I9. Heleractaa.

20. Eriphia.

I. ceratopus.

I. gonagra.

2I. Domecia.

I. hispicla.

Family Portunidze.

Subfamily I. Lupine.

I. Neptunus.

I. sayi.

2. cribrarius.

3. anceps.

4. rentralis.

5. sulcatus.

6. sebre.

7. ordwayi.

8. spinimanus.

9. depressifrons.

Io. spinicarpus.

2. Callinectes.

I. diacanthus.

2. bocourti.

3. cayennensis.

3. Lupa.

I. forceps.

4. Cronius.

I. ruber.

Subfamily II. Carcinine.

I. Portunus.

I. guadulpensis.

2. Platyonycbus,

r. ocellatus.

Tribe III. Catometopa.

Family Thelphusidze.

Subfamily I. Pseudothelphusine.

I. Pseudothelphusa.
I. americana.
2. denticulata.
3. fossor.
4. xantusi.
5. garmani.
6. dentata.
7. reflexifrons.

2. Potamocarcinus.

I. latifrons.

2. nicaraguensis.

3. armatus.

3. Epilobocera.

I. gilmanii.

2. armata.

3. cubensis.

4. sranulata.

5. haytensis.

6. sinuatifrons.

4. Rathbunia.

I. festre.
Subfamily II. Trichodactyline.

I. Trichodactylus.

I. quinquedentatus.

2. dentatus.

3. quadratus.

2. Sirlviocarcinus.

I. devillei.

3. Tilocarcinus.

I. margaritifrons.

2. emarginatus.

3. spinifrons.

4. pictus.

5. cartilmani.

6. spinifer.

7. dentatus.

Family Geocarcinide.

I. Geocarcinus.

I. lateralis.

2. ruricola.

3. depressus.

4. planatus.

5. lagostoma.

2. Gecarcoidea.

I. lalandii.

3. Cardiosoma.

I. carnifex.

2. armatum.

3. guanhumi,

4. Uca.

4. cressum.

I. cordata.

2. una.

3. levis.

Family Ocypodide.

Subfamily I. Carcinoplacine.

I. Euryplax.

I. niticlus.

2. Speocarcinus.

I. carolinensis.

3. Geryon.

I. incertus.

4. Frevillea.

I. rosia.

2. sigsbei.

3. tridentata.

5. Bathyplax.
I. iyphlus.

Subfamily II. Ocypodinæ.

I. Ocypoda.

I. macrocera.

2. arenaria.

2. Gelasimus.

I. maracoani.

2. heterocheles.

3. vocator.

4. pugellator. 
Family Grapsidie.

Subfamily 1. Grapsine.

I. Goniopsis.

I. cruentatus.

2. Grapsus.

I. maculatus.

3. Geograpsur.

I. hillii.

2. lividus.

4. Leptograpsus.

I. variegatus.

5. Pachygrapsus.

I. transversus.

2. gracilis.

6. Nautilograpsus. I minutus.

7. Fuchirograpsus. I. americanus.

8. Sarmatium.

I. pectinatum.

9. Sesarma.

I. cinerea.

2. angustipes.

3. miniata.

10. Aratus.

4. americana.

I. pisoni.

I I. Cyclograpsus.

I. integer.

Subfamily 1I. P'lagusine.

I. Plagusia.

I. depressa.

2. gracilis.

Family Pinnotheridx.

Subfamily 1. Pinnotherine.

Subfamily II. Ilexapoline.

Subfamily III. Myatirine.

Subfamily IV. Hymenosomine.

Tribe IV. Oxystomata.

Family Calappidx.

Subfamily Calappine.

I. Calappa.

I. angustata.

2. gallus.

3. marmorata.

2. Acinthocarpus.

I. lispinosus.

2. alexandri.

Family Matutidic.

Subfamily llepatine.

I. Hepatus.
I. tuberculatus.
2. fasciatus.

2. Osachelia.

I. tulurosa.

Family Lencoside. Subfamily Iline.

I. Ilia.

I. punctata.

2. Iliacantha.

I. subglolusa.

3. Myropsis.

I. quinquespinosa.

2. constricta.

4. Ebalia.

I. stimpsonii.

5. Persephona.

I. punctata.

2. latreilli.

3. lamarckii.

4. lichtenstenii.

Family Dorippida.

I. Cyclodorippe.

I. nitida.

2. antennaria.

2. Cymonomus.

I. quadratus.

3. Cymopolus.

I. asper.

4. Cymopolia.

I. sica.

2. dilatata.

3. obessa.

4. dentata.

5. gracilipes.

6. cursor:

Suborder Anomoura.

Group Dromidea.

Family Dromide.

I. Dromia.

I. lator.

2. Dromidia.

I. antillensis.

3. Hypoconcha.

I. sabulosa.

4. Acanthodromia.

I. erinace:2.

Family Homolide.

I. Dicranodromia.

I. ovata.

2. IIomolodromia.

I. paradoxa.

3. Ilomolia.

I. vigil.

4. Homolopsis.

I. rostratus. 
Group Raninidea. Family Raninidæ.

I. Raninoides. I. nitidus.

2. Zanclifer. I. caribensis.

Group Hippidea. Family Hippidæ.

I. Remipes.

I. scutellatus.

2. Hippa.

I. emerita.

Family Albuneidix.

I. Albunea.

1. gibbesii.

2. oxyophthalma.

2. Lepidops.
I. scutellata.

2. venusta.

Group Paguridea.

Family Lithodidx.

I. Lithodes.

Family Ceenobitidx.

I. Conobita.

I. diogenes.

Family Paguridxe.

I. Calcinus.

I. tuberculosus.

2. tibicen.

3. sulcatus.

2. Clibanarius.

I. anomalus.

3. Pagurus.

1. striatus.

2. insignis.

3. granulatus,

4. Pylopagurus.

I. discoidalis.

2. boletifer.

3. erosus.

4. bartletti.

5. rosaceus.

6. gibbosimanus.

5. Ostraconotus.

I. spatulipes.

6. Spiropagurus.

I. iris.

7. Anapagurus.

I. marginatus.

8. Catapagurus.

I. sharreri.

2. gracilis.

b
9. Paguristes.
I. spinipes.
2. triangulatus.
3. sayi.
4. planatus.
5. lymani.

10. Sympagurus.

I. arcuatus.

2. pictus.

3. pilimanus.

II. Tomopagurus.

I. rubropunctatus.

12. Xylopagurus.

I. rectus,

Family Parapagurida. ?

I. Parapagurus.

I. pilosimanus.

2. Mixtopagurus.

I. paradoxus.

3. Pylocheles.
I. agassizii.

Group Galatheidea.

Family Porcellanidæe.

I. Petrolisthes.

I. magnifica.

2. armatus.

3. marginatus.

2. Pisosoma.

4. tridentatus.

I. reisei.

3. Porcellana.

I. robertsoni.

4. Megalobranchium.

I. granuliferum.

Family Galatheide.

I. Galathea.

I. agassizii.

2. Munida.

1. iris,

2. caribxa.

3. miles.

4. constricta.

5. longipes.

6. stimpsonii.

7. microphthalma.

3. Munidopsis.

I. sigsbei.

2. simplex.

3. nitida.

4. spinoculata.

5. abbreviata.

6. serratifrons.

7. robusta.

s. erinacea.

9. spinifer. 
Io. latifrons.

I I. tridens.

4. Elasmonotus.

I. squamosts.

2. abdominalis.

3. armatus.

4. longimanus.

5. Galacantha.

I. spinosa.

6. Ptychoraster.

I. spinifer.

7. Uroptyclus.

I. nútidus.

2. uncifer.

3. rugosus.

Suborder Macroura.

Division I. Trichobranchiata.

Gromp Aberrantia.

Family Callianasside.

I. Callianassa.

I. occidentalis.

2. major.

2. Cheramus.

I. occidentalis.

Family Thaumastochelidit:

I. 'Thaumastocheles.

I. zaleuca.

Group Normalia.

Tribe I. Synaxidea. Family Scyllaride.

I. Ibaccus.

1. parlie.

2. Scyllarus.

I. squamosus.

2. equinoxialis.

3. Arctus.

I. americanus.

Family Palinuride.

I. Palinurus.

I. longimanus.

2. Panulirus.

I. guttatus.

2. americanus.

3. argus.

Tribe II. Astacidea.

Family Eryonidx.

I. Polycheles.

I. crucifera.

2. Pentacheles.

I. agassizii.

2. spinosus.

3. validus.
Family Homaride.

I. Phoberus.

I. crecus.

2. Nephropsis.

I. rosea.

Family Astacidie.

I. Cambarus.

2. P'arastacus.

Tribe III. Stenopidea.

Family Stenopida.

I. Stenopus.

I. hispidus.

Division II. Dendrobranchiata.

Group Normalia.

Family Peneidie.

I. I'enceus.

I. brasiliensis.

2. Sicyonia.

I. carinata.

3. Benthesicymus.

I. pleocanthus.

Division III. Phyllobranchiati. Tribe I. Polycarpidea.

Family Nikidae.

I. Glyphocrangon.

I. spinicauda.

2. nobilis.

3. aculeata.

Famıly Alpheidx.

I. Alpheus.

I. armillatus.

2. bermudensis.

Family IIippolytide.

I. Latrentes.

I. ensiferu.

2. Ilippolyte.

I. bidentatus.

Family Pandalidix.

I. Heterocarpus.

I. ensifer.

2. oryx.

2. Pandalus.

I. longipes.

Tribe II. Nonocarpidea.

Family Atyida.

I. Aiya.

I. scabra. 
Family Acanthephyridie.

I. Acanthephyra.

I. ensis.

2. armata.

3. debilis.

2. Oplophorus.

I. gracilirostris.

3. Gonatonotus.

I. crassus.

Family Palemonide.

I. Haliemon.

I. natator.

2. Bithynis.

I. jamaicensis.

2. aztecus.

3. montezumite.

4. brasiliensin.

5. nattereri.

6. lamarrei.

7. forceps.

S. ensiculus.

9. jelskii.

o. spinimanus.

3. Brachycarpus.

I. sarignyi.
Family Nematocarcinide.

I. Nematocarcinus.

I. cursor.

Family Tropiocaride.

I. Notostomus.

I. gibbosus.

2. elegans.

Family Stylodactylidix.

I. Stylodactylus.

I. serratus.

Family Pasiphreidre.

I. Leptochela.

I. serratorbita.

Order II. Stomapodia. Family Squillidie.

I. Gonodactylus.

I. chiragra.

2. I'seudosquilla.

I. ciliata.

3. Squilla.

I. vittata.

2. scabricauda. 



\section{STALK-EYED CRUSTACEA.}

\section{Class CRUSTACEA.}

AnImals having the body composed of segments, in general very distinct, motile, and of considerable hardness, without an internal skeleton properly so called, and carrying a double series of appendages, almost always very distinctly articulated, consisting of antennæ, jaws, etc., and of limbs of which the number is usually five or seven or eight pairs; the nervous system is in general very distinct, being composed of ganglionic centres and connecting cords; the respiration, in general aquatic, carried on by means of gills or membranes; the circulation, in general very distinct, is almost always through a special heart and blood-vessels; the sexes are distinct.

\section{Subclass Podophthalmata.}

Podophthalmata . . Miers.

Podophthalmia. . . Dana.

Podophthalmiens . . H. Milne Edwards.

Podophthalmar. . . Leach, Linné.

Crustaces pidiocles. . Lamarck.

Mouth armed with mandibles and jaws for mastication; in general gills properly so called; eyes on stalks, and movable; rod-like thoracic limbs; a carapace. 


\section{Order I. Decapoda.}

Order II. Stomapoda.

\section{SyNOPSIS OF THE ORDERS.}

A. Gills internal.

a. Head and chest form one piece. The limbs always five pairs.-(Decapoda.)

$B$. Gills external or wanting.

b. Head and chest more or less in segments. The limbs usually seven or eight pairs; one or two posterior pairs often wanting.-(Stomapoda.)

\section{Order I. Decapoda.}

Decapoda . . . . . . . Latreille, White.

Decapodes . . . . . . . H. Milne Edwards.

Decapoda vel Eubranchiata. Miers.

Eubranchiata. . . . . Dana.

Having gills fixed on the sides of the thorax, and covered in a cavity. The head soldered on to the chest, and covered with a carapace that reaches as far as the abdomen. The limbs-walking and holding-almost always five pairs.

\section{Suborder I. Brachyura. \\ Suborder II. Anomoura. \\ Suborder III. Macroura.}

\section{SINOPSIS OF THE SUBORDERS.}

I. Abdomen bent under the body, without swimming appendages, and without appendages upon the under surface of last segment but one. Sternum broad. 
Flagella of antenne very short. External maxillipedes flat, closing the mouth like a door. Buccal cavity distinctly defined in front.-( rrach $^{\prime}\left(y^{\prime} u r^{\prime}(r)\right.$

II. Abdomen sometimes bent under the body, sometimes extended, nearly always having some appendages. Sternum very narrow between the last three pairs of legs. Last pair of legs usually atrophied.-(Anomoura.)

III. Abdomen large, extended backwards, with lamellar appendages beneath. The appendages of the last segment and of the last segment but one enlarged, forming a fanlike swimming organ. Sternum narrow. Antennæ well developed. External maxillipedes pediform. Buccal cavity not distinctly defined in front.-(Macroura.)

\section{Suborder I. Brachyura.}

Brachyura. . . Leach, Latreille, Dana, Linné, Claus, Haswell, Miers.

Brachyures . . . H. Milne Edwards.

Cancri Braclyuri. Lamarck.

Klistognatha . . Fabricius.

\begin{tabular}{l|l} 
Tetrogonostoma ! . Macleay. \\
Trigonostona
\end{tabular}

The abdomen, folded under the body into a median groove, is little developed, never has false swimming feet, and is never used as a swimming organ. The sternal plastron is of some size and never linear. The genital orifices of the female are always situated on the sternal plastron. The flagella of the antennæ and antennules are generally short or rudimentary. The external maxillipedes, flat, are like doors hinged at the lower external corner, and may completely close the mouth, which 
is distinctly defined in front. The first pair of legs only have pincers, although the others are sometimes formed for holding; the last pair are sometimes formed for swimming, or may be little developed.

\section{Tribe I. Oxyrhyncha \\ Tribe II. Cyclometopa. \\ Tribe III. Catometopa. \\ Tribe IV. Oxystomata.}

Sy NOPSIS OF THE TRIBES.

I. The canal from the branchial cavity opens at the sides of the palate. The buccal cavity, quadrilateral, is wide in front and long from before backwards. The genital orifice of the male is hollowed in the basal joint of the last pair of legs, and is not continued in a transverse canal of the sternum. The gills to the number of nine almost fill the branchial cavity.

$A$. The space in front of the mouth is almost as long as the buccal cavity.

a. The carapace is pear-shaped, narrowed in front, where it is usually produced into a rostrum. Orbits directed outwards.-(O.y rhy'ncha.)

$B$. The space in front of the mouth is very short; wider than long.

b. The carapace is wide and regularly bowed in front; not produced into a rostrum. Orbits directed forwards.(Cyclometopa.)

II. The canal from the branchial cavity opens at the sides of the palate. The buccal cavity, quadrilateral, is wide in front, and long from before backwards. The genital appendages of the male are either inserted in 
the sternum or in the basal joint of the last pair of legs, thence passing through a channel in the sternum beneath the abdomen. Gills, usually fewer than nine, occupy but a small space in the branchial chamber.

$C$. Space in front of the mouth very short, but broad.

c. Carapace broad in front, often subquadrate, sometimes subglobose, transverse or arcuate; never rostrate in front.-(Catometopa.)

III. The canal from the branchial cavity passes out at the middle of the palate, which is produced forwards. The buccal cavity is narrowed and produced in front, triangular. The male genital appendages are inserted in the basal joint of the fifth pair of legs. The gills are seven to nine in number.

$D$. Space in front of the mouth very small.

d. Carapace is transverse; arcuate anteriorly, or subglobose.-(O.ry'stomata.)

\section{Tribe I. Oxyrhyncha.}

Oryrhyncha. . . . . Miers.

Oxyrhynchi (part) . . . Latreille.

Oryrhinques . . . . . H. Milne Edwards.

Meroider ad Oryrhynctu. Dana.

Carapace more or less narrowed in front, and usually rostrated, with the branchial regions well developed. Hepatic regions small. Epistome usually large. Buccal cavity quadrate, with the anterior margin straight. Gills nine in number; their efferent channels terminating at the sides of the palate. Internal antenne longitudinally plicated. The fifth articulation of the external 
maxillipedes articulates with the fourth at the summit, at the antero-external, or at the antero-internal angle. The genital appendages of the male are inserted at the bases of the last pair of legs.

\section{Legion I. Maiinea.}

Basil joint of external antenna large.

\section{Legion II. Parthenopinea.}

Basal joint of external antenne small.

\section{Legion I. Maiinea.}

Maiined. . Dana, Miers.

Basal antennal joint well cleveloped, inserted beneath the eyes, and usually occupying a great part of the infraocular space; body elongate, rounded behind, narrowed and rostrate in front. I.egs of normal shape.

Family I. Inachidæ.

Family II. Maiidæ.

Family III. Periceridæ.

SrNomsis of the FAMLILS.

A. Orbits not defined.

a. Basal antenmal joint slender orenlarged.-(Inachidu.)

B. Orbits defined, but incomplete below, or with fissures above and below.

b. Basal antennal joint enlarged.-Mcriake.

C. Orbits well defined ; never incomplete below.

$\therefore$ Basal antennal joint enlarged, and forming the greater portion of the floor of the orbit.-(I'ricuride.) 


\section{Family I. Inachidæ.}

\section{Inachide . . . Miers.}

Eyes non-retractile, or retractile against the sides of the carapace. No defined orbits, but there is often a welldeveloped preocular and postocular spine. Basal joint of external antennæ usually slender, sometimes moderately enlarged. Rostrum simple or bifid, sometimes very short. First pair of legs with the fingers never excavated at the tips. Walking legs sometimes very long. Abdomen of male four to seven-jointed; two or thrce joints often coalescent.

\section{Subfamily I. Leptopodinæ. \\ Subfamily II. Inachinæ. \\ Subfamily III. Acanthonychinæ. \\ Subfamily IV. Microrhynchinæ. \\ Subfamily V. Stenocionopinæ.}

Sriopsis of the Subfamiles.

I. Basal joint of the external antenna slender.

A. Basal joint of external antenne slender throughout its length.

a. Eyes slender, non-retractile, and laterally projecting; preocular and postocular spine minute or wanting.

$a^{1}$. Carapace subtriangular.

$a^{2}$. The fourth joint of the external maxillipedes truncated, or elongated and rounded distally; the fifth joint articulates with it at the summit, at the external, or at the internal angle.

$a^{3}$. The first pair of legs has the palm cylindrical or inflated; fingers acute. Walking legs slender and very long.-(Leptopodince.) 
B. Basal joint of external antenna slender, not narrowing distally.

b. Eyes slender and retractile; præocular spine usually wanting, postocular spine distinct.

$b^{1}$. Carapace triangular or subpyriform.

$b^{2}$. The fourth joint of the external maxillipedes truncated, or elongated and rounded distally; the fifth joint articulates with it at its antero-internal angle.

$b^{3}$. The first pair of legs of the male small, or has the palm inflated and the fingers acute. Walking legs usually slender, and often very long.-(Inachine.)

II. Basal joint of the external antennze enlarged.

C. Basal joint of external antenna enlarged at base, narrowing distally.

c. Eyes small and immobile, or partially retractile; preocular spine prominent, postocular spine minute or wanting.

$c^{1}$. Carapace oblong and flattened, or elongate and subcylindrical or subtriangular.

$c^{2}$. The fourth joint of the external maxillipedes is truncated distally; the fifth articulates with it at its antero-internal angle.

$c^{3}$. The first pair of legs in the male usually has the hands compressed. Walking legs of moderate length.(Acanthonychine.)

D. Basal joint of external antenne enlarged throughout its length.

d. Eycs short and completely retractile; preocular spine short or absent, postocular spine large.

$d^{2}$. Carapace triangular.

$d^{2}$. The fourth joint of external maxillipedes cordiform or truncated distally; the fifth joint articulates with it at its antero-internal angle. 
$d^{3}$. Legs usually slender.-( Microrhynchina.)

e. Eyes elongated and retractile; præocular spine greatly elongated.

$e^{1}$. Carapace oblong, prolonged posteriorly.

$\epsilon^{2}$. The fourth joint of the external maxillipedes has its antero-external angle produced, lobed, or it is dovetailed into the third joint.

$e^{3}$. First pair of legs little developed. Walking legs thin, with curved terminal joint.-(Stenocionopina.)

\section{Subfamily I. Leptopodinæ.}

Leptopodince. . . . Miers.

Leptopodide (part) . . Dana, Stimpson.

Macropodiens (part) . . H. Milne Edwards.

Carapace subtriangular; rostrum simple. Eyes slender, non-retractile, and laterally projecting; preocular and postocular spines minute or wanting. Basal joint of external antenna slender throughout its length. The fourth joint of the external maxillipedes is truncated, or elongated and rounded at its distal end; it articulates with the fifth joint at its summit, its antero-external or antero-internal angle.

The first pair of legs has the palm cylindrical or inflated; fingers acute. Walking legs slender and very long.

Synopsis of TIE GeNerA.

A. Rostrum a long single spine.

a. A postocular spine present. First pair of legs with the palm elongated, cylindrical.

$a^{1}$. Carapace smooth. Fxternal antennce concealed bencath the rostrum.-(Leptopodia.)

$b^{1}$. Carapace uneven above. Flagellum of Leptofodiu. 
external antennæe exposed on each side of rostrum.(IIctoporaphis.)

b. Rostrum very short and simple.

b. No postocular spine. First pair of legs with the palm inflated.

$c^{1}$. Rostrum acute, or rounded and hood-shaped. Pterygostomian regions naked, or with lamelliform ridges defining afferent branchial channels.-(Podochcla.)

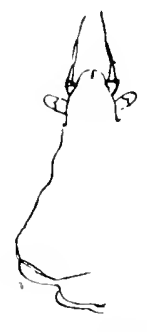

Podocheli.

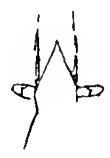

\section{Leptopodia.}

Leptopodia . . Leach, H. Milne Edwards, Micrs.

Inachus . . Fabricius.

Cancer . . 1 lerbst.

Macropi . . Latreille.

Stcrooryque . Lamarck.

The carapace, not tuberculated, has the posterior margin straight and not prolonged over the posterior segment of the thorax. Rostrum very long, horizontal, with the lateral margins scrrated. Eyes short. A small postocular spine present. The basal joint of the cxternal antenne is elongated ; the flagellum is in great part conccaled beneath the rostrum. The endostome is without longitudinal ridges; the epistome very large. The third joint of the external maxillipedes is somewhat produced at its antero-internal angle; the fourth joint is obversely triangulate, and truncated distally; the fifth joint articulates with it at its antcro-external angle.

The first pair of legs in the male is slender anci elongated, with the fourth and fifth joints and the hand subcylindrical; fingers much shorter than the palm, toothed on their inner margins. The last joint of the 
walking legs is styliform. The fourth joint of all the legs has spines. The abdomen has six joints; the last two segments being coalescent.

RANGE.-West Indian Sea, Gulf of Mexico, Canary and Cape Verde Islands, Madeira, Brazil, West Coast of Central and South America.

\section{Leptopodia sagittaria.}

Leptopodia sagittaria. Leach, H. Milne Edwards.

Inachus sagittarius. Fabricius.

Cancer scticomis . . Herbst.

There is a spine on each side of the carapace at some distance behind the orbits. The rostrum is almost twice as long as the postfrontal portion of the carapace. Ocular peduncles are completely circular. One spine on the inferior face of the basal joint of the external antenna near the insertion of the eyes. Hands finely granular. The spines of the terminal edge of the fourth joint of the walking legs very short.

Not found along the shore; it is frequently caught at Barbados in the traps set in deep water.

RANGE.-Barbados, Jamaica.

\section{Metoporaphis.}

Metoporaphis . . Miers.

Netoporhaphis. . Stimpson.

Leptopodic . . . Say, H. Milne Edwards.

Upper surface of carapace irregular and tuberculated. Rostrum long, projecting. External antenne long; the movable part not corered by the rostrum. The third joint of the external maxillipedes is produced at its antero-internal angle; the fourth joint is obversely triangulate, and truncated distally; the fifth joint articulates 
with it at its antero-external angle. The last joint of the walking legs is almost straight, ciliated.

RANGE. - West Indian Sea to the Guiana Coast, Beaufort Harbour; at moderate depths.

\section{Metoporaphis forficulatus.}

\section{Metoporaphis forficulatus . A. Milne Edwards.}

The carapace is not very hard; it is wide behind, and imperfectly hides the sternum; it is contracted in front of the hepatic regions. The gastric region has four tubercles, three arranged transversely and one behind the central one; there is another tubercle in the middle line on the cardiac region. The eyes are large, and terminate in a point in front of the cornea. The fourth joint of the external maxillipedes is notched for the insertion of the fifth; its antero-internal angle is very prominent.

The first pair of legs of the female is very thin, and hairy above and below; there are small spines on the arm and forearm; the palm is short; the fingers are long, and have hairs along their prehensile border. The walking legs are about of equal length; there are three spines on the extremity of the fourth joint, the middle one being large and straight.

RANGE.-Coast of Guiana.

\section{Podochela.}

Podochela . . Stimpson, Miers, A. Milne Edwards. Podonimer. . Stimpson.

Coryrlynthus . Kingsley.

Dryopi . . Desbonne and Schramm.

trorlyuchus. A. Milne Edwards.

Carapace clepressed, with the gastric region prominent and narrow. Rostrum short, triangular, hood-shaped or 
rounded. Eyes project laterally. The basal joint of the external antenne keeled, without spines or teeth; the flagellum is not concealed beneath the rostrum. The fourth joint of the external maxillipedes is shorter than the third, and for the most part narrower, but very variable in width; apex obtuse or produced; the fifth joint articulates with it at its antero-internal angle. The first pair of legs in the male moderately robust, with the palm slightly swollen. The walking legs have the last joint curved or hook-shaped.

The first segment of the abdomen is large; the second, third, and fourth, narrower; the three last segments coalesce.

RANGe.-West Indies, Gulf of Mexico, California.

\section{Subgenus I. Podochela. Subgenus II. Coryrhynchus.}

Synopsis of the Subgenera and Species.

A. Rostrum short, triangular-(Subgenus Podochelu.)

a. The two terminal joints of the two last pairs of legs curved, forming a hook.

1. Antero-external angle of the fourth joint of external maxillipedes rounded; rostrum longer than broad.-(P. grossipes.)

2. Antero-external angle of fourth joint of external maxillipedes sharp; rostrum as long as broad.-( $P$. macrodera.)

b. The two terminal joints of the fourth and fifth pairs of legs straight.

3. Antero-external angle of fourth joint of external maxillipedes sharp; rostrum much longer than broad.(P. gracilipes.) 
B. Rostrum rounded and hood-shaped.-(Sulgenus Coryrhynchus.)

c. The last joint but one of walking legs more or less straight.

4. Antero-external angle of fourth joint of external maxillipedes sharp.-(P. reisii.)

5. Antero-external angle of fourth joint of external maxillipedes rounded.-(P. spatulifrons.)

\section{Subgenus Podochela.}

Rostrum short, triangular.

I. Podochela (Podochela) grossipes.

Podochela grossifes . . . . . Stimpson, A. Milne Edwards.

Acrorlyuchus depressus. . . . A. Milne Edwards.

Rostrum acute; longer than broad; setose. The fourth joint of external maxillipedes oblong, much narrower than the third, with the external angle rounded and the inner incised; incision broad and shallow. Pterygostomian regions naked.

Fingers, shorter than the palm, are slender, gaping, and annulated with crimson near their tips. First pair of walking legs with a single series of short tufts of curled hair along the upper side; last joint but one thick, with a tooth on the inferior edge, against which the hookshaped last joint closes. The legs become progressively shorter, with the last two joints of the two last pairs of legs curved.

RANGE. - St. Thomas, St. Lucia; at moderate depths. 


\section{Podochela (Podochela) macrodera.}

Podochela macrodera. Stimpson, A. Milne Edwards.

The carapace widens in front. The rostrun is as long as broad. The fourth joint of the external maxillipedes is short and broad, with the antero-cxternal angle acute. Pterygostomian regions naked. The fingers not gaping, and without pink bands. WValking legs slender; the last joint but one of the first pair has no tooth on its inferior edge, and is long and slender. The last two joints of the fourth and fifth pairs of legs are curved.

RAnge. - Guadaloupe, St. Thomas, Florida; at moderate depths.

\section{Podochela (Podochela) gracilipes.}

Podochela gracilipes . Stimpson, A. Milne Edwards.

The carapace is more or less straight in the hepatic region; the cardiac region has a large tubercle. The rostrum is long, and terminates in a sharp point. The antero-external angle of the fourth joint of the external maxillipedes is sharp. The pterygostomian regions naked. The pincers of the male are long; the fingers meet only at their extremities when closed. The walking legs are long and thin, with the last joint but one more or less straight, and without elevations to meet the terminal joint when closed. The sternum of the male has two tubercles between the bases of the first pair of legs. These tubercles are replaced in the female by a median ridge.

Range.-Caribbean Sea, Gulf of Mexico, South Carolina; at moderate depths. 


\section{Subgenus Coryrhynchus.}

Coryrhynchus . . . Kingsley.
Podonema . . . . Stimpson.

Rostrum rounded and hood-shaped.

\section{Podochela (Coryrhynchus) reisei.}

Podechela reisei . . . Stimpson, A. Milne Edwards, Miers.

$\left.\begin{array}{l}\text { Podonema reisei } \\ \text { Podochela deftexifrons }\end{array}\right\}$. Stimpson.

Coryrhynchus reisei. . Kingsley.

Dryope falcipoda . . . Desbonne and Schramm.

The carapace is narrow anteriorly, especially behind the eyes, but depressed and broadly expanded posteriorly at the bases of the walking legs. Gastric region prominent. Cardiac region sharply prominent, tuberculiform. Hepatic region with a strong, deflexed lateral tooth. Frontal region protuberant, setigerous. Rostrum depressed much below the level of the frontal region, broader than long, more or less expanded, naked, with a slight median keel; margin rounded. The basal joint of external antenne is deeply concave on each side of the keels or crests, which meet at its anterior extremity where the flagellum is inserted. The fourth joint of the external maxillipedes is expanded, with the antero-external angle prominent and sharp. The pterygostomian regions have lamelliform ridges defining the afferent branchial channels. The hands have long, non-gaping fingers, finely toothed along their cutting edge. The external half of the walking legs are hairy, with the last joint but one more or less straight. 
Range. - Guadaloupe, St. Thomas, Florida, Bermuda, Brazil, Gulf of Mexico; at moderate depths.

\section{Podochela (Coryrhynchus) spatulifrons.}

\section{Podochela spatulifirons. . . A. Milne Edwards.}

Carapace contracted in front. Hepatic region has one tubercle. The antero-lateral border has one tooth situated a little in advance of the level of the hepatic tubercle. The front has a small keel in the middle line branching backwards towards each eye. The basal joint of the external antenne has an external keel, and a prominent inferior keel on its inner edge. The epistome has two tubercles on each side. The fourth joint of the external maxillipedes has its antero-external angle rounded, and its antero-internal angle deeply notched. The pterygostomian region has no ridges defining the afferent branchial channels; there is a tubercle.

The pincers are weak, and in the female the fingers meet along their entire length when closed; they have five teeth. There are a few tubercles on the forearm. The walking legs have tufts of curled hairs, and their last joint but one is more or less straight.

RaNGE.-Guadaloupe; at great depths.

\section{Subfamily II. Inachinæ.}

Inachince . . . . Miers.

Macropodiens (part) . H. Milne Edwards.

Eurypodidide. . . . Stimpson.

The carapace is subtriangular or subpyriform; its margin is often slightly produced over the base of the eye-peduncles. Rostrum simple or two-spined. Eyes 
slender and retractile. Preocular spine usually wanting, postocular usually distinct. Basal joint of external antenne not narrowing distally. The fourth joint of the external maxillipedes is either truncated and articulated with the next joint at its antero-internal angle, or elongated and rounded at its distal end. The first pair of legs, in the male, small, or has the palm inflated and the fingers acute. The walking legs are usually very slender. The abdomen is five to sevenjointed.

RANGE. - In all seas, in shallow and very deep water.

\section{Synopsis of the Genera.}

A. Rostrum a single spine.

a. Postocular spine developed.

$a^{1}$. Last two joints of walking legs not forming hoolis.

$a^{2}$. Carapace subtriangular.

$a^{3}$. Antero-internal angle of fourth joint of external maxillipedes rounded.

$a^{4}$. Rostrum directed forwards and laterally.

-(Anisonotus.)

$b^{4}$. Rostrum styliform.-(Inachoides.)

$b^{2}$. Carapace subpyriform.

$b^{3}$. Antero-internal angle of fourth joint of external maxillipedes prominent and pointed.

$c^{4}$. Rostrum directed forwards and upwards. -(Anasimus.)

$B$. Rostrum two-spined; spines diverging.

b. Rostrum about as long as broad.

$b^{1}$. The division between the horns a notch.

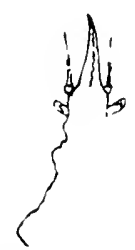

Anisonotus.
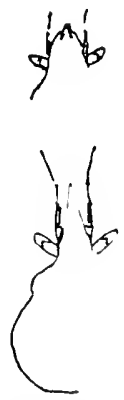

Inachoidis. $d^{t}$. Fourth joint of external maxillipedes broader 
than long. Postocular spine long, with rounded end.(Arachnopsis.)

$e^{4}$. Fourth joint of external maxillipedes L-shaped. Postocular spine long and sharp.(Euprognatha.)

$c^{1}$. The division between the horns about as broad as the length of the horns; no spine in centre of notch.

$f^{\ddagger}$. Postorbital spine small. - (Trachy'maic.) base.

c. Rostrum much longer than broad at

$d^{1}$. External antennæe exposed on a dorsal view.

$d^{2}$. Carapace subpyriform, almost as broad as long.

$g^{4}$. Fourth joint of external maxillipedes elongated and rounded distally.-(Lispognathus.)

$\epsilon^{2}$. Carapace subpyriform, longer than broad, with lateral spines.

$h^{4}$. Fourth joint of external maxillipedes with the antero-external angle dilated, internal angle truncated.-(Ancmathic.)

$i^{ \pm}$. Fourth joint of external maxillipedes deeply notched distally where the fifth joint articulates.-(Nibilia.)

$f^{2}$. Carapace subtriangular, without lateral spines.

$j^{4}$. Fourth joint of external maxillipedes with antero-internal angle notched, anteroexternal angle dilated.-(Chorinus.)
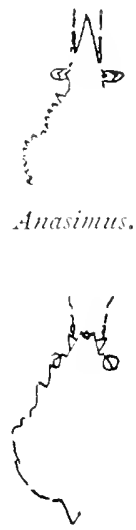

Arachnofsis.

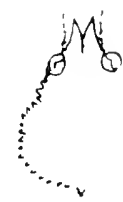

Trachymair.

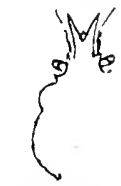

Lisposnathus.

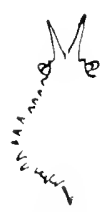

Anamathia. 
A. Rostrum a single spine :-

\section{Anisonotus.}

Anisonotus . . . M. Milne Edwards.

The carapace is subtriangular; elevated anteriorly, wide and depressed posteriorly. It extends, forwards, far beyond the bases of the first pair of lcgs, and belind it scarcely hides the sternum. The rostrum is very large, a single spine, curved downwards. The eyes terminate in a small point. Postocular spine very prominent, and directed outwards. The basal joint of the external antenne is keeled below, and partly exposed upon the sides of the front; the flagellum is thin, and scarcely exceeds the rostral point. The antennular fosse are wide and deep. The edges of the buccal cavity are prominent. The fourth joint of the external maxillipedes has the antero-external angle rounded.

The pincers are weak, and the fingers are in contact along their entire length when closed. The walking legs are very long, especially those of the first pair. The sternum of the male is keeled; and the sixth and seventh segment of the abdomen are soldered together.

RANGE-IVest Indian Sea.

\section{Anisonotus curvirostris.}

Anisonotus curvirostris . A. Milne Edwards.

The gastric region is prominent, with a median spine behind some tubercles; at their base are some hooked hairs. The cardiac region has a conical spine. There are some hairs in the branchio-cardiac grooves. The hepatic regions are narrow, and have on their edge a 
sharp, flat tooth directed downwards. The postocular spine is in the form of a horizontal wing, and more or less pointed. The suborbital border is raised and toothed. The rostrum is in the form of a triangular pyramid, covered with hooked hairs, spinous above, smooth below; it is curved laterally. The basal joint of the external antenne is bowed downwards; its lateral edges are developed into prominent ridges, bound to each other by a small transverse ridge. The antennular fossce are bounded by a ridge; the partition between them is prolonged below into a triangular and pointed tooth. The epistome is straight and granular. The pterygostomian region has a strong spine, situated below and behind the hepatic spine.

The pincers are ornamented with sharp granulations and a fringe of long hairs. The walking legs have straight hairs and bunches of curled hairs. The last joint is hairy. The sternum has two pointed elevations between the bases of the first pair of legs; its divisions are well marked. The abdomen of the male is short and smooth.

RANGE.-Barbados, Montscrrat, Grenadines, St. Vincent, Havana; in cleep water.

\section{Inachoides.}

Inachoides. Dana, A. Milne Edwards and Lucas, Miers.

Tiphus. . Eydoux and Souleyet.

Carapace subtriangular, pointed in front, wide and swollen posteriorly; the regions well defined. The rostrum a single styliform spine. The orbits are entire; no preocular spine; postocular spine well developed. The basal joint of the external antenna is straight, 
and the flagellum is cxposed on the sides of the rostrum. The epistome is large and almost quadrilateral. The fourth joint of the external maxillipedes is notched in front for the insertion of the fifth, with the antero-external angle rounded.

The walking legs are of molerate length, and their terminal joint is styliform. The abdomen of the male has seven segments; that of the female has five, the three last segments being soldered together. They are of small size.

RANGE.-IVest Indian Sea, Coasts of Brazil and Chili.

\section{Sinopsis of the Siecies.}

1. Rostrum short, about as long as front between the eyes is broad. More or less rounded anteriorly.-( $I$. obtusus.)

2. Rostrum long, about one and a half or twice as long as the breadth of front between the eyes; sharp anteriorly.-(I. foriess. $)$

\section{Inachoides obtusus.}

Inachoides obtusus . . A. Milne Edwards.

The gastric region has six slightly elevated tubercles, of which four are arranged transversely in front and two behind. There are two tubercles on the cardiac region in the middle line; the branchial and hepatic regions have each two spines. The rostrum is short with a broad base, about as long as the width of the front between the eye-peduncles, triangular with rounded edge. The basal joint of the external antenne has on the outside a notched ridge which extends on the buccal cavity. 
The pincers of the male are strong and granular. The walking legs of the first pair are thin. The sternum has two tubercles between the bases of the first pair of legs. There is a pointed tubercle on the first segment of the abdomen.

RANGE.-Guadaloupe.

\section{Inachoides forceps.}

Inachoides forceps . . A. Milne Edwards.

Body and legs slightly hairy. The carapace is very much swollen in the branchial and cardiac regions. The surface is smooth. The rostrum is long, about once and a half or twice as long as the front between the bases of the eye-peduncles is wide, and tapers to a rounded point.

The pincers are large. In the male the arm is almost cylindrical; the hand has granulations. The palmer portion is more developed than the fingers, which meet only at their extremities when closed; their prehensile edge has short hairs; the movable finger has above and inside some granulations. The walking legs are long, with their last joint curved and flattencd. The sternum is wide and smooth.

RANGE.-Coast of Guiana, Brazil.

\section{Anasimus.}

Anasimus . . . A. Milne Edwards.

The carapace is subpyriform; it contracts much in the orbital region. There is a postorbital spine. The rostrum is sharp, and directed forwards and upwards. The eyes are large. The basal joint of the external 
antenne is long and straight; it has below, on a level with the eyes, a tubercle ; the flagellum is large, exposed, and exceeds the rostrum in length. The internal antenne are long and folded longitudinally in the hollow fossa at the base of the rostrum; the partition between the fossæ has a strong triangular tooth. The third joint of the external maxillipedes is contracted towards its extremity; the fourth is straight at its base, and deeply cut at its antero-internal angle for the insertion of the fifth joint, where it projects much.

The walking legs are very thin; the two first pairs are of about equal length, the third and fourth are a little shorter. The terminal joint is clongated, and does not form a hook.

RANGE.--West Indian Sea; at great depths.

\section{Anasimus fujax.}

Anasimus fujar . . A. Milne Edwards.

The carapace has in the middle line thrce erect spines: the first on the gastric region, the second of the same size is placed on the anterior cardiac lobe, the third, smaller, is placed on the posterior cardiac lobe; there are spines on the postgastric lobes, and branchial regions have three spines or tubercles arranged longitudinally; the surface is granulose. The orbital borders are spinose. The rostrum has spines. The first pair of legs of the male is weak; it has stiff hairs. The arm has some small spines, and the fingers of the pincers are in contact along their whole length when closed. The walking legs are formed of cylindrical and smooth joints. The sternal plastron has granulations; the abdomen is also granular, and has one spine on the first segment.

RANGE.-Barbados, Santa Cruz; in deep water. 


\section{1). Rostrum troo-spined; spines dizarging. \\ b. Rostrum about as long as broad:-}

\section{Arachnopsis.}

Arachnopsis . Stimpson, A. Milne Edwards.

Carapace oblong, narrow, and somewhat truncated in front. Rostrum short, the space dividing the horns being only a notch; in the centre of this notch appears a small spine from the ridge on the interantennular partition. Orbital arch high, protuberant. Postocular spine long, and separated from the orbit by a deep, narrow fissure. Eye long, considerably overreaching the tip of the postocular spine, but capable of being drawn back beneath it. Basal antennal joint, with a small, sharp spine at its extremity, pointing obliquely forwards and outwards, between which and the rostrum the flagella are exposed, and with a crest on its under surface extending backwards. Fourth joint of external maxillipedes broader than long, with the antero-external angle rounded but prominent. Walking legs long, filiform; the second pair the longest; last joint straight, acute, and nearly as long as the next joint.

RANGE.-Western Atlantic; in dcep water.

\section{Arachnopsis filipes.}

Arachnopsis filipes . Stimpson, A. Milne Edwards.

The carapace has two fine spines, one on the gastric the other on the cardiac region. There is a third smaller spine, placed also in the middle line, on the first segment of the abdomen. The hepatic regions are well developed, and have small spines. The branchial regions have hairy 
tubercles. The subhepatic and pterygostomian regions have sharp spines.

The first pair of legs is bowed, and about as long as the carapace; the superior border of the arm and forearm has spines; the hand is almost smooth, and is as long as the fingers. The legs of the second pair are twice as long as the carapace.

The sternum, the abdomen, and the external maxillipedes are granular.

RANGE.-Dominica, Barbados.

\section{Euprognatha.}

Euprognatha . Stimpson, A. Milne Edwards.

The carapace is subpyriform. The rostrum appears to be composed of three spines, the central spine being the interantennular spine, which points forwards and downwards; or of four or five spines, from the presence of a spine from each basal antennal joint. There is an erect spine on the orbital arch. Postocular spine reaches beyond the end of the eye. Eye is large; peduncle short. Basal antennal joint is armed at the anterior extremity with a slender spine reaching forward as far as the rostral horns; the flagellum is exposed from above. The fourth joint of the external maxillipedes is L-shaped, and strongly produced beyond the insertion of the fifth joint. Legs long and slender. Last joint but one of the walking legs of first pair more than twice as long as the terminal joint; and three times as long as the joint next it on the inside.

RANGE.-West Atlantic.

Sinorsis of the SPECIES.

A. Rostrum appears to be composed of five spines, the central being from the ridge on the interantennular 
partition, the two lateral being on the extremity of the basal antennal joint.-(E. rastelliferr.)

B. Rostrum appears to be composed of four spines, there being no central spine from interantennular partition.

،. Median and branchial spines present on carapace. -(E. gracilipes.)

b. No median and branchial spines present on carapace, only elevations.-(E. inermis.)

\section{Euprognatha rastellifera.}

Euprognatha rastellifera . . Stimpson, A. Milne Edwards.

Carapace naked, with the regions well defined, and minutely and irregularly granulated. There are three spines in the middle line: one on the gastric, one on the cardiac, and one on the first ring of the abdomen; there is one similar spine on each branchial region, making a transverse row with the spine on the cardiac region. There are a few small spines on the sides of the branchial, hepatic, and pterygostomian regions. The rostrum has besides its own two horns, a central spine from the interantennular partition, and one on each side from the extremity of the basal joint of external antenna.

The first pair of legs is nearly twice as long as the carapace; hands swollen; fingers not gaping. The walking legs have the first pair nearly one-third longer than the legs in front.

The sternum is regularly granulated, except the concave portion between the first pairs of legs.

RANGe.-Martinique, St. Vincent, Grenada, Barbados, Santa Cruz; in deep water. 


\section{Euprognatha gracilipes.}

\section{Euprognatha sracilites. A. Milne Edwards.}

The carapace is slightly flattened. The median and branchial spines are short; the spines on the lateral edges are well developed; the surface is granular. The horns composing the rostrum are short, and the spine from the interantennulary partition is not visible on a dorsal view; consequently there appears to be only four spines forming the rostrum. The basal joint of the external antennx has below two longitudinal series of toothed granulations forming two crests, one inside and one outside this joint.

The external maxillipedes are granular, and the sternal plastron has granular ridges. There are fine granulations on the legs.

The first pair of walking legs, in the male, is long and thin: shorter in the female. Below the insertion of each leg there is a flat granular expansion of the sternum. These prolongations border the carapace in its posterolateral part, and resemble a series of teeth.

Range.-Dominica, Barbados, Santa Cruz; in deep water.

\section{Euprognatha inermis.}

Euprognatha inermis . A. Milne Edwards.

The median and branchial spines of the other species are represented by elerations. The granulations are well marked. The rostrum appears to be composed of four spines, the interantennular spine not being visible on a dorsal view.

RANGE-Guadaloupe, the Grenadines; in deep water. 


\section{Trachymaia.}

Trachymaia . A. Milne Edwards.

The carapace is subpyriform, short, wide, and curved posteriorly. The interorbital space of moderate width. The floor of the orbit has a spine at its edge. The rostrum is small, composed of two diverging spines separated by a deep notch. The eye, of which the cornea is a little compressed in front and behind, is folded in a fossa at the base of the postorbital spine. The orbits are very open above and below. The basal joint of the external antenne is very narrow, and does not enclose the orbit below; the flagellum is exposed at each side of the rostrum.

The walking legs diminish gradually in length from first to last, and the difference in size is very considerable among them. The terminal joint is not prehensile; their inferior border is smooth.

Range--Barbados, Santa Cruz; in deep water.

\section{Trachymaia cornuta.}

Trachymaia cormuta. A. Milne Eclwards.

The carapace granular and convex. It has a few small spines. Upon the gastric region there are four arranged in the shape of a cross. The anterior cardiac lobe has two, situated in the middle line. The branchial region has four or five spines. The lateral edge has a row of short spines. The superior orbital border has a spine directed forwards. The basal joint of the external antennx has thrce small spines, one terminal, the two others situated at the orbital border.

The arm and forearm of the first pair of legs are 
spinous; the hand is smooth. The walking legrs are clothed with some short and very scanty hairs.

The abdomen and sternal plastron have some very fine granulations.

RAN(iE.-Barbados.

c. Rostrum much longer than broad:-

\section{Lispognathus.}

Lispognathus . . . A. Milne Edwards.

Dorhynchus . . . . Norman.

The carapace is subpyriform and moderately convex, with well-developed pre- and postocular spines. The spines of the rostrum are straight, slender, and slightly diverging. The eyes are short.

The basal joint of the external antennæe is slender, reaches the front, and is armed on its inferior surface with small spines and with large spine at its anteroexternal angle. The fourth joint of the external maxillipedes is somewhat elongated and rounded at its distal extremity.

The first pair of legs, in the male, is well developed, with the fingers incurved. The walking legs are moderately elongated. The abdomen is six-jointed in both sexes.

Range-Caribbean Sea, West Africa, New South Vales; in deep water.

\section{Lispognathus furcillatus.}

Lispoguathus furcillatus. A. Milne Edwards.

The carapace has above in the middle line two spines: one gastric and one cardiac; the protogastric and the 
branchial lobes have each one spine. The gastric groove is deep. The hepatic regions are smooth, and have two or three small spines; there are also some spines on the edge of the branchial region. The rostral horns are cylindrical, pointed, and slightly diverging.

The first pair of legs of the female has some spines and stiff hairs. The hands are bowed within, and their fingers are in contact along their entire length when closed. The fourth joint of the walking legs has a terminal spine above the articulation of the fifth joint; the last joint is long and slightly curved towards its extremity.

RANGE.-Grenada.

\section{Anamathia.}

Ancrmathica . . Smith, Miers.

Amathia . . . Milne Edwards, Roux.

The carapace is in the form of an elongated triangle, rounded behind; its upper surface and edges armed with long spines. Rostrum almost as long as the postorbital portion of the carapace, bifid; the horns slender and diverging. Eyes small; a præocular spine present or absent; postocular spine distinct. The basal joint of the external antennæ is slender, and usually armed with a tooth at its antero-cxternal angle. The flagellum is inserted under the rostrum, at some distance in front, on a level with the eyes. The epistome is almost as broad as it is long. The fourth joint of the external maxillipedes is dilated on the outside, and truncated at its two internal angles.

The first pair of legs is shorter than the other legs, filiform in the female, slightly swollen in the male; the other legs are long and filiform, with the second pair 
more than three times the length of the postocular portion of the carapace, posterior spine not included; the other legs are slightly shorter. The last joint of the four last pairs is long, sharp, and without spines or teeth on its under surface.

The abdomen is seven-jointed in both sexes.

RANGE.-Mediterranean Sea, IVest Indian Sea, Coast of the United States, the Phillipines; in deep water.

\section{Synopsis of the SPECIES.}

A. Spines on the extremity of the fourth joint of the legs present.

a. Horns of rostrum diverging, then parallel. A spine on the antero-external angle of basal joint of external antennæ. A spine on external angle of buccal cavity.(A. hy'strix:)

b. Horns of rostrum diverging from root. A spine on antero-external angle of basal joint of external antenna: a second spine on outer side of this joint. No spine at antero-external angle of buccal cavity.-(A. crassa.)

B. No spines on extremity of fourth joint of legs.

c. No spines on antero-external angle of buccal cavity. - (A. modesta.)

\section{Anamathia hystrix.}

Anamatlia liy'strix. . Stimpson.

Amathic hystrix. . . A. Milne Edwards.

Carapace with long sharp spines; on the gastric region four, two in the middle line, one behind the other, and one on each side; one on the cardiac region, also in the middle line, and one behind this on the postcrior margin; on each branchial region three spines, one projecting outwards laterally; on each side of the gastric 
region there is a large lateral spine almost as large as the lateral branchial spine; the spine curves outwards and forwards. Rostrum long; the horns at first diverging then more or less parallel. A large preocular and a small postocular spine. Basal joint of external antenne has a sharp spine on antero-external angle. Buccal cavity has a large spine at antero-external angle. The extremity of every fourth joint of legs spinous.

RANGE.-St. Kitts, Martinique, St. Lucia, St. Vincent, Havana.

\section{Anamathia crassa.}

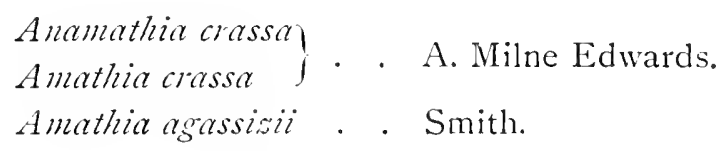

Carapace has the spines smalle:; the anterior lateral spine being much smaller than the lateral branchial spine. The rostral horns are large, and diverge from their origin. A long preocular and a small postocular spine. Basal joint of external antenne has a spine at its anteroexternal angle and a sccond spine half-way on its external edge. There is no spine at antero-external angle of buccal cavity. There are spines on the extremity of each fourth joint of legs.

RANGE.-Cuba, Florida.

\section{Anamathia modesta.}

Amathia modesta . . A. Milne Edwards.

Carapace has twelve spines, the two on the gastric region being only spiniform tubercles. The lateral and posterior spines are longest; that on the outer edge of the branchial region being one-fifth the width of the 
carapace. Rostrum is nearly as long as the postfrontal part of the carapace; horns rather short, diverging and curving outwards at the tips. Preocular spine small; postocular spine smaller. No spine on antero-external angle of buccal cavity. Legs have no spine on extremity of fourth joint.

RANGE.-Sand Key.

\section{Nibilia.}

Nibilia . . A. Milne Edwards.

Herbstia . . Desbonne and Schramm.

The carapace is subpyriform, very curved, longer than broad. The internal orbital angle is prolonged into a point above. The superior ocular border has a spine; a straight fissure separates the suborbital border from the basal joint of the external antennx, which is long. The rostrum is composed of two slightly diverging horns. The basal joint of the external antenne is prolonged on the outside into a spine; the second joint is inserted on the sides of the rostrum; it is long and cylindrical. The fourth joint of the external maxillipedes is deeply notched on the inside for the insertion of the fifth joint.

The legs of the first pair the longest. The pincers are large and almost cylindrical; the fingers do not terminate in a spoon, they are in contact in their whole length when closed. The walking legs of the first pair are longer than the others. The last joint is unarmed below. The abdomen of the male has seven joints.

RANGE.-Caribbean Sea.

\section{SinOPSIS OF THE SPLCIES.}

A. External antenne as long as rostrum.

a. Spine at root of rostral spine small. 
$a^{1}$. No remarkable spine on lateral edge between eye and branchial region.-(N. armata.)

B. External antenne not as long as rostrum.

b. Spine at root of rostral spine nearly half as long as rostral horn.

$b^{1}$. A large lateral spine, curving forwards half-way between cye and branchial region.-( $N$. érinacca.)

\section{Nibilia armata.}

Nibilica armata . . A. Milne Edwards.

Carapace slightly enlarged behind and covered with sharp and unequal spines, of which the arrangement is very irregular. Lateral spine between orbit and branchial region not very remarliable for size. The rostral horns fine; there is a long preorbital spine followed by a shorter spine. The external antenne are as long as the horns of the rostrum; their basal joint terminates in a spine shorter than the preorbital spine.

The fourth and fifth joint of the first pair of legs and the fourth joint of the walking legs have spines. The body and legs have short stiff hairs.

RANGL.-Barbados, St. Vincent, Grenadines.

\section{Nibilia erinacea.}

Nibilia crinacea. . A. Milne Edwards.

Carapace much swollen; very spinous. The front is prominent, and formed of six spines; two of the rostrum long, almost cylindrical, united at their base, but separated and diverging through four-fifths of their length; two preocular spines nearly half as long as the rostral horns, pointed and directed outwards and a little upwards; at the base of these latter there is a small spine. The 
superior orbital border has two broad spines in the form of triangular teeth. There is a large spine, curved forwards, on the lateral edge, half-way between the orbit and the branchial region.

The basal antennal joint has a broad base, contracted towards its extremity; its external border has two spines, of which the last is situated near the fissure separating the antennx from the suborbital border of the carapace. The antenna are not as long as the rostral horns.

The under surface of the lateral parts are spiny, but the external maxillipedes, the sternum, and the abdomen are smooth.

The first pair of legs is thin. The palm is as long as the arm; the surface is scarcely granular. The arm and forearm are spiny above and below. In females and young males the fingers are in contact in their whole length when closed. The walking legs are long and thin; some spines, arranged longitudinally, are found on the fourth and fifth joint; the last joint is long and large.

There are short hairs on the ends of the legs, and here and there on the carapace, giving to these parts the appearance of a piece of cloth, but for the most part the carapace is naked.

RANGE.-Guadaloupe; in deep water.

\section{I0. Chorinus.}

Chorinus . . Leach, H. Milne Edwards, Dana.

Cancer. . Herbst.

Pisa . . Latreille.

Carapace is subtriangular, elongated, convex, and without lateral marginal spines. A prominent pracocular spine. The rostrum is formed of two large pointed and 
horizontal horns. The eyes are small. The orbits are directed outwards and downwards, but the floor of their cavities is very incomplete. The basal joint of the external antenne is straight, and without remarkable spines at its extremity. The flagellum is inserted under the rostrum, and is in great part hid by it. The third joint of the external maxillipedes is prolonged in front; the fourth joint is longer than wide, and dilated externally; it is not auriculated.

The first pair of legs is long, especially in males, and the pincers are strongly curved inwards, toothed, and pointed. The walking legs are cylindrical; those of the third pair are of moderate length, but the second pair is very long; in the male these legs are in general one and a half or twice as long as those of the third pair. The sternal plastron is longer than wide. The abdomen is seven-jointed.

RANGE.-West Indies, Coromandel Coast, Seas of Asia; in deep water.

\section{Chorinus heros.}

Chorimusheros . Herbst, H. Milne Edwards, Leach, Desbonne and Schramm.

Maia heros . Bosc.

Pisa heros. . . Latreille.

The carapace is almost twice as long as broad, and convex above; the gastric region is very large, swollen, and tubercular anteriorly; branchial regions slightly developed, and almost smooth. Rostrum very long. The anterior and superior angle of the orbit has a large horizontal spine; antero-lateral borders armed in front with two round teeth.

First pair of legs of the male twice as long as the 
postfrontal portion of the carapace, cylindrical; the legs of the second pair are once and a half as long as the postfiontal portion of the carapace. Rostrum, sides of carapace, and four last pairs of legs have hairs; colour, ycllow-red.

RAN(iE.-Barbados.

\section{Subfamily III. Acanthonychinæ.}

Acanthonychina.

Miers.

Acanthonychide

Stimpson.

Maiens phanerophthalmes (part). Milne Edwards.

Carapace usually more or less oblong and flattened, more rarely elongated and subcylindrical or subtriangular. Rostrum simple or bifid. Eyes small, and immobile or partially retractile, and concealed beneath the præocular spine. Postocular spine small or absent. Basal joint of external antenne usually enlarged at base, and narrowing distally. The fourth joint of the external maxillipedes is truncated at its distal end, and articulated with the next joint at its antero-internal angle.

The first pair of legs, in the male, usually has the palm compressed. The walkng legs are of moderate length. Abdomen four to seren-jointed.

\section{Synopsis of the Genera.}

A. Carapace elongated, ovato-cylindrical. Rostrum elongated, emarginate or bifurcated. Praocular spine minute or wanting. Eyes immobile. Antenna visible from above. Last two pairs of legs very short.-(Anomalothir.)

$B$. Carapace more or less oblong or orbiculate. Rostrum flattened, emarginate or

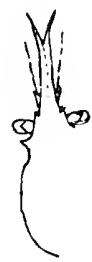
two-spined. Præocular spine usually well 
developed. Eyes mobile. Walking legs of moderate length.

a. Flagellum of external antennxe concealed beneath the rostrum and not visible from above. Walking legs have the last joint but one not dilated and compressed.(Epialtus.)

b. Flagellum of external antennæ exposed and risible from abore at side of rostrum. Walking legs have the last joint but one

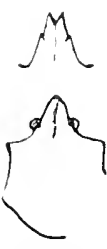

Efialtus. dilated and compressed.-(Acanthonj'1:)

\section{Anomalothir.}

Anomalothir . . . Miers.

Anomalopus . . . A. Milne Edwards, Stimpson.

Carapace is elongated, almost subcylindrical. Rostrum very long, slender, two-horned. Eyes without orbits, immobile; procular spine small, acute, postocular spine minute. External antenne exposed from above; basal joint narrow. Antennulary fosse large. Epistome twothirds as long as broad. Fourth joint of external maxillipedes without any notch at the internal angle where it articulates with the next joint; external angle prominent.

First pair of legs, in the female, shorter than the carapace. Walking legs have the first pair very long, twice as long as the carapace, with the last joint nearly straight, and three-fourths as long as the next joint; last two pairs shorter than the others; terminal joint formed for holding. Of very small size.

RANGF-Western Atlantic; in deep water. 


\section{Synopsis of the Species.}

A. The rostral horns have their terminal half forked. Spine on antero-external end of basal joint of external antennxe well developed.-(A. furcillatus.)

$B$. The rostral horns have their tips close together. Spines on antero-external end of basal joint of external antenna small.-(A. frontalis.)

\section{Anomalothir furcillatus.}

Anomalothir furcillatus . Stimpson. Anomalopus furcillatus . A. Milne Edwards.

Carapace minutely pubescent, unarmed, except in front; regions scarcely defined. Rostrum equalling in length two-thirds that of the postfrontal part of the carapace, forked at the terminal half of its length; horns but slightly divergent. External antenna shorter than rostrum; flagellum as long as the two preceding joints taken together. Internal antenne reaching to the extremity of the peduncle of the external antenna. Basal joint of the external antennæ, smooth below, terminates outside in a small spine.

The first pair of legs is not much developed; the arm is long and almost cylindrical; the forearm has outside a small spine; the hand is slightly swollen; the fingers are in contact at their tips when closed. The terminal joint of the last pair of legs but one is large, curved and formed for holding; these legs are the shortest.

Rasge. - Dominica, St. Vincent, Grenada, Santa Cruz. 


\section{Anomalothir frontalis.}

\section{Anomalopus frontalis . A. Milne Edwards.}

The carapace is wide behind, and not so elongated. The rostral horns approach each other to their cxtremities. The suborbital border is unarmed. The spine on the basal joint of the external antennæ is very small.

Range.-Barbados, Montserrat, Guadaloupe, Dominica.

\section{Epialtus.}

Epialtus . . . H. Milne Edwards, Dana.

Carapace oblong or orbiculate, more or less hexagonal in outline, sometimes with lateral expansions. The rostrum is wide, simple, emarginate or bifid. The eyes are short. The orbits are incomplete below.

The external antenne are hid under the rostrum: the flagellum very short. The fingers of the first pair of legs are excavated at their extremities. The walking legs often have, on the inferior border of the last joint, a setiform tubercle. The last joint but one has no lateral tooth. The first pair of walking legs is the longest.

The abdomen of the male has six or seven segments. Crabs of small size.

RANGE.-East and West Coast of North and South America; in deep water.

Synopis of tIIE SPecies.

A. Rostrum an equilateral triangle.

a. Front angle rounded.-(E. bituberculatus. $)$

b. Front angle notched.-(E. dilatatus.)

$B$. Rostrum long and narrow, with rounded end.(E. longirostris.) 


\section{Epialtus bituberculatus.}

Epialtus bituberculatus. H. Milne Edwards, A. Milne Edwards and Lucas, Desbonne and Schramm.

Epialtus affinis . . . Stimpson.

Epialtus brasilionsis. Dana.

The lateral edges of the carapace have two expansions, -one hepatic, one branchial. The rostrum is entire with a blunted angle, forming more or less a triangle of three equal sides.

The first pair of legs of the male is strong; the hand is broad and compressed; the movable finger has a large tooth on its holding edge. The walking legs are thin, and have no tooth on their last joint but one; this joint has a bunch of hairs.

The body and legs have brown hairs.

RANGE.-Guadaloupe, St. Thomas, Brazil, Chili.

\section{Epialtus dilatatus.}

\section{Epialtus dilatortus. . A. Milne Edwards.}

The distance between the tips of the hepatic lateral expansions is about equal to the distance between the branchial. The rostrum forms an equilateral triangle, but the front angle is divided into two by a notch: the under surface has an $\mathrm{X}$-shaped ridge.

RANGE.-St. Thomas.

\section{Epialtus longirostris.}

Efialtus longirostris . Stimpson, A. Milne Edwards.

The rostrum is about a quarter of the total length of the carapace; it is thin, its edges are parallel, and its 
extremity is truncated. The first and second pairs of legs are long.

RANGE-St. Thomas.

\section{Acanthonyx.}

Acanthonj.x. . . Latreille, H. Milne Edwards,

Miers.

Maia . . . . Risso.

Carapace suboblong, rounded behind, and with the dorsal surface depressed, not markedly constricted behind the prominent antero-lateral angle; the lateral branchial spine small. Preocular spines prominent, acute. The rostrum is horizontal, triangular, with its extremity notched. Eyes small, mobile. The orbits are circular. Basal joint of external antenne narrowing slightly from base to dilated extremity, which is unarmed; flagellum visible on a dorsal view at each side of the rostrum. The fourth joint of the external maxillipedes is truncated distally, and slightly notched at its antero-internal angle.

The first pair of legs, in the male, is well developed; palm compressed, but slightly turgid in the middle, and often slightly keeled above; fingers acute, but having between them, when closed, an interspace at the base. Walking legs short, with the last joint but one flattened, dilated, and notched on its inferior margin, against which the curved last joint, closing, forms a hook.

Abdomen in the male six-jointed. Of small size.

RANGE.-Atlantic and Pacific Oceans; in shallow water. 


\section{Acanthonyx petiverii.}

Acanthony'x petiocrii

A. Milne Edwards, Miers, Bell, Dana, Smith, Von Martens, Dcsbonne and Schramm.

Acanthony'x cmarginatus. . Milne Edwards and Lucas.

Acanthony'x debilis . . . . Dana.

Acanthony'x concameratus . . Kinahan.

Cancer muricatus comprissum. Petiver.

The lateral edge of the carapace is armed with three teeth, of which the anterior is very large, flat, rounded, and not curved in front, and of which the two posterior are very small and obtuse; there are no spines at the external angle of the orbits; the teeth of the antcrior orbital angles are strong and elevated. The rostrum is flat and terminates in two little teeth more or less sharp.

The first pair of legs in the male is strong; the hand has straight edges. The fingers are scarcely toothed, and meet only at their extremities when closed. The forearm has a ridge outside. The arm has a tubercle near its base. The walking legs are compressed.

The fourth and fifth segment of the abdomen, in the male, are soldered together.

RANGE.-Guadaloupe, Brazil, California to Chili, Galapagos Islands.

\section{Subfamily IV. Microrhynchinæ.}

Microrlynnchine . Miers.

Carapace more or less triangular and convex. Rostrum simple, or more or less bifurcated. Eyes short and 
completely retractile. Preocular spine short or absent; postocular spine or lobe largely developed. Basal joint of external antenne considerably enlarged throughout its length. The fourth joint of the external maxillipedes truncated distally. Legs usually rather slender.

Abdomen six to seven-jointed in both sexes.

\section{Esopus.}

Esopus. . A. Milne Edwards.

The body and legs are almost completely glabrous. The carapace is thick, gibbous, and as it were bloated elongato-oval. The front is formed of a large projecting round tubercle. The orbits are incomplete below, and the superior orbital margin is cut by a large fissure. The ocular peduncles are large, and can be retracted into a fossa. The basal joint of the external antenna reaches almost to the front. The buccal cavity is wide in front. The fourth joint of the external maxillipedes is a little dilated outwards and anteriorly, and has not a notcl inside for the articulation with the next joint.

The walking legs are very thin, very long, and terminate in very delicate tips. The abdomen of the female is broad, curved, and formed of three segments, the third, fourth, fifth, sixth and seventh being soldered together. Of small size.

RANGE.-West Indian Sea; in deep water.

\section{Esopus crassus.}

Lsopus crassus . . . A. Milne Edwards.

The carapace is slightly contracted in front; it is completely covered with shining granulations. Anteriorly it is much swollen. The interorbital space is divided 
into three lobes of about the same size by two longitudinal depressions, which join the cervical groove behind. The protogastric lobes are well marked on the outside, but on the inside they join the metagastric lobe; this latter is raised to a point upon the others, where it is separated from the urogastric lobe by a deep groove. The anterior cardiac lobe is conical, prominent, and surmounted by a large tubercle; the posterior cardiac lobe is much more depressed, and divided into two parts by a transverse groove. The hepatic region is small and rounded. The branchial region has on its middle a tubercle smaller than the cardiac lobe. The branchial border, over the base of the legs, is cut into three small lobes. The pterygostomian region is cut into lobes.

The basal joint of the external antenne las the same granulations as the carapace. There are large granulations on the epistome as well as on the abdomen.

The first pair of legs, in the female, is cylindrical. The walking legs are smooth; the three first pairs are about the samc length, the fourth pair is a little shorter.

RANGE.--Barbados.

\section{Subfamily V. Stenocionopinæ.}

Stenocionopince. . Miers.

Carapace somewhat oblong, and posteriorly prolonged. Rostrum composed of two spines. Eyes elongated and retractile, partly concealed by the prococular spine, which is greatly elongated. Basal joint of external antennx considerably enlarged throughout its cntire length.

The articulation betwcen the third and fourth joint of the external maxillipedes is often peculiar, the latter being dovetailed into the former. 


\section{Tyche.}

Tyche . . . Miers, A. Milne Edwards, Bell.

Platyrhynchus . Desbonne and Schramm.

Carapace produced behind and laterally. The rostrum composed of two diverging horns. The pracocular spines extend forwards and outwards beyond the rostral spines. The superior orbital order is developed laterally, almost hiding the eyes. There is no orbital floor. The external antenna are hid under the rostrum; their basal joint is wide, and its antero-external extremity forms a small blunt point; the succeeding joints are cylindrical. The fourth joint of the external maxillipedes is dovetailed into the third in an S-shaped joint; the internal margin of the third reaching almost to the summit of the fourth joint.

The first pair of legs is little developed. The walking legs are thin, and have a much curved terminal joint.

RANGE.-East and West Coast of America ; in shallow water.

\section{Tyche emarginata.}

Tyche emarginata . . . . White, Stimpson, A. Milne Edwards.

Platyrlynchus trituberculatus. Desbonne and Schramm.

The carapace is prolonged backwards into two flat lobes. The gastric region is on a more elevated plain than the front; it has three tubercles, two anterior and one posterior and median. There is a large tubercle on the anterior branchial lobes; a strong tuberculous crest extends upon the lateral border of the branchial regions. The cardiac lobe has three tubcrcles. 
The first pair of legs of the male is twice as long as the postorbital portion of the carapace.

There are curved hairs on the rostrum, on the prominent parts of the carapace, and on the legs.

The carapace is grecnish above, with two white triangular patches; it is clark above the base of the legs.

RANGE.-Guadaloupe, Key West.

\section{Family II. Maiidæ.}

\section{Maiide . . Miers.}

Eyes retractile within the orbits, which are distinctly defined, but often more or less incomplete below, or marked with open fissures in their upper and lower margins.

Basal antennal joint always more or less enlarged.

\section{Subfamily I. Maiinæ. Subfamily II. Schizophrysinæ.}

Sinopsis of tile SubFAMILIES.

A. Carapace subtriangular. Rostrum well developed. First pair of legs, in the male, enlarged; fingers not excavated at tips.-(Mraina.)

B. Carapace broadly triangular, or oval, or nearly circular. Rostrum short or wanting First pair of legs, in the male, small, slender; the fingers usually excavated at tips.-(Scliwoparysince)

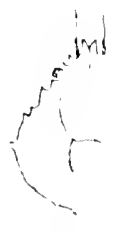

Maiina.

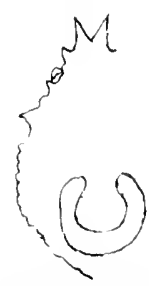

Sihisophosinu. 


\section{Subfamily I. Maiinæ.}

Haince . . . . . . . . Niers.

Maiens cryptophthalmes (part). Milne Edwards.

Carapace usually subtriangular. Rostrum well developed. First pair of legs, in the male, enlarged; fingers not excavated at tips.

\section{Synotsis of the Genera.}

A. Rostrum vertically compressed and laminated, bifid or notched.

a. Orbits shallow and open above, so that the eyes, when retracted, are more or less visible from above; the eyes short and thick.-(Herlbstic.)

B. Rostrum composed of two more or less distinct divergent spines.

b. Orbits deep, so that the eyes, when retracted, are concealed; the eyes small, eye-peduncles slender.

$b^{2}$. Carapace triangular, rounded behind.-(Pisa.)

$c^{1}$. Carapace pear-shaped.-(Sisyphus.)

\section{Herbstia.}

Herbstia . . . . . H. Milne Edwards, Micrs.

Cancer . . . . . . Herbst.

Inachus . . . . . . . Fabricius.

Maia . . . . . . Latreille.

Mithrax . . . . . Risso.

Rhodia . . . . . . Bell.

Micropisa, Herbsticlla. . Stimpson.

Carapace is depressed, broadly triangular, with the dorsal surface usually spinose or tuberculated; the gastric and the branchial regions are about equally developed. 
Rostrum small, scarcely longer than wide, and is formed of two flat horns, pointed and diverging, of which the base occupies almost the whole width of the front.

The eyes are large. The orbits are oval and directed obliquely forwards, outwards, and upwards; their superior border presents two small fissures, through which the retracted eyes are visible, and terminates anteriorly in a small spine, less projecting than the spine situated below it, which belongs to the basal joint of the external antenne; the inferior border is complete and has no fissure.

The arrangement of the antennary region, of the external antenne, of the cxternal maxillipedes, of the sternal plastron, and of the legs, is essentially the same as in the genus $P$ isa.

The abdomen is seven-jointed.

RANGE.-The Mediterranean Sea, Tropical Atlantic, West Coast of Mexico, Australia; at moderate depths.

\section{Herbstia depressa.}

Herbstia depressa . A. Milne Edwards, Stimpson. Herbsticlla depressa. Stimpson.

Carapace generally covered with sordes adhering to a slight pubescence easily detached, beneath which the surface is glabrous and slightly tuberculose. There is a median protuberance on the gastric, and one on the cardiac region; two tubercles on the intestinal region in a transverse row. Lateral and posterior margin armed with small spiniform tubercles. A stout spine on the hepatic region.

Rostrum with the horns triangular. Frontal region and the surface of the rostrum with a median longitudinal sulcus between two short prominent ridges. 
Basal spine of external antenne long, projecting almost as far as the horns of the rostrum.

First pair of legs shorter than the second pair; fourth joint has a row of spines; hands smooth. Walking legs hairy above, slender: second and third pairs longer than the carapace; fourth joint armed above (sometimes below) with a row of spines.

RANGE.-St. Thomas.

\section{Pisa.}

Pisa . . . Leach, Milne Edwards, Bell, Miers.

Cancer. . Herbst, Montagu.

Inachus . Fabricius, Risso.

Macia . . Latreille.

Carapace rounded behind, with the regions well defined, the gastric region especially. The front is wider than the buccal cavity, and is armed with four horns directed forwards, of which the two external occupy the anterior extremity of the superior orbital border, and the two middle ones, with diverging ends, form the rostrum, which is always less than one and a half times as long as wide.

The eyes are scarcely thicker than their stalks. Orbits deep, concealing the eyes when retracted, oval, and directed outwards and downwards; the superior edge has two clefts separated from each other by a triangular tooth; their external angle is situated rather below than above the lateral edge of the carapace, which ends here; below, the orbital border is interrupted by a large hollow.

The basal joint of the external antennx, much longer than wide, extends beyond the inner canthus of the orbit, but is concealed by the spine from the prolongation of the superior orbital border; the second joint, frail and cylindrical, is inserted at about an equal distance from the 
fossæ and from the orbits, a little outside the level of the external border of the rostrum, so as to be exposed between this prolongation and the lateral horns of the front; the third joint is small and cylindrical; the fourth is very long. The antennary region is about the size of the buccal cavity, and the epistome is large and almost square.

The external maxillipedes are very broad; the third joint is produced at its antero-internal angle; the fourth is triangular, being broad at the outer margin.

The first pair of legs, in the adult male, is very large, and larger than the second pair of legs; the hands are thick; the fingers, when closed, meeting onty at the outer margin of their points, which are toothed; those of the female are much smaller, the fingers meeting when closed throughout nearly their entire length, and are shorter than the second pair. The remaining legs, moderately long, diminishing gradually from the second to the fifth pair, are cylindrical; the last joint is curved.

The abdomen is seven-jointed in both sexes.

RANGE. - Mediterranean Sea, Coast of the British Isles, Azores, Cape Vercle Islands, West Indies, Zanzibar; at moderate depths.

\section{SyNOPSIS OF TIIE SPECIES.}

\section{A. Carapace suboval.}

a. The horns of the rostrum diverging then straight, or turned inwards towards their tips; one-third the length of the postfrontal portion of the carapace.-( $P$. antilocapra.)

$B$. Carapace long and narrow.

b. The horns of the rostrum diverging.-(P. prolonga. $)$

C. Carapace pyriform. 
$c$. The horns of the rostrum diverging throughout their course; soldered together to half their length at their base.- $(P$. erinacea. $)$

\section{Pisa antilocapra.}

Pisa antilocatra . Stimpson, A. Milne Edwards.

Carapace subovate, rather narrow, pubescent, and spinous, with a strong acute spine on the hepatic region; seven to ten smaller spines on the branchial regions, and four, forming a rhomb, on the intestinal region. There are some sharp tubercles on the cardiac and gastric regions. Rostrum horizontal, equalling in length more than a third of the length of the postfrontal portion of the carapace; horns diverging in the basal third, rather slender, acute and straight, or slightly curved inwards near their extremities. Prococular spine slender, less than a third as long as the rostrum. On the superior margin of the orbit there are two spiniform teeth between the base of the preocular spine and the external angle, which is also acute. Spine of basal joint of external antennxe much smaller than the preocular spine.

Legs pubescent, with their fourth joint spinous above. Last joint of walking legs unarmed on their inferior edge.

RANGE.-West Indian Sea.

\section{Pisa prælonga.}

Pisa frelonga . Stimpson, A. Milne Edwards.

Carapace long and narrow, the width across the branchial regions being very little greater than that between the orbits; sparsely hairy, and has a few small spines on the sides. Surface under the hairs smooth. Rostrum large, as long as one-third the length of the 
postfrontal portion of the carapace; horns slender, acute, diverging. Orbit large, with one sharp tooth on the upper margin, near the base of the postocular tooth. Preocular pine slender, acute. Basal joint of external antennæ has a spine in front, which is smaller than the præocular spine, and a second spine on the inner side near its base.

RANGE.-West Indian Sea.

\section{Pisa erinacea.}

Pisa crinacer . . A. Milne Edwards.

Carapace pyriform, covered with short hairs; regions well marked; there are five spines in the middle line, two in the gastric region, the posterior is the larger, and resembles a sharp tubercle; three on the cardiac region, the central one the shortest. The branchial region has two large spines and two tubercles placed more in front. The lateral borders have four tubercles. The rostrum is formed of two long thin horns, soldered together at their base, free and diverging at their extremities. Internal orbital angles spiniform, but slightly advanced. Basal joint of external antenne broad, and separated from the suborbital border by a deep notch. Walking legs thin and long.

RANGE.-West Indian Sea.

\section{Sisyphus.}

Sisyfhus. . A. Milne Edwards, Desbonne and Schramm.

Carapace oval or pear-shaped, depressed, covered, as well as the legs, with short brown hairs. There is no praocular spine. The front is formed of two rostral 
horns. The orbits are deep and tubular; the ocular peduncles are very thin; the superior orbital border is cut by deep fissures. The basal joint of the external antenna is wide, and in uniting with the carapace closes the orbit below; the second joint is large, slightly flat, and almost as long as the rostrum; the third joint is thin but well developed; the flagellum is small. The antennulary fosse are wide behind, very narrow in front. The external maxillipedes are wide; the fourth joint is auriculate at its antero-external angle, and deeply notched inside for articulation with the next joint.

The legs of the first pair of the male are of an equal size, and are slightly swollen; the fingers of the pincers meet only at their tips when closed. The walking legs are folded forwards and terminate in a very small joint, very crooked, very pointed, and folded under the leg. The abdomen of the male has seven joints.

RANGE.-West Indian Sea.

\section{Sisyphus compressus.}

Sisyplus compressus. . Desbonne and Schramm, A. Milne Edwards.

The regions on the carapace are not well marked; surface almost smooth. The gastric region has indications of four tubercles, of which the three anterior are arranged transversely and the posterior one is on the middle line; there are two longitudinal projections on the interorbital space. There is a very faintly marked tubercle on the hepatic region, which forms a slight projection outwards; there is a tubercle on the lateral edge behind the branchio-hepatic groove. Rostral horns, thin, flat, almost straight, and parallel to each other, being separated by a narrow interval, are a little inflected below. 
The interorbital space is wide; the orbital borders are rounded in front and behind.

The fourth joint of the first pair of legs of the male is frail and unarmed; the fifth joint is a little rough; the hand is smooth, laterally compressed, without ridges; the fingers are thin, the movable finger has a strong tooth near its base. The walking legs are large, subcylindrical ; those of the first pair are the longest; the last pair is the shortest. The colour is brown.

RAN(:E.-Guadaloupe.

\section{Subfamily II. Schizophrysinæ.}

Schizophrysinc. . . . . Miers.

Carapace very broadly triangular, oval, or nearly circular. Rostrum short or obsolete. First pair of legs of the male small, slender; the fingers usually excavated at the tips.

\section{Temnonotus.}

\section{Temnonotus . . A. Milne Edwards.}

Carapace ovato-elliptical, convex, and tuberculated, with a horseshoe-shaped pit on the dorsal surface, circumscribing the cardiac region. The front is composed of two rostral horns in the middle, slightly elongated and diverging, and of two prieocular spines, one on each side, directed forwards and outwards. The superior orbital border has a fissure above. Eyes short and thick. The basal joint of the external antennix has a wide base and narrows distally; it is separated from the inferior orbital border by a notch. The front completely hides it on a dorsal view, but the flagellum is cxposed on each side of the rostral horns. The fourth joint of the external 
maxillipedes has its external angle dilated and its internal angle notched for the insertion of the next joint.

The walking legs are short. The first pair of legs is the largest.

RANGE.-West Indian Sea; in deep water.

\section{SyNOpsis OF THE SPECIES.}

A. An interocular groove present. Three spines on basal joint of external antenne. Anterior cardiac lobe flat and granular.-(T.gramulosus. $)$

$B$. No interocular groove present. One spine on basal joint of external antennæ. Anterior cardiac lobe smooth and prominent.-( $T$. simplex. $)$

\section{Temnonotus granulosus.}

\section{Temnonotus gramulosus. A. Milne Edwards.}

The carapace is covered with large granulations, between which are fine points. The regions are well marked; the interorbital portion is taken up by the epigastric lobes, which are cut off from the rest of the body by a transverse groove uniting the two fissures of the superior orbital border; the hepatic region has a slightly projecting lateral spine; similar smaller spines border the branchial regions. The anterior cardiac lobe is circumscribed behind and on the sides by a deep depression in the form of a trench, inside smooth and edged with a granular ridge on each margin. This trench is incomplete in front; the circumscribed lobe is flat and granular. The two rostral horns are small and a little flattened in their free portion. They have no granulations. The præocular spines scarcely reach the level of the division of the rostral horns. The superior orbital 
border has two teeth, one superior, the other lateral. The basal joint of the external antenne has three spines; the largest at the antero-external angle, the next at the inferior and internal angle, and the third, the smallest, between these two; the second and third joints are cylindrical.

The first pair of legs of the female is scarcely longer than the second pair. The hand is smooth; the fingers are acute. The arm and forearm have pointed tubercles. The walking legs are smooth. The sternal plastron, in the female, is oval.

RANGE.-Barbados.

\section{Temnonotus simplex.}

Tomnonotus simplex . . A. Milne Edwards.

The carapace has no interorbital groove ; the branchiohepatic groove is wide and deep; the branchial regions have many spines; the edges of the trench circumscribing the anterior cardiac lobe have no projecting ridge, and the circumscribed lobe is prominent and smooth. The basal joint of the external antennx has only a small spine at its antero-external angle.

RANGE.--Barbados.

\section{Family III. Periceridæ.}

Periceride. . . . . . . . Miers.

Maiens cryptophthalmes (part) . H. Milne Edwards.

Eyes retractile within the small circular and welldefined orbits, which are never incomplete. Basal joint of external antenne well developed, and constituting the greater portion of the inferior wall of the orbit; this joint is usually very considerably enlarged. 


\section{Subfamily I. Pericerinæ. \\ Subfamily II. Othoninæ. \\ Subfamily III. Mithracinæ.}

\section{Synopsis of tile SUbFanilies.}

A. First pair of legs with the fingers acute at the tips. Rostrum well developed.

a. Carapace more or less subtriangular. Second joint of external antenne not dilated.-(Pericerina.)

$B$. First pair of legs with the fingers excavated at the tips. Rostrum short or wanting.

b. Carapace suboblong; interorbital space broad Second joint of external antenne enlarged.-(Othoninc.)

c. Carapace broadly triangular, sometimes transverse; interorbital space narrow. Second joint of external antennæ not dilated.-( Mithracince)

\section{Subfamily I. Pericerinæ.}

$$
\text { Pcriccrince . . Miers, Stimpson. }
$$

Carapace more or less subtriangular. Rostrum well developed. Second joint of external antenne not dilated. First pair of legs with the fingers acute at the tips.

\section{Synopsis of THE GenerA.}

A. Rostrum emarginate at apex.

a. Basal joint of external antennie moderately enlarged.

$a^{1}$. Præocular spine distinct.-(Libinie.)

$B$. Rostrum composed of two distinct

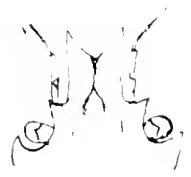

Libinia. spines. 
b. Basal joint of external antenna without a spine at its distal extremity.

$b^{1}$. Præocular spine present.

$b^{2}$. Spines of rostrum lamellate at base, acute distally. Basal joint of external antenna narrow.-(Scyra.)

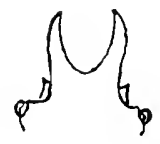

Sijra.

$c^{2}$. Spines of rostrum flattened, contiguous, and produced at their extremities into a lateral lobe. Basal joint of external antenna much enlarged.--(Lissa.)

$c^{1}$. Preocular spine absent.

$d^{2}$. Rostrum elongated, its spines contiguous to within a very short distance of their extremities, which are acute.-(Sphenocarcinus.)

c. Basal joint of external antenne often very much enlarged, with one or more spines at its distal extremity.

$d^{1}$. Carapace subtriangular, not deflexed in front.

$\epsilon^{2}$. Spine at antero-external angle of external antennal joint very short, not visible from above-(Pericera.)

$f^{2}$. Spine at antero-external angle of external antennal joint very long, visible from above.

$f^{3}$. Branchial spine small. Horns of rostrum more or less divergent.-(Microplirys.)

$g^{3}$. Branchial spine large. Horns of rostrum parallel. -(Macrocaloma.)

A. Rostrum emarginate at afex:-

\section{Libinia.}

Libinir . Leach, Say, Latreille, H. Milne Edwards, De IIaan, Dana, Miers.

The carapace very convex above, in general almost circular, and its dorsal surface is covered with numerous tubercles, which are sometimes developed as spines. The 
gastric region is not much developed, but the branchial regions are so, and have lateral spines. The rostrum is well developed, sometimes rather small, emarginate, or bifid at the apex, and so terminating in two teeth or spines.

The eyes small, very short. The orbits directed very obliquely forwards and outwards. Their external angle is formed by a large compressed tooth, which is separated from the sides of the cavity by two fissures, the upper one very narrow, the one below more or less open. Præocular spine usually distinct.

The basal joint of the external antenne is short, and is armed with a spine at the antero-external angle, behind which, on the exterior margin, is usually another tooth; the second articulation is thick, short, cylindrical, and inserted upon the sides of the rostrum at almost an equal distance from the orbit and antennulary fossæ; the third joint is a little smaller than the second, and the fourth is very frail and very short. The flagellum is not concealed by the rostrum. The epistome is very small, and all the antennary region is a fraction of the size of the buccal cavity.

The legs of the first pair are well developed, and are always about the same size as those of the second pair, and in general not as long, even in the male; the hand is almost cylindrical, and slightly swollen; the fingers are minutely and evenly denticulated on the inner margins, where they touch in almost their entire length when closed. The walking legs are well developed, sometimes elongated, with the joints subcylindrical, unarmed; the last joint nearly straight.

The abdomen is composed of seven segments in both sexes.

RANGE-Atlantic and Pacific, on both coasts of America. 


\section{SyNOPSIS OF THE SPECIES.}

A. Rostrum long, horns diverging. Gastric region has five spines, three in young specimens. A spine at antero-external angle of basal joint of external antennx. - (L. dubia.)

$B$. Rostrum small, horns directed forwards. Gastric regions has six spines. Two spines on the external lateral border of basal joint of external antenne.(L. rhomboidea.)

\section{Libinia dubia.}

Libinia dubia. . . Milne Edwards, Deliay, Gibbes, Hale Streets.

Libinia distincta. . Guérin-Meneville, Von Martens.

The carapace almost circular, and very curved. The body and the legs are covered with a short pubescence. The gastric region has in front a transverse row of five tubercles; the middle and two external ones are the largest; sometimes spiniform. There is another tubercle on the urogastric lobe. On the cardiac region there are four spines in the middle line; the last is the longest and most pointed. The hepatic region is smooth, or may have a tubercle or a spine. There are three spincs on each branchial region; sometimes a fourth marks with these a rhomboidal figure. The latcral edges have five spincs, and there are two spines below on the hepatic region; the first is the largest, and may be seen on a dorsal view.

The rostrum is long and bifurcate at its extremity, forming two diverging teeth; at the base of the rostrum, between the orbits, there is a triangular depression. The preorbital angle is directed slightly outwards. The 
basal joint of external antennæe has a small spine at its antero-external angle; there is a second spine behind it on the same side.

The length of the pincers varies. The hand is finely granular.

In the female the carapace is more curved and the pincers are weaker.

In young specimens the carapace is straighter; the rostrum is shorter and less emarginate; the gastric region has three tubercles; the antero-external angle of the basal joint of external antenne is not so sharp, and is sometimes obtuse.

RANGE.-West Indian Sea, Cuba.

\section{Libinia rhomboidea.}

Libinia rhomboidea . . A. Milne Edwards, Hale Streets.

Carapace almost circular. Regions distinct. Those occupying the middle line of the body are flat. There are six sharp spines on the gastric region, five in a transverse row, the two outer and the middle one being largest; the sixth spine is behind this row. All the spines of the central regions are small. The genital region is quadrilateral, and has a spine. There is a spine on the cardiac region, and one on the intestinal region. Upon the posterior portion of the cardiac region is an elevation with a depressed centre. The branchial region has four spines, independent of those on the edge; these form a rhomboidal figure. Hepatic region has one spine. The lateral border has five spines. Those on the hepatic region form an almost complete semicircle. Below the lateral spines in front are two spines.

The rostrum has the teeth directed almost directly 
forwards. There is a prominent spine at the internal angle of the eye, and a small spine at the external canthus. The external antenne are cylindrical. There is a spine on their external edge, and one lower down, directed downwards.

The first pair of legs is short and granular. There is a short spine at the base of the arm. The first pair of walking legs is one and a half times as long as the body.

RANGE.-West Indian Sca.

B. Rostrum composed of tro distinct spines.

b. Basal joint of extcrnal antinne aithout a spine at its distal ond:-

\section{Scyra.}

Seyra . . A. Milne Edwards, Dana.

Carapace triangular, tuberculated. Præocular spines present. Spines of rostrum lamellate at base, acute at distal end. Basal joint of external antenne straight, narrow; its extremity is exposed upon the sides of the rostrum. The second joint is flat, and longer than the third. First pair of legs rather long; palm carinated. Valking legs not compressed.

RANGE.-Atlantic and Pacific Ocean; in deep water.

\section{Scyra umbonata.}

Scyra umbonata. Stimpson, A. Milne Edwards.

The carapace has six flat protuberances on its surface, situated one on the posterior part of the gastric region, one upon the cardiac region, and two on each branchial region. These last have outside a sharp and triangular tooth, directed forwards and outwards. All are not 
only flat, but also wide above. They are naked, but the grooves which separate them have hairs. The gastric region has three small tubercles, and the hepatic region has a strong tooth. The gastric region and the sides of the branchial regions are hairy. The rostrum is a little longer than the interorbital diameter. It is hairy above. The abdomen and the sternum are hairy. The sternum of the male has deep excavations between its segments; these excavations are wider than the ridges which separate them.

RANGE.-St. Vincent.

\section{Lissa.}

Lissa . . Leach, H. Milne Edwards.

Cancer. . . Herbst.

Inachus . . Fabricius.

Pisa . . Latreille.

Carapace very convex. Praocular spine present. Spines of rostrum flattened, contiguous, and produced at their extremities into a lateral lobe. Basal joint of external antenne much enlarged. First pair of legs with the palm compressed, but not carinated. Walking legs of moderate length.

RANGE.-Mediterranean Sea, West Indies.

\section{Lissa chiragra.}

Lissa chiragra . . H. Milne Edwards, Leach, Risso. Pisa chiragra . . Latreille.

Cancer chiragra. . Herbst.

Inachus chiragra. Fabricius.

Carapace almost hexagonal, about one quarter longer than broad, contracted in front, very strongly embossed, 
and knobby above. The anterior angle of the superior orbital border is prolonged in front in the form of a large round tubercle. The rostrum is very large and armed in front with two teeth directed outwards. The second joint of the external antenne is thin, cylindrical, and twice as long as the third. Legs of the first pair small and tuberculated; those of the second pair not so long as the carapace. Legs have hairs in bunches.

Colour, intense red.

RANGE.-West Indian Sea, Mediterranean Sea.

\section{Sphenocarcinus.}

Sphenocarcinns . . . A. Milne Edwards.

The carapace subpentagonal, wide behind, tapering in front. There is no preocular spine. Rostrum elongated, its spines contiguous to within a very short distance of their extremities, which are acute. The basal joint of external antenne straight, and the flagellum is inserted under the rostrum, which hides it completely. The epistome is straight and long. The fourth joint of the external maxillipedes is slightly dilated at its antero-external angle, and is slightly notched at its inner angle for the insertion of the next joint.

The legs of the first pair are small and symmetrical. The first pair of the walking legs is the longest.

RANGE.-West Indies.

\section{Sphenocarcinus corrosus.}

Sphenocarcinus corrosus . A. Milne Edwards.

The body and legs are free of hairs; the carapace is depressed, and the different regions are formed of projections rescmbling islands separated by wide spaces, 
deep and abrupt at their margins. All the projections are marked with deep and irregular depressions; the spaces between them are fincly granular. The gastric region is formed of threc lobes: two protogastric, rounded and lateral; the other, mesogastric, is prolonged into a point between them. The anterior cardiac lobe is wide, notched behind, and separated from the posterior cardiac lobe by a broad space; this lobe is continued into a ridge which follows the posterior border of the carapace. The hepatic region is small and almost fused with the branchial regions, which are much dilated on the outside.

The rostrum is longer than the postorbital portion of the carapace; it is formed of two horns soldered together at their base, free, but placed side by side to their extremities, and almost smooth. The suborbital border is thick and corroded. The legs are cylindrical and unarmed. The sternal plastron has ridges and depressions, which gives it a corroded appearance.

RANGE.-Barbados; in deep water.

c. Basal joint of external antenne often aery much cnlarged, with one or more spines at its distal entremity.

$c^{2}$. Spine at antero-external angle of antennal joint wery short, and not visible from above:-

\section{Pericera.}

Pericera . Latreille, A. Milne Edwards, Miers.

Cancer . Herbst.

Maia Pisa. Latreille.

The carapace is subpyriform, rather convex, with the dorsal surface uneven, tuberculated, or spinous, lateral margins armed with a series of long spines; the 
preocular spine is well developed. The rostrum is composed of two well-developed spines, which are not deflexed and are divergent from their base. The front is very large, and occupies twice as much space as the base of the rostrum. The eyes are small. The orbits are very deep; they are directed outwards; their upper border does not project. The basal joint of external antennx is larger at the distal end, where it terminates in a broad transverse edge, than at its base, soldered to the front at the sides of the rostrum; it is armed with one or two small distal spines or tubercles, not visible on a clorsal view; the flagellum is sometimes concealed by the rostral spines, sometimes laterally exposed at the sides, but always very near the antennulary fosse, and very far from the orbits. The fourth joint of the external maxillipedes is distally truncated, with the antero-external angle rounded or subacute.

The first pair of legs, in the adult male, is well developed ; palms elongated and subcylindrical or somewhat compressed, but not dilated or enlarged; fingers without any, or with but a small, intermarginal hiatus at the base when closed. Walking legs moderately elongated, with the joints subcylindrical, without spines; terminal joints nearly straight.

Abdomen is seven-jointed.

RANGE.-West Indian Sea, Brazil, the Cape; at moderate depths.

\section{Synopsis of the SPECIES.}

$A$. The upper surface of the carapace has no spines; the antero-lateral edge has five; one spine on posterolateral edge.- $(P$. cormuta. $)$

$B$. The upper surface of the carapace has many spines; 
the antero-lateral edge has six spines; the postero-lateral edge has many spines.-(P. spinosissima.)

$C$. The upper surface of the carapace has spines on the cardiac region only; the antero-lateral edge has four spines; the postero-lateral edge one spine.-(P. colata.)

\section{Pericera cornuta.}

Pericori cornuta . Milne Edwards, Miers.

Cancer cornudo. . . Herbst.

Maria taurus . . . Lamarck.

Horned crab. . . . Griffith Hughes.

Carapace irregular, and without remarkable spines on its upper surface, but armed along the edge with a row of large, very long, sharp spines; on the hepatic region one, on the branchial region three, and one on the intestinal region. The anterior angle of the superior orbital border is prolonged into a strong spine, which exceeds much the basal articulation of the external antenne. The rostrum is styliform, very diverging, and in length equals the breadth of the front. The basal joint of external antenne is armed in front with a sma!l spine which does not exceed the front; the second joint is cylindrical, slender, elongated, and inserted under the rostrum; the third is very small.

The first pair of legs is cylindrical, of the size of, or a little stronger and longer than, the succeeding pairs; arms spinous; pincers thin. The other legs are of moderate size, those of the second pair not being one and a half times the length of the postfrontal portion of the carapace.

Body covered with a brownish down. Length three to four inches.

Range.-Barbados, Florida, Brazil. 


\section{Pericera spinosissima.}

Periccra spinosissima . Saussure, Milne Edwards.

The upper surface of the carapace has many spines; there are ten in a row in the middle line of the back, of which four are on the gastric region, three on the anterior, and three on the posterior cardiac lobes. The gastric region has also on each side two very small points, behind which there is one stronger. Two other spines occupy the hepatic region; there is a longitudinal series of three small spines on the branchial region. The antero-lateral edges have six strong points; and there are small spines on the postero-lateral edges.

The first pair of legs is short; the arms have above a line of five spines and some tubercles. The hand is long and smooth; the fourth joint of the walking legs is tuberculous above.

The colour under the hairs is red; fingers brownish.

RANGE.-Guadaloupe.

\section{Pericera cœlata.}

\section{Pericera calata . . . A. Milne Edwards.}

The carapace is wide in front, oval behind, and covered with hairs. Regions marked by elevations surmounted with tubercles which are sometimes pointed, but there are no spines, with the exception of the cardiac region, which has behind and in the middle line a sharp spine with a smaller one in front of it. The laterai border has four spines, one liepatic, three branchial. Rostral horns of moderate size and very. diverging. Orbital edges large and armed with two spines: the one, antero-superior, large and wide at its 
base; the other, posterior, much shorter. The basal joint of external antenna has in front three small points, and outside an obtuse crest.

RANGE.-Barbados, Havana.

f: Spine at antero-ertomal angli of basal antennal joint aery long, wisible on a dorsal wiew:-

\section{Microphrys.}

Microphrys . . A. Milne Edwards, Miers.

Pericora (part). H. Milne Edwards.

Milnea . . . . Stimpson.

Perinca . . Dana.

Fisheria . . Lockington.

The carapace is broadly subpyriform, and somewhat depressed, with the dorsal surface uneven and tuberculated, with a small epibranchial spine. Preocular spine sometimes not developed. Rostrum bifid; horns slender and more or less divergent. Eyes small. Orbits with closed fissures. Basal joint of cxternal antenna armed with a long spine at the antero-external angle, which is visible in a dorsal view; the movable joints and the flagcllum are not concealed by the rostrum. The fourth joint of the external maxillipedes is distally truncated, with the antero-external angle somewhat produced and rounded.

The first pair of legs is moderately developed, with the palm compressed and more or less enlarged; fingers with a wide intermarginal hiatus when closel. The walking legs are short, with the fourth and fifth joint sometimes armed with spines; the last joint is slightly curved.

The abdomen of the male is seven-jointed. 
Range.-West Indies, Gulf of Mexico, Brazil, Peru, Galapagos Islands, California.

\section{Synopsis of tile Species.}

$A$. Spine on antero-external angle of basal joint of cxternal antenne nearly as large as the rostral horns; spines on the hepatic region are almost as large as antennal spines; two large spines on branchial margin. -(M. weddellii.)

B. Spine on antero-external angle of basal joint of external antenna much smaller than the rostral horns; hepatic spines much smaller than these; one small spine on branchial margin.-( MI. bicomutus.)

\section{Microphrys weddellii.}

Microphry's aceddellii . A. Milne Edwards.

The booiy and the legs are slightly hairy; there are stiff, curved hairs on the rostrum, on the projecting parts of the carapace, and on the upper surface of the legs. These hairs hold a great number of foreign bodies, under which the crustacean lives. The carapace is wide in the branchial regions. The regions are knobby, and have on their projecting parts some tubercles, which on the branchial regions become spines. On the posterior border there is a row of pearl-like knobs extending as far as the legs of the fourth pair. The superior orbital border has in front a small spine. The lateral border of the carapace has a series of spines. There are two spines on the hepatic region, three of the same size on the epibranchial lobe, and two large spines on the metabranchial lobe.

The front is formed of two moderately long, diverging 
horns; on each side of them there is the spine of the basal joint of external antenrixe nearly as large.

In the male the first pair of legs is very robust; the hand is elevated and slightly compressed. In the female these legs are frail, and the palm is almost cylindrical. In both sexes the arm has on its upper surface about three spines. The walking legs are large and short; those of the second pair are longer than the succeeding pairs, they are armed on the fourth and fifth joint with a series of sharp spines; the other legs have none on their fourth joint.

Colour is brown-red; the legs have a violet tint. RANGE.--Guadaloupe.

\section{Microphrys bicornutus.}

Microphry's bicornutus . Latreille, A. Milne Edwards, Miers.

Pisa galibica ) Pisa purpurar o

Desbonne and Schramm.

Omalacanthe hirrsuta. . Streets, A. Milne Edwards.

Pisa bicormata . . . . Latreille.

Pericera bicorna . . . H. Milne Edwards.

Pisa bicoma. . . . . Gibbes.

Pericera bicornss. . . Saussure.

Milnia bicomata. . . Stimpson.

Carapace rounded behind, and without median spine over the insertion of the abdomen; covered with round tubercles, armed with a small spine on each branchial region, two small spines on the hepatic region, one small spine on the epibranchial region, but otherwise few or no spines. The rostral horns diverge from base, or may converge at their tips. The superior orbital border projects slightly at the angles, and is marked with two 
fissures. The movable part of the external antennie is inserted between the border of the rostrum and the terminal tooth of its basal joint, which is visible on a dorsal view, but much smaller than the horns of the rostrum. The basal joint is almost as long as the second joint. Colour is yellow.

Range--Barbados, Bermudas, Florida, Brazil.

\section{Macrocœloma.}

Macrocaloma . . . Miers.
Pericera (part). . .

The carapace is rather convex, usually broadest at the branchial regions; the interorbital space broad; the dorsal surface unarmed or tuberculated, or with a few long spines; the margins without a series of elongated spines, but often with a strongly developed lateral epibranchial spine, preceded sometimes by some smaller spines; the preocular spine is small. The spines of the rostrum are well developed. The tubular orbits project laterally. The external antenne have the basal joint armed with a spine on the distal margin, which is usually visible on a dorsal view, and sometimes with another placed immediately beneath the first mobile joint; the mobile part of the antenne is sometimes concealed in a dorsal view by the rostral spines, sometimes visible at their sides. The fourth joint of the external maxillipedes is distally truncated, with the antero-internal angle emarginated. The palm of hand of the first pair of legs are either somewhat elongated and compressed or shorter and more dilated; fingers with or without an intermarginal hiatus when closed. The walking legs are rather short and moderately robust; last joint slightly. curved. 
Abdomen is seven-jointed.

RANGE.-Warm parts of the Atlantic and Pacific Oceans; in shallow and deep water.

Srnopsis OF TIIE SPECIES.

A. Lateral epibranchial spine well developed.

a. Tooth on the antero-external angle of basal joint of external antenne prominent.

$a^{1}$. One median spine, directed backwards, between the epibranchial spines.-( M. trispinoser.)

$b^{1}$. A row of spines across the back, directed backwards, between the epibranchial spines.-( M. subforalleld.)

b. Tooth on the antero-external angle of basal joint of external antenna not prominent.

$c^{1}$. No spines on back between the epibranchial spines. - (II. diplacantha.)

b. Lateral epibranchial spinc small or none.

c. Antenna longer than rostrum.

$d^{1}$. One spine only, on intestinal region.-(M.laizgata.)

A. Lateral epibranchial spine awell developed:-

\section{Macrocœloma trispinosa.}

Macrocaloma trispinosa. . Latreille, Miers.

Pericera madifes . . . Desbonne and Schramm.

Pericere trispinosa . . . 11. Milne Edwards.

Pisa trispinosa. . . . . Latreille.

The posterior portion of the carapace is triangular, and armed with three strong spines, two laterat and onc median, directed backwards; surface embossed; the front is large. The anterior and external angle of the orbit is 
very obtuse. The rostrum is short. The terminal tooth on the basal joint of external antennæe exceeds much the anterior angle of the superior orbital border; the flagellum is inserted immediately below the lateral border of the rostrum. The second pair of legs is as long as the postfrontal portion of the carapace, and the fourth joint is a little nodular towards the end.

The body is covered with a rough yellow down.

Length about one and a half inches.

RaNGE.-West Indies, Bermuda, Bahia.

\section{Macrocœloma subparallela.}

Macrocaloma subparalleler. Stimpson, Micrs. Pericra ailpini. . . . . Desbonne and Schramm. Pericera subparallela. . . Stimpson.

Body covered with a short, tough pubescence. Carapace triangular, narrow, and with the antero-lateral sides not concave. Lateral spines subtriangular, sharp, and connected with each other by a nearly straight row of short spines or sharp tubercles crossing the back. A tubercle on the posterior part of the gastric, and one on the intestinal region; both small. Orbital tubes prominent. The rostrum forms one-fourth the length of the carapace, with the horns nearly parallel; their base is connected for one-third of their length by a web-like expansion of the front. The distance between their tips equals three-fifths the distance between the tips of the preocular spincs. The movable part of the external antenne is concealed bencath the rostrum; the anterior spine on basal joint is small, slender, and visible on a dorsal view. First pair of legs, in the male, a little shorter than the carapace. Walking legs rather short.

RANGE.-St. Thomas, Guadaloupe. 
3. Macrocœloma diplacantha.

\section{Hacrocalona diplacantha) Pericera diplacantha}

Body pubescent and provided with curled hairs above. Carapace subtrigonal, narrow; back protuberant. Lateral spines rather long, and double, seeming to consist of two spines, one above the other, connected nearly to their tips by a web-like expansion, concave anteriorly, convex posteriorly. Antero-lateral margin concave, unarmed except with a small hepatic tuberclc. There are five conical tubcrcles on the posterior half of the back, and a few minute ones interspersed. Gastric region strongly inclined anteriorly with the frontal region; præorbital tooth obtuse and not prominent.

Orbital tubes moderately protuberant.

Rostrum forms nearly one-third the length of the carapacc; horns very long, slender, cylindrical, acute, diverging, but at base connected by a web-like expansion for one-fifth their length. Spine on base of external antenne minute.

RANGE,-St. Thomas.

B. Latcral epibranclial spine small or none :-

\section{Macrocœloma lævigata.}

Macrocaloma lcevigata. Stimpson, Miers.

Pericera curvicorna. . Desbonne and Schramm.

Pericera lavigata. . . Stimpson.

Carapace elongated; surface pubescent and partly hairy; hairs crispate; back and sides smoothly rounded, with no spines or tubercles except a minute one on the 
intestinal region; postocular teeth more prominent than the præocular; the distance between their tips equalling five-sixths of the greatest breadth of the carapace. The rostrum forms between one-fourth and one-fifth of the length of the carapace; it is deflexed, curving downwards, bifid, with the horns united at base for one-third their length, then divergent. Orbital tubes rather large. The movable part of the external antennie is longer than the rostrum; the spine on their basal joint is visible on a dorsal view, divergent from the rostrum and nearer to the orbital tubes. Obtuse spines on the fourth joint of first pair of legs; hands compressed; distal half of fingers black, with white tips.

RANGE.-Guadaloupe, St. Thomas.

\section{Subfamily II. Othoniinæ.}

Othoniince. . . Miers.

Othonince. . . Dana, Stimpson.

Carapace suboblong; interorbital space very broad. Rostrum almost obsolete. Second joint of external antenna enlarged. First pair of legs with the fingers excavated at the tips.

\section{Othonia.}

Othonia . Bell, A. Milne Edwards, Miers. Pitho. . . Bell.

The carapace is truncated in front; the frontal region is wide. Its general form is suboval, the antero-lateral borders with the postero-lateral being a slightly bowed line bearing teeth. The orbits are tubular. The rostrum is very short, and formed of two small teeth. The external 
antennæ have stiff hairs. They are short; their basal joint is flat, and forms the floor of the orbit; the sccond joint is flat, short and wide, especially in its terminal portion; the third joint is also flat, but smaller; the flagellum is much reduced. The external maxillipedes have the antero-external angle of their fourth joint dilated, and the antero-internal angle slightly notched for the insertion of the next joint.

The first pair of legs of the male terminates in fingers with spoon-shaped tips, where they only meet when closed. The hands are more or less compressed. The walking legs are robust and slightly elongated; their last joint is sharp, and has below a few teeth.

Range.-Atlantic and Pacific on the American Coast, West Indies.

\section{Synopsis of the Species.}

A. Carapace longer than wide.

a. Orbital angles acute.

$a^{1}$. External anterior edge of extremity of basal joint of external antennat toothed.

$a^{2}$. Fingers almost in contact along their entire length when closed.- $O$. aculeata. $)$

$b^{1}$. External anterior edge of extremity of basal joint of external antennre not toothed.

$b^{2}$. Fingers, when closed, touch only at tips. - $(0$. lherminierii.)

$B$. Carapace wider than long.

$b$. Tecth on antero-lateral margin about of equal size.

$c^{2}$. First pair of legs of male very long.- (O. lavigata.) 


\section{Othonia aculeata.}

Othonia aculeata. . . Stimpson, A. Milne Edwards.

Othonia sexdentata. . White.

Othonia anisodon. . Von Martens.

Hyas aculcata . . . Gibbes.

The carapace is longer than wide, almost smooth in adults, more or less tubercular and granular in the young. The preocular angle and the external ocular angle is sharp. The antero-lateral border has about five teeth, not counting the external ocular tooth, more or less triangular, the first and the third often joined at their base; they are sharp and short in the young; they are wide and blunted in older specimens. The front is formed of two small, flat, and triangular teeth. The basal joint of external antenne is wide; the part of its anterior border outside the insertion of the second joint is toothed. The first pair of legs of the male is always weak. The arm has behind about three small tubercles; the fingers of the pincers are in contact in the greater part of their extent when closed; they have only a small space at their base.

Range.-St. Thomas, Cuba, Florida.

\section{Othonia lherminieri.}

Othonia lherminieri . . . A. Milne Edwards, Schramm.

Microrhynchus lherminiori. . Desbonne.

The carapace longer than broad; the front is not much advanced; the orbital angles are obtuse. The antero-lateral edge is armed with large blunt teeth; the two last are small and inclined to disappear. The basal 
joint of the external antenne has no teeth on its anterior and external border. The first pair of legs of the male is very large. The arm is smooth, almost cylindrical, and stretching much beyond the carapace. The hand is high, very compressed, its upper and lower border has a crest; the fingers, when closed, have a large space between them.

RANGE.-Guadaloupe, St. Thomas.

\section{Othonia lævigata.}

Othonia lavigata . . A. Milne Edwards.

The carapace is broader than long. The surface smooth, and marked only with some fine punctuations. The proocular angles are obtuse; the external orbital angle is sharp. The antero-lateral edge is cut into five almost equal, well-developed, very strong and sharp teeth, with their points directed outwards and a little forwards.

The anterior edge of the basal joint of external antennxe is straight. The first pair of legss of the male is very long.

RANGE.-West Indian Sea.

\section{Subfamily III. Mithracinæ.}

Mithracine . . . . Stimpson, Miers.

Carapace broadly triangular, sometimes transverse, with the sides slightly arcuate; interorbital space narrow. Rostrum short or obsolete. Second joint of external antenna not dilated. First pair of legs with the fingers elevated at the tips. 


\section{Synorsis OF TIIE GENERA.}

A. Rostrum very short, its spines reduced to tubercles.

a. Basal joint of cxternal antenna with a very short spinc at its distal end.

$a^{1}$. Walling legs compressed.---(Thoe.)

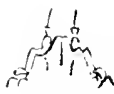

Thoc.

b. Rostrum well developed, short, or wanting.

b. Basal joint of external antenne with a long spine or short spines at its distal end.

$b^{1}$. Walking legs not compressed.--(Mithrar.)

\section{Thoe.}

Thoe . . Bell, A. Milne Edwards.

The carapace is slightly elongated, depressed, its surface lobulated ; the interorbital region is wide. There are no præocular spines; the superior orbital border is unarmed. The rostrum is slightly advanced. The basal joint of external antenne is short and extremely wide; the second joint is slightly flattened, and almost reaches the extremity of the rostrum; it is inserted in the sides of the rostrum at a great distance from the orbit. The external part of the fourth joint of the external maxillipedes is very wide in its middle portion. The first pair of legs of the male is long and strong; the hand is compressed ; the fingers are excavated, when closed there is a considerable space between them which varies with age and sex. In the young and in females the fingers are in contact through almost their entire length. The walking legs are large; the fourth joint has longitudinal ridges; the last joint is very small and has nodules. The 
first pair of walking legs is the longest; the last pair is small. The sternal plastron is almost circular.

RANGE.-American Coast, West Indies.

\section{Thoe puella.}

Thoe puella . . Stimpson, A. Milne Edwards.

Pisc latipes . . Desbonne and Schramm.

The carapace is wide in the interorbital region; the antero-lateral edges are straight or slightly concave; the regions are well marked and covered with granulations. The superior orbital borders are very granular. The rostral horns are granular, and separated by a deep notch. The hand is smooth and polished, except at the joint, where there are a few granulations; the superior border is sharp at its terminal portion. The fingers in the male are very gaping ; the movable finger has a tooth near its base; it is finely serrated at its extremity. The arm and forearm have no excavations, but have small granulations outside and below. The walking legs are depressed; the fourth joint of the three first pairs has longitudinal ridges ; the ridges have deep concavities separated from each other by small transverse ridges.

Colour, red, with yellow spots on the carapace.

RANGE.-Guadaloupe, Gulf of Mexico.

\section{Mithrax.}

Mithrax . . . Leach, Latreille, Milne Edwards, Miers.

Nemansa. . . A. Milne Edwards.

Mithraculus . . Stimpson, Miers.

Teleoplery's . . Stimpson.

The carapace is depressed or moderately convex, sometimes longer than broad, but usually transverse and 
very broadly rounded at the branchial regions, where it is armed with teeth or spines; the dorsal surface is uneven, tuberculated, or spinous. The rostrum is bifid, in general very short, and separated from the inner canthus of the eye by a very considerable space. The eyes are small. The orbits are almost always armed with two or three spines on their superior border, with one on their external angle, and with one or two on their inferior border. The internal antennæe are bent a little outside, and the frontal portion of the partition which separates them is armed with a spine recurved in front. The basal joint of external antenne is almost always armed in front with two strong spines. The second joint is inserted on the side of the rostrum, nearer to the antennulary fossa than to the orbit; the third joint is almost as large and as long as the second; the last joint is generally short. The epistome is transverse. The first pair of legs, in the male, is in general much larger and longer than the second pair; sometimes twice the length of the postfrontal portion of the carapace; the hand is dilated and compressed; the fingers, when closed, have a wide intermarginal space, rarely slender, and the fingers almost in contact when closed. The second pair is about once and a quarter the length of the postfrontal portion of the carapace, and the succeeding pairs become progressively shorter. The last joint is hooked, short, and often armed with a few points on the inferior face.

The abdomen is seven-jointed in both sexes. Females, when young, may have the second to fifth segment inclusive soldered together. The sternal plastron is almost circular.

RANGE.-Warm seas on both coasts of America; at moderate depths. 


\section{Subgenus I. Nemausa. \\ Subgenus II. Mithrax.}

Sycopsis of the Sublexera hND the Species.

I. Carapace longer than broad.

Rostrum well developed.

Long spines on distal end of basal joint of external antenne. First pair of legs of moderate size.-(Subgenus Nemansa.)

I. Carapace almost smooth. Preocular spine short.(MI. rostrata.)

II. Carapace transverse. Spines of rostrum short or wanting. Short spines on distal end of basal joint of external antenne. First pair of legs often large.-(Subgenus Mithrar.)

A. Carapace with the branchial regions not dorsally sulcated ; the lateral margin usually armed with spines.

a. Spines of rostrum distinct, acute. Palm of hand of first pair of legs with or without spines on superior margin.

$a^{1}$. Palms with spines on superior margin.

2. Carapace covered with spines.-(MI. spinosissimus.)

3. Carapace tuberculous.- $(\lambda /$. cornutus. $)$

4. Carapace covered with large round granulations.(II. aculeatus.)

b. Spines of rostrum short or wanting. First pair of legs with the palms unarmed.

$b^{1}$. Two spines on basal joint of external antenne.

5. Carapace with a few spines on upper surface.-( $M$. hispidus.)

6. Carapace flat.-( $M$. depressus.)

7. Spines on border of carapace broad and tuberculous.--( $/$. pleuracanthus.) 
$c^{1}$. Three blunt spines on basal joint of external antennx.

S. Carapace smooth.-M. levimams.

9. Carapace with flat granulations.-( M. a'crucosus.)

$a^{1}$. A prominent spine between internal antenna.

Io. Carapace has no spines on lateral and posterior angles.-( $M$. leucomelas.)

$B$. Carapace very much depressed, with smooth, shallow sulci between the tubercles of the dorsal surface of the branchial regions. Lateral margins tuberculated.

c. Antero-lateral edge of carapace cut into four or five tubercles, not counting postocular spine.

I I. No teeth on extremities of pincers; one large tooth in centre of fixed finger.-( $M$. sculptus.)

12. Movable finger has one large tooth.-( $M$. cinctimanus.)

I3. Fingers large and wide at extremity; one large tooth in middle of each finger.-( $M$. forceps.)

d. Antero-lateral margin of carapace has four tubercles, second and third the largest.

I4. The movable finger has one large tooth. The fixed finger has fine teeth only at extremity.-( $M$. mudus.)

$c$. Antero-lateral margin of carapace has three lobes.

I 5. Last tubercle is sharp and curved forward.-( $M$. ruber.)

I6. Fixed finger has tecth only at extremity,- $M$. coronatus.)

\section{Subgenus Nemausa.}

Nemausa . . . . . . . A. Milne Edwards.

Nemausa (subgenus). . . Miers.

Carapace subpyriform, much longer than broad. Spines of rostrum well developed, slender, acute. 
Epistome scarcely transverse. Basal joint of external antenne with a long spine at its antero-external angle. Fourth joint of the external maxillipedes produced at its antero-external angle. First pair of legs of moderate size ; palm rather slender, compressed.

\section{Mithrax (Nemausa) rostrata.}

Ncmouse rostrata . . . . A. Milne Edwards. Mithrar rostrata . . . . Miers.

The carapace is smooth; it has some tubercles slightly marked on the gastric region, better marked on the cardiac region, and spiniform on the branchial regions. The lateral edges have sharp spines; the first is formed by the external orbital angle; the sccond is in the hepatic region; the branchial regions have spines weaker and more irregular in their size. The preocular spine is short. The rostral horns are pointed. The basal joint of the external antenne is wide, and slightly exceeds the frontral border ; it has in front a pointed spine; a second spine, less strong, is placed on its external edge below the first.

The first pair of legs of the male is short; the hand is smooth. The forearm and the arm have above some pointed tubercles. The fourth and fifth joint of the walking legs have spines on their superior border.

RANGe--Montserrat, Martinique, Grenadines, Bermuda, Gulf of Mexico.

\section{Subgenus Mithrax.}

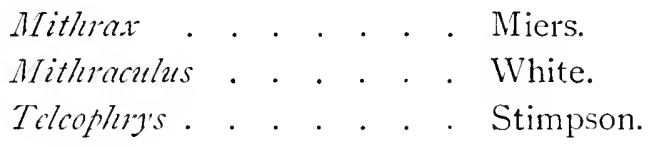

Carapace very broad, and depressed, usually transverse. Spines of rostrum very short or obsolete. Basal joint of 
external antenne very much enlarged, with short spines at the distal extremity. First pair of legs often large, with the palm compressed and more or less dilated.

\section{Mithrax (Mithrax) spinosissimus.}

Mithrax spinosissimus. . . Milne Edwards, Gibbes, Stimpson, Desbonne and Schramm, Von Martens.

Maia spinosissima . . . . Lamarck.

The carapace, contracted in front, is covered with spines more or less elongated, but smooth in the space which these points have between them, and ornamented, as well as the legs, with a multitude of stiff hairs; with age some of the spines disappear. The antero-lateral borders of the carapace are armed with five or six large spines, of which the two first are bifurcated. The superior orbital border has three or four spines, of which the anterior is very strong and directed forwards. The rostrum is formed of two diverging spines, directed forwards. The basal joint of external antenna terminates in two spines, of which the internal is very long; the third joint is very short. Legs very spinous. Palm of hand with spines on upper edge.

Colour, red.

RANGE. - Barbados, Guiana, Florida, Guadaloupc, Cuba.

\section{Mithrax (Mithrax) cornutus.}

Mithrax comutus. . . Saussure, A. Milne Edwards, Micrs.

The body and the legs are covered with a short pubescence resembling cloth. The carapace is ovoid 
longer than wide. The orbital border, independent of the large superior and internal spines, has six spines. The three inferior and lateral are larger than the thee superior; sometimes one of these teeth is wanting. The anterolateral borders have five or six large spines, of which the two first are double, and the sixth, smaller, is situated on a plain higher than that occupied by the others. The regions are not well marked; their surface is covered with tubercles, small in front, large and pointed behind and on the sides. A row of seven tubercles, of which the middle and the two at the extremes are the largest, exists on the posterior border. The latero-inferior regions have spiniform tubercles.

The rostrum is horizontal; the two horns are sharp, flat, scarcely diverging, and almost straight; their length equals the distance which separates the basal joints of the external antenna, which has a very long spine at its internal angle; a shorter spine forms the external angle. There is a tubcrcle below the insertion of the flagellum.

The first pair of legs of the male is long and thin. Two rows of pointed tubcreles follow the superior border of the hand; the fingers are very large, finely toothed, and gaping. The arm and forearm are spinous. The pincers of the female are very frail; and the tubercles on the border of the hand slightly apparent. The walking legs are long and thin. The fourth and fifth joint have a row of spines above; the other joints are unarmed. The last joint is long and slightly crooked.

RANGE.-Martinique, Florida, Bahia. 


\section{Mithrax (Mithrax) aculeatus.}

Mithrex aculeatus . H. Milne Edwards, Stimpson, Herbst, Desbonne and Schramm, Von Martens.

Cancer aculeatus . . Herbst.

The carapace, contracted in front and with large spines on its edge, has a raspberry appearance, due to a coating of small circular and flat granulations placed between the spines. It is covered with short hair. The spines on the lateral border are very sharp; the anterior ones are often double or triple, especially in specimens of large size. The fourth joint of the external maxillipedes is deeply notched at its internal angle. The pincers of the male are large. In young specimens the tubercles on the hand may be wanting. The arm and forearm are very spiny. There are spines on the walling legs.

Colour, a violet brown. The pincers of the male are flesh-coloured; those of the femalc, brown or white, spotted with violet. The ends of the pincers are white.

RANGE-Guadaloupe, Barbados, St. Thomas, Aspinwall, Cuba, Vera Cruz.

\section{Mithrax (Mithrax) hispidus.}

Mithrox hispidus . . Milne Edwards, Guérin, Gibbes, Saussure, Stimpson, Smith, Desbonne and Schramm.

Cancer hispidus . . . . Herbst.

Maicr spinicincta . . . Lamarck.

Mithras spinicinctus . . Desmarest.

The carapace is curved, wider than long, smooth and glabrous; it has some knobs which become pointed upon 
the metabranchial lobe. The front is wide, little advanced. The preorbital spines reach the level of the notch which separates the rostral horns. The orbital border has four small tubcrcular projections, of which one forms the external orbital angle; the two which occupy the inferior orbital border are larger than the teeth of the superior border. The lateral edge of the carapace has five spiniform teeth; the first is obtuse and often bifid; the second is bifid, sharp, and curved forwards; the third is thin; the fourth is the same; the fifth is smaller and placed higher up upon the border of the carapace. The hepatic region has two tubercles. Other tubercles, more or less pointed, exist on the under surface of the cephalo-thoracic bucler. The horns of the rostrum are short, straight and obtuse at their extremitics; at their base and above there are two small tubercles. The internal tooth of the basal joint of external antenne is large, and scarcely less prominent than the rostrum; there is a second shorter blunt point outside this onc. The fourth joint of the external maxillipedes has its internal angle notched for articulation with the fifth. The pincers are smooth; the forearm is unarmed; the arm has spines above. The walking legs are hairy; there are spines on their terminal joint.

RANGE. - Guadaloupe, Martinique, Cuba, Florida, Brazil.

\section{Mithrax (Mithrax) depressus.}

\section{Mithrax depressus . . A. Milne Edwards.}

This species is the same as Mithrar (Mithrar) pleurocanthus, except that the carapace is longer, flatter, and less cmbossed than in the latter. The antero-lateral edges are less swollen and longer.

RANGE.-Guadaloupe, Florida. 


\section{Mithrax (Mithrax) pleuracanthus.}

Mithrar fleuracanthus . . . Stimpson, A. Milne
Edwards.

These crabs are very small.

The carapace is less curved than in Mithrer hisfidus. The regions are clearly delineated, and have also very plain tubercular nodosities upon the branchial and cardiac regions. The teeth and spines of the orbit are more pronounced, and those of the lateral edges are wider and more tuberculous. In young specimens the three first lateral projections are completely blunt.

RANGE.-Martinique, Guadaloupe.

\section{Mithrax (Mithrax) lævimanus.}

Mithrar lavimanus . . Desbonne and Schramm, A. Milne Edwards.

The carapace is smooth, and has only a few round projections resembling MI. hispidus, only it is not so wide, and the front is much more advanced. The preocular spines are represented by a round projection of the superior orbital border. The orbital border has three tubercles. The lateral edges have five almost cylindrical spines, simple and directed forwards; the first and the fifth are the smallest. There are three strong projections on the branchial regions. The basal joint of the external antenne has three blunt spines; the one, which does not exist in Mr. hispidus, is placed below the insertion of the second joint; another, stronger, forms the antero-external angle; the third, of the same size, is placed on the anterointernal angle.

The stemal plastron, in the male, is deeply notched in 
front to receive the seventh segment of the abdomen; the sixth abdominal segment is very wide anteriorly.

The carapace is violet brown; the legs and the pincers are spotted with light violct.

RANGE.-Guadaloupe.

\section{Mithrax (Mithrax) verrucosus.}

Mithrax acrucosus . A. Milne Edwards, Stimpson, Desbonne and Schramm.

The carapace is wide, slightly curved, and covered with very flat and serrated granulations, with some tubercles on the posterior part of the branchial regions. The praocular spine is slightly projecting, and directed a little outwards. The orbital border is cut into four small blunt projections. The lateral borders have five or six spines, of which the two first are double. The rostrum is formed of two short obtuse teeth. The basal joint of external antenna has three tubercular teeth. The fourth joint of the external maxillipedes has its antero-internal angle notched.

The pincers are smooth. The forearm has on the inside three large tubercles. The arm is spiny. The walking legs are robust; their fourth and fifth joint have spines. The two last joints have hairs. These crabs are nocturnal.

Colour, a vinous red.

RANGE:-Martinique, Guadaloupe.

I0. Mithrax (Mithrax) leucomelas.

Mithrer leuconeless . Desbonne and Schramm, A. Milne Edwards.

Carapace depressed, rough, without spines, slightly longer than wide, subtriangular, antero-lateral edges 
slightly toothed; lateral and posterior angles of the carapace rounded, not spinous. Rostrum very small, horizontal, bifid. The eyes can be folded into a postforaminal cavity. The orbits are directed forwards and outwards, with a spine on the external border and two spines on the internal, one superior the other inferior. The internal antennae are directed forwards, and separated by a spiniform prolongation. The cxternal antenne have their first joint soldered with the front, forming a part of the sides of the orbit. The legs of the first pair are of the same size, a little more developed than the succeeding ones, once and a quarter the length of the carapace, glabrous and smooth; fingers bent; pincers wide, with bunches of hairs in the depression of finger-tips, which have toothed margins. The legs of the second pair are as long as the first pair ; the three other pairs decrease in length; the last joint of the four last pairs of legs has four or five spines underneath.

Colour, white, with black patches.

RANGE.-Guadaloupe.

\section{Mithrax (Mithrax) sculptus.}

Mithran sculptus . . . A. Milne Edwards, Gibbes. Mithax minutus . . . Saussure, Desbonne and Schramm.

Maic sculpta . . . . Lamarck.

Mithraculus coronatzis. White.

Mithraculus sculptus. . Stimpson.

The carapace is wider than long, with rounded margin. The internal orbital angles are obtuse, and very little adranced. The orbital border has three small tubercules, one inferior, one external, and one superior. The carapace is covered with projections posteriorly, but almost smooth 
in front. The antero-lateral edges are cut into four round lobes, which in the young are pointed. The front is wide, a little advanced, formed of two small tubercles separated by a notch. The basal joint of external antennze is very dilated on the outside, where it forms a part of the floor of the orbit and of the inferior orbital border; its anteroextcrnal angle has a tubcrcle and is scarcely more advanced than the superior and internal orbital angle. Fourth joint of external maxillipedes is not notched anteriorly and internally. The first pair of legs of the male has the hand smooth, laterally compressed; the fingers are well developed, their extrcmity not toothed. The fixed finger has on its cutting border, about the middle, onc strong tooth. The forearm is smooth; the arm has in front two spiniform tubercles. The walking legs are hairy and have a few spines.

RANGE. - Barbados, Guadaloupe, Martinique, St. Thomas, Florida.

\section{I2. Mithrax (Mithrax) cinctimanus.}

Mithraculus cinctimanus . A. Milne Edwards, Stimpson.

Mithrax affinis . . . Desbonne and Schramm.

The carapace is covered, especially behind and laterally, with nodosities. The antero-lateral borders are a little oblique and obscurely cut into four small teeth or tubercular eminences, more pointed when the specimens are young. The external orbital angle is sharp. The rostral horns are small, but advanced, and exceed the preocular angles and the spine on the basal joint of the external antenna. The pincers are slightly swollen. The hand is smooth, with one tooth on movable finger. The forearm is smooth in young specimens, with tubercles on 
the inside in adults; the arm has many tubercles. The walking legs are very long, slightly spinous, and hairy only on their last joints; terminal joint long and curved.

The colour is yellow, with a large brown spot which covers a great part of the cardiac region. The legs and pincers are spotted with brown and white, the brown sometimes forming a ring on the hand.

RANGE.-Guadaloupe, St. Thomas, Florida, Mexico.

\section{Mithrax (Mithrax) forceps.}

Mithrax forceps . . Miers. Mithraculus forceps. A. Milne Edwards.

The carapace is slightly curved, subtriangular, with the surface scarcely uneven; there are some tubercular elevations upon the border of the branchial regions. The antero-lateral edges are armed with four pointed teeth, simple and directed forwards; behind the last there is a small pointed tubercle. The front is wide. The praocular angle is a little advanced; the superior orbital border is scarcely interrupted by two small fissures; the external orbital angle is sharp, and there is a small spine upon the inferior orbital border. The horns of the rostrum are small, flat, obtuse, almost side by side. The basal joint of external antenne is flat; the antero-external angle is advanced and forms a point; there is a second very small spine below the insertion of the flagellum. The fourth joint of the external maxillipedes is very dilated outwards, and is not notched in the antero-internal angle for the insertion of the fifth joint. The first pair of legs of the male is little developed; the hand is frail, smooth, and terminates in fingers relatively very large and very wide at the end; one large tooth in centre of cutting edge of each. The forearm has inside one or two small 
tubercles. The arm has spines in front and behind, and slightly tuberculous above. The walking legs are very long, spiny, and slightly hairy.

RANGE.-Guiana, Bermuda, Bahia.

\section{I4. Mithrax (Mithrax) nudus.}

Mithrax nudus. . . . Miers.

Mithraculus mudus . . A. Milne Edwards.

The carapace is much wider than long; the anterolateral borders have four obtuse prominences, of which the second and third are largest; the fourth is small. There are some round prominences on the branchial regions, but the surface of the carapace is smooth. In young specimens these projections are more marked, and the prominences of the lateral borders are sharper. The front is straight, little advanced. The rostrum is formed of two round tubercles, behind which are two small projections. The basal joint of external antennæe is wide, and has outside two round projections, of which one constitutes the anterior angle. The external maxillipedes are wide; the fourth joint is slightly dilated outside; not notched on the inside. The first pair of legs of the male is long and strong. The hand is smooth, slightly swollen, rounded above. The movable finger has one strong, pointed tooth situated on about the first one-third of its cutting edge. The fixed finger has only fine teeth at its extremity. The forearm is smooth. The arm has nodes above, and in front a thick and wide projection. In young specimens there are only some pointed tubercles. The walking legs are strong, spiny, and hairy.

The sternal plastron is rounded, and the abdomen of the male is narrow.

RANGE,-Guadaloupe. 


\section{I5. Mithrax (Mithrax) ruber.}

Mithrax merer. . Miers.

Mithraculus ruber . A. Milne Edwards, Stimpson.

The carapace is subtriangular, about one-fifth wider than long. The surface is naked, with few protubcrances. These projections are rounded and not elongated, and some have scattered tubercles. The antero-lateral border has three teeth, independent of the orbital angle. The last tooth is sharp, spiniform, and curved forwards; the other two are tubercular. The middle tooth is composed of two tubercles, and there is a small tubercle between it and the last tooth. The postero-lateral border has a small sharp tubercle situated behind the last tooth. The external maxillipede has its fourth joint slightly sinuous in front, showing an indication of a slight notch. The first pair of legs is long and thin. The arm has six small tubercles, conical and of equal size; the forearm and hand are smooth. The walking legs are cylindrical, and have above short hairs; they are spinous above, the spines being arranged in two series.

The colour of the carapace is chestnut brown, bluish behind.

RANGE.-Cuba.

\section{I6. Mithrax (Mithrax) coronatus.}

Mithrax coronatus . Miers.

Mithraculus coronotus. A. Milne Edwards, Stimpson, White, S. Smith.

Mithrax sculptus . . Desbonne and Schramm.

Cancer coronatus. . . Herbst.

The carapace is about one-third wider than long, and strongly curved in front as well as behind. The furrows 
which separate the projections are wide and deep; those of the branchial regions like those on the cardiac region. The antero-lateral border is cut into three large round lobes. There are two or three projections behind the last lobe, upon the branchial region. The basal joint of cxternal antenne is not broad. The first pair of legs is of moderate length; the extremities of the pincers are finely toothed; the movable finger is unarmed, even in adult males. The arm is nodulus, and has in front two small tubercles.

The females are much smaller than the males. In the young the antero-lateral lobes are more pointed. The first pair of legs is more spiny on the arm; the walking legs are thinner, longer, and the hairs upon them are more abundant.

RANGE,-Guadaloupe, St. Thomas, Florida, Gulf of Mexico, Brazil.

\section{Legion II. Parthenopinea.}

\section{I'arthonopined . . . Dana, Miers.}

Basal joint of external antenne very small, and embedded with the next joint in the narrow hiatus between the front and the inner suborbital angle; the infraocular space being mainly occupied by the inferior wall of the orbit.

\section{Family IV. Parthenopidæ.}

Parthenopida . . Miers.

Eyes usually retractile within the small circular and well-defined orbits; the inferior wall of the orbit is continued to within a very short distance of the front. The external antenne are very slender; the basal joint does 
not constitute a great part of the inferior orbital margin, but is very small and usually does not reach to the front, and, with the next joint, occupies the narrow hiatus intervening between the front and the inner subocular angle of the orbit.

\section{Subfamily Parthenopinæ.}

\section{Parthcnopince . . . . Miers.}

Carapace equilaterally or transversely triangulate or elliptical. Strongly marked depressions exist, separating the branchial from the cardiac and gastric regions. Rostrum simple. First pair of legs greatly developed, with the palm trigonous; fingers acute.

\section{Synopsis of TIIE GENERA.}

I. Carapace not laterally cxpanded.

A. Carapace triangular.

a. Basal joint of external antennx short; second joint is longer or as long as the first.-(Lambrus.)

b. Basal joint of external antenna is longer than the second joint.(Parthenope.)

B. Carapace pentagonal.

c. A sharp ridge separates the pterygostomian from the subhepatic region.--(Solenolambrus.)

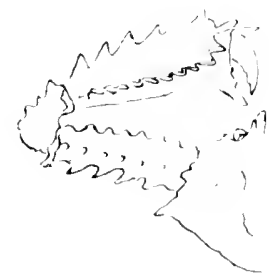

Lambrus.

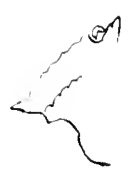

Solendambins.

d. The efferent branchial channels meet in the middle of buccal cavity.-( Mesorhera.)

11. Carapace more or less laterally expanded.

e. Carapace triangular, without posterior expansion.--(Itetrocrpter.)

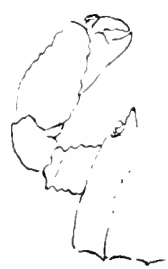

Heterocryta. 


\section{Lambrus.}

Lambrus . Leach, Milne Edwards, Miers.

Carapace equilaterally subtriangulate, convex or depressed, with the lateral margins rounded at the branchial regions, and armed with tubercles or spines, which, on the postero-lateral margins, are sometimes considerably elongated. Rostrum usually prominent, triangulate, and somewhat deflexed. Eyes short, robust. Orbits small and well defined, with a fissure in the superior margin; the interior subocular lobe is sometimes greatly developed. Internal antennxe usually obliquely folded, with the basal joint considerably developed. The basal joint of external antenna is short, dilated, but does not reach the front; the next joint occupies the interior hiatus of the orbit. Epistome usually transverse. The third joint of external maxillipedes is not produced at its antero-internal angle; the fourth joint is distally truncated, and articulates with the fifth at its anterointernal angle. The first pair of legs of the male is subequal, and elongated or of moderate length; the fourth joint and the palm are elongated and usually spinous or tuberculated; palm trigonous, and armed with a denticulated or spinous crest along the superior and the internal margin ; fingers short, distally acute, and dentated on the internal margins. Walking legs slender and of moderate length, with their fourth joint sometimes denticulated or tuberculated on the margins; last joint styliform.

The abdomen of the male covers the sternum between the base of the fifth pair of legss, and is five or six-jointed, with two or three of the intermediate segments soldered together.

RANGE. - Mediterranean Sea, Atlantic and Pacific 
Oceans; in warm seas, among rocks, in shallow and deep water.

\section{Subgenus I. Lambrus. Subgenus II. Pisolambrus.}

Srnopsis of time Subgenera ani Species.

I. Carapace moderately convex, not produced over the legs, rarely depressed; rostrum and epistome well developed; lateral epibranchial spinie small or absent: first pair of legs elongated; palm and fourth joint with strong spines; pterygostomian regions sometimes slightly excavated and carinated.-(Subgenus Lambrus.)

$A$. Fourth joint of walking legs spinose or tuberculated.-(L. pourtalesii.)

$B$. Fourth joint of walking legs without spines or tubercles.

a. Carapace broader than long, without angles at the sides.-(L. agonus.)

b. Carapace with antero-lateral edges with eight to nine teeth, last tooth long.-(L. serratus.

II. Carapace rounded; eyes very large; basal joint of internal antenna large and swollen; basal joint of external antenna very small; the efferent orifice of the branchial chamber is continued in a canal on the pterygostomian region.-(Subgenus Pisolambrus.)

c. (arapace quite smooth.-(L. nitidus.)

\section{Subgenus Lambrus.}

Lambus . . A. Milne Edwards, Miers.

Platylambrus. Stimpson.

Rhunclambrus. A. Milne Edwards.

Carapace moderately convex, and not produced ower the base of the legs, rarely depressed, with the rostrum 
and the epistome well developed; the lateral epibranchial spine absent or but slightly developed. Pterygostomian regions are sometimes slightly excavated and carinated. First pair of legs considerably elongated; palm and fourth joint usually armed with strong spines.

\section{Lambrus (Lambrus) pourtalesii.}

Lambrus pourtalesii . . . . . Stimpson, A. Milne Edwards.

The carapace is much wider than long, with a median row of four spiniform tubercles, of which one is placed on the gastric and three on the cardiac regions. In front of the gastric tubercle there are two smaller tubercles, arranged in a transverse line. The oblique ridge on the branchial region is surmounted with three unequal tubercles; one strong tooth, spiniform, and provided with a small tooth at its base, exists on the edge of the carapace. There are some small scattered tubercles, principally in the branchio-cardiac grooves. The grooves separating the regions are of moderate depth. The general surface is punctuate and granular, having an eroded appearance. The largest tooth is on the hepatic region. The antero-lateral cdge, behind the cervical groove, has nine small teeth. The rostrum is of moderate dimensions; it is advanced obliquely downwards and forwards, and has a tooth on each side near its base, and one smaller tooth near its extremity. On a level with the second tooth the rostrum contracts suddenly about one-half its breadth.

The first pair of legs is very long, their edges being armed with teeth. The arms are convex, with granules and tubercles on their superior surface; the large tubercles on their centre are spiniform. The forearm has abuve 
and outside large and small tubercles. The superior surfacc of the hand has two or three tubercles about its middle. The teeth of its edges are larger and more triangular than those on the borders of the arms; those on the internal border are larger than those on the external border, especially towards the extremity of the hand. The inferior surface of the hand is punctuated, with a regular median row of tubercies. The walking legs are a little compressed, the fourth joint spiny above and below.

The ridges of the abdomen, sternum, and external maxillipedes are tuberculated.

RANGE.-Grenada, Florida.

\section{Lambrus (Lambrus) agonus.}

Lambrus agonus . . A. Milne Edwards, Stimpson.

The carapace is wider than long, rounded, without angles on the sides; the regions are but slightly marked. The surface is finely tubercular and granulated. The largest tubercles are spiniform, and are arranged thus:Five upon the gastric region, of which four are placed towards the middle, upon a transterse line, and another, larger than the others, on the middle line behind these; three in a longitudinal row upon the cardiac region; onc on each side of the urocardiac lobe; five upon each branchial region, and one upon the hepatic region. There is a line of tubercles, forming a $\mathrm{V}$, starting from the central cardiac and each hepatic tubercle. The antero-lateral border behind the hepatic region has six very small tecth; below and behind the last there is a short and dentiform ridge.

The rostrum has two or three small teeth near the basal teeth. 
There are two prominent teeth upon the external orbital border, and a minute spine at the summit of the eye. The first pair of legs is long and slender; upper surface minutely scabrous, and with an irregular row of teeth-like tubercles which is median upon the arm and forearm, but approaches the outer margin of the hand. The edge of the fourth and fifth joint has small irregular teeth. The superior edge of the hand has nineteen teeth, at first increasing in size then diminishing. On the outer edge of the hand there are four to five large and about eleven small teeth, alternating by threes with the larger ones. Fingers are white, and not much bent downwards. The walking legs are long, thin, naked, unarmed or having only obscure indications of teeth on their fourth joint.

On the sternum near the base of the first pair of legs there is a conical tubercle on each side. Tooth of basal joint of first pair acutely triangular. On the second joint of abdomen there is a transverse crest, with a tooth on each side; on the last joint but one there is a crest.

RANGE.-West Indies, Florida.

\section{Lambrus (Lambrus) serratus.}

Lambrus serratus . . . H. Milne Edwards.

Lambrus cremulatus . . . Saussure, Stimpson.

Platylambrus crenulatus . Desbonne and Schramm.

Platylambrus serratus . . A. Milne Edwards.

Lambrus lapoides. . White.

Cancer macrochelos. . . Scba.

Carapace wide, depressed, and rough; antero-lateral edges armed with eight or nine triangular teeth, of 
which the last is directed outwards and is very long; the latero-posterior border is armed with three small spines. The rostrum is small, triangular, depressed in the centre. The superior face of the hands is more or less smooth, granular on their inferior edge and smooth on the remaining faces; the superior and external edges are armed with compressed teeth, so arranged as to form a crest. The last segment but one of the abdomen of the male has a pointed central tubercle.

Colour, light rose, sometimes marked with black; the fingers are carmine; the teeth of the pincers have a black margin.

RANGE.-Guadaloupe, Vera Cruz, Florida.

\section{Subgenus Pisolambrus.}

\section{Pisolambrus . . A. Milne Edwards.}

The carapace is rounded, smooth, and without pyramidal projections. The eyes are very large. The basal joint of the internal antenna is large and swollen ; it margins the eye on the inside in almost its whole length. The extcrnal antenne are much reduced, and their basal joint is three or four times smaller than that of the internal antenne, so that the eye is almost completely exposed below. The fourth joint of the external maxillipedes is dilated in front and outside, but truncated on the inside.

The efferent orifices of the branchial chamber is continued on the pterygostomian region in a canal. The third to fifth segment inclusive of the abdomen of the male is soldered into a single piece. The legs are long and frail. 


\section{Lambrus (Pisolambrus) nitidus.}

Lambrus nitidus.

Pisolambrus nitidus.
Miers.

A. Milne Edwards.

The carapace is wider than long, little raised, but rounded above; the branchial regions are prominent and distinctly separated from the hepatic regions. The test magnificd is finely punctuated, but to the naked eye it is smooth and shining. There are neither granulations nor tubercles. The front, morc advanced than the cyes, forms a trilobed and slightly depressed lamina in the middle line. The antero-lateral border, very bowed and slightly laminate, is obscurcly divided by fissures into very faintly marked teeth; it is continued directly with the postero-lateral border, which is also fused with the posterior border. The external maxillipedes have on their third joint a line of tubercles which limits on the inside the efferent canals of the branchial chambers.

The first pair of legs is very thin and long; the fourth joint, smooth in its whole extent, has its edges finely toothed like a saw; the fifth joint is small, and has three longitudinal lines of granulations. The hand is smooth on its faces, but has its supcrior border cut into ten or twelve slightly projecting saw-like teeth, at the base of which is a small group of granulations. The first, which surmounts the movable finger, is in the form of a spine. The external border has about twelve much smaller tecth, at the base of each is a small group of granulations forming a line parallel with the border. The inferior border is finely serrated. The walking legs are very thin; the extremity of the first pair does not reach the articulation of the arm with the forcarm. The sternal plastron and the abdomen are smooth.

RANGe-Barbados, St. Vincent, Santa Cruz. 


\section{Parthenope.}

I'arthenot . . . H. Mihne Edwards, Fabricius, Latreillc.

Cancer. . . . . Ilerbst.

Maria . . . . . Latrcille.

The carapace, the eyes, the rostrum are as in the genus Lambrus.

The basal joint of the external antennxe is not soldered to the ncighbouring parts, but reaches almost to the front; the second joint is slightly shorter than the first, and is lodged in the cavity at the orbital angle; this cavity connects the orbit with the antennulary fosse.

The abdomen is composed of seven joints in both sexes.

RANGE.-Atlantic and Indian Oceans.

\section{Parthenope horrida.}

Parthcnopehorrida. . II. Milne Edwards, Leach, Fabricius, Latreille, Guérin.

Cancer spinosus . . . Rumph.

Cancer horridus . . . Ijinné.

Main horrida. . . . Bosc.

Lasy crab . . . . . Griffith Hughes.

Carapace pentagonal, much wider than long, horizontal, strongly embossed, and tuberculate above; the antero-lateral border is very oblique, and armed with spines. Orbits circular, with a fissure in their upper edge. Rostrum short, triangular, and armed bolow with a strong interantennulary tooth. The first pair of legs is very large, of mequal size, and corcred with large spiniform tubercles; the other legs, to the origin of the 
terminal joint, bristle with very large and sharp spines, forming one row above and two below.

Length, from two to thrce inches; colour, grey, test having the appearance of a rough stone.

RANGE.-Barbados.

\section{Solenolambrus.}

Solenolambrus . . Stimpson, A. Milne Edwards, Miers.

Carapace pentagonal, more or less broader than long. The posterior side of the pentagon is the shortest, the other four are about equal. The margin is acute on all sides, forming a slight crest. The upper surface is naked, glossy, strongly convex, and has four protuberances, one gastric, one cardiac, two branchial. The gastric and cardiac ones are triangularly pyramidal, and the branchial one has an acute ridge rumning obliquely to the posterolateral margin of the carapace. Frontal region is slightly convex, and there is no protuberance on the orbital region. Orbits round, upper margin entire and smooth. The rostrum is short, blunt, or faintly tridentate. The basal joint of external antenne is about as long as the next joint. The epistome is concave. From the anteroexternal angle of the buccal arca a sharp ridge extends to the outer base of the first pair of legs, separating the concave pterygostomian from the subhepatic region, which is also concave and channel-like. When retracted the extremity of the hand covers the pterygostomian region, forming the efferent passage. The extemal maxillipedes fit accurately the buccal area, and the external appendage is concave, forming part of the wall of the channel; the fourth joint has a prominent anteroexternal angle, its surface is concave towards the antero- 
internal angle, where it is not notched for the inscrtion of the next joint, which, except at its origin, is concealed beneath the other parts of the maxillipede. The pincers resemble those of Lambrns, but the fingers are weaker, and the movable finger forms a right angle with the palm when it approaches its companion. The superior edge of the fourth joint of the walking legs is more or less crest-like.

The third to fifth abdominal segment, inclusive, of the male are soldered together.

\section{Solenolambrus ty picus.}

Solcnolambrus typicus . A. Milne Edwards, Stimpson.

The carapace has its posterior part produced. In the male each protuberance has an acute spine. The antero-lateral margin concave anteriorly, convex posteriorly. Posterior margin straight. Eyes large, with a minute tubercle on the anterior side of the extremity Basal joint of the external antenna somewhat longer than the next joint. Epistome of moderate length. External maxillipedes naked; third joint with onter ridge tuberculated, and a few tubercles on the surface near the extremity.

The tubercles on sternum, between bases of the first pair of legs, one on each side of the middle linc. First pair of legs long, naked. The fourth joint has teeth on margin, upper surface smooth, glossy, except at both extremities, which have tubercles above. The fifth joint has five crests; the hand has ten regular teeth upon superior edge, twelve on outer margin and fiftcen on lower margin; upper surface has two rows of tubercles, lower surface three rows, inner surface is smooth in middle. Fingers small and slender, one-fifth as long as 
the palm; when retracted, almost at a right angle with the palm. Walking legs compressed, naked, with crests above; third and fifth joints have crests below.

Abdomen tuberculated on its sides; third segment of the male not narrowed.

RANGE-St. Vincent, St. Lucia, Guadaloupe, Florida, Mexico; in deep water.

\section{Mesorhœa.}

Mesorhar . . . Stimpson, A. Milne Edwards.

Resembles Solenolambrus in the form and ornamentation of the carapace, the arrangement of the fect, pterygostomian and hepatic regions. The efferent canals meet in the middle of the epistome, which has a triangular projection and a deep notch on its vertical and laminiform wall. The fourth joint of the external maxillipedes is advanced in front, with a sharp point at its internal angle, and the fifth joint is completely hidden behind it. The epistome is very short.

The eyes are small, and can hide themselves completely within their deep orbits.

The basal joint of external antenna is shorter than the second joint.

\section{Mesorhœa cristatipes.}

Mesorteca cristatipes. . . . A. Milne Edwards.

The gastric and cardiac regions are very elevated, and form in the middle line an elevated ridge; there are three tubercles, one posterior and median, the two others anterior and arranged symmetrically on the gastric region; there are two median elevations on the cardiac region. The branchial regions are very prominent, and 
they terminate outside in a sharp ridge which extends as far as the lateral angle. The antero-lateral edges are cut into a great number of small teeth, and are ornamented with short hairs. The external maxillipedes have a very prominent crest along their whole length. The first pair of legs is long and strong; the arm has behind two or three large compressed tubercles which have hairs; it has in front a sharp crest. There is one toothed crest on the internal border of the hand; the external border is sharp and cut into four teeth; two crests ornament the superior border of the movable finger; the fourth joint of the walking legs has crests above and below.

RANGE.-St. Vincent; in deep water.

\section{Heterocrypta.}

Hiterocrypta . . . . Stimpson, A. Milne Edwards. Cryptopodia (part). . Gibbes.

The carapace is wide, and its lateral angles extend over the walking legs, without completely hiding them. The pterygostomian and hepatic regions have a granular crest almost parallel with the lateral edge.

\section{Heterocrypta granulata.}

Heterocrypta gramulata . Stimpson, Milne Edwards. Cryptopodia gramulata. . Gibbes.

The carapace is triangular, and very wide behind; the regions are slightly marked; the branchial region has an elevated and very finely granulated crest which runs parallel with the antero-lateral edge as far as the sides of the gastric region, where it becomes transverse; 
another ridge, not so prominent, starting from the angle formed by the preceding, edges the gastric region and is prolonged above the orbit. The urocardiac lobe is prominent, and has some granulations. The general surface is smooth. The front is triangular and slightly advanced. The antero-lateral edges are laminiform and almost straight; magnified, they appear finely ridged. The postero-lateral border has a prominent point situated at the origin of the branchial ridge; the portion of this border between this projection and the lateral angle is straight. The posterior edge forms with the preceding a very indistinct angle. The external maxillipedes and the sternum are granular. The pincers are of unequal size, short, and have on their edges finely cut crests. The faces are smooth. The hand is sivollen, and the movable finger is robust and bowed. The fourth joint of the walking legs is hidden under the lateral expansion of the carapace.

RANGE.-St. Thomas, Charlestown.

\section{Tribe II. Cyclometopa.}

Cyclometopa . . . Miers, White.
Cyclonetopes . . . H. Milne Edwards.
Arcuata. . . . . Latreille.
Cancroidea. . . . De Haan.

The carapace is very large and bowed in front, contracted posteriorly, being generally broader than long; sometimes it is circular. The hepatic regions are well developed, and occupy the most of the lateral portion of the test. The front is transverse and slightly or not turned down. The orbits are directed upwards and forwards. The eyes are always perfectly mobile, and 
retractile within the postforaminal portion of the orbits, which is very deep. The internal antenna are always lodged in fosse under the front. The basal articulation of the external antenne always separates the antennulary fossa from the orbits; sometimes free, sometimes soldered to the test. The antennary region is not as great as the buccal cavity. The epistome is very short, much wider than long. The buccal cavity is very wide in front, and long from before backwards.

The genital orifices of the malc, the efferent canals of the respiratory regions, and the gills are arranged as in the Oryrhymila.

\section{Legion Cancrinea.}

Cancrinea, or Cancroidea typica . Dana, Miers.

The carapace is not antero-laterally convex, and largely developed so as to form a vaulted respiratory chamber. The buccal cavity is usually well defined. The flagella of the antenna are not elongated. The last joint of the walking legs is styliform and unarmed, or in the fifth pair expanded into an ovate swimming organ.

\section{Family I. Cancridæ.}

Family II. Portunidæ.

\section{Sinopsis OF tIIE FAMILIES.}

A. The last joint of all the walling legs is the same shape.-(Cancrida.)

$B$. The last joint of the last pair of walking legs does not resemble that of the others in shape, being flattened, expanded, and used for swimming.-(Portunida.) 


\section{Family I. Cancridæ.}

Cancride . . . . . Miers.

Cancride and Eriphide. Dana.

Cancéricus . . . . . H. Milne Edwards, A. Milne Edwards.

The carapace is in general very strongly curved above, and raised and rounded on the edges; its upper surface only forms a sharp angle where it joins the inferior and lateral portion. The sternal plastron is almost always as long as broad; the last thoracic segment is much smaller than the preceding segments, and is separated from them by an almost straight and transverse suture; the thoracic ring corresponding to the anterior legs is well developed; the arch of the flanks is very oblique; the posterior groove is very large.

The fourth joint of the external maxillipedes is usually almost quadrilateral, and slightly or not truncated at its internal and posterior angle. The first pair of legs usually very large, long, and swollen; the succeeding pairs are uniform, short, and for walking, those of the second pair being usually less than once and a half times the length of the carapace.

\section{Section Cancrinæ.}

Cancrince . . . . . Miers.

\begin{tabular}{l|l} 
Cancéricus arqués \\
Cancíricns quadrilatóres
\end{tabular} . H. Milne Edwards.

Carapace usually convex, with the antero-lateral margins arcuated, and armed with lobes, teeth, or spines. The front is of moderate width, and usually does not project over the atennules and the bases of the antennx, which 
are seldom excluded from the interior hiatus of the orbits.

\section{Sinol'sis OF TIE GeNeRA.}

A. Endostome without distinct longitudinal ridges.

a. Tips of fingers of first pair of legs acute.

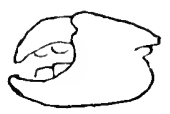

$a^{1}$. Carapace smooth.

I. Antero-lateral margins smooth, entire, without crest; one blunt epibranchial lobe--(Carpilizs.)

2. Antero-lateral margin defined by a crest which is interrupted by fissures.--(Lophactear.)

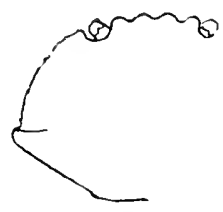

Carpiliuts.

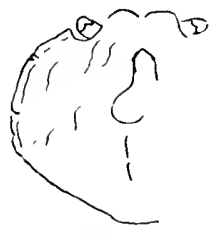

Lophation.

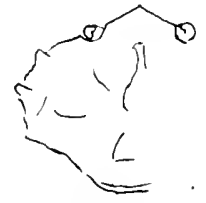

Midicus.

$b^{1}$. Carapace transverse, slightly convex; regions well marlied, granular.

3. Antero-lateral margins have three to five teeth.(Medieus.)

4. Antero-lateral margins have rounded lobes which may not be well marked.-(Atcer.)

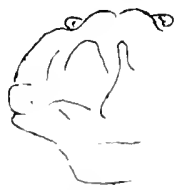

diluet.

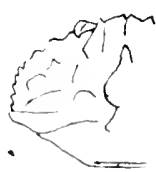

linulho.

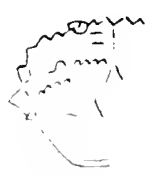

Ainthode's,

$c^{-1}$. Carapace transverse, depressed. 
5. Antero-lateral margins are arcuated, and divided into four or five lobes.-( Tantho.)

6. Antero-lateral margins are not thin-edged or cristiform, and their teeth are in the form of tubercles or spines.-(. Tanthodes.)

7. Front separated from the antero-lateral angle of the orbit by a notch. Antero-lateral margin is cut into five teeth.-(Panopeus.)

$d^{1}$. Carapace is wide and slightly convex.

8 . The front is a continuation of the antero-lateral borders which are thin, and their teeth scarcely exceeds the general curve of the carapace.-(Eurponopius.)

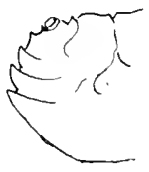

Panopeus.

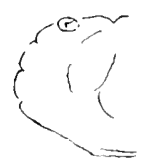

Eurponopews.

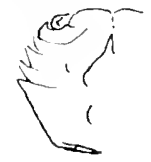

Mivepanofi.

9. The antero-lateral border is short and toothed. The second tooth is usually soldered with the orbital angle.-(Micropanope.)

b. The tips of the fingers of the first pair of legs are excavated and spoon-shaped.

$\iota^{1}$. The antero-lateral margins of the

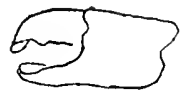
carapace are armed with lobes.

Io. Antero-lateral margins not cristated; only the three posterior lobes are distinct.-(Carfilodes.)

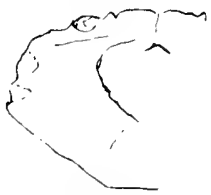

Carpilodes.

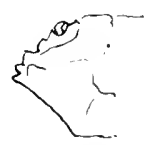

Chlorodius.

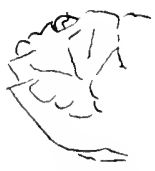

Liflodius.

II. Carapace hexagonal. Two first antero-lateral 
teeth, not counting the external orbital angle, are rounded; last two more or less sharp.-(Chlurodius.)

12. The lobes are more or less pointed.-(Leptodizs.)

13. The lobes are more or less tooth-shaped, the space between being wide.-(Phymodits.)

B. Endostome with distinct longitudinal ridges.

c. Antennæ not excluded from the orbit.

$f^{1}$. Carapace transverse, smooth.

14. The front is formed of two lobes.-(Eurytium.)

15. The front is formed of four teeth. Fingers not spoon-shaped.-(Ozius. $)$

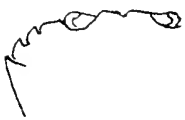

Lityium.

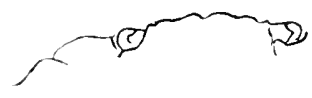

Osius.

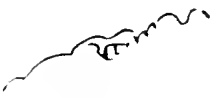

Meniffe.

I6. The front is notched in the centre, and each side is cut into small lobes. Fingers not spoon-shaped. -(Mtrifpe.

$s^{-1}$. Carapace is transverse, hairy or covered with down.

I7. The front is formed of two lobes; exterior to each is a lobe or tooth. Fingers acute or subacute.-(Pilummus.)

IS. The front is formed of two lobes; cxterior to each is a notch.-(Iobopilnmmus.)

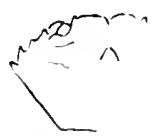

I'ilummus.

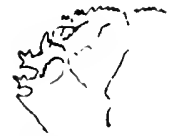

lobopilummes.

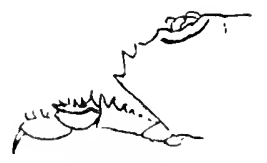

Mitiratera.

19. The front terminates in a thick and straight edge. A horn-like crest on fifth joint of walking legs.--(Iteteractea.) 
d. Antennze excluded from the orbit, whose interior hiatus is closed.

20. Carapace but little broader than long, with the antero-lateral borders much shorter than the posterolateral. Fingers acute or subacute--(Eriphia.)

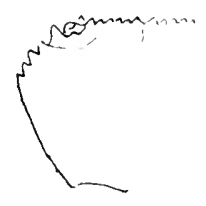

Erifhia.

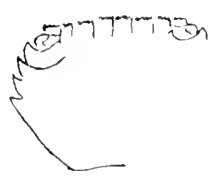

Domeria.

21. Carapace wider than long. The fronto-orbital border occupies almost the whole breadth of the carapacc. Fingers acute.-(Domeciar.)

A. Endostome without distinct longitudinal ridges defining the openings of the efferent branchial channels.

a. Fingers of the first pair of ligs acute or subacute:-

\section{Carpilius.}

Carpitius . Leach, Desmarest, Milne Edwards.

Cancer . . Linné, Fabricius, Latreille.

Carapace convex, without dorsal tubercles or sulci defining the regions; with the antero-lateral margins regularly arcuated and entire, terminating in a blunt lobe or tooth (the lateral cpibranchial tooth) and slightly longer than the postero-lateral margins, which are ncarly straight. The front is rather narrow, deflexed, and is divided into three lobes, the median being prominent, with the anterior margin slightly concave, and the lateral ones rounded and but little developed. The orbits are small, without marginal fissures, and with a rounded lobe or 
tooth at their external angle. The eyes are set on short thick peduncles.

The basal joint of the external antenne is elongated, and enters well within the long and narrow hiatus existing between the front and the orbits, but does not reach the inner and inferior angle of the orbit, and the very small flagellum is contained within this hiatus. The fourth joint of the external maxillipedes is very obliquely truncated at the distal extremity, and not (or slightly) emarginated at the antero-internal angle. The first pair of legs in the adult male is large and massive, unequal; the palms without ridges or tubercles; the fingers of the larger one are armed with one or two large rounded tubercles on its inner edge. The walking legs are moderately long and smooth; subcylindrical or slightly compressed.

The abdomen is six-jointed in the male and sevenjointed in the female.

RANGE.-Indo-Pacific region, West Indies; in shallow water beyond low-water mark.

\section{Carpilius corallinus.}

Carpilius corallinus . . H. Milne Edwards, Fabricius. Carpitius floridus. . Rumph.

Carpilius flosculosus . Seba, Herbst.

Carpilius adsporsus. . Herbst.

Carpilius maculatus. Latreille.

The carapace is smooth, and has no hairs anywhere: it is a little broader than long. The front, in breadth, does not exceed the length of the space between the sternal plastron and the anterior edge of the antennulary fossa ; it is divided into three lobes by deep notches, the middle one being largest and having an indistinct division in its centre; there is a small tubercle at the outer angle 
of the orbit. The basal antennal joint is very oblique. The epistome is smooth; the anterior edge of the buccal cavity scarcely projects, and is without a tubercle at its extremities. The first pair of legs are not twice as long as the carapace; the second pair are shorter than the third.

The colour of the upper surface of the carapace is dark lake with a narrow border of brick-red, yellow spots appearing through. The lake patch joins the front in three lines forming two equal curves directed forwards, and is produced posteriorly with a lobe of the same shape as the carapace; round this lobe the yellow spots form a more or less continuous border. The under surface is bright yellow. The eyes and eye-peduncles are brickred, of a shade of the margin of the carapace. The legs are dark mahogany colour, with orange bands near the articulations. The tips of the fingers of the first pair of legs are black. These legs are dark mahogany colour, with orange markings near the articulations.

RAxce.-Barbados, Guadaloupe, Mexico, Brazil.

\section{Lophactæa.}

Lopharted . . A. Milne Edwards, Miers.

Carapace transverse, convex, its dorsal surface distinctly lobulated in its anterior half, and often granulated. The antero-lateral margins are longer than the concave postero-lateral margins, and are not dentated, but defined by a crest which is interrupted by fissures. The regions are distinctly defined and smooth. The front is deflexed not prominent, rough and about one-third the breadth of the carapace; its anterior margin is wavy and nearly straight, generally with a median fissure. The basal joint of the cxternal antenna attains the infero-lateral process of the front, but is not prolonged within the orbital hiatus. 
The fourth joint of the external maxillipedes is slightly truncated distally. The legs of the first pair in the adult male are moderately robust and subequal; fourth joint short; fifth and palm smooth or granulated above; palm sometimes carinated; fingers usually carinated on the superior margin. Walking legs short, compressed; fourth to the sixth joint dilated and carinated above; last joint slender, nearly straight, and longer than the preceding joint.

Abdomen of male five-jointed; third and fifth coalescent.

RANGE.-Indo-Pacific region, West Indian Sea, Bermuda.

\section{Lophactæa lobata.}

Laphactaa lobata . . A. Milne Edwards, Miers.

Comerer lobatus . . . H. Mine Edwards, Guérin.

Cancer aemustus. . . Desbonne and Schramm.

Atergatis lobatus . . Stimpson.

The carapace is wide, very curved from before backwards, strongly lobulated in front, very contracted behind. The front is sloped, lamcllate, with a rouncled outline, slightly projecting, and divided in the middle line by an indistinct fissure. The antero-lateral borders are prolonged very far behind, where they are continued in a small ridge, where they form a right angle and are continued towards the cardiac region. They are divided into four lobes by very narrow and short fissures. The postero-lateral margins are short and concave. The first pair of legs about the same size. The hand is short, compressed, surmounted by a smooth crest; the external face has numerous granulations arranged irregularly towards its superior border, but arranged below in three or four 
regular lines. The fingers are grooved and armed upon their prehensile border with fine teeth. The walking legs are short, compressed, and with a fine crest terminating in a very sharp nail.

In young specimens the carapace and the pincers are more granular than in adults.

The colour is chocolate-brown with yellow spots bordered with blue and black, with similar spots on the first pair of legs. The walking legs are red, with yellow, blue and black bands. The eggs are yellow-red.

RANGE,-Bermuda, West Indies, Gulf of Mexico.

\section{Medæus.}

\section{Medeus . . Dana, Miers, Milne Edwards.}

Carapace moderately transverse and convex, with the surface more or less lobulated or granulated, and with the antero-lateral margin armed with from three to five tecth ; the front projects slightly beyond the orbits, and is usually divided into two lobes by a median notch. The anterolateral margins may be continued beneath the inferior margin of the orbit as a toothed crest. The eyes and orbits are small. The basal antennal joint attains the infero-lateral process of the front, and may enter within the inner orbital hiatus. The external maxillipedes are truncated distally, and slightly emarginate at the anterointernal angle. The legs of the first pair are of moderate size, and the palms are usually tuberculated above; fingers dentated on the inner margins. The walking legs are rather slender, and the fourth joint may be toothed above. The abdomen in the male is five-juinted, with the third to fifth joint coalescent.

RANGE.-West Indian Sea, Australia, East Coast of Africa; shallow water and shore. 


\section{Medæus spinimanus.}
Hedeus spinimanus
A. Milne Edwards, Miers.
Cancer miniatns.
Desbonne and Schramm.
Cancer spinimamlis.
I1. Milne Edwards.

The carapace is smooth, slightly swollen, subhexagonal, strongly lobulated, especially in front; all the projecting parts are granular; the grooves are smooth. The front is less advanced upon the sides than in the middle line, where it is traversed by a straight fissure, very visible below where it terminates at the epistomian point. The orbits are circular; their inferior internal angle exceeds the basal antennal joint. The antero-lateral border is cut into four triangular teeth, joined the one to the other by a small granular or spinous ridge; the first tooth is the smallest, it is placed below the external orbital angle.

The pteryogostomian regions, the external maxillipedes, and the sternal plastron are granular. The legs of the first pair are short; the fourth joint does not exceed the edge of the carapace; it is covered below with granulations. The fifth joint has a few tubercles at its internal angle; it is rough and granular above and outside. The hand is surmounted by a crest cut into five large teeth; it has on the outside raspberry-like tubercles, with numerous confluent and irregular granulations between the tubercles; the movable finger has above an elevated ridge not toothed. The walking legs are long, covered with granulations or spines, and with a few hairs on the last joint.

The abdomen of the male is narrow; its first segments are granular, the last are smooth.

The colour is yellow-grey spotted with red; the first pair of legs vermilion-red, and the fingers of the pincers brown.

RANGE.-Barbados, Guadaloupe. 


\section{Actæa.}

Actaa . . De Haan, Dana, A. Milne Edwards, Miers. Cancer. Linné, Fabricius, Latreille, Desmarest, H. Milne Edwards.

Zosymus. H. Milne Edwards.

Trutho . Rappell, A. Milne Edwards, Lucas. Actodes . Dana.

Carapace transverse and slightly convex; lobes well marked, granular; front with two or four lobes; anterolateral margins have round lobes, which may not be well marked. Orbits are small, and may have closed fissures. The eyes are on short stalks. The basal antennal joint reaches the infero-lateral process of the front ; the flagellum lies within the interior orbital hiatus. The fourth joint of the external maxillipedes is quadrate, distally truncated, and slightly emarginate at the antero-internal angle. The legs of the first pair are subequal and of moderate size; fifth joint and palm usually granulated. The walking legs are of moderate length; usually compressed, not distally carinated; superior margin of fourth joint is sometimes acutc.

The abdomen in the male is five to seven-jointed. RANGE.-Australia, Cape, Red Sea, West Indies

\section{Sinofsis OF the Silecies.}

A. The front has four lobes.

a. The antero-lateral border has four lobes.- $A$, setigera.)

b. The front has two lobes.

b. The general surface is spiny.--(A. acontha.)

c. The general surface is tubercular. - ( H. nodosa. $)$ 


\section{Actæa setigera.}

Actea setigera . . A. Milne Edwards, Stimpson.

Acter setiger. . . Stimpson.

Fantho setiger . . Milne Edwards.

The carapace is wide, oroid, slightly convex, covered with short hairs and with granulations, and has four lobes in front. The lobes are flat and are separated by deep grooves. The antero-lateral edges are very curved; they are divided into four lobes which do not exceed the general curve of the carapace; the two first lobes are almost one. The postero-lateral borders are short and concave. The front is very strongly notched in the midclle. The basal antennal joint is wide, but very short ; it is united with a long and narrow subfrontal prolongation. The pterygostomian regions are finely granular.

The fingers of the pincers are black, and this coloration extends, in very old males, upon the external and internal face of the hands as far as the articulation of the fifth joint ; in the female the fingers only are black. The walking legs are covered with hairs like that on the carapace. The fourth joint is smooth on the outside, and granular above and below; the fifth and the sixth joints are granular. The last joint is long, granular, and terminate in a sharp point.

The abdomen of the male is long and narrow.

RANGE.-West Indies, Florida, Cuba.

\section{Actæa acantha.}

Actar acantha. A. Milne Edwards.

Canceraconthus. H. Milne Edwards, Desbonne and Schramm.

The body and legs are covered with stiff hairs. The carapace is oval, slightly convex, very wide in front and 
very lobular. The lobes of the anterior portion are prominent, covered with pointed tubercles or with spines, between which extend wide grooves, deep and smooth. The front is formed of two lobes very advanced, and separated in the middle line by a notch relatively wide. The frontal and suborbital borders bristle with spines. The antero-lateral borders are long, regularly bowed, and divided into five lobes armed with thrce or four spines; the external orbital angle is also spiny. The posterolateral borders are concave. The posterior border has a row of tubercles. The basal antennal joint has spines. The fourth joint of the cxternal maxillipedes is short, wide, and deeply notched on the inside for articulation with the fifth joint; its anterior and internal border is slightly toothed. The first pair of legs subequal; the hand is covered with spines upon the superior and external face ; the fingers are short, spinous, black, with a white extremity; the black, in males, cxtends upon almost the whole of the hand. The fifth joint is spiny. The walking legs have many spines.

RANGE.-Guadaloupe.

\section{Actæa nodosa.}

Acter nodosa . . . Stimpson, A. Milne Edwards. Actaer rufopunctertar. Milne Edwards, Miers.

Carapace broad and deeply lobulated both in front and behind; the lobes forming prominent granulated nodes, mostly of nearly equal size, about forty, including the antero-lateral teeth. These lobes are strongly convex in the anterior, but flattened in the posterior, regions of the carapace. The furrows separating them are wide and deep, and more or less thickly pubescent. The median gastric lobe, which is usually long and slender, reaching 
far forwards, is in the present species almost obsolete, being represented only by its tubercular posterior extremity. The front is formed of two lobes. The legs are nodose and granulated like the carapace. The outer surface of the hand is tuberculated, the tubercles being arranged, inferiorly, in three longitudinal rows.

Range.-Barbados, Santa Cruz, Florida, Bahia; in shallow water.

\section{Xantho.}

Tantho . Leach, Desmarest, H. Milne Edwards, De Haan, Dana, A. Milne Edwards, Cancer. . Miers. Linné.

Carapace transverse and depressed, often nearly flat above, with the dorsal surface lobulated, at least near the front and antero-lateral margins. The front projects slightly and is usually divided by a small median notch ; the antero-lateral margins are arcuated and divided into four or five lobes. The eyes have thick short stalks. The orbits have a fissure beneath. The external antennæe are short; the basal joint reaches the infero-lateral frontal process, and the flagellum lies within the interior orbital hiatus. The external maxillipedes have the fourth joint quadrate; the inner angle is truncated. The first pair of legs large, with the palms compressed, rounded above, and the fingers toothed on their inner margins. The walking legs are of moderate length, without keels or spines.

The abdomen is five to seven-jointed.

RANGE-Atlantic and Pacific Ocean; in shallow water. 


\section{Xantho denticulatus.}

Xantho denticulatus. White, Miers, S. Smith, A. Milne Edwards.

Tantho humilis . Desbonne and Schramm.

The carapace is one-third wider than long. The regions are well marked in front, and the lobules which form them are prominent and ornamented anteriorly wits punctuations and rugosities. The front is almost straight, edge emarginatc, separatcd in the middle line into two indistinct lobes. The antero-lateral edges are large, more bowed behind than in front; they are divided into from eight to ten small tubercular teeth. The pterygostomian regions and the external maxillipedes are covered with granulations and rugosities. The legs of the first pair are strong and of unequal size, their superior surface is rough and eroded; the fifth joint of the large pincer has two tubercles at its internal angle; the fingers are short and strong, those of the small pincer are longer and more compressed.

The colour is grey, with red spots; the fingers of the pincers are black.

Range.-West Indies, Vera Cruz, Mexico, Brazil; in shallow water.

\section{Xanthodes.}

Xanthodes . Dana, Miers, A. Milne Edwards.

(Xantho part). II. Milne Edwards.

The carapace is convex, deflexed near the front and antero-lateral margins, depressed postcriorly; the anterolateral margins are not thin-edged or cristiform, and their teeth are in the form of tubercles or spines. The basal 
antennal joint is short and barely reaches the infero-lateral process of the front, it joins a fine and narrow prolongation of the front. The legs are cylindrical or flat, but they have no crest.

The abdomen of the male is fire-jointed.

RANGE.-Pacific and Atlantic Oceans; at moderate depths.

\section{Xanthodes bidentatus.}

\section{Tanthodes bidentatus . A Milne Edwards.}

The body is entirely smooth and naked. The gastric and hepatic regions are scarcely marked; the dorsal surface is almost flat from side to side, and slightly prominent before and behind. The front is formed of two truncate lobes, finely granular, separated in the median line by a small notch. The internal orbital angles are less projecting than the front. The antero-lateral edges are fine. The postorbital angle constitutes a small lobe scarcely projecting, behind which exists two tecth; the first is lobiform and rounded, the second is large and obtuse. The orbits are very feebly notched above and below. The basal joint of the external antenne is thin, and joins the front at its antero-internal angle. The first pair of legs of the male short and unequal; the fourth joint is hid under the carapace; the fifth is armed on the inside with two teeth. The hand is rounded, and the movable finger has, at its base, a large round tooth. The walking legs are fecble, and slightly hairy towards their extremity.

The sternal plastron and abdomen of the male are covered with a short down and are slightly toothed.

RANGL.-Grenada; at moderate depths. 


\section{Panopeus.}

Panopeus . H. Milne Edwards, Miers, A. Milne Edwards.

Carapace transverse, depressed, with the dorsal surface often marked with transverse prominences which are minutely granulated. The cervical and mesogastric sutures are distinct. The front projects but slightly beyond the level of the orbits, and is divided by a median notch into two truncated or sinuated lobes, which are separated by another notch from the antero-lateral angle of the orbit, whose margins are interrupted by fissures or notches, and there is a distinct emargination immediately below the tooth at the external orbital angle. The antero-lateral margins, shorter than the postero-lateral margins, are regularly divided into five teeth, of which the first or exterior orbital tooth is united more or less completely with the next; there is often a small tubercle on the subhepatic region below the interspace between the first and second antero-lateral tooth. The eyes are small. The basal antennal joint reaches the infero-lateral process of the front, but not the extremity of the subocular lobe of the orbit, which is often prominent and spiniform, and the flagellum occupies the inner orbital hiatus. The fourth joint of the external maxillipedes is often somewhat produced at its antero-external angle. The first pair of legs, in the adult male, is moderately developed. The walking legs are of moderate length, with the joints neither carinated nor spinose; the terminal joint is styliform and straight.

The abdomen, in the male, is usually five-jointed, with the third to the fifth coalescent; it completely covers the sternum at its base. 
RANGE.-Both sides of the Atlantic, Florida, Brazil, West Indies, West African Coast; it may be found at some depth.

\section{Synotsis of tile Species.}

A. The external orbital angle is separated from the next antero-lateral tooth by a notch, the two teeth almost forming one. The last tooth is pyramidal.-(P. herbstii.)

$B$. The second antero-lateral tooth is very small, and is situated behind the external orbital angle; the third and fourth teeth are large; the last tooth is small and pointed.-(P.xanthiformis.)

\section{Panopeus herbstii.}

Panofeus horbstii . . H. Milne Edwards, Deliay, Gibbes, Heller, S. Smith, Kingsley, A. Nilne Edwards.

Panopeus lacustris. . . Desbonne and Schramm.

Cancer panope . . . . Herbst.

Panopeus herbstii gran-

Panopens herbstii obesns $\}$.

Panopeus occidentalis. . I Saussure, Smith, Desbonne Panopens serratus. . . . and Schramm.

Panopcus americamus. . Saussure, Desbonne and Schramm.

The carapace is slightly curved from before backwards, and from side to side. The regions are indistinct, and the mesogastric lobe is produced into a long point between the protogastric lobes. This point is prolonged in a groove which separates the epigastric lobes and extends to the median notch of the front. There is upon each of 
these lobes a granular transverse line. There is a similar line upon the epibranchial lobes; it is arranged a little obliquely from before backwards. A small granular crest takes its origin at the base of the last lateral tooth, and it extends a short distance upon the mesobranchial lobe. The surface of the carapace is covered, in all its anterolateral portions, with fine granulations. The front is advanced, almost horizontal; its inferior border is granular and slightly notched laterally. The orbit is large, and the two fissures of the superior orbital borcler are well marked. The external orbital angle is separated from the second antero-lateral tooth by a round notch, and these two teeth appear to form a single lobe. The third tooth has a wider base than the fourth; the fifth is the smallest, more pointed, and, in place of being flat, is in the form of a triangular pyramid. The inferior orbital border has on the outside a wide hiatus, and its internal angle is produced into a prominent tooth; its middle portion is fine and straight. There is a subhepatic tubercle below the second lateral tooth. The pterygostomian regions are finely granulated and slightly hairy.

The first pair of legs strong and of unequal size. The fourth joint is completely hid under the carapace; its posterior border is cristiform, and it has two teeth near its extremity. The forearm is a little rough, and it is armed on the outside with a large tubercle. The hand is swollen and smooth or slightly rough. The larger has strong fingers, and at the base of the movable finger there is a large round tubercle. The fingers of the small pincer are thin, almost straight and scarcely dentated. The walking legs are feeble, and hairy towards their extremities.

The colour is red or yellow, with the legs of a dark or brown shade. 
RANGE.-Bermuda, Guadaloupe, Bahamas, Florida, Carolina, Aspinwall, Bahia.

A. Milne Edwards considers the following species to be only varieties of l'anoperts herbstii; while accepting his opinion, I give descriptions of them :-

\section{Panopeus herbstii granulosus.}

Carapace wide and granular; granulations very fine; a small transverse crest upon each of the protogastric lobes.

Bahia.

\section{Panopeus herbstii obesus.}

Carapace strongly convex, the front wide, sloping, slightly advanced, and terminating in a straight border. The external orbital angle is slightly projecting, and is scarcely separated from the second antero-lateral tooth. The other teeth are slightly prominent; the third is wide, and its external border is truncated; the fourth is very wide, but its anterior border is short; the last is very small.

Florida, Aspinwall.

\section{Panopeus occidentalis.}

The carapace is vaulted; regions are slightly marked and smooth. Front scarcely two-lobed, not granular. The antero-lateral borders of the carapace reach the level of the posterior border of the gastric region; two first teeth obtuse; three last teeth sharp. The fourth joint of the first pair of legs has a tooth at the external extremity of its superior border. The fifth has a tooth at its internal 
angle, with a wide and sharp marginal groove. Colour is red, fingers brown.

Guadaloupe.

\section{Panopeus serratus.}

Carapace flat, with transverse folds upon anterior part. Front not much adranced, scarcely bilobed. Internal orbital angles prominent. Antero-lateral teeth sharp. Fifth joint rough, with one tooth at internal angle. Hands large, finely rugose towards their upper part; their superior border has two blunt, very faint crests. Colour is yellow or brown.

Guadaloupe.

\section{Panopeus americanus.}

Carapace flat. Antero-lateral teeth not very prominent and blunt. The front is sightly more advanced in centre. Orbital border almost entire; inferior border not toothed but slightly sinuous, having at its internal extremity a slightly marked notch. Fourth joint and hands almost smooth; fifth joint without groove or depression; its internal angle slightly sharp. The colour is yellow or red.

Guadaloupe.

\section{Panopeus xanthiformis.}

Panopeus ranthermis . . A. Milne Edwards.

The carapace is depressed, slightly wide and granulose towards the antero-lateral edges. The front is formed of two lobes separated in the median line by a narrow fissure. The orbits are large, and their inferior border is 
finely denticulated; their superior border is interrupted above by two fissures, and their inferior border is cut within by a small and triangular notch, behind which is seen a very small subhepatic tooth. The antero-lateral borders are divided into four teeth: the first is very small, rouncled, and situated behind the postorbital angle; the second and the third are large and granular upon their edges; the fourth is very small and pointed. The latero-inferior regions are covered with granulations.

The first pair of legs is made rough with very fine granulations.

R.lnge.-Barbados, Grenada, Dominica.

\section{Eurypanopeus.}

Euryanopus . . A. Milne Edwards.

Panopeus (part) . It. Milne Edwards, Stimpson.

Carapace wide, slightly conves, with the regions slightly indicated. The front is a little advanced, and is continued into the antero-lateral borders; these latter are thin, and their teeth scarcely exceeds the general contour of the carapace; the external orbital angle is completely fused with the first tooth. The orbital fissures are narrow and shallow. The subhepatic tubercle is small or wanting The buccal cavity is rounded and slightly widened in front. The external maxillipedes are narrow.

RANGe--Chili, Peru, Panama, Florida, Barbados, California, Brazil, West Indies.

\section{Synopsis OF THE SPECIES.}

A. Antero-lateral border has four teeth, the first and the second bcing connected, forming one tooth.

a. The space between the antero-lateral teeth is a notch.--(E. abbreriatus. $)$ 
b. The space between the first and second and the second and the third tooth is a fissure; that between the third and fourth and between the fourth and fifth tooth a notch.- E. paratus.)

\section{Eurypanopeus abbreviatus.}

Eurypanopas abbreviatus . A. Milne Edwards.
Panopeus abbreviatus. . . Stimpson.

Carapace transversely rugose; regions well defined but not protuberant. Front rather narrow, but little projecting; margin, seen from above, nearly straight; and obliquely truncated or bevelled, the bevelled surface bcing granular. Supcrorbital fissure distinct. Anterolateral teeth normal in number, and rather prominent; the space between them a notch. Subhepatic regions granulated; a slight tuberculiform prominence beneath the first antero-lateral tooth. First pair of legs smooth; surface microscopically punctuated.

Colour yellowish or brownish; first pair of legs and front margin of carapace roseate; fingers black with paler tips.

RANGE.-Barbados.

\section{Eurypanopeus parvulus.}

Eurpanopeus paranlus . . A. Milne Edwards.

Cancer paraulus . . . Fabricius.

Tantho paroulus . . . . H. Milne Edwards.

The carapace is covered with rough elevations anterolaterally, arranged irregularly in transverse lines. The regions are distinct, and the branchio-hepatic groove, wide, extends as far as median notch of the lateral border. The front is notched in the middle, with a 
slightly wavy border; its lateral angles are teeth-like, but not projecting much. The supcrior orbital border is interupted by two small fissures; the external orbital hiatus is narrow, and the internal suborbital angle is distinct from the rest of the floor of the orbital cavity. The antero-lateral edges are cut into four truncated and tooth-like lobes. The external orbital angle and the second lobe counting as one. The division between the two first is a fissure, that between the other lobes, a notch. The latero-inferior regions are granular, and the subhepatic tooth is scarcely visible.

The legs of the first pair are of unequal size; that of the right side is much swollen and smooth. It has strong fingers; the movable finger has a strong basal tooth. The walking legs are thin.

RANGE.-West Indies, Brazil.

\section{Micropanope.}

Micropanope. Stimpson. A. Milne Edwards, Miers.

The carapace is nalied; it is slightly convex, and the regions are distinctly lobulated, especially in front. The front is wide, and is formed of two lobes with a more or less rounded outline. The orbits are directed forwards, and their superior border is either entire or interrupted by two very small fissures. The antero-lateral border is short and armed with many teeth, but the second tooth is usually soldered with the orbital angle, which is slightly prominent; the posterior tooth is very small. The basal antennal joint is fastened, at its internal angle, with the subfrontal prolongation. The antennulary fosse are hollowed out almost transwersely under the front. The endostome may have, on each side, a feeble 
crest which scarcely extends as far as the anterior border of the buccal cavity. The first pair of legs of unequal size, with elongated fingers.

The abdomen of the male has five joints, the third, fourth, and fifth segment being soldered into one piece.

RANGE.-Pacific Coast of America, Brazil, West Indies; in deep water.

\section{SyNopsis OF THE SPECIES.}

A. The antero-lateral border of the carapace has five teeth.

a. The third antero-lateral tooth is the largest.

$a^{1}$. Carapace granular. Forearm has, inside two spines. -(MI. sculptipes).

$b^{1}$. Carapace smooth. Forearm has, inside, one spine. -(M. pugilator:)

b. The fourth antero-lateral tooth the largest.

$c^{1}$. Carapace almost smooth. Parallel lines upon the upper border of the palm.-( M. lobifions.)

\section{Micropanope sculptipes.}

Micropanope sculptipes. Stimpson, A. Milne Edwards.

The carapace has in front some scattered hairs. The regions are covered with granulations, often arranged in a transverse series. The frontal lobes are a little advanced, and they are granular in front. The superior orbital border has granulations. The antero-lateral edges are cut into sharp teeth with granular borders. The third tooth is the largest; the posterior tooth is pointed. The pterygostomian regions are granular. The internal suborbital angle is rounded.

The first pair of legs, weak, is covered with pointed granulations. The fifth joint has on the inside two 
spines. The hand is surmounted with two series of small spines, arranged longitudinally ; its external surface is covered with granulations arranged in irregular longitudinal series. The walking legs are thin and armed above with small spines, which, upon the fourth joint, form two rows. RANGE-Barbados, Florida.

\section{Micropanope pugilator.}

\section{Micropanope prigilator. A. Milne Edwards.}

The carapace is more or less quadrilateral; its surface is smooth and covered with very small granulations, visible only with the aid of a strong glass. The front lobes have an almost straight border. The antero-lateral borders are slightly oblique, and the teeth have not a crenulated edge; the third tooth is large. The largest pincer is, in the male, thick and massive; the fourth joint exceeds a little the border of the carapace; the fifth is granular above and on the outside, the granulations forming a projecting row; one pointed tooth exists on the inside. The hand has above a longitudinal groove, within which is a line of granulations; the external face of the palm is finely granular. The fingers of the small pincer are relatively longer, and the granulations of the palmer region are larger. The walking legs have small spines above.

The carapace is often iridescent. The fingers of the pincers are black.

R.scGe-Barbados, Grenada, Santa Cruz, Florida.

\section{Micropanope lobifrons.}

Micropanope lobifrons . A. Milne Edwards.

The carapace is almost smooth; there are only some very small granulations on the gastric lobes and on the 
branchial regions. The antero-lateral borders have five teeth, of which the fourth is the most prominent. The first pair of legs is covered with small pointed granulations arranged in lines upon the upper surface of the palm; the walking legs are long and strong.

R.LNGE.-Montserrat, Grenada, Barbados.

b. Fingers of first pair of lews cxavated at tips and spoon-shaped:-

\section{I0. Carpilodes.}

Corpilodes. . . . . A. Milne Edwards, Dana, Miers.

Carpilizus (part). . . Adams and White.

Liomera (part). . . . A. Milne Edwards, Dana.

Zooymus (part). . . . H. Milne Edwards.

Carapace widely transverse, longitudinally convex, and usually but not invariably distinctly lobulated in its anterior half. The front is somewhat deflexed, with its anterior margin sinuated and usually with a small median notch. The antero-lateral margins are not cristated, and are divided into rounded lobes (not teeth), of which only the three posterior are usually distinct. The orbits are small, and the fissures of their upper margins very slightly marlied; the interior subocular angle is not produced. The eyes are set on short, thick peduncles. The basal antennal joint is somewhat elongated, and produced along the exterior margin of the infero-lateral frontal process so as to enter partly within the exterior orbital hiatus. The fourth joint of the external maxillipedes is usually transverse and distally truncated. The legs of the first pair in the malc are subequal and moderately developed, with the palms rounded, not carinated above. The walking legs 
are of moderate length, with the joints (except the last) slightly compressed, but not carinated; the last joint is styliform and straight.

The abdomen, in the male, is usually five-jointed, with the three intermediate segments united.

R.NNGE.-Pacific Ocean, Red Sea, IVest Indies; in shallow water.

\section{Carpilodes longimanus.}

Carpilodes longimanus. A. Milne Edwards.

Cancer nigerrimus . . Desbonne and Schramm.

Liomera longimana. . A. Milne Edwards.

The carapace is thick and very wide, convex in front and behind, but flattened transversely, and smooth, except at the anterior border, where there are some irregularities. The grooves of the gastric and of the hepatic regions are very visible. The front is wide, sloped, and formed of two rounded lobes but little advanced. The antero-lateral borders are short and very bowed, they are entire in front and present behind two lobiform, slightly projecting prominences. The antennary region is very elliptical; the basal antennal joint is short, but wide. The external maxillipedes are smooth.

The first pair of legs of unequal size; the largest leg, not always on the same side, is very strong. The arm usually exceeds the edge of the carapace. The forearm is rounded on the outside, and unarmed within. The hand is thick, its length is more than two-thirds the breadth of the carapace. The small pincer is thin; it is as long as the one on the other side, but one-third less in height and thickness. The walking legs, short, are slightly hairy above. 
The sternal plastron is smooth; the abdomen of the male is very small.

In the female the first pair of legs is shorter: the fourth joint does not exceed much the cdge of the carapace, but there is the same disproportion in size.

The colour is brown, with the fingers of the pincers black.

RANGE,-Guadaloupe, St. Thomas.

\section{Chlorodius.}

Chlorodius. . . . A. Milne Edwards.

Chlorodius (part). . Milne Edwards, Dana, Ruppell.

The carapace is narrow, and in form almost a regular hexagon; the antcro-lateral, the front, the postero-lateral and the posterior borders being almost of equal length; it is very flat, smooth, or slightly lobular antero-laterally, where it is thick and toothed. The front is wide, with a wavy margin; the orbits are very open. The basal antennal joint is widely joined to the front, and its movable part is lodged in the internal orbital hiatus. The fourth joint of the external maxillipedes is subrectangular its antero-external angle is slightly prolonged, its anterointernal angle is truncated for the insertion of the fifth joint. The first pair of legs long, and in general smooth ; the fourth joint exceeds by more than a half of its length the border of the carapace. The walking legs are thin and long, usually they have above a few hairs and spines.

The abdomen of the male is narrow, and composed of five joints, the third, fourth, and fifth segment being soldered together. 


\section{Chlorodius longimanus.}

Chlorodius longimanus . . Milne Edwards, Guérin, Stimpson, Desbonne and Schramm.

The carapace is smooth, but the hepatic regions and the anterior branchial lobes are separated by grooves of some depths. The antero-lateral 'border is cut into four tecth, not counting the external orbital angle; the two first are obtuse and tuberculiform; the last two are about of a size, and sharp. The front is horizontal, emarginate, and slightly notched in the middle line. The anterior border of the fourth joint of the external maxillipedes has a shallow notch. The first pair of legs of the male are very long. The fourth joint, almost completely exposed, has on its anterior border four or five teeth or spines. The fifth is smooth, and has a spine or tubercle at its internal angle. The hand is long and smooth; the fingers are large and coloured black, the black in the fixed finger extends a little on the hand. The walking legs are slightly hairy and granular above.

RANGE.-iVest Indies, Cuba, Florida.

\section{I2. Leptodius.}

Leptodius . . . . A. Milne Edwards.

Chlorodius (Sect. 2). . Dana.

Tanthodius (subgenus). Stimpson.

Chlorodius (part) . . . H. Milne Edwards, Stimpson.

The carapace is widely transverse, somewhat depressed, and very distinctly lobulated in its anterior half, posteriorly nearly plain; the frontal margin is truncated and slightly sinuated, with a median notch or fissure; the antero-lateral 
margins are longer than the postero-lateral margins, and are normally divided into four teeth or lobes, besides the exterior orbital tooth, which is usually obsolete; behind the last antero-lateral tooth are occasionally one or two smaller teeth on the postero-lateral margin; the marginal teeth are usually dentiform, not rounded.

The superior margin of the orbits are marked with two slight notches and fissures. The basal antennal joint reaches the infero-lateral process of the front, or even entcrs slightly within the interior orbital hiatus. The external maxillipedes have the fourth joint truncated or slightly notched at the distal extremity, and its anterointernal angle is slightly emarginate or sinuated; its antero-external angle is often slightly produced. The legs of the first pair, in the adult male, are moderately developed; the fourth joint (arm) is short and almost invariably covered in a dorsal view by the antero-lateral margins of the carapace; the fifth is toothed on the inner margin; palm not cristated above. Walking legs are moderately developed, with the fourth to the sixth joint slightly compressed, but not carinated or spinose; last joint styliform.

The abdomen in the male is five-jointed; the three intermediate segments coalescent.

RANGE.-Pacific and Atlantic Oceans; in shallow water.

\section{Subgenus I. Leptodius. Subgenus II. Xanthodius.}

Synopsis of the Subgenera and the Species.

I. Endostome without trace of longitudinal carinx. (Subgenus Leptodius.)

$A$. The arm of the first pair of legs not visible on a dorsal view.-(L. floridamus. $)$ 
$B$. The arm of the first pair of legs, visible for about one-third of its length on a dorsal view.-(L. caribaus.)

II. Endostome with the longitudinal carine partially developed.-(Subgenus Tanthodius.)

$C$. The arm of the first ,pair of legs not visible on a dorsal view.-(L. americanus.)

\section{Subgenus Leptodius.}

Lcptodius . . . Micrs.

The endostome has no trace of longitudinal carina.

\section{Leptodius (Leptodius) floridanus.}

Leptodius floridanus . A. Milne Edwards, Gibbes, Miers.

Chlorodius limosus . . Desbonne and Schramm.

Etisus occidentalis. . White.

Chlorodius floridanus . Gibbes, Stimpson, S. Smith.

Chlorodius exaratus. Dana.

The carapace is depressed, much wider than long, and lobulated in front; the lobules are flat, marked with small transverse lines, slightly granular or punctuated, and separated by deep grooves. The front is formed of tivo lobes, with an emarginate border. The anterolateral borders are armed with five triangular teeth of which the points are directed forwards-the first forms the external orbital angle.

The first pair of legs of unequal size. The fourth joint does not exceed the carapace. The fifth and the hand are slightly rough. The fingers of the pincers have a tuft of hair near the excavation; they only meet at their 
tips when closed. The walking legs have a few hairs above. The colour may be grey, or yellow with red spots; the fingers of the pincers are black.

RaxGe,-Barbados, Florida, Brazil.

\section{Leptodius (Leptodius) caribæus.}

Leptodius caribaus. . A. Milne Edwards.

Chlorodius caribias . Desbonne and Schramm.

The fourth joint of the first pair of legs exceeds the border of the carapace by one-third of its length, otherwise like L. floridanus.

RANGE.-Guadaloupe.

\section{Subgenus Xanthodius.}

Tanthodius . . Stimpson.

The endostome with longitudinal carinæe partially developed.

\section{Leptodius (Xanthodius) americanus.}

Letpodius americanus. Saussure, A. Milne Edwards.

Yanthodius americanus. Stimpson.

Chlorodius americanus. Saussure, Desbonne and Schramm.

Chlorodiz's floridanus. Stimpson.

The carapace is smooth behind. The lobules are prominent, and are ornamented with punctuations. The frontal border is emarginate. The antero-lateral border is divided into five rounded and obtuse teeth, including the external orbital angle. The first pair of legs strong; the fourth joint does not exceed the border of the carapace; the fifth and the hand are rough above and have 
some irregular inequalities. The walking legs are short, smooth, and slightly hairy. The endostome has a ridge, but this ridge is incomplete.

RANGE:-Barbados, Florida.

\section{I3. Phymodius.}
Phymodius . . . . A. Milne Edwards, Miers.
Chlorodius (Sect. I) . Dana.
Chlorodius (part) . . H. Milne Edwards.

The carapace is strongly lobed anteriorly and posteriorly. The front is formed of two wide and rounded lobes and of two lateral tecth. The antero-lateral borders are thick and lobed. The basal antennal joint is united to a wide and short prolongation of the front. The fourth joint of the external maxillipedes is subrectangular ; its anterior border is sometimess lightly notched, and its antero-internal angle is truncated for the insertion of the fifth joint. The walking legs are long, thin, and spiny above. The abdomen of the male has five joints.

RANGE.-Indian Occan, Red Sea, IVest Indies.

\section{Phymodius maculatus.}

Ply'modius maculatus . Stimpson, A. Milne Edwards. Chlorodius maculatus. Stimpson.

The carapace is yellow, with numerous brown spots; it is narrow, equally convex, lobulated; the lobes are more prominent upon the anterior and antero-lateral parts; their surface is almost smooth. There are four antero-lateral teeth, without counting the orbital angle, of the same size, small but sharp; the space between them is wide and concave. The front is prominent, sublaminate, and divided into four teeth; the two median teeth are 
wide; the two orbital teeth are prominent. There is a tooth upon the subhepatic region, immediately below the first tooth of the antero-lateral margin.

The legs of the first pair are short, robust, and spotted with red; the fourth joint is spiny above. The fingers are short and strong. The three last joints of the walking legs are very spiny and hairy above.

RANGE.-West Indies.

B. The cndostome with distinct longitudinal ridges defining the apertures of the efferent branchial channels.

$c$. The antenne not excluded from the orbit:-

\section{I4. Eurytium.}

Eurytium . . . Stimpson, A. Milne Edwards, Miers. Panopeus (part). H. Milne Edwards.

Carapace broadly transverse, nearly smooth, and not lobulated on the dorsal surface; convex longitudinally not transversely. There is a sternal canal through which the deferent canal from the basal joint of the last pair of legs passes to the copulatory appendages.

RANGE.-Eastern Atlantic, California.

\section{Eurytium limosum.}

Eurytium limosum . Say, Stimpson, Miers, A. Milne Edwards.

Cancerlimosus . . Say.

Panopeus limosus. . H. Milne Edwards, Dekay, Gibbes.

The greatest breadth of carapace is at a level with the last lateral tooth. The regions are very slightly 
marlied; there is only the point of the mesogastric lobe which is prolonged in a small median groove; the branchio-cardiac and the cardio-gastric grooves form an H. Very fine granulations ornament the circumfercnce of the carapace; in the centre the granulations are almost completely effaced. The front is sloped and formed of two lobes separated in the middle line by a narrow notch ; these lobes are more adranced outside than inside. The superior orbital border is divided by two faintly marked fissures. The antero-lateral edges are very short and scarcely exced the level of the middle of the gastric region. The first lobe, formed by the union of the orbital angle with the first tooth, terminates in a straight edge; the two teeth which follow are a little sharp, the last is strong and pointed. The border of these teeth have a granular line which is prolonged backwards upon the border of the branchial region; these are very swollen. The latero-inferior regions are granular, and there is a small subhepatic tubercle below the first lateral lobe. The external orbital hiatus is widely open; the inferior orbital border is advanced below the cornea in the form of a small rounded lobe, distinctly separated from the internal orbital angle, which is dentiform.

The basal antennal joint is very short and wide; it joins the front at its antero-internal angle. The internal antennie are long, and they are folded almost transwersely in the orbits. The buccal cavity is strongly notched on each side, and is prolonged in the middle line in a linel of beak. The external maxillipedes are wide and short. The fourth joint is truncated in front and on the inside for the insertion of the fifth joint; its antero-internal angle is rounded. The legs of the first pair are of unequal size. The fourth joint is hid under the carapace; it has some 
hairs in front and a prominent granular ridge terminating in a tooth-like projection behind. The fifth is rounded, smooth, and armed on the inside with a pointed tooth. The hand is smooth, rounded above, and terminates in very long fingers provided with moderately strong teeth. The walking legs are long, slightly hairy, with their terminal joint thin. The abdomen of the male is narrow, with the edges of the fifth and sixth segment parallel. The last sternal joint is slightly exposed in the notch existing between the second and the third abdominal segment on account of the narrow second segment.

The colour is purple-brown, with grey-blue upon the legs. The fingers of the pincers are white in almost their whole extent.

RAnGe.-West Indies, Florida, Brazil, Bermuda; in the mangrove swamps.

\section{I5. Ozius.}

Osius . . A. Milne Edwards, Dana, II. Milne Edwards.

The carapace is smooth, a little curved and more or less wide, with the antero-lateral edges slightly toothed. The orbits are small, and have not a large external hiatus. The front is formed of four teeth. The basal antennal joint is united with the front. The buccal cavity is notched on each side to give passage to the water from the branchial chamber. The pincers terminate in sharp fingers. The walking legs are short and have no ridges.

The abdomen has seven joints.

RANGE.-Atlantic and Pacific Oceans. 


\section{Ozius reticulatus.}

Osius reticulatus . . . A. Milne Edwards.

Lagostoma reticulata. . Desbonne and Schramm.

The carapace, wide behind, is more than once and a half times as broad as long; it is sloped anteriorly but flat behind and transversely. It is deeply eroded along its antero-lateral borders; the regions are not well marked. The front is inclined, bimarginate. The antero-lateral borders are long and thin, and their contour is regular.

The colour is red with yellow patches; the pincers are brown.

RANGE-Jamaica, Martinique, Guadaloupe.

\section{I6. Menippe.}

Menippe . . . De Haan, Milne Edwards. Pseudocarcinus. H. Milne Edwards.

The carapace is broadly oval, the antero-lateral margins being cut into lobes. The front has a notch in the middle line, and is divided on each side of this notch into small lobes. The surface of the carapace is more or less smooth, with the regions indicated by faint lines or furrows. The basal antennal joint, instead of being joined to the front, is very small, and it is the second joint which at its extremity reaches the frontal border; the antennulary fossa is imperfectly separated from the orbit. The external maxillipedes are short, and the fourth joint is subquadrilateral and truncated on the inside for the insertion of the fifth joint; their edges do not meet in front of the buccal cavity, but have a wide interspace 
The first pair of legs, strong, has the tips of the fingers not excavated.

The abdomen of the male has seven free joints. RANGE.-West Indian Sea, Brazil, Mexico, Panama.

\section{Menippe mercenaria.}

Menipte mercenaria . . . A. Milne Edwards.
Cancer mercenarius . . . Say.
Pscudocarinus ocellatus . . H. Milne Edwards.
Pscudocarcinus mercharius. Gibbes.

The carapace is curved and smooth; seen under a magnifying glass the surface appears finely granular. The protogastric lobes are slightly raised above the general surface. The front is slightly sloped and formed, independently of the internal orbital angles, of two large lobes, separated in the middle line by a triangular notch ; their contour is bowed and indistinctly trilobed. The orbital borders are thick and almost entire; there are, above, the traces of two superficial fissures. The external orbital angle is not prominent. The antero-lateral edges are cut into four lobes, of which the two first do not excced the contour of the carapace; the third is dentiform and larger than the fourth, which is pyramidal. The first pair of legs very large and of unequal size; the surface is smooth; on the inside of the large hand there are fine inequalities, which are capable of producing a noise when rubbed against the rough ptcrygostomian region. The walking legs are robust, and hairy towards their extremities.

The body is reddish, with darker round spots; the legs have red and yellow bands; the tips of the fingers are black.

RANGE.-West Indies, Cuba, Florida. 


\section{I7. Pilumnus.}

Pilumnus . . . Leach, Milne Edwards, Miers. Acanthus . . . Lockington.

\section{Parapilummus Eupilumnizs $j \cdot$ Kossmann.}

The carapace is longitudinally convex, a little broader than long, with the regions distinctly defined; it is thickly covered with hair on the dorsal surface, extending over the legs, not lobulated; the antero-lateral margins, regularly bowed, are shorter than the postero-lateral margins, and are normally armed with short spines in place of teeth.

The front is rather narrow; its anterior margin has spines or is granulated, and is divided into two lobes by a median emargination; outside cach there is usually a small lobe or rounded tooth.

The orbital margins are sometimes entire, sometimes have spines. The ey'es are of moderate length. The basal antennal joint is short, slender, and scarcely reaches the infero-lateral frontal process, or sometimes falls short of it ; the next joint lies within the interior orbital hiatus. The fourth joint of the external maxillipedes is distinctly truncated, and in typical specimens is not narrower than the third joint. The legs of the first pair are moderately robust and usually unequal, with the fourth joint short and trigonous; the fifth and palm are more or less granulated, and spinuliferous on the superior margin and exterior surface; fingers, distally acute or subacute, are dentated on the inner margins; walling legs of moderate length, slightly compressed, but not carinated, fourth to sixth joint sometimes armed with spinules: last joint slender, styliform, and nearly straight. 
Abdomen in the male seven-jointed; its base usually occupies the whole width of the sternum, between the fifth pair of legs.

RANGE.-Atlantic and Pacific Oceans; in shallow and deep water.

Synopsis of the Siecies.

A. Frontal lobes armed.

a. Spines on orbital border.

$a^{1}$. Spines on both borders, superior and inferior.

I. Carapace with spines on hepatic regions. $-(P$. aculicatus.)

2. Carapace without spines on hepatic regions. $-(P$. vinacus.)

3. The superior orbital border has among its spines two large spines separated by a fissure; antero-lateral spines bifid.-(P. carilicus. $)$

61. Spines on inferior orbital borders only.

4. Inferior border has four spines. A row of long, thin spines on walking legs.-( $P$. sracilipes.)

$B$. Frontal lobes unarmed.

b. No spines on orbital borders.

$c^{1}$. Carapace smooth.

5. Spines on walking legs.-(P. lactuts.

$c^{\circ}$. No spines on walking legs.

6. Inferior orbital border with small granulations. $-(P$. quoyi.)

7. Inferior orbital border with many pointed granulations.-(P. miersii.)

$d^{2}$. Carapace with tubercles.

8. Superior orbital border has two or three almost spiniform tubercles.--(I'. gemmatus.)

9. Frontal and orbital borders a continuous line. $-(P$. nudifrons.) 
c. Spines on inferior orbital border.

IO. Inferior orbital border has three tecth. - $(P$ reticulatus.)

II. Tubercles upon carapace fungiform. Two teeth on inferior orbital border.-(P. frogrosus.

\section{Pilumnus aculeatus.}

Pilumnus aculeatus . Say, A. Milne Edwards, Miers, H. Milne Edwards, Gibbes, Stimpson, Kingsley.

The front is formed of two lobes, separated in the middle line by a deep notch, another wider notch separates them from the orbital angles; each of them has upon their anterior border three or four spines. The external orbital angle has two similar spines; one internal or frontal, directed forwards; the other external, directed a little outwards. The superior and inferior orbital border have spines. The antero-lateral border of the carapace has four spines stronger than the preceding; the first forms the external orbital angle. There is, in the space that separates the first from the second spine, a small spine upon the border of the subhepatic region, its point being visible on a dorsal view; these antero-lateral spines are sometimes bifurcated. The hepatic region has usually two or more spines above.

The first pair of legs, large, of unequal size, is very spiny above; this armature disappears more or less upon the inferior part of the external face of the pincers. The walking legs are strong; the fourth juint has above very small spines; those on the fifth are larger and arranged in two rows. 
Colour is yellow; the spines are black or dark brown ; the fingers of the pincers are black.

RANGE-Guadaloupe, Florida; in deep, water.

\section{Pilumnus vinaceus.}

Pilumms vinaceus . . A. Milne Edwards, Miers.

Resembles Pilummus aculeatus in the arrangement of the hairs of the front and the orbital borders. The antero-lateral borders have spines. The carapace, in place of being smooth, has interiorly some very small granulations slightly elevated and often arranged in groups; these replace the spines on the hepatic regions. There is a prominent wavy ridgc, ornamented with a row of granulations, from the last lateral spine to the gastric region. The frontal lobes are advanced, rounded, with numerous spines on their edges. The superior orbital border has spines. The legs of the first pair are of unequal size; the spines on the largest hand are short, almost tubercular. The walking legs are shorter and less spiny.

The colour is red-brown; the legs are brighter. The fingers of the pincers and the end of the spines are brown.

RANGE--Martinique, Florida; in deep water.

\section{Pilumnus caribæus.}

Pilumnus caribaus . Desbonne and Schramm, Miers, A. Milne Edwards, Stimpson.

The length of the carapace is to its breadth as four is to five, slightly convex transversely, sloping in front, almost smooth, except for small tubercles which become spines in front. The antero-lateral borders have, on each side, three long and sharp spines placed in the same line: the first bifid; in front of it and a little above, a fourth 
spine situated very near the spine upon the external angle of the orbit; lower down, upon the pterygostomian region and obliquely under the fourth, there is another small spine. Front spiny, divided by a very narrow fissure continued backwards in a deep groove. Orbital borders spiny; two spines stronger than the others upon the superior border, separated by a wide fissure. Posterior borders long, straight, and oblique.

Legs of the first pair of unequal size; fourth joint with granular borders; fifth spiny outside; hands with spines upon the borders and upon their external face in eight rows; internal face smooth; fingers strongly toothed terminating in a point, that of the movable fingers crossing that of the fixed fingers on the inside. Walking legs long, the second pair being longer than the first.

All the back is covered with long red hairs.

RANGE.-Guadaloupe.

\section{Pilumnus gracilipes.}

Pilumnus gracilifes . A. Milne Edwards, Miers.

Resembles Pilummus aculeatus. The carapace is much thicker and more quadrilateral than usual; it is covered with short hairs, claviform, and scattered so as not to hide the details of the surface. The regions are a little rough from the punctures out of which the hairs spring. The front is wide and formed of two spinous lobes, slightly bowed in front. The internal orbital angle has two spines. The superior orbital border is unarmed, it is scarcely cut by a few pointed granulations; the inferior orbital border has about four spines, and terminates in an internal angle with two spines. There are some spiniform tubercles and a number of granulations upon the subhepatic and pterygostomian regions. The antero-lateral borders are short 
and have three spines, without counting the one forming the orbital angle.

The walking legs are long and thin, with a row of sharp spines on the upper surface.

RANGE--Barbados; in deep water.

\section{Pilumnus lacteus.}

Piluminus lacteus . . Stimpson, A. Milne Edwards, Miers.

Resembles Pilummus semmatus, except that the carapace is much wider and almost flat transversely. The regions are well marked in front, but completely smooth. The frontal lobes are slightly advanced.

The antero-lateral teeth are spiniform; there is no subhepatic tubercles or spines.

RANGE.-West Indies, Cuba; in deep water.

\section{Pilumnus quoyi.}

Pilumms quoyi . A. Milne Edwards, Miers, H. Milne Edwards.

The carapace strongly convex, and covered, as well as the legs, with short hairs, regularly arranged and not hiding completely the test; on the legs there are some longer hairs. The regions are distinctly marked, but their surface has no spines, tubercles, or granulations. The front is formed of two sloping lobes, with rounded and granular edge. The superior orbital border is unarmed, the inferior border is granular. There are, independently of the postorbital spine thin strong spines on each anterolateral border, and in front of these, another shorter subhepatic spine. The pterygostomian regions are granular. The legs of the first pair, very strong, are of unequal 
size; they have shining and pointed tubercles upon the whole of the external face of the small hand and upon part of the external face of the large hand. The walking legs are short, strong, and unarmed. The fourth joint of the external maxillipedes is truncated at its antero-internal angle, and not notched.

RANGE.-Guiana, Rio de Janeiro.

\section{Pilumnus miersii.}

Pilumnus miersii . A. Milne Edwards.

Resembles Pilumnus lactcus; it is covered with a very short down, with longer hair on the legs. The carapace is wide, smooth, and the regions are scarcely indicated. The front is a little advanced and ornamented anteriorly with granulations. The orbits are unarmed above; their inferior border bristles with pointed granulations. The anterolateral border has five spines, counting the orbital angle. The two first are very small and pointed, the three others are well developed; there are some subhepatic tubercles between the second and the third of these spines.

The legs of the first pair are of unequal size; the largest is very swollen and has, above, perliform tubercles, which are absent from the external face of the hand; the smallest is spiny above and on the outside. The walking legs have no spines.

RANGE.-West Indies.

\section{Pilumnus gemmatus.}

Pilumnus gemmatus . . Stimpson, Miers, A. Milne Edwards.

Carapace areolated, and with scattered granules or small tubercles, from three to six, on each areola; the 
spines or teeth on antero-lateral margins are short. There are two or threc tubercles on superior margins of orbit, not acute. Lobes of the front prominent, rounded, granulated; there is a transverse series of long hairs above the margin. Lower margin of orbit not spinous.

Walking legs studded above with scattcred granules smaller and sharper than those of the hands and carapace.

Granules and spines bright ruby red; upper surface of carapace and feet covered with a cream coloured velvetlike pubescence.

RaNGE.-St. Thomas, Florida; in deep water.

\section{Pilumnus nudifrons.}

Pilumnus nudifrons . . Stimpson, Miers, A. Milne Edwards.

The body and the legs are covered above with down, except upon the fronto-orbital regions. The carapace is about seven-eighths wider than long, very wide behind and convex; the regions are slightly marlied; the test is rendered rough by scattered tubercles of variable size, and more numerous upon the gastric and hepatical regions. The frontal region is continued with the orbit, and they are without teeth or spines, so constituting the anterior border of the carapace, which is prominent, wide, naked, and ornamented with very small tubercles; a depression in the form of a canal separates it from the rest of the carapace; there is no notch where the front joins the orbits, and the median notch of the frontal contour, which is straight or slightly convex, is very shallow. At the external angle of the orbit the border continues a little backwards upon the antero-lateral edge; posteriorly, the antero-lateral border is almost parallel with the axis of the body, and is armed with three small 
triangular teeth. The orbital border is smooth and entire below, without fissure or tooth, with the exception of the large tooth which usually forms the internal angle. The subhepatic tooth is distinct, and forms part of an irregular toothed or granular line which extends from the posterior extremity of the anterior border of the carapace to the angle of the buccal cavity.

The basal antennal joint, small, is separated from the front by a space almost equal to its length.

The legs of the first pair are very strong and short; they are armed above and on the outside with tubercles resembling those on the carapace; upon the superior border of the hand there are three prominent tecth.

RANGE.-Barbados; in deep water.

\section{Io. Pilumnus reticulatus.}

Pilummus reticulatus . . Stimpson, Miers, A. Milne Edwards.

Carapace slightly convex. Carapace and legs clothed above with short clavate setre arranged in reticulating lines, enclosing small, naked, polygonal areole, which, in the anterior half of the carapace and on the first pair of legs, are each usually occupied by a tubercle projecting forwards but flattened on its superior and posterior surface. There are about twelve tubercles on the carapace, excluding marginal ones, and about thirteen on each first leg. On the walking legs the naked areolæ form deep cavities not occupied by tubercles; about two arcola occupy the width of the foot. Anterolateral margin with four teeth, and one at the external angle of orbit. The anterior tooth is situated on the subhepatic region. A tooth on the subbranchial region beneath the third tooth. 
Three teeth on inferior margin of orbit; inner one large, and flattened on its outer surface.

External antennæe are long.

Fingers and infero-exterior surface of hands smooth and naked; the naked part sharply defined by an oblique line on the outer surface.

RANGE.-St. Thomas.

\section{Pilumnus fragosus.}

Pilumnus fragosus . . . A. Milne Edwards.

The carapace is flat behind and sloped in front. The regions are distinct, but the grooves which separate them are not very deep. The gastric region has five tubercles, one median, at the extremity of the mesogastric lobe, and one on each epigastric and protogastric lobe. These tubercles have thin stalks and broad flat heads. There is a similar tubercle upon the hepatic region. The front is sloped and is formed of two lobes more advanced in the middle than on the sides; their edge is unarmed, straight, or slightly concave. The superior and internal orbital angle is flat and thick. The superior orbital border has no granulations or fissures; it terminates on the outside in a fungiform projection; the inferior border has two teeth. The antero-lateral border is clivided into three teeth; the first, contracted at its base, is wide and thick at its extremity; the second is thinner, but swollen a little at its end; the last is very small and pointed. The space which separates the orbital angle from the first tooth is occupied bclow by a lobiform subhepatic tooth.

The inferior orbital angle forms a thick and prominent lobe.

The first pair of legs has large fungiform tubercles 
with flattened tops, except at the external angle of the forearm and upon the superior border of the hand, where they are compressed and dentiform. There are two large fungiform tubercles upon the superior border of the fourth joint of the walking feet; there are two smaller tubercles on the upper border of the foot.

The abdomen of the male has seven joints.

R.NGE.-St. Thomas.

\section{I8. Lobopilumnus.}

Lobopilumnus . . . A. Milne Edwards.

The front is formed of two rounded lobes separated from the internal orbital angles by a small notch. The lobes are divided above by two small indistinct fissures; there is another fissure outside upon the inferior border. The antero-lateral borders are cut into many teeth or spines. There is a tubercular tooth upon the subhepatic region. The basal joint of the external antennce is very short, and scarcely reaches the frontal prolongation. The fourth joint of the external maxillipedes, slightly notched in front, is wider than long. The buccal cavity is wide in front, and the endostome has a small crest on each side.

The abdomen of the male has seven distinct joints.

RANGE.-East Coast of America.

\section{Lobopilumnus agassizii.}

Lobopilummus agassizii . . A. Milne Edwards. Pilumms agassizii . . . Stimpson.

The carapace is covered with a short down; it is wide and very lobulated, especially in front. The grooves 
which separate the lobes are deep, smooth, and very wide. In front the lobes are ornamented with granulations which project through the down. The front is formed of rounded and very granular lobes. The orbital borders have granulations. The antero-lateral borders have thin spiniform and granular teeth without counting the orbital angle, which is not prominent. The subhepatic tooth is tubercular and of a raspberry appearance. The basal antennal joint is smooth. The first pair of legs strong, short, thick, and of unequal size. The fifth joint is covered above with tubercles, forming groups, arranged in transwerse series, especially on the outer side; the hand has above and outside perliform tubercles, which project through the downy covering. The walking legs have long and short hairs; they are short and strong, and have sometimes, on their superior border, spiniform granulations.

The carapace of the male is thicker and flatter than that of the female.

RANGE.-Bermuda, Florida.

\section{I9. Heteractæa.}

Hiteractar. . . A. Milne Edwards, Lockington.

Is a Pilummus in the form of Tantho, with the carapace slightly curved. The front terminates in a straight and thick edge; the orbital borders are unarmed above and below; the antero-lateral edges of the carapace are spiny; the fifth joint of the walking legs have. above, a raised crest in the form of a horn.

The abdomen of the male has five joints.

R.NNGE.--Atlantic and Pacific Occans, on both sides of America. 


\section{Heteractæa ceratopus.}

Heteractea coratopus . . . . A. Milne Edwards.
Pilummus coratopus. . . . Stimpson.

The carapace is slightly curved, and covered with short brown hairs arranged in groups and not covering the body uniformly. The regions are marked and have tubercles or granulations; the gastric region has only some roughness corresponding to the insertion of hairs. The front is almost straight, it is formed of two lobes with very thick borders; there is a small transverse crest extending above and parallel with its border. The superior orbital border is unarmed, and constitutes a sort of strong circular pad dilated on the outside, where it is continued with the external orbital angle that has the appearance of a large flat tubercle; a fissure divides this pad into two portions. The inferior orbital border is two-lobed; cach lobe is wide, triangular, and advanced; the external lobe is separated from the orbital angle by a deep notch.

The antero-lateral borders have three longr and sharp, and two small spines; one situated behind the cxternal orbital tubercle, the other between the two first principal spines; the subhepatic region has two small spines visible on a dorsal view, and a number of granulations; these latter are also upon all the pterygostomian regions.

The legs of the first pair are of unequal size, and very spiny above and on the outside. The walking legs are short and very compressed; the fourth joint is spiny above; the fifth has upon its inferior border a series of very large spines; and, a little bchind, a horn-shaped ridge terminating below in a long and sharp 
point exceeding the next joint; these are spiny. There are some long stiff hairs upon the edge of each of the large spines; a short down covers the rest of the $\operatorname{leg}$.

The colour of the carapace is white, with a rose tint on the legs; the pincers are reddish, their fingers are black. The last joint of the walking legs are brown; the hairs are tawny.

R.NGE.-Guadaloupe, Florida.

d. The antenna excluded from the orbit, whose interior hiatus is closed:-

\section{Eriphia.}

Eriphic . . Latreille, Milne Edwards, Micrs.

Carapace moderately convex, but little broader than long, with the antero-lateral margins much shorter than the postero-lateral margins; the frontal region broad, but the front not prominent. The antero-lateral margins (and usually the front) are spinous; the parts adjacent are usually armed with tubercles or short spines. The eye-peduncles are short and deeply set in the orbits, whose prominent margins are often granulated; it is broadly united with the front at the interior angle. The basal antennal joint barely reaches the inferior margin of the front, but the flagellum is well developed. The epistome is transverse. The third joint of the external maxillipedes is not produced at its anterointernal angle; the fourth joint is truncated but not emarginate at the distal extremity, and scarcely, if at all, emarginate at its antero-internal angle. The first pair of legs in the male is considerably developed, and usually unequal; fingers distally acute, or subacute. Walking legs of moderate length, with the joints neither 
carinated nor spiniferous; last joint styliform, nearly straight.

RANGE.-Pacific Ocean, Mediterranean Sea, Atlantic Occan.

\section{Eriphia gonagra.}

Eriplia gonagra . . Fabricius, A. Milne Edwards, H. Milnc Edwards, Miers, White, Gibbes, Dana, Krauss, Stimpson, Haller, Smith.

Cancer gonasra. . Fabricius, Desbonne a n d Schramm.

The carapace is modcrately wide; regions defined anteriorly. The branchio-hepatic groove deep, the postorbital grooves wide. A granular transverse line extends in front of the epigastric lobes; another toothed ridge exists upon the protogastric lobes. The anterolateral portions have some tubercles arranged parallel with the antero-lateral borders. These are armed with six spiniform teeth, including the external orbital angle. The front is very wide, sloped, and divided into four lobes; the two median are wider and more advanced than the lateral, truncated in front and terminating in an entire or finely granular border; the lateral lobes are smaller and slightly concave. The fronto-orbital suture is very wavy. Below there is a line of large tubercles.

The first pair of legs of unequal size. The hand is corcred with large tubercles, very wide, rounded, depressed, squamiform, and higher upon the small than upon the large pincer. The movable finger of the latter has at its base a large round tooth. The forearm has in front a few tubercles. The walking legs are covered with small 
stiff hairs upon their three last joints. The abdomen of the male is narrow at its base; the fourth and fifth segments are longer than those of the other species of this genus. The colour is a greenish-brown, mixed with yellow and violet upon the legs; the pincers are brown. They build houses of mud on the roots of the mangrove trees at the edge of the water, in which they live.

RAnge.-Bermuda, Barbados, Florida, Brazil, Aspinwall, Panama.

\section{I. Domecia.}

Domeciar . . A. Milne Edwards, Eydoux and Souleyet, Dana.

Neleus (?) . . Desbonne and Schramm.

The carapace is wider than long, very flat and contracted behind. The fronto-orbital border occupies almost the whole breadth of the carapace; the front is sping. The basal antennal joint has on the outside a prolongation which, inserted between the inferior orbital border and the front, is prolonged as far as the angle of the orbital cavity. The movable part is inserted under the front, and is excluded from the orbit. The basal joint of the internal antenne is wide, but very slightly clevated. The buccal cavity is wide in front; it is notched on each side for the passage of the water from the branchial chamber. The fourth joint of the external maxillipedes is wider than long. The first pair of legs is short, and the fourth joint is hic under the carapace; the fingers of the pincers are pointed. The walling legs are short, compressed, and the last joint is curved and pointed.

The abdomen of the male is seven-jointed.

RANGE.-West Indian Sea, Pacific Ocean. 


\section{Domecia hispida.}

Domecia hisfida. . . A. Milne Edwards, Souleyet, Stimpson, Dana, Desbonne and Schramm.

Nelus acanthophorus. Desbonne and Schramm. Eupilummus acbsteri. Kingsley.

The same as the genus. The colour is yellow-red; the spines are black, as well as the end of the legs.

RAnge. - Guadaloupe, St. Thomas, Cuba, Florida, Sandwich Isles, Cape Verde, Senegal.

\section{Family II. Portunidæ.}

Portunida. . . . . . . Miers.

Portunicns. . . . . . . . Milne Edwards.

Portunide and Platyonjelider. Dana.

Carapace never very convex, hexagonal. Fifth pair of legs used for swimming, the last joint being ovate, expanded, and lamellate.

\section{Group Portuninæ.}

Portnnina. . . . Miers.

Portunicns normant. A Milne Edwards.

Carapace moderately transverse ; usually widest at the last antero-lateral marginal spine. Front horizontal, not spatuliform. Orbits and eye-peduncles of moderate length; the spine or tooth at the exterior angle of the orbit does not project laterally beyond the antero-lateral marginal teeth; of these, more than one (usually five to nine) are developed. 



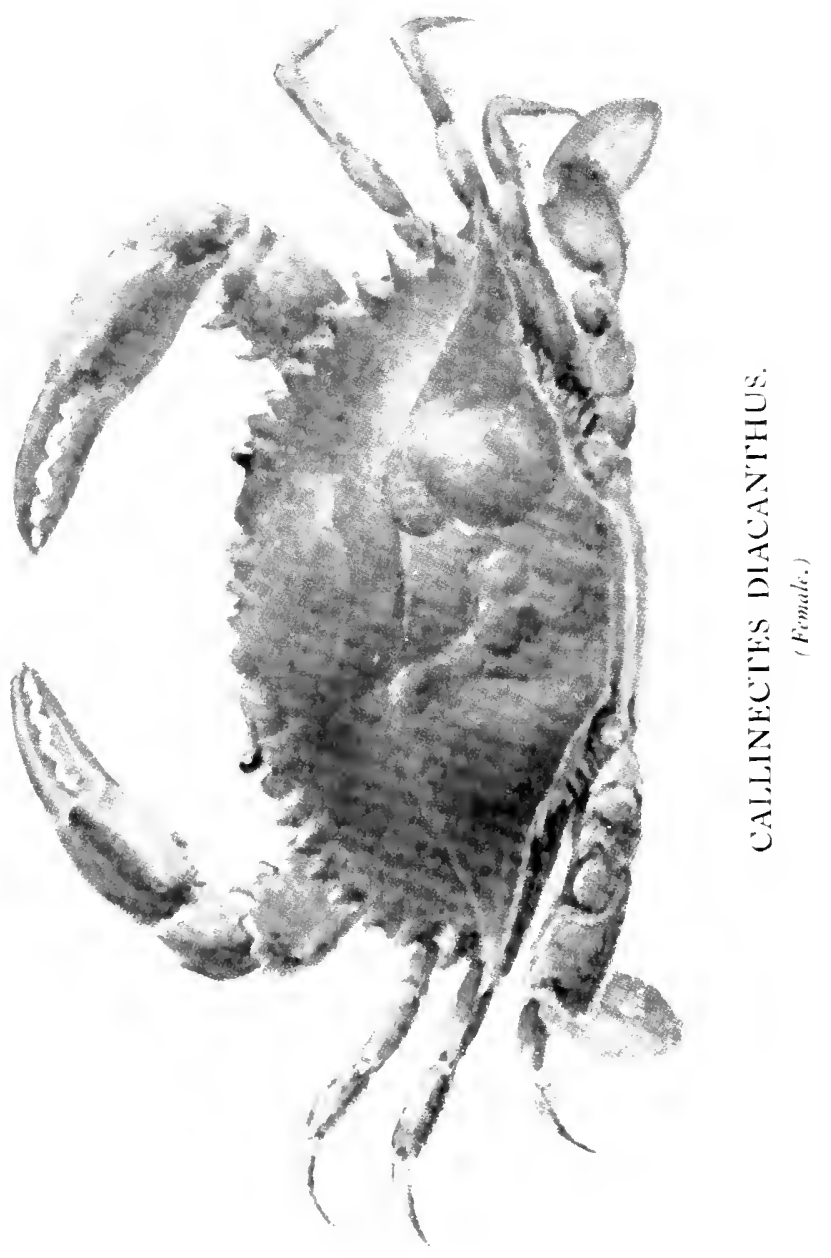




\section{Subfamily I. Lupinæ. Subfamily II. Carcininæ.}

Synopsis of the Subfamletes.

A. Basal antennal joint moderately developed. Last pair of legs used for swimming, with its terminal joint more or less expanded and ovate.

a. Carapace transverse, with the antero-lateral margins oblique; usually armed with from five to nine marginal teeth.

$a^{1}$. First pair of legss usually elongated.-(Lupinc.)

b. Carapace slightly, if at all, transverse, with the antero-lateral margins arcuate, and armed with five or fewer marginal teeth.

$b^{1}$. First pair of legs rather small.--

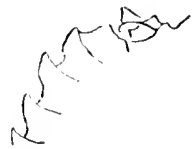

Carininine. (Carinina.)

\section{Subfamily I. Lupinæ.}

Lupina . . . . Miers.
Lupiens
Carupicus
Lupocyclicus

Carapace moderately transverse, with the antero-latero margins oblique; usually armed with more than five (five to nine marginal teeth. Basal antennal joint moderately developed. First pair of legs elongate; last pair of legs formed for swimming, with the terminal joint expanded and oval. 


\section{StNOPSIS OF THE GENERA.}

I. Lateral epibranchial spine the largest of the anterolateral marginal series of teeth; preceding teeth subequal.

$A$. The flagellum of the external antenne occupies the interior orbital hiatus.

$a$. The abdomen of the male is more or less triangular ; the epistome does not project in front so as to be visible on a dorsal

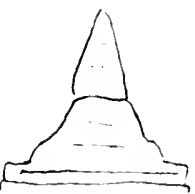

Neftunus. view.-(. Veptumus.)

b. The abdomen of the male has a broad base, then suddenly becomes thin, terminating in a narrow lancet-shaped point; the epistome projects in front and is visible on a dorsal view.-(Callinectes.)

$B$. The flagellum of the external antennce

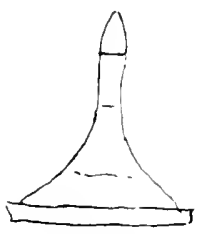

Calinincites. is excluded from thei nterior orbital hiatus by a process of the basal antennal joint.

$c$. The fourth joint of the external maxillipedes is rounded anteriorly, and exceeds the front; its terminal joints are flattened.-(Lupa.)

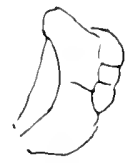

Lufu.

II. The antero-lateral marginal series of teeth are alternately large and small.

d. The fourth joint of the external maxillipedes is dilated externally and does not exceed the front; its terminal joints are cylindrical.(Cronins.)

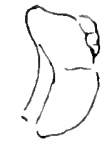

cronius.

I. The lateral chibranchial spine is the laresest of the antero-lateral mareinal sories of teth.

1. The flasellum of the citcrmal antenne ocoupies the interior orbital hiatus:- 


\section{Neptunus.}

Veptums . . . . . . De Haan, A. Milne Edwards, Miers.

Achclous, Amphitrite Pontus. De Haan.

Arencus . . . . . . . . Iana.

Euctenotir . . . . . Gerstaclier.

Hellenus. . . . . . . . A. Milne Edwards.

Carapace nearly flat, with the dorsal surface granulated, rarely tuberculated, usually marked with several transverse lines, of which one is prolonged inwards for a short distance from the lateral epibranchial spine. The front projects but little, is divided into from five to eight lobes or tecth, of which the two exterior constitute the interior lobes of the orbits. The antero-lateral margins are arcuated or nearly straight, and are divided into eight nearly equal and well-developed teeth, including the tooth or lobe at the exterior angle of the orbit, and excluding the ninth or lateral epibranchial spine; the postero-latcral angles of the carapace are either rounded, angular, or spiniferous. The orbits are widely open above ; their superior margin is usually marked with fissures, and sometimes dentated, and the infraocular lobe is produced and dentiform or spiniform. The basal (or real second) joint of the antennal peduncle is moderately dilated, and barely reaches the frontal margin. The third joint of the external maxillipedes is usually not at all produced at its antero-internal angle. The endostome is longitudinally ridged.

The legs of the first pair are well developed, sometimes considerably elongated; the fourth joint is armed with spines on its anterior and sometimes on its posterior margin. The fifth and palm are usually longitudinally 
ridged; the ridges may terminate in spines; the palm is elongated and somewhat prismatic; the fingers, straight, incurved at the apices, are armed with numerous unequal lobes or tubercles on the inncr margins. The walking legs are considerably elongated, with the two last joints compressed and longitudinally sulcated; in the last pair these joints are usually smooth, dilated, and the last joint oval and flat.

RANGE.-Warm and temperate seas in shallow and deep water; also in the gulf weed on the surface of the sea.

\section{Subgenus I. Neptunus. \\ Subgenus II. Amphitrite. \\ Subgenus III. Achelous. \\ Subgenus IV. Hellenus.}

Srinopsis of the Subgenera Axd Species.

A. Spine on the interior margin of the fifth joint of the first pair of legs normally developed.

a. Iateral epibranchial spine much longer than the preceding tooth of antero-lateral border.

$a^{1}$. Carapace broadly transverse : antero-lateral margins forming with the frontal margin a regular curve with a long radius.-(Subgenus . Viftunus.)

I. The fourth joint of the first pair of legs has four spines in front, no spine behind.-(.. sayi.)

2. The fourth joint of the first pair of legs has three spines in front, one spine behind.- 1 . cribrarius.)

6. Carapace narrower; antero-lateral margins forming with the frontal margin a curve with short radius, or an angle.-Subgenus Amphitriti.)

3. The fourth joint of the first pair of legs has four small curved spines in front; one spine at external angle The sternal plastron is smooth.- $(\Lambda$. ancefs. 
4. The fourth joint of the first pair of legs has two spines, and some spinules on anterior border; a short flat spine at extremity of posterior border. Sternal plastron with grooves. Carapace more or less smooth. $-(N$. ventralis. $)$

5. Carapace with deep grooves. Sternal plastron smooth.-( N. sulcatus. $)$

6. Carapace almost hexagonal. A round red spot on each side of posterior portion.- (N. scbee.)

7. The fourth joint of the first pair of legs has four spines in front, one behind. The external plastron is rough.-( N. ordwayi.)

b. Lateral epibranchial spine no longer or very little longer than the preceding tooth of the antero-lateral border.-(Subgenus Achelous.)

8. The front is cut into eight teeth; the internal orbital angle bifid.-( N. spinimanus.)

9. The front is cut into six teeth.-( $N$. depressifrons.)

$B$. Spine on inner margin of fifth joint of first pair of legs abnormally developed; in adult male longer than the palm.-(Subgenus Hellenus.)

Io. Spine on carpus reaches the anterior third of hand. Middle teeth of front the longest.-( $N$. spinicarpus.)

\section{Subgenus Neptunus.}

Neptunus . . . . . Miers.

Neptunes arques. . . A. Milne Edwards.

Carapace broadly transverse; antero-latcral margins forming with the frontal margin a regular curve with a long radius. Lateral epibranchial spine much longer than the preceding teeth of the antero-lateral border. The spine on the inner margin of the fifth joint of the first pair of legs normally developed. 


\section{Neptunus (Neptunus) sayi.}

Neptunus sayi . . A. Milne Edwards, Stimpson, Miers. Lupa sayi. . . . Gibbes, Dana, Stimpson. Lupapelergicar . Dekay, Say.

Portumus pelagicus. Bosc.

Carapace convex, marbled, smooth. Lateralepibranchial spine short. Front divided into six teeth, of which the two median are almost equal to the lateral. The first pair of legs has the fourth joint long and thin, with four spines on the inner border; there are no spines upon the posterior margin; the fifth (carpus) has two spines; one upon the antero-internal angle and the other upon its external face: the hand has smooth crests, and above two spines; one upon the internal border above the articulation of the movable finger, the other upon the external border above the articulation of the fifth joint. The fourth joint of the external maxillipedes is very little notched on the inside.

RaNGE.-Gulf weed, Guadaloupe.

\section{Neptunus (Neptunus) cribrarius.}

Neptunus cribrarius. . Lamarck, A. Milne Edwards. Portunus cribrarius. . Lamarck.

Lupa cribraria. . . . H. Milne Edwards.

Areneus cribrarius. . Dana.

Carapace wide, almost completely smooth. Teeth of the antero-lateral border pointed and wide at their base; the anterior are slightly smaller than the posterior. Lateral horns directed outwards. Front cut into six teeth, the two median fine and long, the intermediate very short, connected with the preceding, of which they appear to be a reduplication. The inferior orbital border is divided into three lobes by two wide fissures; the middle lobe is 
more prominent than the others. The epistomian apophysis is short, and exceeds slightly the front. The endostome is smooth. Legs of the first pair are short and robust. Fourth joint has three spines on its anterior border, and one on its posterior border a little behind the extremity. The fifth has two spines, that of the anterointernal angle almost as short as the spine on the external face. The hand has ridges, slightly granulated and armed with two short spines, one above the articulation of the fifth joint, the other above the base of the movable finger. Abdomen of male triangular, its edges slightly sinuous and very pointed.

Colour yellow or red, with numerous small black circular spots.

RANGE. - Guadaloupe, Gulf of Mexico, Vera Cruz, Brazil, New York.

\section{Subgenus Amphitrite.}

Amphitrite. . . . . Miers.

Neptunes angulaires. A. Milne Edwards.

The carapace narrower; antero-lateral margins forming with the frontal margin an angle or a curve with a short radius. Lateral epibranchial spine well developed.

The spine on the inner margin of the fifth joint of the first pair of legs normally developed.

\section{Neptunus (Amphitrite) anceps.}

Neptumus anceps . . . A. Mihne Edwards.

Lupa anceps. . . . . Saussure.

Lupea duchassagni . Desbonne and Schramm.

Achelous anceps . . . Stimpson.

The carapace is a little wide; the antero-lateral edges are much more wide than the postero-lateral borders, 
which are short and concave. The surface is unequal and downy. The antero-lateral teeth are very small and sharp; the lateral horn is thin and long. The front is little advanced; the two median teeth are very small, the intermediate wider and larger; the internal orbital angles are rounded.

The first pair of legs is weak; the fourth joint has in front four small very curved spines; there is a spine upon the external angle. The fifth has two spines; the hand has three; one below the articulation with fifth joint; the two others, very close, occupy the extremity of the superior border. The walking legs are thin. The fourth joint of the last pair is short and has no spines; its terminal joint is long and oval. The sternal plastron is completely smooth.

The abdomen of the male is triangular.

RANGE.-West Indies, Cuba.

\section{Neptunus (Amphitrite) ventralis.}

\section{Neptunus aentratis . . A. Milne Edwards.}

The carapace moderately wide; it is covered with short down, in the midst of which the granulations lift themselves from the projecting parts of the carapace. The front is a little advanced. The two middle teeth are a little smaller than the lateral; the internal orbital angles are rounded. The antero-lateral teeth, very granular at their base, are small and thin, with the point directed forwards. The lateral horn is as long as the space occupied by the three last of these teeth.

The pterygostomian regions are covered with hairs which hide the granulations. The fourth joint of the external maxillipedes is a little advanced.

The legs of the first pair of the female are short; the 
fourth joint has in front two spines and some spinules. A very short and flat spine exists on the extremity of the posterior border. The fifth joint has two spines, one inside, the other outside; also it is provided with strong parallel ridges, of which three occupy the external face, and one the superior face of this joint. The hand has three spines, one above the articulation with fifth joint, the second above the base of the movable finger, and the third about the anterior third of the superior border. The walking legs are short. The fourth joint of the last pair has no spines. The sternal plastron has a long depression on each side of its joints.

RANGE.-Guadaloupe.

\section{Neptunus (Amphitrite) sulcatus.}

\section{Niptumus sulcatus . . A. Milne Edwards.}

Resembles Neftums (Amphitrite) antralis in the general form of the carapace, the arrangement of the frontal teeth, and those of the antero-lateral border; but the grooves which separate the lobes of the carapace are deeper, and the sternal plastron is completely smooth.

The walking legs are relatively very long.

RANGE.-Guadaloupe; in deep water.

\section{Neptunus (Amphitrite) sebæ.}

Neptumus sebce.

H. Milne Edwards, A. Milne Edwards.

Cancer marinis scutiformis . . Seba.

Lufa scba.

II. Milne Edwards.

Carapace hexagonal, almost flat, marked with a few granulations upon the gastric and hepatic regions. Epigastric and epibranchial lines slightly projecting. On 
each side, behind and above the base of the swimming feet, there is a circular red spot. Antero-lateral edges are armed with eight similar teeth, succeeded by a lateral horn, sharp and curved forwards. The front is cut into six sharp and very large teeth; the middle ones are more advanced than the intermediate, which are separated from the external by a wide and deep notch; these last teeth are sharp. The superior orbital border is divided by two fissures. The epistomian apophysis does not exceed the front. The fourth joint of the external maxillipedes is very deeply notched inside.

The legs of the first pair are long and thin. Fourth joint armed with five or six long and bent spines on its anterior edge, and with a spine at the extremity of its posterior border. The forearm has projecting ridges, and two spines; one on the antero-internal angle, the other on its external face. The hand has granular ridges, and three spines; one above the articulation of the fifth joint, the other two on the upper surface at its extremity. The other legs are thin; there is a strong spine, directed upwards, above the articulation of the haunch of the swimming feet. The fourth joint of this last has at the extremity of the inferior border a spine.

Abdomen of the male is triangular.

RANGE.-Martinique, Mexico, Brazil.

\section{Neptunus (Amphitrite) ordwayi.}

Neptumus ordwayi.

A. Milne Edwards, Stimpson, Smith.

Neptums cruentatus . A. Milne Edwards.

Carapace wide, and very finely granular on its projecting parts. Upon the gastric region, towards the 
centre, above the epigastric line, there is a blood-red spot, and another a little smaller more behind. Teeth of the antero-lateral border directed forwards and unequal. Lateral horns sharp, and directed slightly in front. Front very advanced, slightly flattened, and cut into six teeth, of which the two median are the most prominent. Between the intermediate teeth and the external there is, on each side of the front, a deep notch. Orbits wide and deep; the superior orbital border is straight. Epistomian apophysis does not exceed the front. The legs of the first pair moderately clongated. Fourth joint has three or four spines on its anterior border, and a small one on the extremity of its posterior border. The fifth has a long and fine spine on its antero-internal angle, and another, not so large, on its external face. Hand, feebly keeled, has two spines; one above the articulation of the fifth joint, and the other about onc-third of the distance of the internal edge of the upper surface. The walking legs are spotted with red. The sternal plastron is rough as well as the first segment of the abdomen.

The abdomen of the male is triangular, with a wavy edge.

RANGe.-West Indies, Florida.

\section{Subgenus Achelous.}

Achelous. . . . De IIaan, A. Milne Eàwards. Achelous (subgenus). Miers.

The carapace is narrower; lateral epibranchial spine no longer or very little longer than the preceding tecth of the antero-lateral margin. The spine on the inner margin of the fifth joint of the first pair of legs is normally developed. 


\section{Neptunus (Achelous) spinimanus.}

Veptunus spinimanus. Miers.

Achelous spinimumus . A. Milne Edwards, De Haan, Leach, Stimpson, Smitll.

$\left.\begin{array}{l}\text { Portumus pelagicus } \\ \text { Portunus spinimanus }\end{array}\right\}$. Latreille.

Lupa spinimana . . Desmàrest, H. Milne Edwards, Stimpson, Dana.

Carapace broad in old individuals, more wide in the young, embossed; projecting parts covered with granulations. Antero-lateral edges armed with nine teeth of an equal size, except the last, which, in the young, is longer than the others; but by age the difference in size diminishes more and more. Front advanced and cut into cight teeth, the two middle the most projecting, and directed forwards, those of the second pair a little shorter, directed outwards and separated from the next by a deep notch. The next short and scarcely separated from the last. The superior orbital border is divided by two fissures. Epistomian apophysis is not projecting. Fourth joint of external maxillipedes, very long, is slightly notched in front. The legs of the first pair very large, especially in the malc. The fourth joint has on its anterior border four strong spines, and at the extremity of its posterior border a small spine. Fifth has two spines, one at the antero-internal angle, the other on its external face. Hand has granular keels, armed above with two spines; one above the articulation of the fifth joint, the other about the anterior third of the internal border of the upper surface. Walking legs long and compressed. Fourth joint of swimming legs short and wide. 
The abdomen of the male is triangular, lanceolate, with a wavy edge.

The ground colour is buff, with the elevations on the carapace, the crests on the hands, fingers and legs red; the upper surface of the fourth joint of the first pair and their spines are marbled with the same colour-red.

RANGE. - Barbados, Martinique, South Carolina, Mexico, Brazil, Chili.

\section{Neptunus (Achelous) depressifrons.}

Neptumus depressifrons. . Stimpson, Micrs.

Amphitrite depressifrons. . Stimpson.

Achelous depressifrons . . Stimpson, A. Milne Edwards.

Carapace convex posteriorly as far as its middle, depressed towards the front and the antero-lateral borders ; surface finely granular. Antero-lateral borders cut into nine equal teeth. The superior orbital border is divided by two fissures. The front is cut into six teeth. Of the legs of the first pair, the fourth joint has a small spine at the extremity of its posterior border, and five spines in front. Fifth joint has a long spine, thin and sharp at its antero-internal angle, and a small spine on its external face. The hand has, above, a prominent ridge, armed with two small spines; one above the articulation of the fifth joint, the other above the base of the movable finger. Surface finely granular. Wakking legs thin; the fourth pair more swollen than the third.

Abdomen of the male is subtriangular.

RANGE.-Bermuda, South Carolina, Florida. 


\section{Subgenus Hellenus.}
Hellenus (subgenus) . . Miers.
Hellenus . . . . . A. Milne Edwards.

The spine on the inner margin of the fifth joint of the first pair of legs abnormally developed, in the adult male exceeding the palm in length.

\section{Io. Neptunus (Hellenus) spinicarpus.}

Neptunus (Hellenus) spinicarpus . Stimpson, A. Mihe Edwards.

Achelous spinicarpus . . . . . Stimpson.

The carapace is a little wide, slightly downy, with its surface irregular. The antero-lateral borders form a curve with a short radius; they are cut into very sharp and fine teeth. The lateral spine is long, but thin. The front is slightly advanced; its teeth are small, sharp, and triangular, the middle ones slightly exceeding the lateral. The postero-lateral angles are well marked, but are not raised up into a tooth or spine.

The first pair of legs long and weak. The fourth joint has in front four large spines; there is another spine at the extremity of the posterior border. The fifth joint has at its internal angle a long spine, its point reaching the anterior third of the hand. The hand has two small spines. The last pair of legs is large and strong; their fourth joint has no inferior tecth. The sternal plastron is finely granular; the abdomen is smooth.

Range.-Barbados, Grenada, St. Kitts, Santa Cruz, Brazil; in deep water. 


\section{Callinectes.}

Callinectes . . . . Ordway, Stimpson, A. Milne Edwards.

Portums (part) . . . Fabricius, Latreille.

Lupea (part) . . . . Leach, Desmarest, H. Milne Edwards, Dana.

Neptumus (part) . . . A. Milne Edwards.

Sherigo crab (local name) Berbice.

The abdomen of the male has a broad base and then, suddenly becoming very narrow, terminates in a narrow lancet-shaped point. The fourth joint of the external maxillipedes is strongly truncated at its antero-internal angle, and very rounded outside and in front. The endostome has a longitudinal canal to limit the anterior orifice of the branchial chamber; the epistome is prolonged in the middle line in a point which exceeds the front and is visible on a dorsal view.

RANGE.-Both coasts of America, West Indies, West Coast of Africa; found both in fresh and salt water in the muddy coast water of British Guiana.

\section{Synopsis of the Species.}

$A$. Lateral epibranchial spine long; much larger than the preceding tooth of the antero-lateral margin- $C$. diacanthus.)

B. Lateral epibranchial spine short.

a. A wide groove on sternal plastron, extending to the base of external maxillipedes.-(C. bocourti.)

b. No groove on sternal plastron.-(C. caynnensis.) 


\section{Callinectes diacanthus.}

Callinetes diacanthus. Stimpson, Ordway A. Milne Edwards.

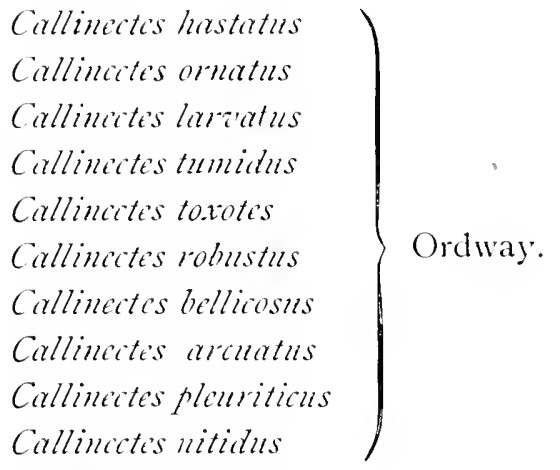

Callinectes dana. . . S. Smith.

Portumus diacanthus. Latreille.

Lupa hastatar. . . . Say.

Luper diacoutha . . . II. Milne Edwards, Dekay, Dana, Saussure, Desbonne and Schramm.

Lupaforrula . . . . Desbonne and Schramm.

Ncptumus diacanthus. . A. Milne Edwards.

The carapace is more than twice as wide as long, and is marked with some transverse granular lines. The front is cut into four teeth, not counting the internal orbital angle; the two central teeth are smaller than the two lateral, and are sometimes only a trace or as large. The superior orbital border is without spiniform prolongation. The last tooth of the antero-lateral border is the largest of the lateral teeth. It may be small or large.

The first pair of legs large. The fourth joint has three large spines upon the anterior border, and one sharp spine at the extremity of the posterior border. The fifth 



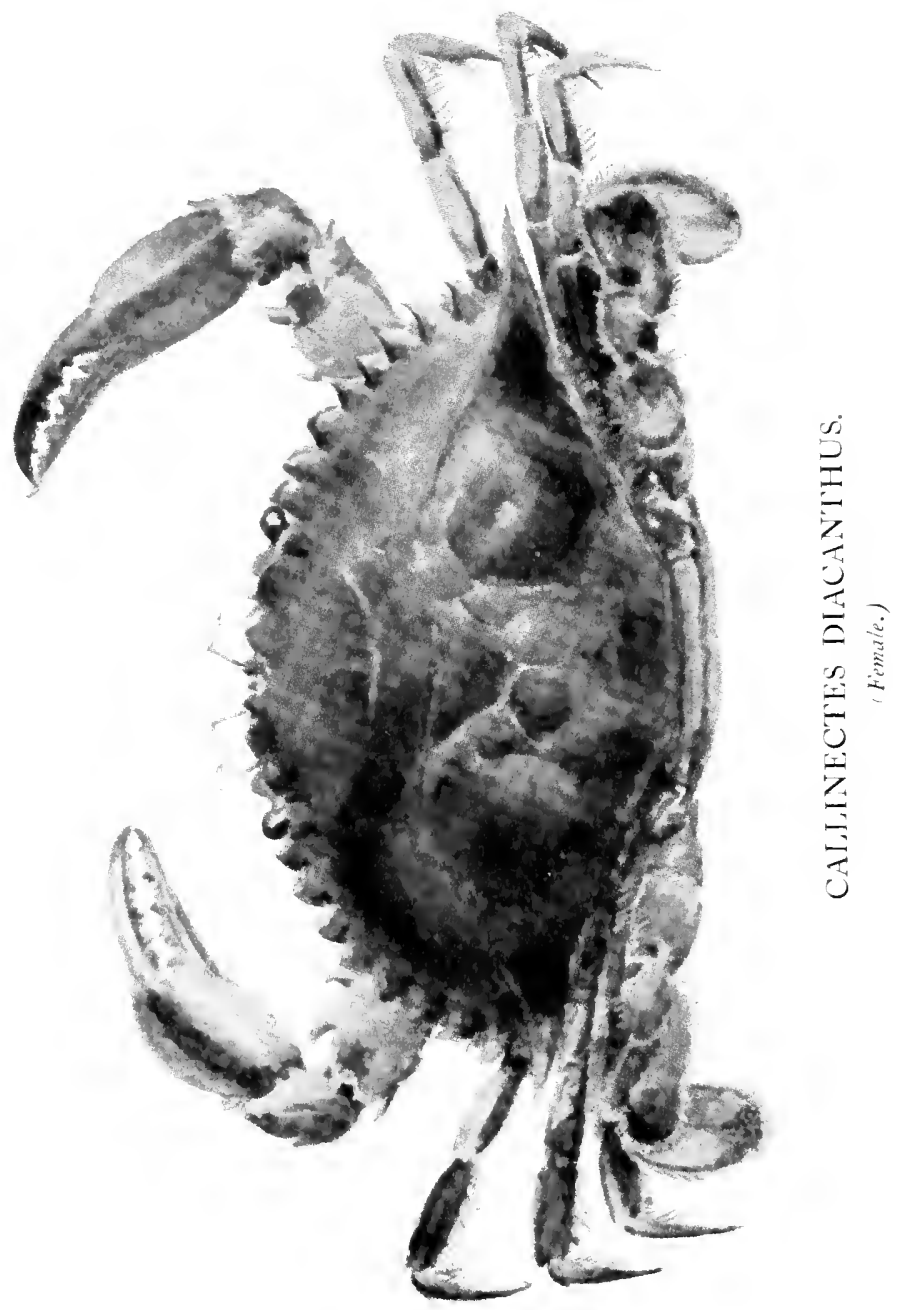


joint has a spine on its external border. The hand has a strong spine upon its outer margin near its articulation with the fifth joint, and a small spine near the base of the movable finger. The verges of the male may be long or short, straight or curved. They are in the form of rounded threads.

RANGE.-British Guiana, French Guiana, Brazil, Chili, Colombia, Panama, Guatemala, Mexico, Vera Cruz, Bahamas, Hayti, Florida, California.

According to A. Milne Edwards, the species described as distinct from Callinectes diacanthus by Ordway are only varieties of the latter. I enumerate Ordway's species :-

\section{Callinectes hastatus.}

Callinectes sapidus . . Rathbun.

The carapace is about twice as wide as long. The anterior portion is ornamented with large and regularly placed granulations; upon the cardiac and branchial regions these granulations are smaller and less numerous. The regions are distinctly marked. The front is formed of two triangular teeth, the median teeth which usually exist having disappeared. The supero-internal orbital angles are truncated and squarely cut. The suborbital angle is a little advanced and subspiniform. The pterygostomian regions are very hairy behind, but naked in front. The antero-lateral teeth are conical and pointed; the lateral horn is long and strong. The fourth joint of first pair of legs has three large spines in front, and a small spine at the extremity of its posterior border. The hand is armed with a strong spine above its articulation with the fifth joint, and an obtuse spine above its articulation with the movable finger. 
The abdomen of the male is very wide; its last joint is wide and triangular; the joint behind it is contracted near its base, and the lateral edges are concave. The verges are very long, and almost reach the extremity of the abdomen. They are twice curved. In young specimens the verges are very short, they do not exceed two-thirds of the length of the abdomen; the last joint but one of the abdomen is not concave laterally.

Brazil, Chesapeake, Texas, Jamàica, Bermuda.

\section{Callinectes ornatus.}

Smaller than the last. The carapace is not so wide as in C. hastatus. The granulations are smaller and more numerous. The front has four teeth, the two external are triangular, the two median are almost rudimentary; the internal suborbital angles are truncated. The lateral horn is shorter. The abdomen of the male is narrow; the sides of the last joint but one are regularly concave, the next joint is narrow. The verges are straight and short, they reach only the penultimate joint of the abdomen.

Bahamas, Brazil, South Carolina, Florida, Hayti, Bermuda, Jamaica, St. Thomas, Colombia, Venezuela.

\section{Callinectes larvatus.}

The carapace is very straight, strongly convex, and very uneven; the regions are marked. The frontal teetli resemble those of $C$. ornatus, but they are obtuse and more developed. The inferior and internal angle of the orbit is prolonged into a very prominent tooth, rounded at its extremity, and as large as those of the antero-lateral border; these last are large, obtuse, and slightly curved forwards. The abdomen of the male resembles that of $c$ : 
ornatus. The verges are very short and curved; they do not reach the penultimate joint of the abdomen.

Florida, Bahamas, Hayti, Mexico, Vera Cruz.

\section{Callinectes tumidus.}

The antero-lateral borders are much more bowed than in any of the preceding varieties, and ornamented with wide and large teeth, directed a little forwards, and with convex sides. The lateral horns are short. The front has four teeth. The penultimate joint of the abdomen of the male is short. The verges, which reach the middle of this joint, are curved, and terminate in a very distinct hook.

Florida, Hayti, Jamaica, Brazil.

\section{Callinectes toxotes.}

The carapace is wide and very convex; it is covered with scattered granulations. The regions are marked; a median groove divides the cardiac region into two lobes. The median region is long and narrow. The front has four obtuse and subequal teeth. The sternum is flat; the abdomen of the male is very wide; the verges are very long, reach the end of the abdomen and are curved, their extremity forming almost a circle.

California, Mexico, Ecuador.

\section{Callinectes robustus.}

Resembles the preceding, but the frontal teeth are of unequal size, the median being smaller than the lateral.

Colombia. 


\section{Callinectes bellicosus.}

\section{Iupa billicosa . . . Stimpson.}

The carapace is smooth and convex. The front has four teeth, the two median being rudimentary, the two lateral being thin and sharp. The sternum is flat, wide, and punctuated. The base of the penultimate joint of the abdomen of the male is wide. The verges reach almost the middle of this joint.

California.

\section{Callinectes arcuatus.}

The carapace is convex and finely granular; the antero-lateral borders are semicircular. The sternum is flat. The abdomen of the male is a little wide; the base of the penultimate joint is not contracted. The verges are long, thin, and straight.

California, Mexico, Panama.

\section{Callinectes pleuriticus.}

The carapace is convex, and the granulations are small. The frontal teeth are not prominent. The anterolateral borders are circular, and the teeth are wide. The sternum is wide and flat. The verges resemble those of C. arcuatus.

Panama.

\section{ro. Callinectes nitidus.}

The carapace is wide, the antero-lateral borders forming a curve with a large radius; the teeth are wide and strong. The front is slightly advanced; its median teeth are rudimentary, being separated, the one from the 
other, by a well-marked notch, below which one sees the epistomian point, which is very prominent. The abdomen of the male is narrow; its penultimate joint has a membranous base. The verges are thin, straight, and prolonged as far as the extremity of the penultimate joint of the abdomen. The carapace is violet, under surface ycllow-grey. The abdomen of the female is red, with a black band on each joint. The legs have a blue and red colour.

Guatemala, Chili.

The two following, the first described by J. S. Kingsley and the second by M. J. Rathbun, are mentioned :-

\section{Callinectes dubia.}

Resembles C.pleuriticus, except the external teeth of the front are more prominent, the antero-lateral teeth are more crowded together, the fissures between them being nearly closed; the male verges are larger, with the extremities straight, and the antero-lateral margin is but slightly bowed.

West Coast of Nicaragua.

\section{I2. Callinectes sapidus acutidens.}

Resembles $C$. hastatus, except the markings and granulations on carapace are more pronounced; there is a transverse granulated ridge on the cardiac lobes. The frontal teeth are narrower and more acute, and there are two small intervening teeth. Subfrontal and suborbital spines acuminate. Lateral teeth broad at base, narrowing abruptly to long, acuminate tips; margins granulate. Last two teeth very long. Lateral spine more than three times the length of the preceding tooth. Ridges on first 
pair of legs prominent and strongly granulate The granules of the inner margin of the fourth joint extend upon the upper surface of the distal half. There are two spines on fifth joint.

Brazil, Santa Cruz.

\section{Callinectes bocourti.}

Callinectes bocourti . . A'. Milne Edwards.

The lateral horns are short. The verges of the male are long, and reach the extremity of the abdomen. The fourth joint of the sternal plastron has, in the middle line, a wide groove which extends as far as the ridge placed between the base of the cxternal maxillipedes, and divides these into two distinct parts.

Range.-Nicaragua, Honduras, Panama, Brazil.

\section{Callinectes cayennensis.}

Callinctes cayennensis. A. Milne Edwards.

The lateral horns are short, and scarcely exceed the other teeth of the antero-lateral border; carapace is not very granular. The first joint of the sternal plastron has a groove in the middle line.

RANGE.-Guiana.

The colour of the species found in British Guiana, and examined by me when they were alive, varies much, and may be any colour from yellow-red to black, passing through many shades of chestnut brown. The lighter coloured crabs are usually found in fresh or nearly fresh water, while the darker and black ones are found in tidal waters of the river or on the seashore. 
B. Flagellum cicluded from the internal orbital hiatus by a process of the basal antennal joint:-

\section{Lupa.}

Lupa (part). Leach.

Lupa . . . H. Milne Edwards, A. Milne Edwards, De Haan.

The carapace resembles that of Ncptunus. The basal antennal joint is prolonged in front and on the outside from its movable part, and is soldered to the external suborbital angle. This angle is very prominent. The fourth joint of the external maxillipedes is very much developed: it is rounded anteriorly, where it exceeds the level of the front; its antero-external angle, which is obtuse, is much prolonged. The following joints are compressed and flat. The fingers of the pincers are very long and feeble; the walking legs are thin and flat.

The abdomen of the male is narrow. The sternum is flat and wide; the median suture is extended upon the four last segments.

\section{Lupa forceps.}

Lupa forceps . . Leach, Desmarest, Latreille, H. Milne Edwards, A. Milne Edwards.

Portumus forceps. . Fabricius, Herbst, Latreille.

In male adults the carapace is very flat, slightly hexagonal, and very finely granular. The posterior border is very wide; the antero-lateral borders are armed with eight very small teeth, pointed and separated by 
wide notches. The lateral horns are long, slender, and directed directly outwards. The front is narrow and cut into eight teeth, of which the two median are short and sharp, the intermediate ones are longer; the external or orbital angles are short and a little obtuse. The superior orbital border is straight, and is divided by two fissures. The epistomian apophysis is a little projecting and does not exceed the front.

The first pair of legs, smooth, is very long and thin. The length of the fourth joint equals the transverse diameter of the carapace near the base of the lateral horns, and the hand is twice this length. The anterior border of the fourth joint has four, five, or six spines; there is another spine on the extremity of the posterior border. The fifth joint has two spines, one at the antero-internal angle, the other upon its external face. The hand is thin, cylindrical, and has filiform fingers; there is a spine above the base of the movable finger and another above the articulation of the fifth joint. The walking legs are very compressed laterally. The fourth joint of the last pair is short, almost orbicular, armed below with a terminal spine and above with a spiniform tubercle; the last joint but one is elongated ; the terminal joint is long and oval.

In young males the pincers are shorter; in females they resemble the pincers found usually in the genus Neptunus; the length of the finger is almost equal to that of the palm, and these appendages are laterally compressed, carinated, straight, and with teeth upon their prehensile edge.

RANGE.-West Indies: at great depths. 
II. Antiro-lateral tecth altimately large and small :-

\section{Cronius.}

Cronins . . . Stimpson, A. Milne Edwards.

Portumus (part) . Lamarck.

Luper (part) . . H. Milne Edwards.

Achelons (part) , A. Milne Edwards.

The front, wide, is divided into cight teeth, counting the internal orbital angle. The antero-lateral borders are cut into nine alternately large and small teeth. The basal antennal joint is advanced in such a way as to exclude the flagellum from the orbit. The fourth joint of the external maxillipedes is slightly prolonged in front, but is dilated externally; the terminal joints are cylindrical. The fourth joint of the last pair of legs has a spine.

Range.-West Indian Sea and Gulf of Mexico, Cape Verde, Pacific Ocean.

\section{Cronius ruber.}

Cronius ruber. . Lamarck, Miers, Stimpson, A. Milne Edwards.

Portunus ruber. . Lamarck.

Lupea mber. . . H. Milne Edwards.

Acliclous rubor. . A. Milne Edivards.

The carapace is hexagonal, smooth, and slightly hairy. The front has the two median teeth advanced, large, and directed forwards; those of the second pair, sharp, directed slightly outward, and are separated from those of the third pair by a deep notch; these are sharp, directed forwards, and slightly separated from the fourth pair, winich constitute the internal orbital angles, and are rounded in 
front. The basal antennal joint has a spine below the insertion of its movable part. The fourth joint of the first pair of legs has in front four or five wide and strongs spines; there is a small spine at the extremity of its posterior border. The fifth joint has granular ridges; there is a large spine on the inside and three small spines upon its external face. The hand has granular ridges, and is armed above with four spines arranged aiternately, two upon the internal edge and two upon the external border of the superior face.

The colour is usually a violet red, more or less marbled; the extremity of all the spines is black.

RANGE-St. Thomas, Vera Cruz, Gulf of Mexico, Panama, Brazil; in deep water.

\section{Subfamily II. Carcininæ.}

Carcinine. . . . Miers.

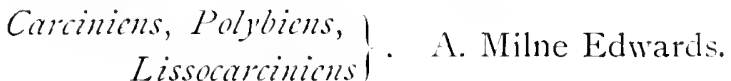

Carapace slightly, if at all, transverse, with the anterolateral margins arcuated, and armed with five or fewer marginal teeth. Basal antennal joint moderately developed. First pair of lergs rather small. Fifth pair formed for swimming.

\section{Srameis of tile Genera.}

I. Antenne not wholly excluded from the orbits.

a. Fourth joint of first pair of legs without spines.-(Portumus.)

b. Fourth joint of first pair of legs with spines.(Platjonychus.) 


\section{Portunus.}

Portums. . Fabricius, the Milne Edwards, Miers.

Liocarimus. De Haan, Stimpson.

Carapace moderately transwerse, iepressed, with the lateral margins arcuated, and armed with five regular and even teeth: the front of moderate width, and divided into several lobes or teeth, which are not very prominent; the last tooth scarcely, if at all, exceeds the preceding one in length. The eyes are set on very short thick peduncles. The orbits are not large, and have two fissures in their superior, and one or two on their inferior margin. The basal antennal joint is short and but little dilated; it is generally united with the frontal margin, but does not always completely fill the interior hiatus of the orbit. The third joint of the external maxillipedes is not produced at its antero-internal angle; the fourth is truncated or very slightly rounded distally, with the antero-internal angle scarcely, if at all, emarginate, and the antero-external angle not procluced. The ridges of the palate are not always developed. The legs of the first pair are subequal and moderately developed; the fourth joint (arm) is smooth, without spines, the fifth joint (carpus, wrist) has a strong spine on its inner margin, palm with a spine near to the distal extremity of the superior margin, and usually somewhat indistinctly costated on the exterior surface. IValking legs of moderate length, with the last joint styliform; fifth pair has the two last joints dilated and compressed ; the last joint ovate.

The abdomen is five-jointed, the third to the fifth segments being consolidated.

Range. - Mediterranean Sea, Atlantic Ocean, Australia, Japan. 


\section{Portunus guadulpensis.}

Portunus guadulpensis . Saussure, A. Milne Edwards.

Carapace convex and long; regions scarcely indicated. Antero-lateral edges cut into five sharp spines. Front has five teeth, of which the two external are rudimentary, the other equally adranced; the middle one is sharp, the intermediate ones more rounded. Of the legs of the first pair, the fourth joint is short and smooth; the fifth has a single spine at its antero-internal angle. Hands strongly keeled, having a small spine above the base of the movable finger: the other legs are thin.

RaxGE-Guarlaloupe.

\section{Platyonychus.}

Platjonychus . Latreille, Milne Edwards, Miers.

Anis ofus. . De Haan.

Carapace depressed and transverse; the dorsal surface without tubercles or transverse ridges; the front is rather narrow, and armed with three or four lobes or teeth; the antero-lateral margins arcuated, and armed with five teeth or spines, including the lobe at the exterior orbital angle and the lateral epibranchial tooth, which is no longer than the preceding tooth.

The eyes are of moderate length. The orbits are rather widely open above, and have one or two fissures in the superior and one in the inferior margin. The ridges of the endostome are obsolete. The basal joint of the external antenne is short, not dilated, and occupies but does not wholly fill the interior hiatus of the orbit, and is not united at its distal extremity with the front. The external maxillipedes are rather large; the third 
joint is not produced at the antero-internal angle; the fourth is obliquely truncate at the distal extremity, with the antero-external angle rounded and not at all produced. The legs of the first pair in the adult male are subequal and not greatly elongated, with their fourth joint with spines on the inner margin, and the palms externally more or less distinctly longitudinally costated; the fingers elongated and armed on the interior margins with large triangular lobes alternating with smaller teeth. The walking legs are of moderate length, with the last joint styliform and compressed. The last pair of legs have their two terminal joints compressed and dilated; the last joint not lanceolate, but broadly ovate and rounded at the distal extremity. The abdomen is usually seven - jointed, but in P. ocillatus it is fire-jointed, with the third to fifth joints consolidated.

RANGE. - Western Atlantic, Chili, Patagonia, Australian and New Zealand Seas, Indo-Pacific region; in shallow and deep water.

\section{Platyonychus ocellatus.}

Platyonychus occllatus . . Milne Edwards, Herbst.

Carapace wide, very finely granular, with the regions scarcely indicated. Antero-lateral edges cut into five well separated teeth, sharp and directed forwards. Front straight and divided into three teeth; the central one long and sharp, the others shorter. The superior orbital border has one fissure. External maxillipedes long; the fourth joint deeply notched for the articulation of the fifth. Endostome smooth. First pair of legs of moderate size. The fourth joint has five teeth on its anterior edge. The fifth has two spines, one at its antero-internal angle, the other on its external face. Hand, traversed longitudinally. 
by slightly granulated ridges, has a spine above the base of the movable finger on the inner side. Walking legs short and thin. The last joint of the fifth pair wide and oval. Abdomen of the male lanceolate; the last segment is very small, and dovetailed into the fourth.

R.Nik: - IVest Indies, East Coast of the United States, Gulf of Mexico, New Zealand.

\section{Tribe III. Catometopa.}

$\begin{array}{ll}\text { Catometopa (part). . } & \text { Miers. } \\ \text { Catometopes I. . } & \text { H. Milne Edwards. } \\ \text { Ocypodida (part) J. } & \\ \text { Grapsoidea . . . } & \text { Dana. } \\ \text { Quadrilatera (part) . } & \text { Latreille. }\end{array}$

The body may be thick or thin from above downwards. The carapace is almost always wicler than long, and regularly rhomboidal or oval, sometimes almost circular. The gastric region is large, and usually divided posteriorly by a median prolongation of the genital region; the hepatic regions, when they are indicated, are very small; the branchial regions occupy almost the whole length of the lateral border of the carapace. The front is never advanced in the form of a rostrum, it is usually strongly curved downwards, and often completely vertical; the fronto-orbital border occupies almost the whole breadth of the carapace; the lateral borders are straight or more or less curved, but never divided into two distinct portions; the posterior border is usually very long. The eyes have usually long and thin peduncles. The orbits are almost always directed upwards and forwards; their internal angle has usually an hiatus which lodges a portion of the base of the external antennæ.

The internal antennæe may be vertical or longitudinal, 
sometimes transverse; their fossæ may communicate with the orbits, or may be circumscribed, then they are very narrow from before backwards. The external antenuae are very short; their basal joint is often wider than long, and their terminal joints, which are sometimes rudimentary. occupy ustrally the hiatus of the internai orbital angle.

The epistome is usually linear. The buccal cavity is usually quadrilateral, and is never advanced to a level with the insertion of the eye; it may be slightly contracted in front, and its anterior border may be a little bowed. The fifth joint of the external maxillipedes articulates with the fourth at the middle of its anterior border or at its internal or external angle, or may be completely hid behind it. The cxternal appendage (cxognath) is usually styliform, or may be rudimentary. The sternal plastron is almost always wider than long, and contracted anteriorly:

RAxGE.-Fresh and salt water of warm and tropical regions, and damp and clry lands of most tropical and subtropical countries.

Family I. Thelphusidæ

Family II. Geocarcinidæ.

Family III. Ocypodidx.

Family IV. Grapsidæ.

Family V. Pinnotheridæ.

\section{SrNopsis of the FAMILIES.}

a. The fifth joint of the external maxillipedes joins the fourth at its extcrnal angle, or at the centre of its anterior border. The fourth joint is broad, with rounded anterior margin, or triangular.

The carapace is transversely oval or rounded. (Thelphusidc.) 
b. The fifth joint of the external maxillipedes is inserted at the external angle of the fourth, or is hid behind it. The carapace is oval--(Geocarcinida.)

$c$. The fifth joint of the external maxillipedes is inserted at the summit or at the external angle of the fourth joint. The carapace is circular or triangulate.(Pinnotherida.)

d. Carapace quadrilateral or rhomboidal ; anterior and lateral borders almost straight or slightly curved.

$d^{1}$. The second joint of the male abdomen does not hide the sternum below it. Eyc-stalks almost always very long.- (Oypodide.)

$e^{1}$. The second joint of the male abdomen almost always hides the sternum below it. Eye-stalks very short.criapside.

\section{Family I. Thelphusidæ.}

Thelphuside . . Dana, Miers.
Thelphcusiens. . H. Milne Edwards.
I'otemonide . . Ortmann, Rathbun.

The carapace, transverse, rounded, or more or less quadrilateral, is slightly or not at all convex, or may be convex antero-posteriorly; its anterior border is straight, and occupies about two-thirds of its transverse diameter, or may be almost as broad as the carapace; the lateral borders may form a regular curve, or may be more or less straight, and armed with teeth that are of some size or are microscopic. The front, wider than the anterior portion of the buccal cavity, may be or may not be bent downwards; if the latter, the bend may be a gradual slope, or a sudden bend, the bending being indicated by a ridge (the superior frontal border) which may be more advanced than the lower free border. The eyes have a large and 
short pedicle, with the cornea well developed. The orbits are oral, and have a narrow hiatus at their internal angle, filled by the external antennæ. The internal antennæe are horizontal and usually entirely hid by the front.

The epistome is linear, and placed on about a level with the inferior border of the orbits. The fourth joint of the external maxillipedes may be broad, with rounded anterior border, or may be triangular; the fifth joint articulates with it at its centre, or external anterior angle. The buccal cavity is almost as wide in front as posteriorly.

The legs of the first pair are stronger, and almost always longer than the others; they are slightly compressed. The last joint of the walking legs may or may not be armed with spines. The male verges arise from the basal joint of the last pair of legs, and are carried through a transverse canal of the sternum. 'The second joint of the abdomen of the male covers the entire breadth of the sternum below it; and it extends as far as the basal joint of the last pair of legs.

RANGE - Usually in or near fresh water in warm countries.

\section{Subfamily I. Pseudothelphusinæ. Subfamily II. Trichodactylinæ.}

\section{Synopsis of the Sumfamilates.}

$A$. Carapace transverse, wider than long. Front with or without superior frontal border, sloping downwards. Fourth joint of external maxillipedes rounded anteriorly ; the fifth joint articulates with it in the centre of its anterior border. Last joint of walking legs armed with spines.(Pseudothelphusince.)

B. Carapace more or less rounded or quadrilateral. 
Front horizontal or sloping, without superior frontal border. Fourth joint of external maxillipedes triangular : fifth joint articulates with it at anterior external angle. Last joint of walling legs not armed with spines.Trichodactyline.

\section{Subfamily I. Pseudothelphusinæ.}

Psendothelphusine. . Ortmann, Rathbun.

Potamocarcinidle. . Ortmann.

Psendothelphusida. . Rathbun.

Bosciade. . . . . Smith.

Bosciacar . . . . Milne Edwards.

Boscia (genus) . . . H. Milne Edwards.

Carapace oval from side to side; margins toothed or tuberculate, sometimes very minutely. Epigastric lobes and cervical sutures present. Median furrow usually present. Front inclined, generally bilobed, either straight or slightly arched, and with or without a superior frontal border. An inner suborbital lobe, distinct from the orbital margin, is always present, and is either separated from the front by the width of the flagellum, or, when united with the front, permits the passage of the flagellum behind it into the orbit.

The fourth joint of the external maxillipedes is broader than long, with the outer marsin arcuate from the articulation of the second to the insertion of the fifth joint, or forms an antero-exterior angle with the anterior margin; posterior margin usually as wide as the anterior margin of the third joint. Its form is subquadrangular or subtriangular; the fifth joint joins it at its anterior inner notch, and is not hid behind it. The third joint has no longitudinal furrow. The external appendage 
(exognath) never reaches beyond the half of the fourth joint, and is often very small.

The palatal ridges reach quite to the anterior margin of the buccal cavity, and form two lateral well-marked channels. The terminal joint of the walking legs is armed with spines. The colour of the carapace is usually some shade of brown.

\section{Stnopsis of the Genera.}

I. The posterior margin of the fourth joint of the external maxillipedes equals the anterior margin of the third joint, against which it is applied.

A. The external appendage of the external maxillipedes is not as long as the third joint ; efferent branchial channel without teeth or spine.

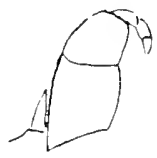

Pricudothilfutuse.

a. Superior margin of front less advanced than inferior margin, or about equally advanced with it ; antero-lateral teeth small, often tuberculiform.-( Pseudothelphusa.)

b. Superior margin of front projecting over the surface of the front, which retreats and is not visible on a dorsal view; antero-lateral teeth large and spiniform.-(Potamocarcinus.)

P. External appendage of the external maxillipedes longer than the third joint; efferent branchial channel with a tooth or spine projecting from the upper side near the anterior end.-(Epiloboccro.)

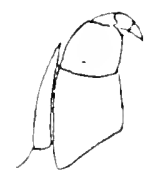

Efilotiocert.

II. Posterior margin of fourth joint of external maxillipedes one-half the width of the anterior margin of the third, and articulated with the outer half of the latter.(Rathbunia.) 


\section{Pseudothelphusa.}

Pscudothelphusa. Saussure, Smith, Rathbun.

Potamia . . Latreille, De Haan, Dana, Saussure. Boscic . . . H. Milne Edwards, A.Milne Edwards. \begin{tabular}{l|l} 
Hypolobocra \\
Potamocarcinus
\end{tabular} \mid Ortmann.

The posterior margin of the fourth joint of the external maxillipedes equals the anterior margin of the third joint, against which it is applied. The external appendage (exognath) is not as long as the third joint; efferent branchial channel without tooth or spine. The superior margin of the front is less advanced than the inferior margin, or about equally advanced with it; antero-lateral teeth small, often tuberculiform. The terminal joint of the walling legs is styliform and has five rows of small spines; three upon its upper surface and two below; these rows can be traced backwards on the other joints of the legs.

\section{Synorsis of the Species.}

1. Front sloping downwards, without line (superior frontal border) indicating bend.

A. Antero-lateral margin of carapace almost smooth. Lower margin of front strongly rimmed, convex. Walking legs not slender.-(P. americana.)

II. Front sloping downwards, with a superior frontal border that is not strongly indicated.

$B$. External appendage of external maxillipedes reduced to a stump.

a. Superior frontal margin unilobate.-(P. denticulata. 
b. Superior frontal margin bilobate.-(P. fossor:

$C$. External appendage of external maxillipedes not reduced to a stump.

c. Inferior margin of front straight or sinuous.- $(P$. ricutusi.)

III. Front sloping downwards, with a strong superior frontal border.

$D$. External appendage of external maxillipedes reduced to a stump.-(P.garmani.

$E$. External appendage of external maxillipedes about one-third the length of the third joint.-(P. dentata.)

$F$. External appendage of external maxillipedes about two-thirds the length of the third joint.-( P. reflerifions.)

\section{Pseudothelphusa americana.}

Psendothelphusa ameriana. Saussure, M. J. Rathbun. Pseudothelphusa dugesi. . M. J. Rathbun.

The lower margin of the front is strongly rimmed, convex. The lateral teeth of the carapace present, though indistinct. The outer margin of the fourth joint of the external maxillipedes is convex, and gradually curving into the anterior margin. Walking legs are not slender. The inner lobe of the abdominal appendage of the first segment in the male is not falcate.

Range.-Hayti, Mexico, Cuba.

\section{Pseudothelphusa denticulata.}

Pseudothelphusa denticulater. M. J. Rathbun.

Boscia denticulata. . . . . I. Milne Edwards.

Carapace finely granulate. Superior margin of front not keeled, tuberculate, unilobate, with median suture 
wanting or faintly indicated. Cervical sutures straight. The fourth joint of the external maxillipedes with outer margin convex, forming a single curve to the insertion of the fifth joint. Exognath reduced to a stump.

RANGE-Guiana. I found specimens in the damp forest on the Calabash Creek behind Plantation Everton, Berbice.

\section{Pseudothelphusa fossor.}

\section{Pscuduthelphusa fossor . . M. J. Rathbun.}

The superior margin of the front not keeled, tuberculate, bilobate, with a median suture. The fourth joint of the external maxillipedes has its outer margin convex, forming a single curve to the insertion of the fifth joint. Exognath reduced to a stump. Carapace finely granulate.

These crabs are of a light colour, and are found under stones.

RANGE.-Venezuela, West Indies.

\section{Pseudothelphusa xantusi.}

\section{Pseudothelphusa rantusi . . M. J. Rathbun.}

Carapace granulate to the naked eyc. Superior margin of front not keeled, tuberculate, with the inferior margin sinuous or straight. The fourth joint of the external maxillipedes has its outer margin convex, forming a single curve to the insertion of the fifth joint. Exognath not reduced to a stump. Walking legs not slender.

RAnge-Costa Rica, United States of Colombia, Venezuela. 


\section{Pseudothelphusa garmani.}

Psendothelphusa gramani . M. J. Rathbun.

Superior margin of front keeled. A tubercle on outer surface of hand at base of movable finger. The fourth joint of external maxillipedes broad, the external and antero-external margin very arcuate. Exognath reduced to a stump.

Range.-Venezuela, West Indies, Trinidad.

\section{Pseudothelphusa dentata.}

Pscudothelphusa dentata . M. J. Rathbun.

Pseudothelphusa temuipes. Pocock.

Boscia dentata. . . . . H. Milne Edwards.

Cancer furiatilis . . . Herbst.

Thelphusa dentata . . . Latreille.

Thelphusa serrata . . . Desmarest.

The carapace horizontal and smooth above, very wide; cervical suture straight; superior margin of front keeled, edge granular. The orbits are entire. The antero-lateral borders are sharp, very bowed, and faintly toothed. The exognath is reduced to a stump, less than one-third the length of the third joint of the external maxillipedes. The part of the pterygostomian region round the mouth is covered with a long and close down. No tubercle on outer surface of hand at base of fingers.

Range.-Guadaloupe, Dominica, Martinique, St. Lucia. 


\section{Pseudothelphusa reflexifrons.}

\section{Psendothelphuser referifions. . Ortmann.}

Carapace very convex longitudinally. Superior margin of front keeled. No tubercle on outer surface of hand at base of fingers. External maxillipedes only a little wider than the buccal cavity, with the exognath not reaching distal third of the third joint. Lateral margins of fourth to sixth segments of abdomen of male arcuate.

Range.-West Indies, Upper Amazon.

The following American species have been described by Miss M. J. Rathbun :-

I. Front without a superior margin or marginal line :-

\section{Pseudothelphusa macropa.}

Pscudothelphusa macropa. A. Milne Edwards. Boscia macropa . . . . H. Milne Edwards.

The outer margin of fourth joint of external maxillipedes straight or concave, forming an angle with the anterior margin. The spines on terminal joint of the walking legs are small and numerous, being fifteen or more in a row.

Bolivia, United States of Colombia.

\section{Pseudothelphusa ecuadorensis.}

The outer margin of fourth joint of external maxillipedes straight or concave, forming an angle with the anterior margin. The walking legs are very slender, with 
the spines on the terminal joint about five or six in a row. The cervical sutures arch towards each other.

Ecuador.

\section{Pseudothelphusa plana.}

Pseudothelphuse pland . . . S. J. Smith.

The outer margin of fourth joint of external maxillipedes straight or, concave forming an angle with the anterior margin, its width being one and a half times the length. The cervical sutures are sinuous. The walking legs are of moderate width, with the spines on their terminal joint about five or six in a row.

Peru.

\section{Pseudothelphusa lindigiana.}

The outer margin of fourth joint of external maxillipedes straight or concave, forming an angle with the anterior margin; this joint is very little wider than long. The cervical sutures are sinuous. The walking legs are of moderate width, with the spines on their terminal joint about five or six in a row.

United States of Colombia, Ecuador.

\section{Pseudothelphusa exilipes.}

The outer margin of fourth joint of the external maxillipedes is convex, and gradually curving into the anterior margin. The walking legs are very slender. The lower margin of sixth joint of the larger hand of the female most convex or protuberant at the middle of the palm. The width of the carapace is less than one and three-fourth times its length.

Costa Rica. 


\section{Pseudothelphusa gracilipes.}

\section{Boscia gracilipes . . . A. Milne Edwards.}

The outer margin of the fourth joint of external maxillipedes is convex, and gradually curving into the anterior margin. The walking legs are very slender. The lower margin of the sixth joint of the larger hand of the female is most convex or protuberant below the articulation of the movable finger. Width of carapace more than one and three-fourth times its length.

Guatemala.

\section{Pseudothelphusa jouyi.}

The lower margin of the front faintly rimmed. The outer margin of the fourth joint of external maxillipedes convex and gradually curving into the anterior margin. The walking legs are not slender. No marginal teeth on carapace.

Mexico, in Lake Chapala, 5000 feet elevation; Falls of Rio San Juan.

\section{Pseudothelphusa agrestis.}

The lower margin of the front is strongly rimmed, being sinuous or trilobed in a front view. The outer margin of the fourth joint of external maxillipedes convex, and gradually curving into the anterior margin. The walking legs are not slender. The external appendage of the maxillipede reaches about half the length of the second joint.

Costa Rica. 


\section{Pseudothelphusa terrestris.}

The lower margin of the front is strongly rimmed, convex. The lateral teeth of the carapace are obliterated. The outer margin of the fourth joint of the external maxillipedes is convex, and gradually curving into the anterior margin. The walking legs are not slender. The inner lobe of abdlominal appendage of the first segment in the male is falcate.

Mexico, found under stones in damp localities; Cuba.

II. Front with a superior margin or marginal line:-

Io. Pseudothelphusa equatorialis.

Iseudothelphuse cquatorialis . . Ortmann.

Superior margin of front not keeled, smooth. Walking legs elongate, the last joint but one at least twice as long as wide. The sixth segment of the abdomen of the male half as long as its proximal width.

Ecuador.

\section{Pseudothelphusa verticalis.}

Superior margin of the front not leeled, smooth. Walking legs elongate, with their last joint but one at least twice as long as wide. The lower margin of larger hand convex; lower margin of fixed finger straight. The sixth segment of the abdomen of the male less than half as long as its proximal width; the appendage of the first segment has a twisted appearance.

Mexico. 


\section{I2. Pseudothelphusa belliana.}

The superior margin of front not keeled, smooth, low, its width being about twelve times its height. Walking legs elongated; the sixth joint at least twice as long as wide. The lower margin of large hand sinuous. The sixth segment of abdomen of the male less than half as long as proximal width.

Mexico.

\section{I3. Pseudothelphusa montana.}

The superior margin of front not lieeled, smooth, its width being about nine times its height. Walking legs elongated; the sixth joint at least twice as long as wide. The lower margin of large hand sinuous. The sixth seginent of abdomen of the male less than half as long as proximal width.

Costa Rica, under trunks of trees.

\section{I4. Pseudothelphusa tumimanus.}

Superior margin of front not keeled, smooth. Hand with a tubercle at base of movable finger. Walking legs not elongated; the sixth joint less than twice as long as wide.

Costa Rica.

I5. Pseudothelphusa tristani.

Superior margin of front not keeled, smooth. Hand without a tubercle at base of movable finger. Walking 
legs not elongated; the sixth joint less than twice as long as wide.

Costa Rica.

\section{I6. Pseudothelphusa chilensis.}

Potamia chilcnsis. A. Milne Edwards and Lucas.

Superior margin of front not keeled, tuberculated. Fourth joint of external maxillipede narrow, the outer oblique margin making an angle with the anterior margin. Cervical suture curved.

Peru, Lima.

\section{I7. Pseudothelphusa nobilii.}

Superior margin of front not lieeled, tuberculated. Fourth joint of external maxillipedes narrow, the outer oblique margin making an angle with the anterior margin; no outer orbital notch. Cervical suture straight. Walking legs slender.

Ecuador.

\section{I8. Pseudothelphusa bouvieri.}

Superior margin of front not keeled, tuberculate. Fourth joint of external maxillipedes narrow; the outer oblique margin making an angle with the anterior margin. A well-marked outer orbital notch. Cervical suture straight. Waiking legs of moderate width.

United States of Colombia.

19. Pseudothelphusa agassizii.

Carapace coarsely granulate. Superior margin of front not keeled, tuberculate, unilobate, with median 
suture absent or faintly indicated. The fourth joint of the external maxillipedes has its outer margin convex, forming a single curve to the insertion of the fifth joint. Exognath reduced to a stump. Cervical sutures curved, arching towards each other.

Brazil.

\section{Pseudothelphusa dilatata.}

Superior margin of the front not keeled, tuberculate, with lower margin convex. Cervical suture sinuous. The fourth joint of the external maxillipedes has its outer margin convex, forming a single curve to the insertion of the fifth joint. The external appendage (exognath) is not reduced to a stump, being about half the length of the third joint.

Mexico.

\section{I. Pseudothelphusa sulcifrons.}

Superior margin of the front not keeled, tuberculate, with lower margin convex. Cervical suture nearly straight. The fourth joint of the external maxillipedes has its outer margin convex, forming a single curve to the insertion of the fifth joint. Exognath is about half the length of the third joint.

Mexico.

\section{Pseudothelphusa bisuturalis.}

Carapace smooth to the naked eye. Superior margin of front not keeled, tuberculate, with the inferior margin sinuous or straight. The fourth joint of the external maxillipedes has its outer margin convex, forming a 
single curve to the insertion of the fifth joint. Exognath not reduced to a stump. Walking legs slender.

Guatemala.

\section{Pseudothelphusa conradi.}

Pseudothelphusa conradi. . . Nobili.

Superior margin of front keeled. The fourth joint of the external maxillipedes narrow, outer margin very oblique. A tubercle on outer surface of hand at base of movable finger, with movable finger of larger hand wide throughout its length.

Ecuador, Peru.

\section{Pseudothelphusa magna.}

Superior margin of front keeled. Orbit more than twice the depth of the eye. A tubercle on outer surface of hand at base of movable finger. The fourth joint of the external maxillipedes broad, the external and anteroexternal margin very arcuate. Exognath not reduced to a stump.

Costa Rica.

\section{Pseudothelphusa tuberculata.}

Superior margin of front keeled. Orbit less than twice the depth of the eye. A tubercle on outer surface of hand at base of movable finger. Fourth joint of external maxillipedes broad; the external and antero-external margin very arcuate. Exognath not reduced to a stump.

Guatemala, Costa Rica. 


\section{Pseudothelphusa affinis.}

Superior margin of front keeled. Cervical suture arching forward in anterior half. Exognath reduced to a stump, less than one-third the length of the third joint of the cxternal maxillipedes. No tubercle on outer surface of hand at base of fingers.

Cuba.

\section{Pseudothelphusa maxillipes.}

Superior margin of front kecled. No tubercle on outer surface of hand at base of fingers. External maxillipedes much wider than the buccal cavity, nearly covering the jugal area, with exognath at least one-third the length of the third joint.

Mexico.

\section{Pseudothelphusa convexa.}

Superior margin of front keeled. No tubercle on outer surface of hand at base of fingers. External maxillipedes only a little wider than the buccal cavity, with the exognath reaching distal third of third joint. Carapace very convex longitudinally. Lateral margins of fourth to sixth segments of abdomen of the male not arcuate.

Costa Rica.

\section{Pseudothelphusa richmondi.}

Carapace flattened or slightly convex longitudinally : cervical suture straight or nearly so; lateral margin armed with rather large separated teeth. Superior margin of front keeled. No tubercle on outer surface of hand at base of fingers. External maxillipedes only a little wider 
than the buccal cavity, with exognath at least one-third the length of the third joint.

Nicaragua, Costa Rica, United States of Colombia.

\section{Pseudothelphusa colombiana.}

Carapace flattened or slightly convex longitudinally, very wide, more than one and two-third times as wide as long; without lateral teeth. Cervical suture curved. Superior margin of front keeled. No tubercle on outer surface of hand at base of fingers. External maxillipedes only a little wider than the buccal cavity, with exognath at least one-third the length of the third joint.

United States of Colombia, Mexico.

\section{I. Pseudothelphusa pittieri.}

A small species, less than $30 \mathrm{~mm}$. wide. Carapace flattened or slightly convex longitudinally, less than one and two-third times as wide as long, funcly granulate. Cervical suture curvect. Superior margin of front keeled, with lower margin tuberculatc. No tubercle on outer surface of hand at base of fingers. External maxillipedes only a little wider than the buccal cavity, with exognath at least one-third the length of the third joint.

Costa Rica.

32. Pseudothelphusa henrici.

\section{Pseudothelphusa henrici. . . Nobili.}

A large species, more than $70 \mathrm{~mm}$. wide. Carapace flattened or slightly convex longitudinally, less than one and two-third times as wide as long, finely granulate. Cervical suture curved. Superior margin of front keeled, 
with lower margin not tuberculate. No tubercles on outer surface of hand at base of fingers. External maxillipedes only a little wider than the buccal cavity, with exognath at least one-third the length of the third joint.

Ecuador:

\section{Pseudothelphusa peruviana.}

Carapace flattened or slightly convex longitudinally, less than one and two-third times as wide as long, coarsely granulate. Cervical suture curved. Superior margin of front keeled. No tubercle on outer surface of hand at base of fingers. External maxillipedes only a little wider than the buccal cavity, with the fourth joint narrow, subtriangulate, and its outer margin straight or nearly so, and with the exognath at least one-third the length of the third joint.

Peru.

\section{Pseudothelphusa bocourti.}

\section{Boscia bocourti . . . A. Milne Edwards.}

Carapace flattened or slightly convex longitudinally; less than one and two-third times as wide as long, coarsely granulate. Cervical suture curved. Superior margin of front keeled. No tubercle on outer surface of hand at base of fingers. External maxillipedes only a little wider than the buccal cavity, with the fourth joint broad, subquadrilateral; outer margin arcuate to the distal extremity, and with the exognath at least one-third the length of the third joint. The sixth and seventh segment of the male abdomen of equal length; appen- 



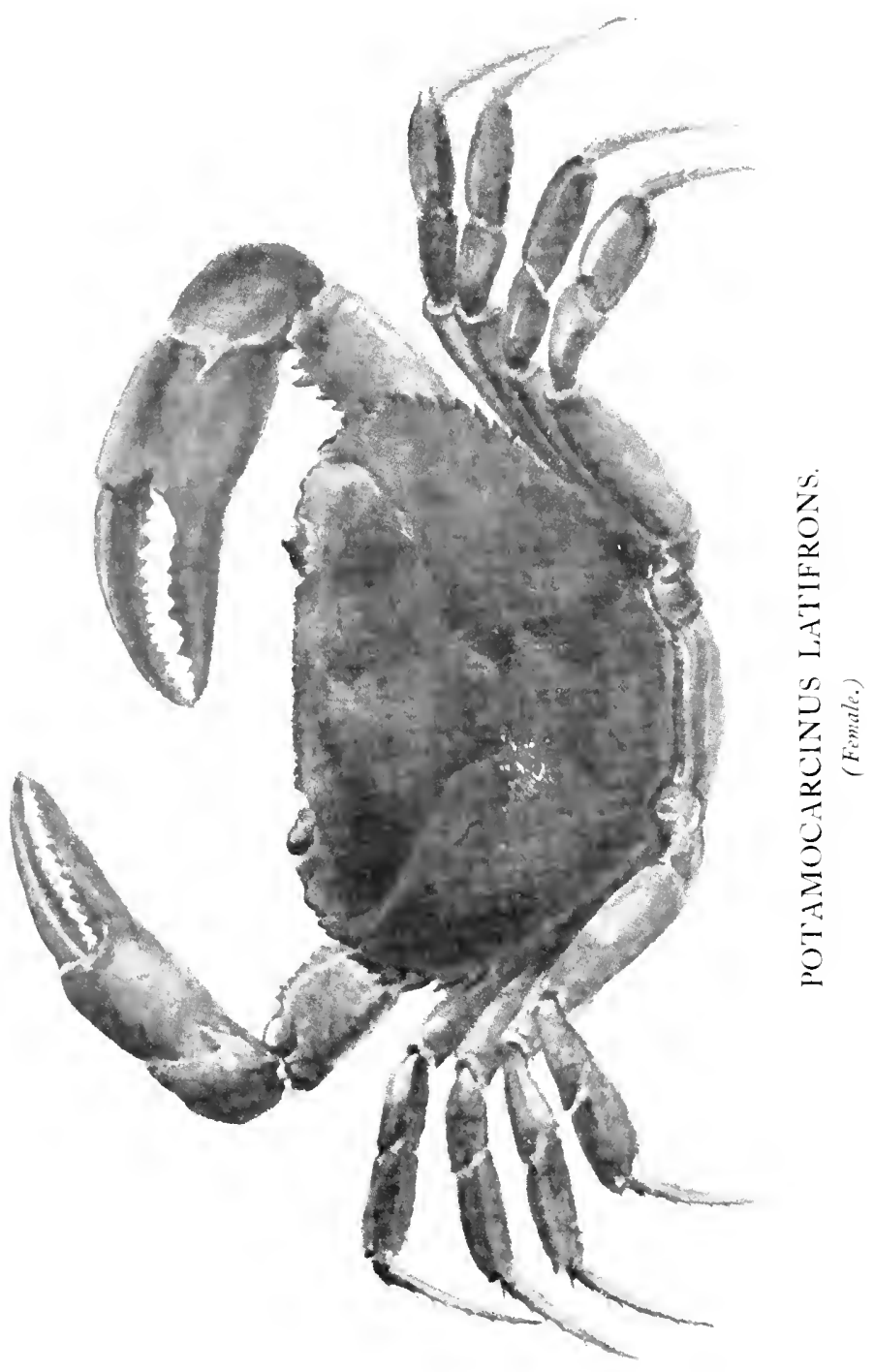


dages of first segment with extremity very large and vertically compressed.

Guatemala.

\section{Pseudothelphusa lamellifrons.}

Resembles Pseudothelphusa bocourti, except the abdomen of the male contracts at the fifth segment, and the sixth segment is longer than the seventh. The extremity of the appendage of the first segment is laminate, and folded and compressed laterally; the outer side has a blunt tooth pointing forward and outward, and the inner side has two lobes. Teeth on lateral edge very minute.

Mexico.

\section{Potamocarcinus.}

Potamocarcinus . H. Milne Edwards. M. J. Rathbun, Ortmann.

Kingsley $\alpha$. . . Ortmann.

Resembles the genus Pseudothelphusa. The superior frontal crest is sharp and lamellate, overhanging the front, which is rapidly retreating; the orbits are very deep, the margins above and below making deep semicircular incisions in the carapace, and having below two angular sinuses; the antero-lateral borders have strong spines.

\section{SyNopsis OF THE SPECIES.}

$A$. External appendage of the external maxillipedes reduced to a stump, being less than one-third the length of the third joint.-(P. latifrons.)

$B$. The external appendage of the external maxillipedes is more than one-third the length of the third joint. 
a. Carapace more than one and a half times as wide as long, including spines.-( P. nicuragucusis.)

b. Carapace less than one and a half times as wide as long, including spines.-(P. armatus.)

\section{Potamocarcinus latifrons.}

Potamocarimus latifions . . . Randall, Rathbun.

Potamocarinus schomburgkii .. White.

The carapace is flat, with the teeth of antero-lateral cdge sometimes bifid. The external appendage of the external maxillipedes is very short, being less than oncthird the length of the third joint. Colour brown.

RANGE.-British Guiana, Cayenne.

\section{Potamocarcinus nicaraguensis.}

Potamocarinus nicaraguensis . . . Rathbun.

The carapace is more than one and a half times as wide as long, including lateral spines, which are of same size, with some bifid. The length of the external appendage of the external maxillipedes is more than one-third the length of the third joint.

RiNGE.-Nicaragua, Costa Rica.

\section{Potamocarcinus armatus.}

Potamocarcinus armatus . Milne Edwards, Rathbun.

The carapace is less than one and a half times as wide as long, including lateral spines. The length of the external appendage of the external maxillipedes is more than one-third the length of the second joint.

RANGE.-Not known. 


\section{Epilobocera.}

Epilobocera. . Stimpson, M. J. Rathbun, Ortmann.

Opisthocera. . Smith.

Resembles the genus Potamocarcinus The internal suborbital lobe covers the external antenne, but does not exclude it from the orbit. The flagellum of the antennæ is situated in the internal canthus of the eye.

The fourth joint of the external maxillipedes is transverse, with the anterior margin rounded. The external appendage (exognath) is longer than the third joint.

There is a projecting process from the upper side of the expiratory canal.

\section{Sryopsis of tile Species.}

"A. Front without superior crest; exognath considerably overlapping fourth joint of external maxillipedes; spine of efferent channel narrow-(E.gilmanii.)

" $B$. Front with superior crest ; exognath slightly overlapping fourth joint of external maxillipedes; tooth of efferent channel short and broad.

" $a$. Fourth joint of external maxillipedes broad, its outer and anterior margin arcuate.

" $a$. Width of carapace varying from 1.56 times the length in small specimens to $1.6+$ times the length in large specimens.

$" a^{2}$. Anterior-lateral teeth spiniform.-(E. armata.)

$" b^{2}$. Antero-lateral teeth dentiform.-(E.cubcnsis.)

" 6 . Width of carapace of small specimens 1.7 times the length.-(E. granulato.)

" $b$. Fourth joint of external maxillipedes narrow, subquadrate, with an antero-external angle. 
" $c$. Inferior margin of front projecting beyond the superior.-(E. haytensis.)

" $d$. Inferior margin of front not projecting beyond the superior.-(E. simuatifrons.)"

M. J. RATHBUN.

\section{Epilobocera gilmanii.}

Epilobocera gilmanii . . .' M. J. Rathbun.

Opisthocera gilmaniz. . . Smith

The carapace is convex in two directions, and nearly smooth. The front, without superior crest, has a smooth margin, which is continuous with the upper margin of the orbits. The orbits are large, open, and shallow, with inferior margin sharp and minutely toothed. The anterolateral margin of the carapace is slightly denticulate anteriorly, but smooth posteriorly.

The external appendage of the external maxillipedes considerably overlaps the fourth joint. The spine of the efferent channel is narrow. The abdomen of the male is widest at the third segment.

RANGE.-Cuba.

\section{Epilobocera armata.}

Epilobocera armata . . Smith, Rathbun.

The carapace is flat, its width varying from 1.56 times the length in small specimens to 1.64 times the length in large specimens. The antero-lateral teeth are spiniform. The front has a superior crest.

The fourth joint of the external maxillipedes is broad, with its outer and anterior margin arcuate; the external 
appendage slightly overlaps it. The tooth of the efferent channel is short and broad.

RANGE.-Cuba.

3. Epilobocera cubensis.

Epilobocera cubensis . . Stimpson, Rathbun.

The carapace is flattened, its width varying from 1.56 times the length in small specimens to 1.64 times the length in large specimens. The antero-lateral teeth are dentiform. The front has a superior crest.

The fourth joint of the external maxillipedes is broad, with its outer and anterior margin arcuate; the external appendage slightly overlaps it. The tooth of the efferent channel is short and broad.

RANGE,-Cuba

\section{Epilobocera granulata.}

Efilobocora granulata. . . M. J. Rathbun.

In small specimens the width of the carapace is I.7 times the length. The front has a superior crest. The antero-lateral teeth are large.

The fourtli joint of the external maxillipedes is broad, with its outer and anterior margin arcuate; the external appendage slightly overlaps it. The tooth of the efferent channel is short and broad.

RANGE.-West Indies.

\section{Epilobocera haytensis.}

Epilobocora haytensis. . . M. J. Rathbun.

Carapace slightly convex, with the antero-lateral margins marked by small blunt teeth, irregular in size 
and shape. The front has a superior crest, with its inferior margin projecting beyond the superior.

The fourth joint of the external maxillipedes is narrow, subquadrate, with an antero-external angle; the external appendage slightly overlaps it. The tooth of the efferent channel is short and broad.

RangE.-Hayti, San Domingo.

\section{Epilobocera sinuatifrons.}

Epilobucera simatifrons. . A. Milne Edwards, M. J. Rathbun.

Carapace slightly convex. Front with a superior crest, with the inferior margin not projecting beyond the superior.

The fourth joint of the external maxillipedes is narrow, subquadrate, with an antero-external angle; the external appendage slightly overlaps it.

Range.-Porto Rico, Santa Cruz.

\section{Rathbunia.}

\section{Rathbunia . . . Nobili.}

Resembles the genus Pseudothelphusa, only the fourth joint of the external maxillipedes is very narrow posteriorly where it articulates with the outer half of the anterior margin of the third joint.

\section{Rathbunia festæ.}

Rathbunia feste. . . . Nobili.

The same as the genus.

RANGE,-United States of Colombia. 



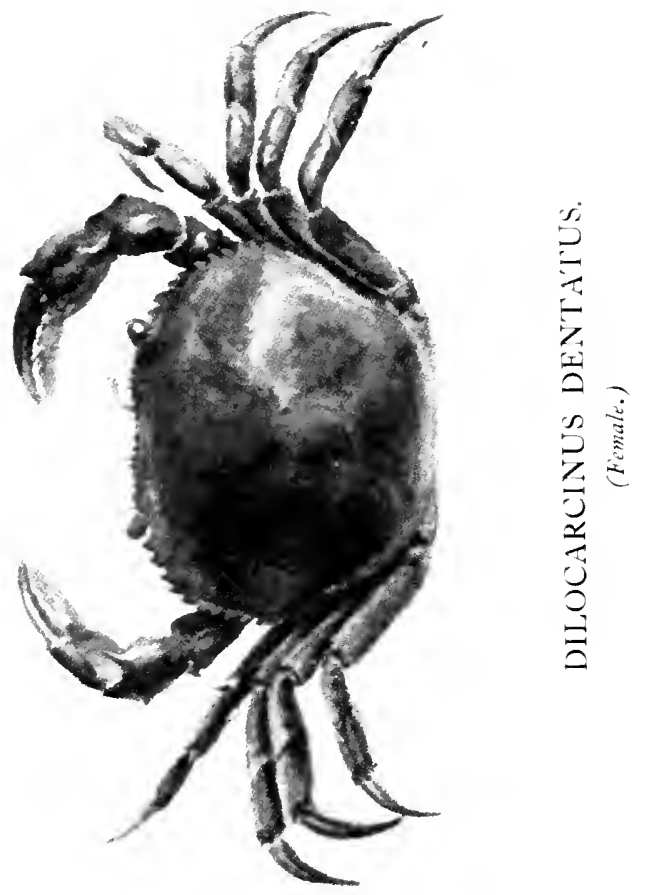




\section{Subfamily II. Trichodactylinæ.}

Trichodactyline . . . Rathbun, Ortmann.

Trichodactylus (genus). . I. Milne Edwards.

Carapace more or less rounded, very little transverse, about as broad as long. Front gradually sloping downwards, without superior ridge. The fourth joint of the external maxillipedes triangular, apex of triangle directed inwards; the fifth joint joining it at the upper angle. Terminal joint of walking legs without spines.

\section{Synopsis of the Genera.}

$A$. Eyes very small, diminishing in size at terminal half.

$a$. Carapace suborbicular; lateral teeth, when present, small, appressed. Lower margin of orbit and buccal ridge unarmed, or feebly tuberculate. Last joint of walking legs narrow, awl-shaped.-(Trichodactyluss.)

$B$. Eyes not diminishing in size towards their tip.

b. Surface of carapace uneven, often with a blunt ridge running transversely or obliquely across the branchial region. Lateral teeth dentate or spiniform. Lower margin of orbit tuberculate, with spines at inner angle. Buccal angle usually not armed. Last joint of last pair of walking legs flat, of the other pairs, styliform. -(Sylviocarcinus.)

c. Carapace very convex antero-posteriorly; lateral teeth spiniform. Lower margin of orbit and buccal angle usually armed with spines. Last joint of walking legs narrow, flat.-(Dilocarcinus.) 


\section{Trichodactylus.}

Trichodactylus . . H. Milne Edwards, A. Milne Edwards, Ortmann, Rathbun.

The carapace suborbicular; lateral teeth, when present, small, appressed. Lower margin of orbit and buccal angle unarmed or feebly tuberculate. Eyes very small, diminishing in size at terminal half. Last joint of walking legs narrow, awl-shaped, cylindrical, covered with a velvetlike down.

\section{Synopsis of the Species.}

A. Lateral border of carapace has five teeth, not counting the external orbital angle.-(T. quinquedentatus.)

$B$. Lateral border of carapace has four teeth, not counting the external orbital angle.--( $T$. dentatus.)

$C$. Lateral border of carapace has no teeth.-( $T$. quadratus.)

\section{Trichodactylus quinquedentatus.}

Trichodactylus quinquedentatus . . . Rathbun.

Carapace very convex longitudinally, slightly convex transversely. Surface smooth, shining, punctate, the puncte irregular in size and numerous. There is an $\mathrm{H}$ shaped depression in the centre of the carapace. The front consists of two broad lobes. External orbital angle obtuse. Lateral margin strongly bowed, armed with five teeth, besides the external orbital tooth, the first three sharp and spiniform, the last two blunt. Carapace widest at the fourth tooth. Frontal, orbital, and lateral margins ridged and smooth. Outer margin of fourth joint of 
external maxillipedes ridged, and strongly produced at its anterior angle.

The first pair of legs of the female unequal, punctate; fourth joint triangular, upper margin acute, with a tooth at the distal end; lower surface with a small sharp spine on the outer and the inner margin, and a blunt projection at the extremity of the outer margin; the fifth joint with a spine on the inner margin. Hands convex beneath, almost straight above; fingers in contact in both hands when closed. Walking legs very slender; fourth joint not dilated. Walking legs, fingers, and upper portion of hand and wrist covered with a close velvety down.

The abdomen of the female covering the sternum; last segment broadly triangular, rounded at the tip.

RANGE.-Nicaragua, found in an almost dry ditch near the Escondido River.

\section{Trichodactylus dentatus.}

Trichodactylus dentatus. H. Milne Edwards.

The front of the carapace is fecbly bilobed. Orbits small. The regions of the carapace well marked. The lateral borders of the carapace are armed with four teeth placed at some distance behind the external orbital angle.

RANGE--Brazil.

\section{Trichodactylus quadratus.}

Trichodactylus quadratus. H. Milne Edwards.

Trichodactylus fuviatilis. Latreille.

The carapace is smooth, with its iateral border slightly raised, without any teeth.

RANGE.-Brazil. 


\section{Sylviocarcinus.}

Sylaiocarcinus . . . Rathbun, H. Milne Edwards, Ortmann.

The carapace has an uneven surface, often with a blunt ridge running transversely or obliquely across the branchial region; lateral teeth dentate or spiniform. Eyes not diminishing in size towards their tips. Lower margin of orbit with a spine at inner angle; remainder of margin tuberculate. Buccal angle usually not armed. The last joint of the first three pairs of walking legs is styliform, thin, and quadrangular ; the last pair of walking legs is compressed, with the last joint flat but narrow; its border is hairy.

\section{Sylviocarcinus devillei.}

\section{Sylviocarcinus devillei . . H. Milne Edwards.}

Carapace slightly convex; regions not well marked; almost circular. The front, wide, advanced, almost horizontal, is divided into two rounded lobes, with a feebly tuberculated edge. The lateral borders have five teeth, not counting the external orbital angle; the last tooth is spiniform; the other teeth are more or less flat, with a broad base. The internal antenne are folded transverseiy into deep fosse. The antero-internal angle of the third joint of the external maxillipedes is produced; the next joint (the fourth) is triangular. The last joint of the last pair of legs is broader and flatter than the last joint of the other three pairs of walking legs, which is styliform.

RANGE,-Brazil. 


\section{Dilocarcinus.}

Dilocarcinus . Rathbun, Ortmann, H. Milne Edwards.

The carapace is very convex in an antero-posterior direction; lateral teeth spiniform. The lower margin of the orbit and the ridge at the angle of the buccal cavity are usually armed with spines. Eyes large, not diminishing in size at terminal half. Terminal joint of walking legs narrow, flat, with hairy borders.

\section{Synopsis of THE SPECIES.}

$A$. Lateral border of carapace has, counting the external orbital angle, four teeth.-(D. margaritifrons.)

$B$. Lateral border of carapace has, counting the external orbital angle, five teeth.-(D. emarginatus.)

a. One tooth on external buccal angle.-(D. spinifrons.)

b. Two teeth on external buccal angle.-(D.pictus.)

$C$. Lateral border of carapace has, counting the external orbital angle, seven teeth.

c. No teeth on external buccal angle.-(D. castelmani.)

d. Six teeth on external buccal angle.-(D. spinifer.)

$D$. Lateral border of carapace has, counting the external orbital angle, ten teeth. External buccal angle has about six teeth.--(D. dcntutus.)

\section{Dilocarcinus margaritifrons.}

\section{Dilocarcinus margaritifrons. . Ortmann.}

The front is cut into two rounded lobes, with pearllike tubercles on anterior margin.

The right hand is usually the largest ; the fourth joint 
is not armed with teeth; the fifth has three curved teeth on inner margin. The lateral borders of carapace, which is almost quadrilateral, is armed with four flat, equal sized teeth, counting the external orbital angle. The whole body and legs are covered with red ring-like spots. The abdomen of the male has six joints; the second to the fifth inclusive being soldered together; the third joint is the broadest.

RANGE.-Peru, British Guiana.

\section{Dilocarcinus emarginatus.}

Dilocarcinus emarginatus . H. Milne Edwards.

The carapace is almost horizontal; the front is flat, and two-lobed. The antero-lateral edges are flat, produced, and armed with five large obtuse tecth, counting the external orbital angle.

RANGE.-River Amazon.

\section{Dilocarcinus spinifrons.}

Dilocarcinus spinifrons . . J. S. Kingsley.

Carapace regularly arcuate, regions not indicated, lateral borders armed with four spines, excluding the spiniform external orbital angle; the margins of the spines serrate. Superior orbital margin crenulate, inferior denticulate, with a strong spine near interior angle. front prominent, armed with about fourteen spines. A spine at antero-lateral angles of buccal area.

First pair of legs subequal; fourth joint with two spines about the middle of posterior margin, a single spine opposite on anterior margin, and a spine on distal portion of upper margin; carpus has a spine on interior surface; 
hand has a spine above articulation of movable finger; finger finely toothed.

RANGE.-Upper Amazon.

\section{Dilocarcinus pictus.}

Dilocurcinus pictus . . A. Milne Edwards, H. Milne Edwards.

The carapace is almost square, and is covered with small red spots. Front slightly sloping, two-lobed. Antero-lateral border armed with five very sharp spiniform tecth, counting the external orbital angle. The lower orbital border has strong teeth, of which the two or three internal are very strong. The anterolateral angles of the buccal cavity have two spiniform tecth.

The two torminal joints of the walking legs have thick cilia on both edges. The third to sixth segment, inclusive, of the abdomen of female are soldered together; it is broad in the middle, and the margins are convex.

Range.-Peru, River Amazon.

\section{Dilocarcinus castelmani.}

Dilocarcinus castclmani. Milne Edwards.

The antero-lateral border has seven spines, counting the external orbital angle. The suborbital spines are sharp. The ridge at the antero-external angle of the buccal cavity has no spines.

Resembles D. pictus.

RANGE.-Brazil. 


\section{Dilocarcinus spinifer.}

Dilocarinus spinifer. H. Milne Edwards.

The carapace is curved above, almost circular; the regions are well marked; the genital and cardiac lobes have small lobes anteriorly, on their anterior border. The antero-lateral borders have seven very sharp teeth, counting the external orbital angle. The front is wide, flat, almost horizontal, feebly two-lobed. The orbits are directed forwards; the superior border is entire; the inferior has eight or ten sharp and pointed teeth. On the epistome there is another row of six pointed teeth. The fourth joint of the largest hand has one or two teeth on its anterior border. The fifth joint has one tooth on its inner border.

RANGE.-Dutch Guiana.

\section{Dilocarcinus dentatus.}

Dilocarcinus dentatus . . . Randali.

Dilocarcinus multidentatus. Von Martens.

Ecta crab (local name). . . Berbice.

The carapace is much curved from before backwards, with the regions slightly marked; antero-lateral borders cut into ten teeth, counting the external orbital angle; sometimes there are nine teeth on one side and eleven on the other. The teeth are flat and of about equal size, with their points dirccted forwards; the front is cut into two slightly bent down, flat lobes, the edge of each lobe having about eight small tubercles. The superior orbital border has no teeth, but may be slightly notched in the centre by an indistinct fissure; the lower orbital border has eight or nine rounded teeth, those on the inner side 



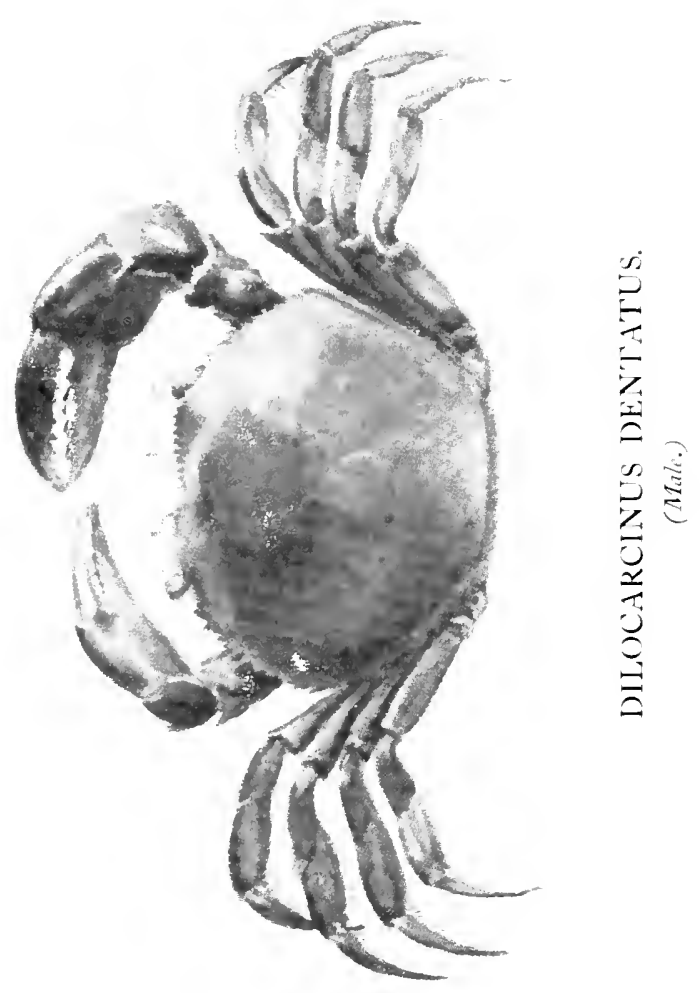


being the largest. There is a notch in the centre of the superior border of the buccal margin; this border is continued to the anterior external angle of the buccal cavity in an S-shaped ridge, which is, over the external angle, cut into six little rounded teeth; from the centre of these teeth there is a raised narrow margin to the sides of the buccal cavity.

The abdomen is six-jointed in both sexes; that of the female is broadest at the junction of the third and fourth joint; that of the male is broadest at the posterior margin of the third joint.

The colour of the male is a magenta-red; of the female, an olive-green.

RANGe.-Venezuela, Berbice.

\section{Family II. Geocarcinidæ.}
Geocarcindec . . . Miers.
Gecarcinida. . . . . Dana.
Gécarcinicns. . . . H. Milne Edwards.

Carapace dorsally very convex, and especially dilated over and in front of the branchial regions, with the anterolaterai margins usually entire and very strongly arcuate, the front of moderate width and strongly deflexed. Orbits and eye-peduncles of moderate size. The fifth joint of the external maxillipedes is sometimes inserted at the anteroexternal angle of the fourth joint, sometimes at the apex or near its antero-internal angle, or it may be inserted behind, on its internal face, and so be completely concealed in a front view. The legs of the first pair in the adult male are very robust, usually of unequal size. The last joint of the walking legs is nearly always granulated, and armed with spines disposed in tongitudinal series. 
The members of this family are the land-crabs, properly so called. They usually live in holes in the ground, made by themselves either in the damp mud on the water edge, or in dry banks a long way from water. They make the hole by forcing the four walking legs on the side opposite the large hand into the ground, and, by keeping those legs together, forming a scoop, they walk out of the hole by the aid of their other four walking legs and carry out all that the scoop formed by the first mentioned legs holds.

When the ground so excavated becomes heaped up at the mouth of the tumnel they flatten it by sitting on the top of the heap and moving the first pair of legs from them, so pushing the accumulation of earth away. They appear to notice the approach of strangers by the vibrations of the ground.

SYMOPSIS OF THE GENERA.

A. The fifth and following joints of the external maxillipedes are completely hid behind the fourth joint.-(Giocarcinus.)

b. The fifth and following joints of the

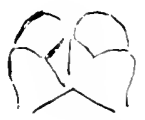

ciogutinus. external maxillipedes are not hid behind the fourth joint.

a. The fifth joint of the external maxillipedes is inserted in a deep notch in the summit of the fourth joint.-(Gccarcoidca.)

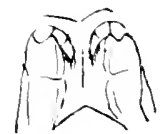

Gecarioider.

b. The fifth joint of the external maxillipedes is inserted at the external angle of the fourth joint.

$b^{2}$. The thind and fourth joint of the external maxillipedes do not close completely the buccal carity, but leave a rhomboidal space between their internal / edges.-(Cardiosoma.)

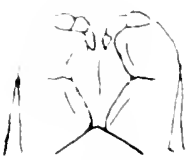

Cardiosoma. 
$c^{1}$. The third and fourth joints of the external maxillipedes close completely the buccal cavity, and have no rhomboidal space between their internal edges.- $(U c a$. $)$

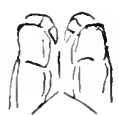

tia.

\section{Geocarcinus.}

Geocarcinus Leach, II. Milne Edwards, Miers.

Carapace with the mesogastric and cervical sutures strongly defined. The antero-lateral margins not distinctly dentated. The front is narrow, anteriorly truncated, nearly reaches the anterior margin of the buccal cavity, and almost completely covers the internal antenna. Orbits with the superior margin subentire, no distinct tooth at the exterior angle, and with a well-marked hiatus in the inferior margin, near the interior subocular lobe, which is in contact with the front, and excludes the short antenne from the orbit. The eyes are set on rather short, thick pedicles.

The antennæe are very short, and occupy the angle formed by the contact of the inner subocular lobe of the orbit with the front; their basal joint is slightly dilated and does not reach the frontal margin. No distinct ridges are developed upon the endostome or palate. The external maxillipedes bulge out externally, and inclose a lozenge-shaped interspace; third and fourth joint are broad; the third joint is not produced at the antero-internal angle; the fourth is distally rounded and conceals the next joints, it has sometimes a fissure in the antero-lateral margin; the fifth joint is articulated to it on its inner surface. The first pair of legs of the adult male is considerably developed, and usually unequal; fourth joint trigonous and somewhat elongated; fifth 
without spine on the interior margin; palm rounded above; fingers distally acute, and dentated on the inner margins. The walking legs are robust and somewhat elongated, with the two terminal joints, and sometimes the three last joints, compressed, and armed with spinules in longitudinal series.

RANGE.-West Indian Islands, California to Brazil, Australasia, Cape of Good Hope, West Africa, Island of Ascension.

\section{Sy NOPSIS OF THE SPECIES.}

$A$. No fissure or notch on the internal border of the fourth joint of the external maxillipedes.

a. Terminal joint of walking legs armed with four rows of spines.-(G. lateralis.)

b. Terminal joint of walking legs armed with six rows of spines.- (G. muricola.)

$B$. A fissure on the internal border of the fourth joint of external maxillipedes.

c. Terminal joint of walking legs armed with four rows of spines.

$c^{1}$. Fourth joint of external maxillipedes oval.--(G. depressus.)

d. Terminal joint of walking legs armed with six rows of spines.

$d^{1}$. Fourth joint of external maxillipedes subquadrate. $-(G$. planatus.)

$c^{1}$. Fourth joint of external maxillipedes subtriangular with very rounded angles (except posterior external).(G. lagostoma.) 


\section{Geocarcinus lateralis.}

Geocarcime lateralis . . Freminville, H. Milne Edwards, Guérin.

Internal edge of fourth joint of external maxillipedes without notch or fissure. No teeth upon the fifth joint of the first pair of legs; the terminal joint of the walking legs has four rows of spines. Abdomen sevenjointed in both sexes. In male-first and second joints broadest, triangular. In female-broadest at junction of fourth with fifth joint, oval. The carapace has a dense black-violet patch with a lobe on its posterior margin on the centre of the carapace, leaving a narrow margin of red at circumference. The first four joints of the first pair of legs are violet-red; the hands red; the walking legs and the under surface are yellow washed with red.

RANGE.-West Indian Islands. Common in Barbados, where it makes holes in the dry banks some distance from the sea. Key Biscayne, Tortugas.

\section{Geocarcinus ruricola.}

Gcocarcinus ruricola . . H. Milne Edwards, Latreille, Lamarck, Desmarest.

Cancer terestris . . . . Seba, Sloane.

Crabe riolet. . . . . Labat.

Black or Mountain crab. Brown

Mango crab (local name). Barbados.

Cancer ruricola . . . . Linné Fabricius, Herbst.

Ocypoda ruricola. . . . Latreille, Bosc.

Carapace very wide. Internal border of fourth joint of the external maxillipedes without fissure or notch. There are some teeth on the internal border of fifth joint 
of the first pair of legs. The last joint of the walking legs is armed with six rows of spines. The carapace is blotched with violet-red. The general colour is yellow washed with red.

RANGE--West Indian Islands, Florida, Key Biscayne, Hayti. They are found in Barbados, but they are not very common.

\section{Geocarcinus deṕressus.}

Gcocarcinus depressus . . . Saussure.

Carapace subcircular, slightly or not truncated upon the postero-lateral faces, very flat and depressed, only being prominent upon the gastric region; the edges have a decided crest, but cccupies only the anterior part, and is very advanced near the edge, beside which it forms a small tooth. Behind the external orbital angle there is a small depression. The front is vertical. The anterior border of the carapace, between the two external orbital angles, is wider than the half of the carapace. It is not smooth, but finely striated, subscaly; its lateral faces finely and densely plaited, and having the pterygostomian regions covered with scaly folds. The internal suborbital lobes are very narrow, almost prismatic, having a strong, oblique, and very prominent ridge which divides the inferior angle of the front.

The fourth joint of the external maxillipedes is oval, much less wide than the third, but not retracted in front, and very little behind; its anterior border is notched; the internal slightly bowed.

The first pair of legs of equal size ; the fifth joint has a tooth at its internal angle, and below this a smaller tooth. The fourth joint of the walking legs has no spines above, and the last joint has four rows of spines. 
The colour is yellow, with the front of the carapace and the anterior legs red.

RANGE.-West Indies, Hayti.

\section{Geocarcinus planatus.}

Geocarcinus planatus . . . Stimpson.

Body depressed, carpace broad, flattened about the middle and posteriorly; median and lateral furrows of gastric region well marked, the median one deep; longitudinal furrows of branchial region, near gastric, obsolete; transverse cardiac furrow deep; no furrow separating genital region from the gastric. Hepatic and anterior part of gastric regions granulated. Frontal margin thin and denticulated; not dilated within to the antennulary fossæ. Fourth joint of external maxillipedes subquadrate, with a very deep notch on its antero-interior margin. The first pair of legs small; fifth joint armed with small spines on the inner margin. Walking legs of moderate length, very spinous towards their extremities; terminal joint with six rows of spines.

Range.-Todos Santos, near Cape St. Lucas, Lower California.

\section{Geocarcinus lagostoma.}

Gcocarcinus lagostoma. . . H. Milne Edwards.

Carapace is not so wide as that of G. murcola; anterolateral borders with a pronounced ridge near the external orbital angle. The regions are well marked, the gastric region being broad. The margin of the branchial lobes have a scaly appearance. The external maxillipedes have their fourth joint more or less triangular, with the anterior 
angle rounded. The internal border is notched below the insertion of the fifth joint, and this border is prominent below the notch. The first pair of legs of the female subequal, with a few fine, small teeth on the inner border of the fifth joint. The walking legs have spines on the two last joints, arranged in six rows on the terminal joint.

RANGE.-Australasia to the Cape of Good Hope, West Africa, Ascension Island, Bermuda.

This description is taken from a picture of a female published in the Challenger Reports by Mr. Miers.

\section{Gecarcoidea.}

\section{Gecarcoidica Pclocarcinus . . H. Milne Edwards.}

The carapace is more oval and less elevated than in Cardiosoma. The front is of moderate length, straight, and very sloping; the antennulary fosse are round, and separated from the front by a small triangular prolongation.

The orbits are small, and their inferior border is much more prominent than in Cardiosoma, and has between its internal angle and the external antenna a wide and deep notch. The buccal cavity is not so clearly defined as usual, and is more circular than square.

The external maxillipedes have between them a large space; their fourth joint, much less large than the third, is almost quachilateral, slightly or not at all contracted behind, and deeply notched on its anterior border, in the middle of which is inserted the fifth joint, which is exposed. 


\section{Gecarcoidea lalandii.}

\section{$\left.\begin{array}{l}\text { Gecaroidea lalandii } \\ \text { Pelocarcinus lalandii }\end{array}\right\}$. . H. Milne Edwards.}

Carapace oval, and without crest upon the lateral borders.

The first pair of legs strong; pincers large, cylindrical, tuberculous; the fingers are in contact through their whole length when closed; anterior border of the fourth joint nodulous. The walking legs are toothed on their edges ; those of the third pair are the longest. The last, terminal, joint has six rows of spines. The colour is a red-brown.

RANGE.-Brazil.

\section{Cardiosoma.}

Cardiosoma . . Latreille, H. Milne Edwards, Miers, S. J. Smith.

Cancer. . . Linné.

Ocypoda . . Latreille.

Gecarcinus . . Latreille, Desmarest.

Carapace transverse, elevated, and sometimes very convex anteriorly; with the branchial regions anterolaterally convex, and very greatly developed. The anterolateral margins are sometimes armed with a small tooth placed at a short distance from that at the external angle of the orbit. Front deflexed, and usually broader than Geocarcinus; it ncarly reaches the anterior margin of the buccal cavity, and conceals, in part, the antennules. Orbits large and widely open, with the margins entire; the interior subocular lobe is separated by a wide hiatus from the frontal margin, and this hiatus is occupied by 
the antennæ. Eye-peduncles of moderate size and thickness; they do not nearly fill the orbital cavities. The basal antennal joint is short and somewhat dilated, and does not usually quite reach the frontal margin; the flagellum is very short. The endostome is without distinct longitudinal ridges. The external maxillipedes do not meet along their inner margins, but enclose a lozengeshaped interspace; the third and fourth joints are rather broad and truncated; the fourth even rather concave at its distal extremity; the fifth joint articulates with the fourth at its antero-external angle.

The first pair of legs usually unequal, the larger one sometimes enormously developed; the fourth joint is more or less trigonous; the fifth usually with a spine on its inner margin; palm often shorter than the fingers, which are more or less distinctly dentate on their inner margins.

Walking legs robust and more or less elongated; the fourth joint with the superior margins acute, and armed with a subterminal spine. The last joint is armed with spines in a longitudinal series. Abdomen sevenjointed in both sexes.

RANGE-A land-crab found in tropical and subtropical countries in both hemispheres.

\section{Synopsis of TIIE SPECIES.}

A. Antero-lateral marginal line on maximum transverse curve of antero-lateral border of carapace.

a. Fourth joint of first pair of legs, and palm of hand, smooth.-(C. carnifex.)

b. Fourth joint of first pair of legs with spines; palm of hand granulated.--(C. armatum.)

$B$. Antero-lateral marginal line does not indicate 
maximum transverse curve of marginal border of carapace.

c. Walking legs with scattered short black hairs.(C.gucruhmmi.)

d. Walking legs have long black hairs.-(C. cressum.)

\section{Cardiosoma carnifex.}

Cardiosoma camifor . . . Herbst, Latreille, Milne Edwards, De Haan.

Cardiosoma obcssum) Cardiosoma hertipes!. . Dana.

Cardiosoma urillei. . . . Milne Edwards.

Cancer camifer . . . . Herbst.

Ocypoda cerdata. . . . . Latreille.

Gecarcinus hertipes . . . Lamarck.

Gecarcinus carnifer. . . . Latreille, Desmarest.

Cancer hydromus (?) . . . Herbst.

Carapace very elevated; its surface very curved from before backwards, but almost flat from side to side; its lateral edges are marked by a prominent and raised line. There is a small tooth behind the external orbital angle. The first pair of legs is unequal in the male and female, but more marked in the former, with the fourth joint and the palm of hand smooth. The hand is very broad, and the fingers touch in almost their entire length when closed. The last joint of the walking legs has four rows of spines; the spines in the two under rows are few in number.

Range.--Oriental Region, Pondicherry, Fiji, Tahiti, Admiralty Islands. 


\section{Cardiosoma armatum.}

Cirdiosoma armatum . Herklots, Milne Edwards, De Haan.

Resembles Cardiosoma carnifex; only the fourth joint of the first pair of legs has many spines; the palm of the hand is granulated.

RANGE.-Cape Verde Islands.

\section{Cardiosoma guanhumi.}

Cardiosoma guanhumi. . . Latreille, H. Milne Edwards, S. I. Smith, Gibbes, Saussure.

Cardiosona diurnum . . . Gill, Smith.

Cardiosoma quadratum. . . Saussure.

Cancer guanhumi. . . . . Margraff.

Crabe blane. . . . . . . Labat.

Bundory crab (local name) . Berbice.

White crab (local name) . Barbados.

Ocypoda gigantea $\}$. . . Freminville.

The colour is a uniform blue-green; in the Barbados specimen, yellowish below.

Carapace, much swollen laterally, is prolonged beyond the line indicating the antero-lateral border, which is indistinct. The tooth, placed at the external orbital angle, very small or only indicated.

First pair of legs long; the largest on either side, usually the left. The hand very large in the male, sometimes as large as the body ; fingers very curved, and meeting at their extremity only when closed; the last joint of 
the walking legs armed with four rows of spines. Hairs on legs short and in tufts.

The abdomen of the male is broadest at the third segment, narrowing to the sixth, which is longer than broad. The last segment is narrow, with a rounded end. The first pair of abdominal appendages reach to the middle of the sixth segment, are triquetal, straight, and stout; their tips are rounded and slightly flattened laterally, and each has a very small, scale-like appendage directed obliquely outward, and on the upper edge, just beyond this appendage, there is a small, straight process, which does not reach beyond the rounded extremity of the thickened portion. These appendages spring from a bony arch under which the intestine passes.

Range. - West Indies, Barbados, Jamaica, Cuba, Hayti, Bermuda, Florida, Mexico, British Guiana ; Berbice, Brazil, Cape Vercle Islands.

\section{Cardiosoma cressum.}

Cardiosona cressum . . . . Smith.

Cardiosoma latimamis . . . Lockington.

Cardiosoma barbatus (?) . . . H. Milne Edwards, Poeppeg.

The regions on the carapace are not well marked. The front is broad and high, and the epigastric lobes are prominent, leaving between them and the front a depressed space, which is thickly covered with coarse granules. The lateral angle of the orbit projects forward as an angular tooth. Just behind this tooth the antero-lateral margin is broken by a sharp notch, above which the carina of the lateral margin begins in a sharp prominence. This carina through its length is 
very high and distinct. The inferior branchial regions are naked, but roughened with numerous short, sharp rugx.

The first pair of legs is of unequal size in both sexes. In the large limb the fourth joint is triquetal, very stout, and reaches slightly beyond the margin of the carapace; the anterior surface is flat, and both its margins are armed with very large and prominent tubercles directed forwards; on the outer surface and the posterior angle, which is obtuse, there are short granulous rugre, which are very conspicuous on the angle. The larger hand is very large and stout; the fingers are very stout, with the outer edge; armed with small, horny tubercles; the prehensile edges gape but slightly, and are armed with large, irregular teeth. The walking legs are stout, with the fifth and sixth joints and the lower anterior angle of the fourth clothed with long black hairs.

In the male the abdomen is broadest at the third segment, then triangular; in the female, at the fifth and sixth joint. The first pair of male abdominal appendages has a long, slender horny tip curved in a spiral.

RANGE.- IVest Coast of America, Lower California, Chili.

\section{Uca.}

$U_{c a}$. . . Leach, H. Milne Edwards.

Cancer . . Herbst.

Gecarcinus . . Latreille, Desmarest.

The carapace is wider than long, oval, and very elevated; very curved from before backwards. The front is narrower than in the other Gcocarcinide; very sloped and almost semicircular. The orbits are very 
large, and their floor slopes outwards and downwards. The antenuulary fosse are oval, small, and clivided by a small triangular prolongation of the epistome. The external antenne occupy the internal canthus of the orbit. The buccal cavity is rhomboid in form. The third and the fourth joint of the external maxillipedes are quadrilateral, almost of the same size, and their internal border forms a straight line, so that, when in place, there is no lozenge-shaped space between them; the fifth joint is articulated at the external angle of the fourth, and rests, exposed, upon its anterior border. The fingers of the first pair of legs are broad, and their tips slightly excavated. Of the walking legs, the terminal joint is compressed and without spines.

RAnGE.-Tropical America, West Indies.

\section{SyNOPSIS OF THE SPECIES.}

A. A prominent ridge on the antero-lateral borders of the carapace.

a. Pterygostomian regions granular.

I. Under border of walking legs with long, close, black-brown hairs. Notch in last joint but one of abdomen of female to receive terminal joint, not so deep as length of last joint- $U$. cordata.)

2. Under border of walking legs with only three or four scattered hairs. Notch in last joint but one of abdomen of female to receive terminal joint as deep or deeper than length of last joint.- $(U . u n \alpha$.)

$B$. Antero-lateral borders of carapace scarcely indicated.

b. Pterygostomian region smooth.-(U. levis. 


\section{Uca cordata.}

Uar cordata

Cancor cordutus.

Cancer uca

Uar lavis (?).

N'on uaca una.

liuck crab, Common crabl
S. I. Sinith.

Linné, llerbst.

Linné (?)

Dana (?)

Guérin.

- Berbice.

The carapace is entirely naked and perfectly smooth above, very broad, the greatest breadth being much anterior to the midule. The regions are well marked. The whole front is bordered by a sharply raised margin. The antero-lateral border is indicated by a prominent, finely toothed ridge. The orbits have an hiatus at the external angle covered by a rounded lobe; the inferior margin is nearly straight, and is formed of two nearly parallel ridges, the inferior of which is armed with a line of small tubercles, and the superior is irregularly granular. The inferior orbital regions are smooth, and are separated from the buccal area by deep sulci. The inferior lateral regions are swollen and nearly smooth, there being only scattered granules on the anterior portion near the inferior orbital regions. On each side of the buccal area there is a high ridge which is armed with a few small tubercles.

The external maxillipedes are smooth and naked on the outside, and the inner edge thickly clothed with coarse hairs.

The first pair of legs unequal and large; the fourth joint is stout, triangular; both the inferior angles are armed with stout spines, and the superior angle is granular; the fifth joint is broad, smooth, and evenly 
rounded on the outside, and spinous along the inner edge and on the anterior edge beneath; the hand is broad, compressed, spinous on the superior margin and on the inside; the inferior margin is granulous, and the outer side is smooth; the fingers are high and compressed, their tips incurved, and the inner edges slightly separated in the middle, and armed with small, irregular teeth except at their tips, which are slightly spoon-shaped, with the edges horny, continuous, and sharp. The walking legs are smooth and naked above, but all the segments in the first three pairs, except the basal ones, are thickly clothed beneath and on the anterior side with very long coarse hair. Those of the anterior pair are longer than the others, and those of the posterior pair are much shorter than the others, and but slightly hairy. The terminal joint of the first two pairs are very long and stout, slightly curved downward, their extremities compressed vertically and five-sided, with the angles sharp; those of the third pair are much shorter, and curved backward as well as downward; those of the posterior pair are still shorter, strongly curved backward and six-sided, the superior side being much broader than the others.

The sternum is narrow, very convex in an anteroposterior direction, and the depression for the lodgment of the abdomen is broad, very deep, and extends quite to the base of the external maxillipedes. The male abdomen is broadest at the third segment; the second segment is very small, and the two segments which precede it arc completely coalesced. The appendages of the first segment are triquetal, very stout, and extend to the extremity of the last joint but one. The appendages of the second segment are very small, extending scarcely beyond the third segment. In the female the abdomen is broadest at about the centre of the fifth segment; the 
articulation, with the sixth is at the expense of the anterior border of the fifth segment, the antero-posterior depth of the fifth being much less than that of its margins; the seventh joint is small and oval, and is let into a notch in the sixth segment to about the level of a half its antero-posterior diameter.

The colour of the carapace is a dirty yellow, with a yellow green centre and anterior margin, the blending of the two colours being gradual; the legs are purple; the first pair of legs are also purple, but the purple is only on the upper margin of the palm, the remaining portion and the under surface of the body being a dirty yellow.

RANGE,-British Guiana, Surinam, Para, Bahia; plentiful along the banks of the Berbice River.

\section{Uca una.}

Uic una . . . . . Margrave, H. Milne Edwards, Seba, Latreille, Guérin.

Cancer wa $\}$ ? . Linné.

Ocypoda cordatir. . . Latreille.

Gecarcimus uca . . . Lamarck.

Resembles Uca cordata, except the smooth suborbital space is better defined; the pterygostomian regions round this smooth space is thickly covered with equal-sized pearl-like tubercles. The entire inner surface of the first pair of legs is spiny, that is, of the fourth and fifth joints and of the palm of the hand and inner face of the fingers. The under surface of the walking legs have very few hairs, some of the joints none: their terminal joint is very short and subequal. The broadest part of 



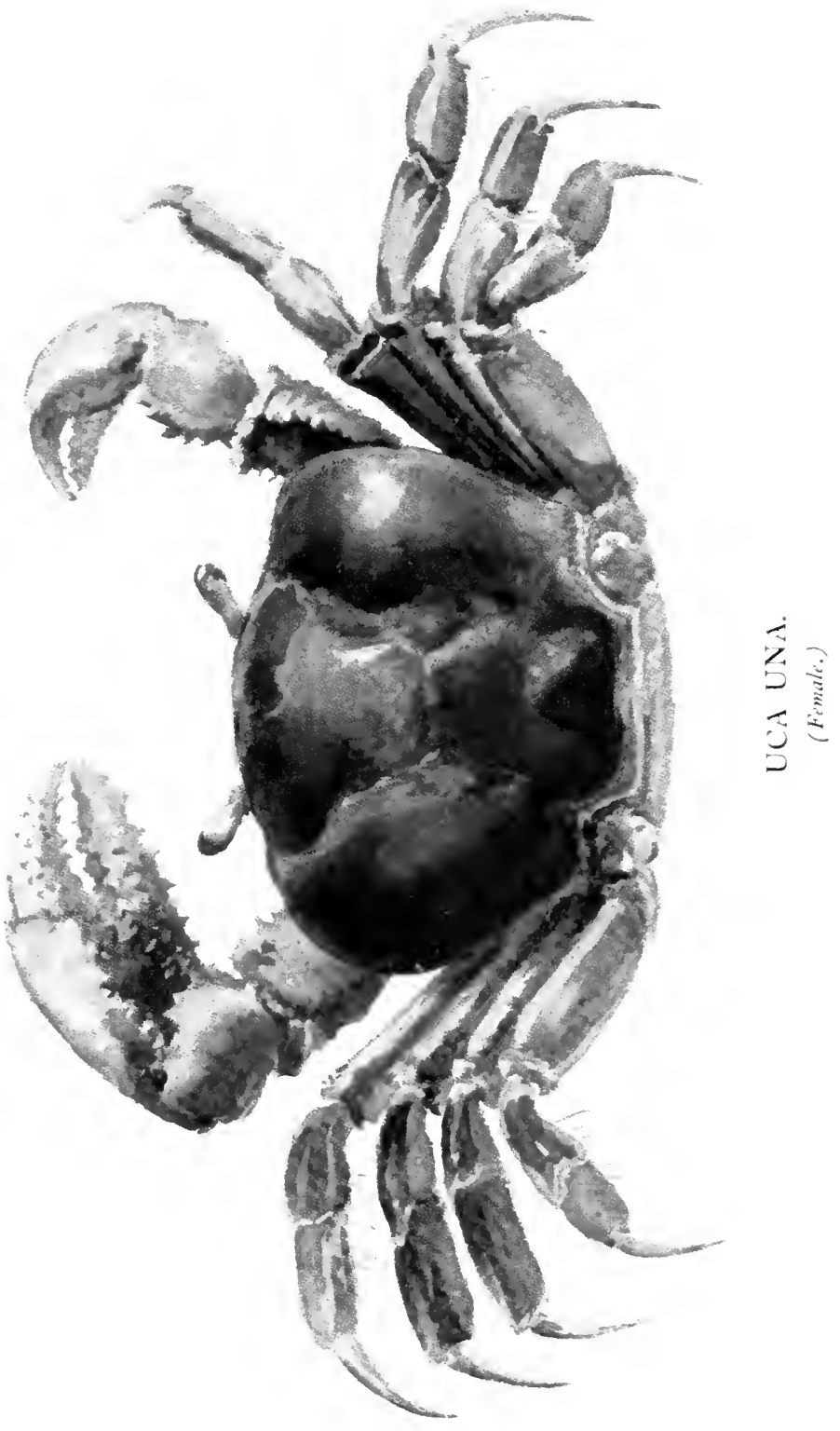


the abdomen of the female is the base of the fifth segment. This organ terminates not in the seventh joint, but in the two lateral lobes of the sixth segment, between which the seventh segment is set; the seventh segment is small and oval. The abdomen of the female covers completely the entire under surface of the body, except the anterior three-fourth of the external maxillipedes and the basal joint of the legs.

The colour of the entire upper surface of the carapace is green, with the warts or teeth in the antero-lateral margin purple. The under surface is dirty yellow-green marbled with green of the same shade as that of the carapace. The walking legs, the joint of the first pair of legs, and the entire hand and fingers, except the under margin and the back of the palm and the fingers, which are a dirty white, are coloured dark purple. The small warts ornamenting the border on the superior and outer margin are also of the same shade of purple. The hairs are brown.

RANGE.-West Indian Islands, Central America, Rio de Janeiro.

\section{Uca lævis.}

Uca lavis . . . H. Milne Edwards.

Lateral border of the carapace scarcely indicated. Pterygostomian regions smooth. First pair of legs of the male very large; the fourth joint and the hand are very long, and are covered with wart-like elevations; the legs of the second pair are a little longer than the others.

RANGE.-West Indies. 


\section{Family III. Ocypodidæ.}
$\left.\begin{array}{l}\text { Ocypodiens } \\ \text { Ocypodiacere (part) }\end{array}\right\}$
H. Milne Edwards.
Ocypodide
Miers, Kingsley.
Ocypodar.
Fabricius, Latreille, Leach, Lamarck, Desmarest.
Cancer . . . . . Linné.
Macrophthalmide(part) Dana.

Carapace usually moderately convex, cancroid or trapezoidal, with the antero-lateral margins straight or arcuated, but the branchial regions not greatly dilated; the front of moderate width or very narrow. Orbits and eye-peduncles sometimes of moderate size, sometimes very greatly developed. The fifth joint of the external maxillipedes articulates with the fourth at its anterointernal or, rarely, at its antero-cxternal angle. The first pair of legs in the male is usually of moderate size, sometimes rather slender and very considerably elongated; the terminal joint of the walking legs is styliform, and not armed with strong spines. The abdomen does not always hide the sternum at the base between the base of the last pair of legs. Usually found on the shore or in shallow water, but may live in deep water.

\section{Subfamily I. Carcinoplacinæ. Subfamily II. Ocypodinæ.}

Srmorsis of the Subfamilies.

$A$. Carapace transverse, with antero-lateral margins bowed; frontal region of moderate width; orbits small. The fifth joint of the external maxillipedes articulates usually at the antero-internal angle of the fourth joint.-(Carcinoplacine.)

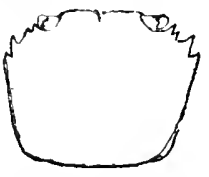

Carcinoplacine. 
$B$. Carapace transverse, trapezoid or quadrate, with the lateral margins straight; front narrow or of moderate width; orbits considerably developed. The fifth joint of the external maxillipedes usually articulates at the antero-external angle of the fourth joint.-(Ocypodine.)

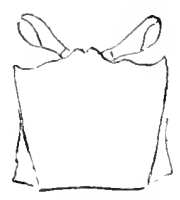

Oiypotina.

\section{Subfamily I. Carcinoplacinæ.}

Carcinoplacine. . Miers.

Carapace transverse, usualiy convex, and more or less cancroid in form, with the antero-lateral margins arcuated, spinose or dentated, rarely entire. Frontal region usually of moderate width; orbits rather small. The fifth joint of the external maxillipedes articulates at the antero-internal angle of the fourth. First pair of legs, in the adult male, usually subequal, sometimes considerably elongated; the walking legs moderately slender, with their last joint styliform, sometimes compressed. The abdomen of the male, at the base, usually covers the whole width of the sternum between the base of the last pair of legs.

\section{Section I. Euryplacinæ. \\ Section II. Carcinoplacinæ.}

Synopsis of time Sections AND the Genera.

I. The abdomen of the male does not completely corer the sternum at the base.-(Sect. Euryplacina.)

I. The anterior corners of the last sternal segment only are exposed at the sides of the male abdomen.(Euryplax.)

2. A large part of the last sternal segment is exposed at the sides of the male abdomen.-(Speocarcinus.) 
II. The abdomen of the male completely conceals the sternum at the base.-(Sect. Carcinoplacina.)

3. Ocular peduncles short and robust.-(Goryon.)

4. Ocular peduncles elongated.-(Frevillea.)

5. Ocular peduncles small, and without cornea.(Bathyplax.)

\section{Section I. Euryplacinæ.}

$$
\begin{aligned}
& \text { Eurylacince. . . . Stimpson, Miers. } \\
& \text { Eucratopsinc. . . . Stimpson. }
\end{aligned}
$$

The antero-lateral margins of the carapace are dentate or spinose; the abdomen in the male does not entirely cover the sternum at the base.

\section{Euryplax.}

\section{Euryplax. . . . Stimpson.}

Carapace broad; antero-lateral margin very short, dentate; facial region of less width than the carapace; front nearly half as broad as the carapace; ocular peduncles of moderate length; external antennæ excluded from the orbit by the internal suborbital lobe, which joins the front. External maxillipedes with the fifth joint articulated to the short fourth joint at its truncated inner angle. Palate with a distinct ridge on each side defining the efferent channel. First pair of legs large and thick; a circular pit on the front side of its fourth joint near its extremity. Walking feet compressed; terminal joint of posterior pair short and compressed.

Verges of the male arising from the coxæ of the posterior feet, and passing to the abdominal appendages through canals in the sternum. Basal joints of the 
abdomen almost entirely covering the seventh joint of the sternum, a portion of which, however, is exposed on each side at the lateral sinuses of the abdomen, which occur between its second and third joint. None of the abdominal segments are soldered together.

RANGE, - East Coast of subtropical and tropical America.

\section{Euryplax nitidus.}

Euryplar. nitichus . . . . Stimpson.

Carapace smooth and shining, convex from before backwards. Proportion of length to breadth as I to I.65. Antero-lateral margins less than half as long as the postero-lateral, and armed with three strong teeth, including the angle of the orbit. Postero-lateral margin somewhat concave. Front deeply notched on each side at the insertion of the antennæ; the interantennal margin straight and smooth, with no median emargination. First pair of legs robust, smooth and glossy above; fourth joint excavated at summit, with a sharp tooth just behind the excavation; fifth joint flattened above, and unidentate within; superior margin of hand almost acute; fingers somewhat deflexed. Inner side of fifth joint, and surface of fourth around the circular pit, densely pilose. Walking legs slender, those of the third pair longest.

Range.-St. Thomas, Florida, New Orleans.

\section{Speocarcinus.}

\section{Speocarcinus . . . . Stimpson.}

Carapace convex from before backwards, almost flat from side to side. Front of moderate width. Facial 
region small. Antero-lateral margin short, toothed. Eyes moderately short; cornea small. Orbits and antennæe resembling those of Panopeus. Palate ridged. Fourth joint of external maxillipedes narrow, the fifth joint articulating with it at antero-internal angle. First pair of legs short. Walking legs thin, with their last joint ciliated. Abdomen of the male, narrow, has the third to the fifth segments consolidated.

\section{Speocarcinus carolinensis.}

Speocarcinus carolinensis . . . Stimpson.

Body depressed, subcylindrical. Carapace nearly smooth above; surface punctate, obsoletely granulated towards the margins; gastric region well defined; genital region depressed; antero-lateral margin five-toothed, including the orbital angle; sccond tooth not distinctly separated from the first, last three teeth sharp and moderately prominent. Front about one-fourth as wicle as the carapace, prominent, straight, and emarginate in the middle. Eye-peduncles depressed and pubescent above. First pair of legs robust, nearly smooth, a strong sharp tooth or spine near summit of fourth joint; inner margin of fifth joint granulated, with a blunt tooth at inner angle; outer surface of hand glabrous, microscopically granulated. Last joint sharp; those of the last pair curved upward. Length of carapace in the male, o.SS; breadth, I.o9 inch.

RANGE.-South Carolina.

According to the same author, this crab lives in holes made in the sand, by other animals, about low-water mark, so I have noted it as it may be found on the muddy shores of British Guiana. 


\section{Section II. Carcinoplacinæ.}

Carinoplacina' . Milne Edwards, Miers.

The antero-lateral margins of the carapace are usually dentate or spinose; the abdomen of the male completely conceals the sternum at the base.

\section{Geryon.}

Geryon . . . . Kroyer, Miers.
Chalcepus (?) . . . Gerstäcker.

Carapace cancroid in form, moderately convex, slightly broader than long; the antero-lateral margins shorter than the postero-lateral margins, and armed normally with three spines, including the spine or tooth at the external angle of the orbit, which is sometimes less developed; the intermediate spines (the second and fourth of the normal series) are sometimes present but rudimentary. Front slightly deflexed, of moderate width, and divided into two or four lobes or teeth. The eyc-peduncles are short and robust. The antennules are transversely plicated. The basal antennal joint is slender, and occupies the interior hiatus of the orbit; its distal extremity is free, not united to the front. The epistome is short, transverse. The ridges of the endostome are faintly indicated or obsolete. The fuurth joint of the external maxillipedes is shorter than the third joint, truncated or slightly rounded distally, and the next joint articulates with it at its antero-internal angle. The first pair of legs, in the male, subequal and moderately robust; third joint trigonous; fourth with a spine or tooth on its interior surface: palm short, rounded above and below; fingers distally acute, and clenticulated on the inner margins. Walking legs are somewhat 
elongated, with the joints subcylindrical; terminal joint slender, styliform, but slightly compressed and not ciliated.

RANGE.-Atlantic; in deep water.

\section{Geryon incertus.}

Miers.

The carapace has its surface uneven and marked with transverse granulated ridges, of which there are two on the gastric region, placed one on each side of the median line, and one crossing the middle of the carapace from the base of the posterior antero-lateral marginal tooth, from behind which also a granulated ridge extends along the postero-lateral margins of the carapace nearly to the postero-lateral angles, which are rounded. The orbit has two small incisions in its superior margin. The anterolateral margins, shorter than the postero-lateral margins, are armed with four teeth, of which the first, second, and fourth are prominent and spiniform; the third is almost obsolete on one side, and on the other side is a small tubercle. The front is rather prominent, about one-third the width of the carapace, and divided by a small median notch into two broad and slightly sinuated lobes, which are rounded at the lateral angles. The antennules have the basal joint very large. The basal antennal joint is longer than the two following peduncular joints; the flagellum is somewhat elongated. The third joint of the external maxillipedes is longer than broad, with the inner margin convexly arcuated; the fourth joint is almost as long as broad. The abdomen, in the female, is subtriangulate, with the segments short; the last segment is rounded distally.

RANGE.-Bermuda; in deep water. 


\section{Frevillea.}

Frevillea . . A. Milne Edwards.

The front is deflexed, the ocular peduncles are elongated; the orbits are well defined, and occupy the width of the space between the front and the anterolateral angles. The basal antennal joint is short and wide, that of the internal antenne is long and round; the two first joints of the flagellum are very long, and extend bcyond the front, where they are folded. The buccal cavity is wider in front than behind, and its anterior border has two fissures on each side. The epistome is large. The first pair of legs is subequal and terminate in pointed fingers; the arms scarcely exceed the borders of the carapace. The walking legs are long, thin, and compressed. The male verges arise directly from the coxal joint of the last pair of legs.

RANGE.-West Indian Sea; in deep water.

\section{Sritopsis OF TIE SPECIES.}

I. A small tubercular swelling behind external orbitai angle.- (F.rosece.

2. Antero-lateral borders have two teeth.-(F. sigshe $i$.

3. Antero-lateral borders have three teeth. - $F$. tridcutata.)

\section{Frevillea rosæa.}

Frevillea rosea . A. Milne Edwards.

The carapace is thick, enlarged in front; the lateral borders are almost parallel. The front is wide and straiglit. The ocular pecluncles are large. The postorbital angle is formed by a pointed tooth, behind 
which is a small tubercular swelling near a short sharp hepatic spine. The first pair of legs smooth, with the hands compressed, the palm being of the same length as the fingers. The forearm is rounded outside, and armed within with a slightly hooked spine. Another short spine exists towards the posterior border of the arm at the junction of the hand.

RANGE.-St. Vincent.

\section{Frevillea sigsbei.}

\section{Freallea sigshi . A. Milne Edwards.}

The pincers are provided with bunches of hairs; the front is almost straight; the antero-lateral borders have two teeth, the first being smallest. The last joint of the legs of the last pair is much enlarged.

RANGE.-Grenada.

\section{Frevillea tridentata.}

Frewllea tratcutata. A. Milne Edwards.

There are three antero-lateral teeth; the pincers have tufts of hairs; the last joint of the last pair of legs is styliform; the forrth joint of the first pair of legs has tro spines, one inside and one outside.

RANGE.-Barbados.

\section{Bathyplax.}

Bathyplaz . . . M. Milne Edwards.

The front is adranced. The ocular peduncles are very small, immovable, and cleprived of cornca, the animal being in consequence blind.

RANGE--West Indian Sea to Brazil; in deep water. 


\section{Bathyplax typhlus.}

Buthyplar typhlus . . A. Milne Edwards.

The carapace flat transversely, but very curved from before backwards; its surface is covered with very fine granulations, slightly elevatcd, and so has a rough appearance. The regions are slightly marked, especially in front; behind these exist very distinct branchio-cardiac grooves, and two grooves surmount the branchial regions outwardly. The latero-anterior borders are bowed, thick, and armed with two spines, one hepatic one terminal. The ocular peduncles have the form of two small projecting warts: they are fastened at their base in the orbits, which allows them no mobility. The basal articulation of the external antenne is large and pressed between the orbital border and the subfrontal prolongation; its flagellum, inserted in the angle of the orbit, is long. The basal articulation of the internal antennæ is remarkably large. The buccal cavity is very open and very notched in front. The third joint of the external maxillipedes is large; the fourth is rounded at its anteroexternal anglc.

The first pair of legs subequal and of moderate length ; the arm does not exceed the carapace, it carries below a spine, and above a sort of transverse rack arranged in such a manner so as to rub against the granulations of the pterygostomian region. The forearm carries on the right side a spine and on the left side a tubercle or a weak spinc. The left pincer is the shortest, and has on the inside a triangular dilatation which is a prolongation of its superior border. The external face of the hand is depressed, and the inferior border very fine and very bowed. The fingers are compressed, pointed, and in 
complete contact when closed. The right pincer is larger, thicker; the fingers are long and meet only at their extremities when closed. The walking legs are long, frail, and hairy. The abdomen of the male has seven joints.

RANGE.-St. Lucia, Brazil.

\section{Subfamily II. Ocypódinæ.}

Ocypodince. . . . Miers

Ocypodicns . . . H. Milne Edwards.

Gonoplacions part. Milne Edwards.

Carapace transverse, trapezoidal or quadrate, with the antero-lateral angles frequently produced and acute, and the lateral margins straight, entire or incised; front narrow or of moderate width. Orbits usually very considerably developed, and occupying nearly the whole or a great part of the anterior face of the body below the front. The fifth joint of the external maxillipedes usually' articulates at the antero-external angle of the fourth joint. The first pair of legs, in the adult nale, subequal or sometimes very unequal. Walking legs moderately elongated, with the last joint styliform, compressed, not spinose.

\section{Section Ocypodinæ.}

Carapace trapezoidal, with the antero-lateral margins not greatly produced, and entire; the fifth joint of the external maxillipedes articulates at the apex, or at the antero-external angle of the fourth joint. The abdomen of the male is usually much narrower than the sternum at the base. 


\section{Synopsis of THE Gener.}

A. Transparent cornea very large, occupying at least the half of the length of the ocular peduncles, commencing near their base.--(Ocypoda.

B. Transparent cornea very small, not occupying a quarter of the length of the ocular peduncles, commencing near their extremity.-(Gelasimus.)

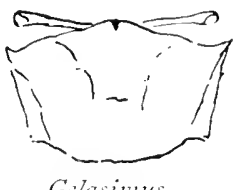

\section{Ocypoda.}

Ocyodar. Fabricius, Milne Edwards, Kingsley, Miers, Latreille, Leach, Lamarck, Desmarest.

Cancer. Linné.

Carapace quadrate, moderately transverse and convex, with the dorsal surface closely granulated, the cervical and cardiaco-branchial sutures in part distinct, the anterolateral angles moderately prominent. The front narrow and deflexed; the orbits, very large and open, extend along the whole anterior face of the body, between the front and antero-lateral angles, which are not very prominent-their inferior margins are usually divided by a hiatus or fissure. The eye-peduncles, very large, are jointed near the base, the basal part is short, and the terminal portion is often prolonged at its distal extremity as a spine or tubercie; the cornee, of great size, cover a great part of the inferior surface of the mobile portion of the eye-peduncle. The antennules are partially concealed by the front; the antenne, rery smail, are placed beneath the eye-peduncles in the narrow hiatus between the base of the antennules and the interior subocular lobe of the orbit, their basal joints are very short; the flagella scarcely exced the peduncles in length. The ridges of 
the endostome are usually not developed. The external maxillipedes are closely applied to the buccal cavity; the third joint is longer than the fourth, and distally truncated; the fourth joint longer than broad, distally truncated, not emarginate, at the antero-internal angle. The first pair of legs, in the adult male, is unequal and well developed; the fourth joint of the larger limb is trigonous, with the superior and inferior margins denticulated; fifth joint short, with usually a lobe or tooth on the inner margin; hand vertically deep and compressed, the palm with a stridulating ridge on its inner surface, composed of a vertical serics of short raised lines or tubercles; fingers, either distally acute or truncated, arc toothed on the inner margins. The walking legs are somewhat elongated, with the joints usually granulated and their last joint styliform. The abdomen, in the malc, is seven-jointed, with the terminal segment small and triangulate.

RANGE--Atlantic and Pacific Oceans, in warm seas, living for the most part near, but out of, the water, in holes in the sand or mud.

\section{Srivutsis of the SPECIES.}

A. Ocular peduncles prolonged beyond the cornea as a spine or style.- (O. macrocera. $)$

$B$. Ocular peduncles not prolonged beyond the cornea as a spine or style.-(O. arenaria.)

\section{Ocypoda macrocera.}

Oypoda macrocera.

H. Milne Edwards, Heller, Kingsley.

Orbits wide, oblique, angle obtuse; eyes with a spine which in most cases is long and cylindrical, extending far 
beyond the orbit. No notch below external orbital angle.

Larger hand very short, broad, and a little spinose above; its palm broader than long. The fingers of the smaller hand lamellate, and very broad at their extremities. Walking legs roughened above.

RANGE.-East Indies, Brazil, Tahiti.

\section{Ocypoda arenaria.}

Ocjpoda arenaria. . . Say, Milne Edwards, Miers, Kingsley, Dekay, Gibbes, Gerstïcker, Von Martens, Smith.

Ocypoda albicans. . . Latreille, Bosc.

Ocypodir rhomber. . . Milne Edwards, Dana, Gibbes, Heller, Smith.

Cancer arencrius. . Catesby

Cancer quadratus ।

Ocypoda quadratal. . Fabricius.

Monolepis inermis . . Say.

Carapace convex, granulate above, front but littie deflexed; lateral angles of carapace acute, extending as far forward as the middle of the front. Lateral margin crenulate, arcuate, the carapace being widest at the anterior third. Orbits below with spiniform tubercles: and occasionally a distinct emargination. Eyes with the extremities rounded and not reaching to the extremity of the orbit. First pair of legs with spines and tubercles; the fourth joint with the upper and lower margins spined, the posterior rounded and crossed by tubercular ruga. Fifth joint with the tubercles obsolete above but pronounced near the margins, the inner margin armed with one or more strong spiniform teeth. Hands tuberculate, 
the upper margin spined, the lower serrate. A tubercular stridulating ridge on the inside near the fingers. Fingers strongly inflexed. Walking legs compressed, hairy, their sides smooth, the upper portion margined and crossed by transverse rugx. Young specimens have the lateral angle farther back than in the adult, while the spines of the first pair of legs are wanting or but faintly indicated.

The colour is yellow-white, the upper surface of entire body being washed with a purple tinge.

RANGE.-United States of America to Rio de Janeiro; Barbados, Jamaica, Mexico. Common in holes in the sand in Barbados. I have heard that they are found in the Essequibo River of British Guiana, but I have not found them there or in the Berbice River.

\section{Gelasimus.}

Gelcrsimus. . Latreille, H. Milne Edwards, Kingsley, Micrs, Dana, Hess, A. Milne Edwards, Desmarest.

Cancer . . Linné, Herbst, Fabricius, De Geer.

Ocypoda . . Bosc, Latrcille.

Rhombille. . Lamarck.

Lea . . . Leach.

Gonoplerentert) Lamarck.

Carapace transverse, longitudinally convex, usually smooth on the dorsal surface, but sometimes granulated, with the cervical and cardiaco-branchial sutures usually more or less distinctly defined, with the antero-lateral angles usually prominent and acute, and the laterat margins nearly straight, and convergent to the posterior margin. The front is deflexed, usually very narrow, almost lincar betwcen the bases of the eye-peduncles, but 
sometimes much broader, and at the base nearly equalling one-third of the width of the carapace at the anterior margin. The orbits are very large, and extend along the whole anterior surface of the carapace, between the front and the antero-lateral margins. The eye-peduncles are very slender and elongated, reaching, or nearly reaching, the antero-lateral angles of the carapace.

The flagella of internal antenne are usually somewhat obliquely plicated. The basal joint of external antenna is small, and placed beneath the base of the eye-peduncles; the flagella are of moderate length.

The longitudinal ridges of the endostome are usually more or less distinctly developed. The third joint of the external maxillipedes is much larger than the fourth, and is not produced at its antero-internal angle; the fourth joint is small, usually transverse, distally truncated, and not emarginated at the antero-internal angle, where the next joint joins it.

The first pair of legs is unequally developed; the fourth joint of the larger is usually triangular on section, and prolonged beyond the antero-lateral angles of the carapace; the next joint is moderately elongated, and has usually no spine on its interior surface; the hand is compressed and very large, usually greatly exceeding in length the three preceding joints; the palm is much shorter than the fingers, and is usually obliquely cristated on the inner surface; the fingers are distally acute or subacute, granulated, and usually lobate on the inner margins; in the smaller hand (and in both hands in the female) the joints are slender and feeble. The walking legs are of moderate length; their fourth joint is compressed, and the terminal joint styliform.

The abdomen of the male is seven-jointed.

RANGE.-In temperate and tropical regions. 


\section{SyNORSIS OF TIIE SieCIes.}

A. Front very narrow between the orbits.

a. Movable finger of larger hand terminates in a sharp point.

I. Movable finger of larger hand broader near extremity than at base. - G. maracoani.)

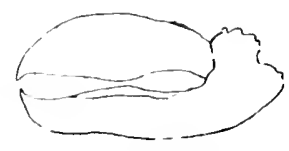

G. maracoani.

2. Movable finger of larger hand,contracts from base to point.- $G$. heterocholes.)

$B$. Front broad between the orbits.

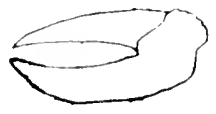

b. Carapace narrowed behind.

3. A ridge on inner surface of palm of larger hand.-(G. a'ocetor. $)$

c. Carapace nearly quadrate.

4. No ridge on inner surface of palm of larger hand.-(G. pugcllator:)

G. helerocheles.

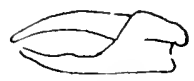

G. rocalor.

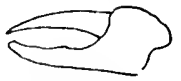

G. fusellator.

\section{Gelasimus maracoani.}

Gelasimus maracoani. I atreille, Desmarest, Milne Edwards, Jana, IVhite.

Gelasimus armatus . . . . Smith.

Gonoplar maracoani. . . . Lamarck.

Ocypoda maracoani . . . Latreille.

Ocjporda heterocheles. . . . Bosc.

Scissor crab (local name). . Berbice.

Regions distinct, each branchial region ornamented with a longitudinal ridge, from which branch off smaller ones. Of the first pair of legs the leg having the largest hand has on its third joint a prominent tooth below; the fourth joint has a tooth on its posterior margin at the 
articulation with the next joint, otherwise smooth and rounded; its upper and lower margins have spiniform teeth which are more prominent above; fifth joint (carpus) elongate, with indistinct tubercles. Hand very large, compressed, externally tuberculate on the basal portion, above with several teeth like those of the fourth joint, inferior margin proximately tuberculate, outer surface of fixed finger with large shallow punctx, the lower portion being marginate. Occludent margin with three rows of tubercles, the middle one forming a prominence at the basal two-fifths, the other rows undulating extremely contorted, acute, inner surface nearly smooth, with a tubercular ridge running from the articulation of the movable finger to the middle of lower margin of the palm; movable finger lamellate, broader near tip than at base, externally granulate. The abdomen of the male is broadest at the junction of the second and third segments; in the female the terminal joint of the abdomen is dovetailed into the sixth segment. Front narrow between orbits.

RANGE.-British Guiana, Cayenne, West Indies, Brazil, Natal, West Coast of Nicaragua.

\section{Gelasimus heterocheles.}

Gelasimus heterocheles. Seba, Kingsley.

Cancer iocans major. . Herbst.

Cancer uka . . . . Shaw.

Ocypoda heterochele's. . Bosc.

Gelasimus maracoani. Desmarest.

Gelasimus platydactylus. Milne Edwards, Saussure.

Gelasimus princeps . . Smith, Lockington.

Carapace transversely, nearly flat. Fourth joint of large pincer rounded posteriorly, its lower margin crenulate, its upper produced into a broad, arcuate, laminiform, 
dentate crest; next joint elongate, externally tuberculate, inner margin crenulate, the inner surface with one or two tubercles. Hand large, compressed, palmer portion swollen, upper and lower margins tuberculate; external surface of palm tuberculate, of fixed finger, smooth, except a crenulated ridge below. The movable finger, wider at base than near tip, has the upper margin and outer basal portion tuberculate. Front narrow between orbits.

The abdomen is broad, the basal segment is shorter than the second and third; the edges approach each other somewhat at the junction of fifth and sixth segment; the terminal segment is nearly twice as broad as long, and its extremity is rounded.

RAxre. - Jamaica, Cayenne, Nicaragua, Mexico, Lower California. I have not found them in British Guiana.

\section{Gelasimus vocator.}

Gelasimus aocator. . Martens, Kingsley.

Gelasimus zocons. . I. Milne Edwards, White, Gould, Dekay.

Gelasimus palustris . H. Milne Edwards, Stimpson, Smith.

Gelasimus pugillator. Leconte.

Gelasimus brevifions. Stimpson, Smith, Lockington.

Gelesimus pugna.r)

Gelasimus mordara' Smith.

Gilasimus repar.

Gclasimus affinis . . Streets.

Gelusimus cremulatus. Lockington.

Jumbi crab(local name) Berbice.

Carapace smooth; fourth joint of large hand with its margins denticulate or tuberculate; fifth joint externally 
granulate, internally with an oblique tubercular ridge. Hand tuberculate, its inner surface with a ridge running up from the lower margin to carpal groove; in front of this are scattered granules. Fixed fingers straight, extremity obliquely truncated, movable finger strongly arcuated, longer than the fixed finger, these meet only at tips when closed. Front broad between orbits.

RANGE.-East Coast of America from Cape Cod to Brazil; West Indies, Barbados, Aspinwall, Panama, West Coast of Mexico, California. Common in British Guiana, on the mud flats washed by the sea, or in brackish water among the trees on the seashore, where they live in holes in the mud. They are also found in almost fresh water on the banks of the canals some distance from the sea. I have found them in similar situations in Barbados, where they appear to live in the same way. There are the following differences between these very small crabs as found in Berbice and in Barbados.

Berbice specimens, male.--Abdomen seven-jointed, tapering rapidly from base to very small terminal segment. Female.-Abdomen wide, oval, with last segment very small and resting on sixth segment. Both male and female are blue-green.

Bardaclos specimens, male-Abdomen seven-jointed, with sides almost parallel; terminal segment broad. Female.-Abdomen a long oval, with seventh segment very small, and half buried in a notch in centre of sixth segment. Both male and female are washed with pink. This description is taken from living specimens in these two localities. 


\section{Gelasimus pugillator.}

Gelasimus pugillator. Kingsley, Latreille, Desmarest, Milne Edwards, Smith.

Gclasimus rocans . . Gould, Dekay.

Ocypoda pugillator. Bosc, Say.

Carapace polished, swollen, nearly quadrate. Fourth joint of large hand with the outer surface rugose, upper and lower margins crenulate; fifth joint granulate externally, its inner margin acute; hand inflated, the basal portion granulate and margined above and below; inner surface rounded, granulate, but without any trace of a tuberculate ridge except one formed by a continuation of the inner margin of the fixed finger. The fixed finger is nearly straight, a ridge on the outer surface, a large tubercle near the middle of the inner margin, the extremity obliquely truncate. The movable finger is longer than the fixed finger, regularly tapering and distally strongly arcuate, meeting its companion only near its tip when closed. Front broad between orbits.

Range. - New Jersey, Manatu River, Mauritius, Greenpoint, Boston Harbour, Florida, Savannah, North Carolina, New Haven, South Carolina, Cayenne.

\section{Family IV. Grapsidæ.}

Grapside. . . . Miers, Dana, Kingstey. Grapsinc (part) | Grapsoidiens + Milne Edwards.

Carapace subquadrate, depressed. Front usually broad, never very narrow. Eyes short; orbits and eyepeduncles of moderate size. Epistome short, sometimes linear. Fourth joint of the external maxillipedes has the 
next joint on its summit or at its antero-external angle. The first pair of legs, of the male, usually subequal, of moderate size. The terminal joint of the walking legs is stiliform, compressed, or may be smooth or armed with spines. The abdomen usually covers the width of the sternum between the basal joint of the last pair of legs.

RANGE.-Shore, shallow or deep water in temperate and tropical seas.

\section{Subfamily I. Grapsinæ. \\ Subfamily II. Plagusinæ.}

\section{Synopsis of the SUbFamilies.}

A. Internal antenne more or less transverse, covered by the front, which is entire and not longitudinally cleft.(Gropsina.)

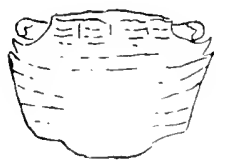

Grafizine.

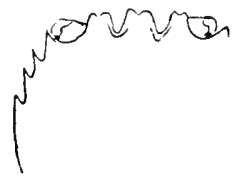

I'logusine.

B. Internal antenne, lodged in longitudinal clefts of the front, are visible on a dorsal view.-(Plagusince.)

\section{Subfamily I. Grapsinæ.}

Grapsince. . . . . . Micrs, Kingsley.

Grapsince and Sescrmina . Dana.

The intcrnal antenna, more or less transverse, are covered by the front, which is not cleft antero-posteriorly. 


\section{Section I. Grapsini.}

No ridge on the third and fourth joint of external maxillipedes.

\section{Section 2. Sesarmini.}

A ridge on the third and fourth joint of external maxillipedes.

\section{Section I. Grapsini.}

Gropsini. . . Miers, Kingsley.
Grafsinu. . . Dana.

No ridge on the third and fourth joint of external maxillipedes.

\section{Sinofsis of the Genera.}

A. There is a rhomboidal space between cxternal maxillipedes.

a. External antenne excluded from the orbit.

I. The fourth joint of external maxillipedes as long as the third joint.-. (Coniopsis.)

b. External antennie not excluded from the orbit.

$a^{1}$. Front less than half the width of the carapace.

$a^{2}$. One tooth behind orbital angle.

2. Fingers of first pair of legs excavated.--(Gropsus.)

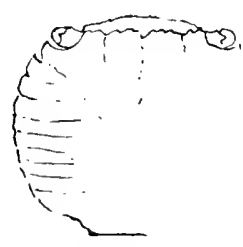

Grapsus.

3. Fingers sharp pointed.--(Geograpsus.)

h?. Two teeth behind the orbital angle.-(Leptograpsus.)

61. Front more than half the width of the carapace.

5. Carapace transverse.-(Pachyoratsus.) 
6. Carapace longer than broad.--(Nautilograpsus.)

B. External maxillipedes without rlomboidal gape.

7. Fifth joint of the external maxillipedes articulating at the inner angle of the fourth. Several teeth behind the orbital angle.- Euchurograpsus.

KINGSLEY.

A. A rhomboidal space betrietn erternal marillipedes:--

\section{Goniopsis.}

Goniopsis.

Goniograpsus (part).
De Haan, Milne Edwards, Miers, Kingsley.

Dana.

Carapace deep vertically, subquadrate, flat above, with the cervical suture strongly defined, the lateral margins armed with a single tooth behind the external orbital angle, the anterior margin abruptly four lobed above the front, which is broad and vertically deflexed. Orbits rather large, with two hiatuses below, and with the interior subocular lobe well developed. Eye-peduncles robust. Internal antenna transversely plicated in the narrow, wide fossettes. Basal joint of external antenne, broad and very short, are completely excluded from the orbit by the subocular orbital lobe. Epistome transverse. The ridges of the endostome distinctly developed. The external maxillipedes narrow, widely gaping, and remote from one another at the base; the fourth joint is nearly as long as the third, widening to the distal extremity, which is truncate; the fifth joint articulates with it near its anteroexternal angle; the external appendage is very slender. The first pair of legs, in the male, robust; the fourth joint is triangular in section, with the anterior margins dentated; the fifth joint and the hand are strongly granulated; palm somewhat compressed; fingers but slightly excavated or 
subacute. Walking legs robust, with their fourth joint broadly dilated and compressed; two terminal joints with strong spines. Abdomen, in the male, broadly triangular, seven-jointed.

RAN(iE.-Tropical seas of America, West Indies, IVest Coast of Africa.

\section{Goniopsis cruentatus.}

Goniopsis cruentatus . De Haan, Kingsley, Miers.

Goniopsis micold. White.

Grapsus cruentatus. . Latrcille.

Grapisus longifis. . . Randall.

Grapsus pelli . . . Herklots.

Goniograpsus cruentertus Dana.

Front granulate, suprafrontal lobes four, margins crenulate, orbits entire above, distally emarginate. Carapace with oblique transverse ridges. Anterior margin of third and fourth joint of first pair of legs cxpanded and toothed, both margins having spiniform tubercles, as is also the upper margins of the fifth joint. Hands with spiniform tubercles above and below, the middle of the outer surface smooth, the inner surface with scattered, pointed granules. The fingers slightly excavated. The walking legs compressed and armed with stiff black bristles. Posterior angle of fourth joint of last pair rounded, in the other fect dentate. The carapace is black-green; the legs are vermilion, with white spots on both carapace and legs.

RANGE. - Surinam, Berbice, Bahamas, Bermuda, Cuba, Florida, West Coast of Nicaragua, West Coast of Africa. Common near Plantation Everton on the Berbice River, and on the mud banks of the same river off New Ainsterdam, where they live more on the land 
than in the water. The water there is not very salt, especially in the wet season.

\section{Grapsus.}

Grapsus. . . Lamarck, H. Milne Edwards, Miers, Kingsley.

Carapace depressed, with the cervical sutures strongly defined; the lateral margins regularly bowed, and armed with a single tooth bchind the exterior orbital angle; the dorsal surface marked with transverse raised lines, which are strongest on the branchial regions; the front is of moderate width, strongly deflexed, its anterior margin is entire and slightly arcuated; the orbits of moderate size, rather deep, and their inferior margins have a fissure or notch near the exterior orbital tooth. The eye-peduncles are robust and short. The internal antenna are transversely folded in very narrow fossets. The basal joint of external antenne is very short, and is produced at its antero-external angle; it lies within the interior orbital hiatus, between the front and the interior subocular lobe of the orbit, which is dentiform and acute; the flagellum is short. The epistome is transverse and rather large; the buccal cavity small, and the ridges of the endostome distinctly defined. The external maxillipedes are narrow; the fourth joint is truncated or slightly concave distally, and it articulates with the fifth joint at its anteroexternal angle. The first pair of legs robust and rather short; their fourth joint is triangular in section, with the anterior margins toothed; the fifth joint has a strong tooth on the inner margin; palm short, granulated above; fingers toothed on their inner margin, and excavated at their tips. Walking legs large and robust, 
with their fourth joint dilated and compressed; terminal joint spiny. The abdomen of the male is seven-jointed.

RANGE.-Atlantic and Pacific Oceans.

\section{Grapsus maculatus.}

Grapsus maculatus. . II. Milne Edwards, Miers, Kingsley.

Grapsus fictus . . . . Latreilhe, Milne Edwards.

Grapsus strigosus. . . Brullé.

Grapsus altifrous. . . Stimpson.

Grapsus a'cbbi

Grapsus ornatus

Milne Edwards.

Grapsus pharaonis)

Cancer grapsus . . . Linné.

Pagurus maculatus. . Catesby.

Carapace transversely plicated, folds anteriorly broken up into flat tubercles. Frontal crest four-lobed, the median lobes the largest, their margins subtuberculate. Frontal margins crenulate, regularly bowed. Inferior border of orbit with a deep fissure. Anterior border of third and fourth joint of first pair of legs spinose; the posterior surface of fourth joint plicate. Fifth joint with distinct tubercles, its interior margin with a laminate spine. Hand above tuberculate, externally with longitudinal ridges below with oblique folds. On the inner surface the tubercles and folds are less prominent. Fingers short.

RANGE.-West Indies (Barbados), Bermuda, Florida, Georgia, California, San Lorenzo, Pernambuco, Central America, West Coast of Mexico, Honduras, Peru, Tahiti, New Zealand, Mauritius, Natal, St. Helena, Cape Verde Islands.

Very common on the rocks at Barbados. 


\section{Geograpsus.}

Geograpsus . . Stimpson, Miers, Kingsley.

Discoplere . . A. Milne Edwards.

Orthograpsus. . Kingsley:

Carapace depressed, plicated only near the lateral margins, with the antero-lateral margins straight or arcuated only at the hepatic regions, posteriorly nearly straight; they are armed with a single tooth behind the external orbital tooth. Front of moderate width, and deflexed. The basal joint of external antennæe is short, and but slightly produced at its antero-external angle. Antenne not excluded from the orbit. The third and fourth joint of the external maxillipedes narrow, especially the fourth joint, which is slender and elongated, distally truncated, articulating with the next joint at or ncar its antero-external angle. The fingers of the first pair of legs have acute tips.

R.ANGF--Atlantic and Pacific Oceans.

Synopsis of THE SPECIES.

$A$. Sides of carapace straight.-(G. hillii.)

B. Sides of carapace bowed in anterior part.- $(G$. (ividus.)

\section{Geograpsus hillii.}

Geograpsus hillii . . . Miers.
Orthograpsus hillii . . Kingsley.

Suprafrontal lobes moderate: front straight, narrow, deflexed. Sides of carapace straight; postorbital tooth small. Fourth joint of external maxillipedes a little longer than broad. First pair of legs have the hands 
granulate above. Posterior distal angle of fourth joint of walking legs rounded, entire or finely serrate.

RANGE-West Indies, Florida.

\section{Geograpsus lividus.}

Geograpsus liwidus. . Stimpson, Kingsley, Miers. Grapsus lividus Giapsus breatipes! II. Milne Edwards.

Geograpsus occidentalis Stimpson:

Carapace much broader than long. Plications nearly transierse. Frontal lobes prominent; front deflexed, its margin nearly straight. Sides of carapace slightly bowed. Orbit with a deep fissure below. Fourth joint of first pair of legs above and below with transwerse ruga, its anterior margin expanded, proximally denticulate: distally the teeth are larger. Fifth joint granulate, with a short spine on the inner margin. Hand and fingers tuberculate above, externally and below with short oblique rugae. Distal angle of fourth joint of the last pair of walking lezs rounded.

RANore--West Indies, Chili, Cape St. Lucas.

\section{Leptograpsus.}

Leptograpsus . . . Stimpson, Miers, Kingsley.

Leptograpsus (part. Milne Edwards.

Carapace with the sides bowed; two teeth behind external orbital angle. Front less than half the width of the carapace, not deflexed. Internal suborbital lobe small; external antennxe entering the orbit. The fourth joint of the external maxillipedes as broad as long, but shorter than the third joint.

RANGE, - Atlantic and Pacific Oceans. 


\section{Leptograpsus variegatus.}

Leptorapsus andigatus. Fabricius, Milne Edwards. Cancer areregatus. . Fabricius.

Grapsus marginatus. . . Latreille.

Grapsus personatus. . . Lamarck.

Grapsus fictus . . . . Quoy and Gavinard.

Grapsus strigillatus. . White.

Grapsus plamifrons. . Dana.

Grapsus areriggatus . . Milne Edwards and Lucas.

Leptograpsus bertheloti

Leptograpsus aerreatui

Leptograpsus ansoni

Milne Edwards.

Carapace nearly flat, transversely plicated. Protogastric region concave, with squamous tubercles; protogastric lobes but little prominent. Front slightly depressed, its margin crenulate, nearly straight. Orbits with a narrow, deep external fissure. Fourth joint of first pair of legs with the anterior border expanded, dentate; the other angles rounded, the posterior surface rugose. Fifth joint tuberculate, and with a short spine on the internal surface. Hand tuberculate above, externally smooth. Walking legs with stiff hairs. In the young there is an elevated line along the outside of the palm.

RANGE.-Pernambuco, Chili, Australia, Isle Guami, Canaries, Norfolk Island, Shanghai.

\section{Pachygrapsus.}

Pachysrapsus . . Randall, Stimpson, Miers, Kingsley, Milne Edwards.

Carapace somewhat narrowed behind, with transverse strix. Front more than half the width of the carapace, sides entire, or with one or two teeth; inner suborbital lobe 
small, allowing the external antenne to enter the orbit. External maxillipedes with fourth joint as broad as long.

Range.-Atlantic and Pacific Oceans.

\section{STNORSIS OF THE SHECIES.}

A. Sides with one tooth behind the external orbital angle.

a. Posterior distal angle of fourth joint of the last pair of legs dentate.

I. Fingers of first pair of legs' smooth.-(P. transi'crisus.)

2. Fingers of first pair of legs dentate or spined above. - (I'. gracilis.)

\section{Pachygrapsus transversus.}

Pachygrapsus transa'ersus . Gibbes, Kingsley, Miers.

Pachygrapsus lavimamu|

Pachygrapsus socius i.

Stimpson.

l'achysrapsus adacna . . Catta.

Pachyorapsus intermedius. Heller.

Leptograpsus regulosus . . Milne Edwards.

Goniograpsus innotatus . . Dana.

Metograpsus dubius et miniatus Saussure.

Grapsus derlizifions. . . . Heller.

Carapace depressed, shining, oblique on the branchial regions. Sides generally slightly bowed, with one tooth behind the orbital angle. Frontal lobes prominent; front stinuate. Fourth joint of first pair of legs with transverse rugx, the inner margin dentate; fifth joint rugose, with an internal rounded tubercle. Hand minutely granulate, a longitudinal ridge on the lower outer surface, margins rounded; fingers with the upper margins smooth. The posterior distal angle of the fourth joint of the last pair of legs dentate. 
Range.-Bermuda, St. Vincent, West Indies, Florida, Brazil, Nicaragua, California, Tahiti, New Zealand, Australia, Madeira.

\section{Pachygrapsus gracilis.}

Pachy'grapsus gracilis . Stimpson, Saussure, Kingsley. Mctopograpsus gracilis. Saussure.

Grapsus guadulpensis. Desbonne and Schramm.

Grapsus (Leptograpsus)

regulosus. . . Von Martens.

The carapace has no folds on the cardiac region; lateral margins nearly straight, one toothed. Frontal lobes nearly obsolete; front nearly horizontal, regularly bowed, and minutcly crenulate. The hand and fingers are spined above. The posterior distal angle of the fourth joint of last pair of legs dentate.

Rangie.-West Indies, Florida.

\section{Nautilograpsus.}

Nantilograpsus . H. Milne Edwards, Kingsley, Miers. I'lanes . . . Lcach, Bowdich, Bell.

Carapace subquadrate, with the postero-lateral margins somewhat convergent, dorsally smooth, slightly convex, and usually with a slightly indicated lateral postorbital tooth. The front is broad, about half the width of the carapace; its anterior margin projecting slightly, nearly straight. The orbits are small, and the margins entire, or with only a very small notch beneath the eye-peduncles near the extcrnal orbital tooth. The cye-pecluncles are short and thick. The basal joint of external antenne is short, robust, and is produced at its antero-external anglc, which forms a lobe or tooth, and lics within the interior hiatus of the orbit; the flagellum is short.

The epistoma is short, broadly transverse. The 
longitudinal ridges of the endostome are well defined. The fourth joint of the external maxillipedes is truncated distally, and slightly concave at anterior margin; it articulates with the next joint at its antero-external angle. The first pair of legs, in the male, robust, subequal, of moderate size; fourth joint has a triangular section, with the anterior border toothed; the fifth joint has a tooth or spine on the inner margin; palm somewhat turgid, rounded above; fingers toothed on the interior margins, and distally acute. The walking legs are short, with the joints compressed and somewhat dilated; the last joint but one is ciliated on the superior margin, and has spines on the inferior margin; the terminal joint is short, compressed, and has spines. The abdomen, in the male, is seren-jointed.

RANGE.-Found on seaweed in Atlantic and Pacific Oceans.

\section{Nautilograpsus minutus.}

Vautilograpsus mimutus . . . H. Milne Edwards, Kingsley, Linné.

Nautilograpsus angustatus . . Stimpson.

Nautilograpsus major et smithii. M'Leay.

Grapsus cincrus . . . . . . Latreille, Say.

Grapsus pelagicus . . . . . Roux, Say.

Grapsus testudineum . . . . Roux.

Grapsus divis . . . . . . . Costa.

Planes cyerneus . . . . . . Dana.

Planes linneana. . . . . . Bell.

Planes minutus. . . . . . White.

Planes clypatus . . . . . . Bowdich.

Ocypoda (Grafsus) pusillus. . De Haan.

Canecr minutus . . . . . . Linné.

Carapace smooth, arcuate in both directions, front 
nearly straight; postorbital tooth small or wanting. Sides bowed. Fourth joint of first pair of legs with inner distal border dentate; fifth joint with a tubercle on the inner surface; hand smooth; fingers deflexed.

RANGE.-Gulf Stream, West Indies, Surinam, Falkland Islands, Peru, West Coast of Mexico, Alaska, China, New Zealand, Natal, Gambia, Mediterranean, France.

B. E.rternal marillipedes without rhomboidal gape:-

\section{Euchirograpsus.}

Euchirograpsus . . Milne Edwards, Kingsley.

Carapace depressed, subquadrate: sides slightly bowed, with three teeth behind the orbital angle; orbits entire. External antenne long, entering the orbit. Fourth joint of external maxillipedes about half the length of the third joint; its outer distal angle rounded, its inner excavate and bearing the fifth joint.

RANGE.--Mediterranean Sea, West Indies.

\section{Euchirograpsus americanus.}

Euchirograpsus americanus . . A. Milne Edwards.

The carapace is very flat, with the lateral edges parallel; the surface is slightly granular, and has short hairs visible only under the microscope. The front is straight, lamellous, advanced, and notched in the middle line. Behind the orbital angle there are three spines, the second the largest. The orbits are large and deep. The external orbital angle is spiniform. The pincers are angular, and have longritudinal ridges.

RANGE--Barbados. 


\section{Section 2. Sesarmini.}

Scsarmini . . . Miers, Kingsley.

Sesarmince. . . Dana.

The third and fourth joint of the external maxillipedes arc crossed by a piliferous ridge.

\section{Sinopsis of the Genera.}

A. The fourth joint of the external maxillipedes is elongate; its apex is rounded. The external antennæe are not excluded from the orbits.

$a$. Carapace subquadrate; sides arcuate.

8. Joints of walking feet without spines.-(Sarmatium.)

b. Carapace quadrate.

9. Sides of carapace straight.-(Ses-

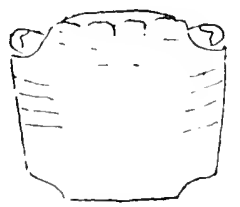

Sesarma. (a)ma).

c. Carapace clongated.

10. Carapace narrowed behind.-(A)atus.)

$B$. The fourth joint of the external maxillipedes is short ; its distal border truncate or excavated.

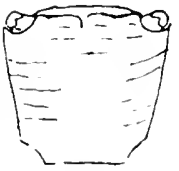

Aratus.

d. External antenne entering the orbit.

11. Sides of carapace bowed and entire- Cyclograpsus).

A. The fourth joint of external marillipetes elongated; its aper rounded. The erternal antenna are not excluded from the orbits:- 


\section{Sarmatium.}

Sarmatium. . . Dana, Kingsley.

Metagrapsus . . H. Milne Edwards.

Carapace convex, sides bowed, entire or toothed. Front inclined, less than half the width of the carapace. External maxillipedes nearly as in Sesarma. Walking legs with the margins entire.

Range.-Martinique, Samoan Islands, Senegal, New Caledonia, Celebes.

\section{Sarmatium pectinatum.}

Sarmatium pectinatum . . Kingsley.

Metagrapsus pectimutus . . H. Milne Edwards.

The sides of the carapace have two tceth behind the orbital angle. The hands are roughened, and have a pectinate crest on the outside.

RANGE.-Martinique.

\section{Sesarma.}

Sesarma . . . Say, Kingsley, Miers.

Pachysoma . . De Haan.

Holometopus . . . Milne Edwards.

Cancer . . . . Linné.

Grapsus . . . Fabricius.

Carapace thick, quadrate; lateral margins straight, entire or toothed, broader than long. Front rather broad, and abruptly deflexed, with the anterior margin straight or sinuated; the epigastric lobes prominent and defined externally by a suture (except in Holometopus, Milne Edwards). Orbits large, with an hiatus below the exterior 
angle; the interior subocular lobe is moderately developed, and does not exciude the external antennæ from the orbital cavity. Eye-peduncles short, robust. Internal antennæ transversely or almost transversely plicated. The basal joint of cxternal antenne is very short, does not reach the front, and is slightly produced at its anterolateral angle; flagellum of moderate length. Endostomian ridges usually distinctly developed. External maxillipedes narrow, with a rhomboidal gape; the external appendage small and slender. First pair of legs, in the male, usually subequal and moderately developed; fourth joint trigonous; fifth joint usually angulated, without a spine on the interior margin; palm slightly compressed; fingers with acute or slightly excavated tips. Walking legs moderately elongated; fourth joint compressed, and usually armed with a subdistal spine or tooth on superior margin; last joint styliform, slightly compressed, and without spines.

RANGE.--All tropical and subtropical seas; in shallow water or on the shore.

\section{SyNOPSIS OF THE SPECIES.}

I. Carapace square and depressed.

Front deeply excavated.

There is no tooth on lateral border behind external orbital angle.

Epistome granular.-(S. cincrea.)

2. Carapace broader behind than in front; legs long and thin.-(S. angustipes.)

3. Frontal lobes not well marked; no median groove.

Anterior part of carapace without folds. - $(S$. miniata.)

4. Frontal lobes well marked, with a median groove. 
Anterior part of carapace with folds.-(S. ameri(ana.)

\section{Sesarma cinerea.}

Sesarma cinerca . . . . . H. Milne Edwards, Say.

Sesarma reticulata

Grapsus reticulatus $\} \cdot \cdot \cdot \cdot$. Say.

Grapsus cinereus . . . . . . Bosc, Latreille.

Carapace square. Front deeply excavated in the middle. There is no tooth on lateral border behind external orbital tooth.

Epistome covered with granulations.

RANGE.-IVest Indies, Virginia, Florida, South Carolina, Berbice River.

According to Stimpson, this species is broader than long in the proportion of I to I.O9.

\section{Sesarma angustipes.}

Sesama angustipes . . Dana, Stimpson.

Dimensions are: - Length, of male, 0.67 ; width, anteriorly, 0.65 ; of female, length, 0.65 ; width, 0.75 inch. The carapace is more convex and narrower than in $S$. cineria; the width, measured between the orbital angles, being less than the length. It is broader posteriorly. The front is narrower, more projecting, and often sparsely tuberculated.

The walking legs are longer and more narrow than in $S$. cineria, to which this species has, in other respects, much resemblance.

RANGE-West Indies, Florida, Brazil. 


\section{Sesarma miniata.}

\section{Sesarma miniata . . . . Saussure.}

Carapace scarcely curved, flat, and slightly convex, presenting only a groove which indicates the genital regions posteriorly.

Frontal lobes slightly elevated, without central groove. Front less than half the length of posterior border of the carapace, less vertical, but longer from above downwards, having some small elevations, especially under the median lobes. Towards the arm it becomes slightly wider from the lateral angles advancing a little laterally, so that the inferior border is wider than the superior portion. The orbits notch slightly the frontal crest. The branchial regions are folded, but not on the anterior portion of the carapace, where there is no trace of ridges. All the carapace is covered with small pits, each pit holding a black hair, and scattered larger ones holding three or four hairs. The sides have no teeth behind the external orbital tooth. Fourth joint of external maxillipedes punctuated, except on the internal marginal portion, which is wide.

Legs covered with large punctuations or scales, especially upon the fourth joint. Sixth joint of the fourth and fifth pair thin. The first pair of legs short, large; the fifth joint large, granular, and has hairs. Hands short, swollen, smooth, and punctuated.

RaNGE.-West Indies, St. Thomas.

\section{Sesarma americana.}

Sesarma americana . . . Saussure.

Carapace striated. Front very wide, being more than half the breadth of the posterior border of the carapace, 
vertical, but having its inferior border strongly upturned in front and arranged in a horizontal lamina. Frontal lobes forming a transverse ridge, and deeply divided by a smooth groove, central and wide, and by two lateral fissures. Branchial regions plicate; anterior portion of the carapace, especially the frontal, transversely ridged, almost scaly. Middle and posterior regions of the carapace well marked, and surrounded with fine folds or ridges. The upturned portion of the front also ridged. The sides of the carapace have no teeth behind the external orbital tooth. The fourth joint of the external maxillipedes is very elongated, triangular, with its edges strongly turned up, especially the internal, of which the upturned border is very narrow. The legs have their joints very compressed; the sixth joint is relatively wide, and the seventh relatively short. The fifth joint of the first pair of legs is very granular, having a faint depression, and the edge ornamented with granular spines. Hands elongated, covered with granular punctures; the fingers longer than the palm.

RANGE.-WVest Indies, St. Thomas.

\section{I0. Aratus.}

Arotus . . . . . . . . H. Milne Edwards, Kingsley.

Sesarma (part) . . . . . H. Milne Edwards.

Carapace trapezoidal, elongated, narrow behind; sides straight; front deflexed, very broad. External maxillipedes as in Sesarma. Walking feet compressed; the last joint very short. 


\section{Aratus pisoni.}

Aratus pisoni . H. Milne Edwards, Kingsley.

Sesarma pisoni. H. Milne Edwards.

Aratapinima. Pison.

Carapace transversely arcuate, the branchial regions obliquely plicate. Front vertical; its margin two-lobed. Fourth joint of first pair of legs triquetral; the margins toothed, the anterior one slightly expanded distally. Fifth joint externally granulate. Hands granulate; the fingers ornamented with pencils of stiff black hairs. The abdomen of the male is of the same shape as that of the female but not so broad.

Fourth joint of the external maxillipedes is short; its distal border truncate or excavated.

The colours of the carapace is green posteriorly, with a yellow tinge in front. The first pair of legs pink. The walking legs green.

RANGE-British Guiana, Brazil, West Indies, West Coast of Nicaragua, Florida.

B. The fourth joint of external maxillipedes short, its distal border truncate or encarated:-

\section{Cyclograpsus.}

Cyclograpsus . . Milne Edwards, Kingsley. Guathochasmus. M'Leay

Carapace depressed, sides arcuate, entire; front about half the width of the carapace. External antenne not excluded from the orbit. The fifth joint of the external maxillipedes articulates with the anterior margin of the fourth.

RANGE.-Pacific and Atlantic Oceans. 


\section{Cyclograpsus integer.}

\section{Cyclograpsus integer. . Milne Edwards. Grapsus integer. . . . Latreille.}

The carapace contracted anteriorly. There is no well-marked gutter behind the external orbital hiatus. The sides of the carapace are entire. The inferior floor of the orbit is well formed, and is separated from the external angle by a notch. Terminal joint of walking legs slightly spiny.

RANGE.-Florida, Brazil.

\section{Subfamily II. Plagusinæ.}

Plagusince. . . . . . Kingsley.
Plagusionce. . . . . Miers, Dana.

Carapace much depressed; internal antenna longitudinally plicated, lodged in notches in the front, are visible on a dorsal view.

\section{Plagusia.}

Plagusia . . Latreille, H. Milne Edwards, Miers, Kingsley, Desmarest.

Cancer . . Fabricius, Herbst.

Carapace depressed, and little, if at all, broader than long, with the antero-lateral margins dentated, and slightly divergent to the bases of the third pair of legs. The front not deflexed, less than half the width of the carapace, is deeply cleft by the antennulary fosse. The orbits are deep, and their anterior hiatus is large and open. The eye-peduncles are very short and robust. The basal joint of extcrnal antenne is considerably dilated, and is slightly produced at its anterior angles; the antero-internal angle reaches the front, and the 
following joint is articulated in the middle of the distal margin of the basal joint. The epistome is transverse. The anterior margin of the buccal cavity is cristated. The endostomian ridges are usually distinctly developed. The external maxillipedes are rather small; the fourth joint is shorter than the third, but not narrower at the base than that joint, distally truncated, and bears the next joint at its summit; the external appendage is slender. The first pair of legs, in the male, is subequal and moderately developed; fourth joint trigonous; fifth joint and the palm usually granulated; palm rounded above and not dilated; fingers distally excavate, with corneous tips. Walking legs large and robust; the fourth joint compressed, with one or more spines on the anterior margin; terminal joint strongly spinuliferous. The abdomen, in the male, broad, triangular, is sevenjointed.

RANGL-Atlantic and Pacific Oceans.

\section{Synopsis of the Species.}

A. Hand granular, having above small tubercles.(P. defresscr.)

$B$. Hand smooth, having above two longitudinal furrows.- $(P \cdot$ gracilis. $)$

\section{Plagusia depressa.}

Plagusia depressa . Say, Miers, De Haan, Desmarest. Plagusia tuberculata Lamarck, Miers.

Camer squamosus. Herbst.

Cancer depressus . Fabricius, Herbst.

Grapsus depressus. Latreille.

Plagusia immaculata Lamarck.

The carapace has above depressed tubercles but no hairs. Front triangular and notched in centre. The 
hands granulous, having above small tubercles; the fifth joint has a notched tooth; the fingers have obtuse tubercles. Legs toothed; a row of small points upon the superior surface of their fourth joint, of which the inferior face is convex and not hairy.

RANGE.-West Indies, Barbados, Cape Verde Islands, China, New Guinea, West Coast of Central America. Found among the stones on the shore, Barbados.

\section{Plagusia gracilis.}

Plağusiugracilis. . . . Saussure.

The epistome is prolonged horizontally in front as a lamina, of which the edge forms four lobes. The antennulary fosse are not prolonged as far as the level of the posterior border of the orbits, and have a slightly raised margin. The lobe placed between the fosse is notched, divided by a groove, and has a tubercule on each side. The superior orbital border has inside an obtuse elcvation placed on a level with the external orbital spine. The carapace has thrce small spines on each side. It is completely covered with small scale-like plaques, surmounted with a tubercle which gives it a warty appearance. These scales are ciliated anteriorly. Upon the cardiac region the warts are arranged in three transverse rows,-the first row has two warts, the last, four. The first pair of legs has one tooth towards the superior extremity of the fourth joint, with inner border ciliated. The fifth joint has above a deep groove, in which are two or three warts. The internal border of this joint has a small ridge strongly ciliated. The hand is smooth, but has on its upper border two strong longitudinal grooves, and more on the inside, a line 
strongly ciliated. The other legs have a line of granules placed upon the anterior face of their fourth joint.

RANGE.-West Indies, Cuba.

\section{Family V. Pinnotheridæ.}

Pinnotheride . . . . Miers.

Pinnothcriens . . . . H. Milne Edwards.

Carapace usually more or less membranaceous, convex or depressed, with the antero-lateral margins entire or but very slightly dentate; front, orbits, and eye-peduncles very small. The buccal cavity is usually arcuate anteriorly. The fourth, and usually the third, joint of the external maxillipedes is well developed, and the fifth joint articulates with it at the summit or at the anterointernal angle, or, more rarely, at the antero-external angle. The first pair of legs, in the adult male, is small or moderately developed. Walking legs are slender and usually naked; terminal joint styliform, unarmed. The abdomen of the male does not cover the sternum between the base of the last pair of legs.

Individuals of this family may be found in the West Indian Sea; they are very small, and usually live in shells along with their legitimate tenant, so may be easily overlooked. It is on this account that I give a definition of the family and of the various subfamilies as given by Mr. Miers in the Challenger Reports.

\section{Synopsis of tile Subamilies.}

$A$. Carapace convex, subglobose, or transverse.

a. Front not rostrated.

$a^{1}$. Third joint of the external maxillipedes rudi- 
mentary or very short; last joint of walking legs very short. Walking legs well developed.-(Subfamily Pinnotherina.)

$b^{1}$. Third joint of the external maxillipedes and last joint of walking legs are distinctly developed. Last pair of walking legs rudimental or wanting.--(Subfamily Herapodince)

$B$. Carapace convex, usually subglobose.

b. Front rostrated; rostrum deflexed. The external maxillipedes bulgre out beyrond buccal cavity, and their third and fourth joints are well developed. Last joint of walking legs styliform and well developed.-(Subfamily Myctirinc.)

C. Carapace flattened, more or less triangulate.

c. Front rostrated. Third joint of the external maxillipedes and last joint of walking legs well developed.(Subfamily Hymenosomine.)

\section{Tribe IV. Oxystomata.}

Orystomata. . . . . . . Miers.

Orbiculata . . . . . . Latreille.

Oxystomes . . . . . H. Milne Edwards.

Leacosoidea vel Orystomatia . Dana.

Carapace convex or depressed, transverse, with the antero-lateral margins arcuate or orbiculate, or even subglobose, or more or less oblong, with subparallel or slightly convergent margins. Internal antenne longitudinally or obliquely plicated. Epistome very much reduced or rudimentary. Buccal cavity more or less triangulate, nearly always produced and narrowed in front, with the margins anteriorly convergent. The afferent channels to the branchix enter either behind 
the pterygostomian region and in front of the first pair of legs, or, more rarely, at the antero-lateral angles of the palate. Branchixe six to nine. The fifth joint of the external maxillipedes is articulated either at the antero-internal angle, at the antero-external angle, or at the distal extremity of the fourth joint, and is frequently concealed beneath it.

The verges of the male exserted either from the sternal surface, or more usually from the base of the last pair of legs, which is either gressorial, natatorial, or feeble, and raised upon the dorsal surface of the carapace.

RANGE.-At great depths of the ocean or at moderate depths, but not shallow-water forms, in temperate and tropical seas.

\section{Family I. Calappidx. \\ Family II. Matutidæ. \\ Family III. Leucosida. \\ Family IV. Dorippidæ.}

\section{Sinolsis of tile Families.}

I. Posterior legs normally developed.

A. Afferent channels to branchia open behind the pterygostomian region in front of first pair of legs.

I. The fifth and following joints of the external maxillipedes not completely hid behind the fourth joint. -(Calappidu.)

2. The fifth and following joints of the external maxillipedes completely concealed behind the fourth joint.-(Matudida.)

B. Afferent channels to branchix open at the anterolateral angles of the palate.

3. The fifth and following joints of the external 
maxillipedes are completely hid behind the fourth joint. -(Leucoside.)

II. Posterior legs feebly developed, and raised on the dorsal surface.-(Doriffide.

\section{Family I. Calappidæ.}

Calappide. . . . . Dana, Miers.

Calappiens (part) . . H. Milne Edwards.

Afferent channels to the branchixe opening behind the pterygostomian regions, and in front of the first pair of legs; the fifth and following joints of the external maxillipedes are not wholly concealed by the fourth joint. The intromittent sexual organs in the male are exserted from the base of the last pair of legs. Posterior legs normally developed.

\section{Subfamily Calappinæ.}

$$
\text { Calappina . . . Dana, Miers. }
$$

The four posterior pairs of legs are formed for walking, not dilated and expanded for swimming.

Synopsis of the Genera.

$A$. No large lateral spine on fifth joint of first pair of legs.-(Calappa.)

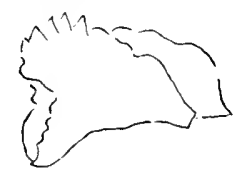

Calaffa.

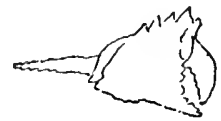

Acanthocarpus.

B. A large lateral spine on fifth joint of first pair of legs.-(Acanthocarpus.) 


\section{Calappa.}

Calapper . . . . Tabricius, H. Milne Edwards, Miers.

$\left.\begin{array}{ll}\text { Lophos } & \text { (subgenus) } \\ \text { Gallus } & \text { (subgenus) }\end{array}\right\}$. De IIaan.

Carapace very convex and tuberculated, rounded in front, with the antero-lateral margins, regularly arcuated and granulated or toothed; and the postero-lateral margins prolonged into two large rounded wings or clypeiform expansions, which partly cover the walking legs, with dentated margins. The front is very small, triangulate or concave in the middle line. Orbits very small, circular. Eye-peduncles short and robust. Internal antenne nearly vertically plicated. Basal joint of external antenne usually more or less dilated, occupying the wide inferior hiatus of the orbit; flagellum short. The external maxillipedes do not entirely cover the buccal cavity, which is narrow and prolonged in its anterior part, and divided by a median septum; the third joint is not produced at its antero-internal angle; the fourth joint is subacute or distally truncated, and emarginate at its antero-internal angle, where the next joint is articulated. The first pair of legs is equal, very large, and can be closely applied to the body; third and fourth joints triangular in section; palm vertically very deep, and laterally compressed, and armed above with a stongly dentated crest; the fingers of the right and left hand are somewhat dissimilar usually, and have acute tips. Walking legs slender and of moderate length, with styliform terminal joints. The abdomen of the ma'e covers the sternum at the base, between the base of the last pair of legs, and is usually five-jointed. 
RANGE.-Mediterranean Sea, Seas of India, Seas of Australia, Mexico, California, West Indies, West Africa, Cape of Good Hope.

\section{SynOpsis OF THE SPECIES.}

A. Latero-posterior expansions of the carapace hardly extend beyond the antero-lateral border.-( $C$. angustata. $)$

$B$. Latero-posterior expansions of the carapace extend beyond the antero-lateral border.

a. Front entire and triangular.-(C.gallus.)

b. Front deeply notched in the middle. $-(C$. marmorata.)

\section{Calappa angustata.}

\section{Calappa angustata. . . . A. Milne Edwards.}

The carapace is straight behind; the latero-posterior expansions scarcely extend farther outwards than the latero-anterior border. The edges are finely granular; the expansions are toothed, and they are united to the posterior border by a slightly cut oblique line. The front is deeply notched in the middle line, and when viewed from above looks two-lobed. The surface of the carapace is covered with protuberances.

RANGE.-Grenada, Barbados, Santa Cruz; in deep water.

\section{Calappa gallus.}

Calappa gallus . . H. Milne Edwards, Dana, Miers, Capello.

Calappa galloides. Stimpson.

Gallus gallus . . . De Haan.

Cancer gallus. . . Herbst.

Carapace very elevated, and covered with large unequal tubercles. Front entire and triangular. Teeth of 
the posterior border of the carapace scarcely prominent. Wing-like expansions very large.

RANGE.-Mauritius, Bermuda; in deep water.

\section{Calappa marmorata.}

Calappa marmorata. . . . Desmarest, H. Milne Edwards, Gibbes, Kingsley, Fabricius.

Calappagramulatar . . . De Haan.

Calappaflammea. . . . . Bosc, White, Herbst, Miers.

Cancer flammea . . . . . Herbst.

Fountain crab (local name). Barbados.

Carapace wide, curved, and entirely covered with granulations; surface raised here and there into conical elevations. Front wide and notched in the centre. Latero-posterior expansions large, exceeding much the antero-lateral border of the carapace, and armed with five wide, obtuse teeth. Vertical crest of the arm strongly toothed. Abdomen of male has seven joints. The general colour is yellow, the conical elevations on the front of the carapace being surrounded with a thin line of red, with blotches of the same colour on the base of the postero-lateral teeth and on the first pair of legs.

RANGE.-Barbados, Bermuda, Florida, Cape of Good Hope; in deep water.

\section{Acanthocarpus.}

Acanthocarpus. . . Stimpson.

Body ovate, convex in its antero-posterior dorsal outline. Carapace as broad as long, broadest in front. 
Antero-lateral and postero-lateral margins continuous; the latter armed with a strong tooth about its middle. Fronto-orbital region very broad, occupying more than one-half the width of the carapace. Eyes large. The external maxillipedes not reaching the anterior extrenity of the buccal area; third joint truncated in front, without projecting at the inner angle, which, like the outer one, is a right angle; fourth joint, shorter and broader than the third, is narrowed in front, with the next joint articulating with it at its antero-internal angle; external appendagc reaching tip of fourth joint. First pair of $\operatorname{logs}$ with a great spine on its fifth joint in a horizontal plane, projecting outwards transverse to the axis of the body. Walking feet with slender terminal joints.

RANGE.-West indian Sea; in deep water.

\section{Synopsis of THE SpeCies.}

$A$. Postero-lateral marginal tooth very long, and projecting laterally outwards.-(A. bispinosus.)

$B$. Postero-lateral marginal tooth short, and projecting backwards.-(A. alexandri. $)$

\section{Acanthocarpus bispinosus.}

Acanthocarpus bispinosus . . A. Milne Edwards.

The carapace circular, with a long well-developed lateral spine directed outwards, behind which, on the border of the carapace, there is a series of small teeth. The rostral tooth is long. The external maxillipedes have, outside, a fringe of hairs. The sternal plastron has no lateral groove upon its first articulation.

RANGE.-Grenadines. 


\section{Acanthocarpus alexandri.}

Acanthocarpus alesandri . . . Stimpson.

Surface of carapace concave, with five rows of tubercles anteriorly, placed longitudinally, one in centre and two on either side; posteriorly three ridges, the lateral terminating in the marginal teeth; granules between the tubercles. Lateral spine short and directed backwards. The posterior margin is arcuate, with a protuberance in middle; margin outsicle orbit wavy for a short distance. Orbits large, without fissures; margin toothed. Front not toothed, and separated from orbits by a projection, not a notch. Spine of fifth joint of first pair of legs half the length of carapace, with a second stout spine, not as long, at its base; both are granulated. Hand has a seven-toothed crest above and a sixtoothed crest on outer surface extending from the base of fingers to postero-inferior angle; other tubercles on surface. Walking legs naked, unarmed, with smooth polished surface.

RaNGE.-St. Lucia, Grenadines.

\section{Family II. Matutidæ.}

\section{Matutide . . . Dana, Miers.}

Afferent channels to the branchix opening behind the pterygostomian region, and in front of the first pair of legs. The fifth and following joints of the external maxillipedes are concealed by the triangular acute fourth joint. Posterior legs normally developed.

\section{Subfamily Hepatinæ.}

Hepatince . . . Stimpson, Miers.

Carapace with the antero-lateral margins arcuated. Legs formed for walking, not for swimming. 


\section{Synopsis of the Genera.}

$A$. Carapace wider than long. Front not in the form of a rostrum.-(Hepatus.)

$B$. Carapace nearly as long as broad. Front produced into a rostrum.-( Osachelar.)

\section{Hepatus.}

Hcpatus . . Latreille, H. Milne Edwards. Calappa. . Fabricius.

Carapace very wide, convex, regularly bowed in front, strongly contracted posteriorly; hepatic regions very large, branchial regrions small. Front narrow, straight, very prominent and placed much above the level of the lateral border of the carapace, which is prolonged under the orbits to reach the sides of the buccal cavity. The orbits are small, circular, and placed upon the level with the front. The internal antennæ, wide apart, are folded under the front. The external antenne occupy the internal angle of the orbit. Their basal joint is narrow, but very long; the second joint is small, and the flagellum is almost rudimentary. The buccal cavity, narrow in front, regularly triangular, is advanced to a level with the inferior border of the orbits, and is completely covered by the external maxillipedes, of which the fourth joint is triangular. The first pair of legs strong, without being very large, and can fold themselves exactly against the front of the body and become concealed. The hand has a crest above, and the pincers are slightly inclined downwards and inwards. The walking legs are of moderate length.

The abdomen has seven segments.

RANGE.-West Indies, warm American Seas. 
Synopsis of the Species.

A. External surface of hands with many wart-like tubercles.-( $H$. tubcrulatus. $)$

$B$. External surface of hands with many rows of small sharp points.-(H. fisciatus. $)$

\section{Hepatus tuberculatus.}

Hepatus tuberculatus. . . ' Saussure.

Each of the antero-lateral borders has a series of twelve obtuse teeth; the lobes of the lateral prolongations of the branchial regions are themselves bi- or tri-lobed; and on the postero-lateral border there is one tooth situated behind the lateral angle. The carapace is much curved in every direction, feebly granular, and has many transverse eminences and tubercles, which have a raspberry appearance; there are two on the gastric region, one on the genital region, one on the cardiac region, and two on each branchial region.

Hands short, with a superior toothed crest, having their external face very warty, arranged in three or four transverse series. The colour is pink.

RANGE.-Guadeloupe, Coast of Guiana.

\section{Hepatus fasciatus.}

Hepatus fasciatus . . Latreille, Say, Desmarest, H. Milne Edwards.

Hepatus angustatus. . White, Dana.

Cancer frinceps . . . Herbst, Bosc.

Culappa angustata. . Fabricius, Bosc.

Antero-lateral borders of the carapace divided into twelve or thirteen more or less rectangular teeth, which 
have each a toothed margin. Anterior border of the front large and obtuse; the line which descends obliquely from the external orbital angle to the anterior border of the carapace is scarcely indicated. The external face of the hands has many rows of small very sharp points. The carapace is yellow spotted with red; legs yellow with transverse red bands. Length about two and a half inches.

RANGE-West Indies, Florida, Aspinwall, Brazil.

\section{Osachela.}

\section{Osachelar . . . Stimpson.}

Like the genus Hepatus. The carapace is nearly as long as broad, depressed, and expanded at the sides, with an uneven surface. Front produced into a rostrum.

R.NGE.--West Indian Sea.

\section{Osachela tuberosa.}

Osachela tuberosa. Stimpson, A. Milne Edwards.

Carapace somewhat octagonal, very slightly broader than long; surface very uneven, deeply pitted on the protuberances, and punctuated on the depressed parts. Three protuberances on the gastric region; one on cardiac region rounded. The branchial lobes are larger than the gastric; no protuberances on hepatic regions. Front bi-lobed, separated by a deep furrow. Anterolateral margins straight or slightly concave anteriorly, but quickly curving backwards and becoming parallel to the axis of body in the posterior part of their length ; they have irregular teeth ; posterior tooth largest. Posterolateral margins nearly straight, obtuse, rugose, and have two or three tuberculiform teeth, of which one, separated from the posterior extremity of the carapace by a con- 
cavity, is the largest. Posterior extremity of carapace narrow, with a rugose margin conccaling base of abdomen ; under surface pitted

First pair of legs stout; outer surface rugose with tubercles and pits; hand with four teeth on superior crest. IValking fect (except last joint, which is stout and hairy below) naked, compressed, and crested above and below.

RANGE.-Barbados, Montserrat, Dominica, St. Vincent, Grenada; in deep water.

\section{Family III. Leucosidæ.}

Lcucosida . . . Dana, Miers.

Leucosiens . . H. Milne Edwards.

Afferent channels to the branchix opening at the antero-latcral angles of the palate, and not behind the pterygostomian region. The fifth and following joints of the external maxillipedes are wholly concealed behind the triangular fourth joint. The intromittent sexual appendages in the male are exserted from the sternum. Posterior legs normally developed.

\section{Subfamily Iliinæ.}

\section{Iliine. . . . . Miers.}

The anterior frontal region of the carapace is not narrowed and produced anteriorly. No thoracic sinus is developed.

Synopsis of the Sections and Genera.

I. The carapace is not produced over the bases of the walking legs. The palms of first pair of legs very slender and elongated; the fingers slender, nearly straight, or with incurved tips. Pterygostomian channels have usually two notches at the distal extremity.-(Sect. I.) 
$A$. Three spines on posterior borcler of carapace. Fingers open in a vertical plane.

a. Three spines conical.-( /lica.)

b. Central spine conical; latcral spines flattened, triangular.-(Iliacanther.)

$B$. Five spines on posterior border of carapace. Fingers open in a horizontal plane.-(Myropsis.)

II. The carapace is not produced so as to cover in great part the walking legs. The first pair of legs robust ; the palm and fingers compressed, not long and slender.(Sect. II.)

C. External appendages of external maxillipedes broad, with external margin curved.-(Ehalia.)

D. External appendages of external maxillipedes narrow, with external margin straight.-(Persiphonc.)

\section{Section I.}

Iline . . . Stimpson.

The carapace is not produced over the bases of the walking legs. The palm of the first pair of legs very slender and elongated; the fingers very slender and nearly straight, or with the tips slightly incurved. The pterygostomian channels have usually two notches at the distal extremity.

\section{Ilia.}

Ilia . . . Leach, Milne Edwards, Desmarest, Latreille, Roux.

Leucosiar . Fabricius.

Cancer . . Linné, Herbst.

The carapace is globular, and rather swollen than contracted about the hepatic regions; the antcrior pro- 
longation which terminates in the front is short, but very distinct and a little elevated. The front, deeply notched in the centre, is advanced in the form of two small obtuse horns in front of the epistome. The superior orbital borders have on the outside two fissures more or less distinct. The antennulary fosse are very oblique, but small, and their external angle is advanced much in front of the orbits. The buccal cavity, triangular, is separated from the pterygostomian regions by a prominent and straight border. The first pair of legs thin and very long, about twice the length of the body; the hand contracts much towards the origin of the pincers, and is twisted on its axis so that the fingers open in a vertical plane. The fingers are armed with small conical and very pointed teeth, separated by similar but longer teeth. The other legs are almost cylindrical and very long; those of the second pair are about once and a half times the length of the carapace; their last joint is styliform, and laterally compressed rather than depressed. The abdomen of the male has the first and last two segments free, and the three intermediate segments soldered together. In the female the penultimate segment is soldered to the preceding scgments.

RANGE.-Mediterranean Sea, West Indies.

\section{Ilia punctata.}

$\begin{array}{ll}\text { Ilia punctata . . . H. Milne Edwards. } \\ \text { Cancer punctatus } & \text {. Herbst. } \\ \text { Leucosia punctata } & \text {. Fabricius. }\end{array}$

Carapace slightly convex and granular, terminating laterally in a granular border. The posterior border has three long conical tecth, situated on the intestinal region and directed backwards. The pterygostomian region is 
slightly swollen. First pair of legs almost three times as long as the postfrontal portion of the carapace.

RANGE،-West Indies, Jamaica.

\section{Iliacantha.}

Iliacantha. . Stimpson, Miers.

Carapace convex, ovoid or subglobose; the lateral margins arcuated, with a protuberance or tubercle upon the pterygostomian region, and with three posterior lobes or spines. The front is narrow, and slightly concave anteriorly; the orbits have indications of three marginal fissures, and a wide interior hiatus. Eyes small. The pterygostomian channels, at thcir anterior extremities, project beyond the orbits, being strongly defined and bi-emarginate. Internal antennæ slightly oblique. Basal joint of external antenne slender, not filling the interior orbital hiatus. The external maxilipedes have their fourth joint triangulate; external appendages rather narrow, with the exterior margin straight. First pair of legs slender and rather long, with the fourth joint subcylindrical and granulated; palm slender, narrowing distally and somewhat contorted, so that the fingers open vertically; the fingers, very slender, are armed with fine, usually spinuliform, teeth. Walking legs slender and of moderate length. The abdomen, in the male, is composed of seven free joints.

RANGE.-Florida Straits to Bahia through the West Indian Sea; in deep water.

\section{Iliacantha subglobosa.}

Iliacantha subglobosa. Stimpson, A. Milne Edwards.

Carapace subglobose, smoothly and evenly convex, and unarmed, except posteriorly, where there are three 
spines, middle one largest, curved upwards; lateral ones flattcned, triangular. Hepatic regions swollen; margin of carapace distinct and acute on hepatic region, and on the anterior part of branchial regions. First pair of legs, in female, two and a half times as long as carapace, including the spine, granulated; fingers very slender, longer than palm, and have thrce ncedle-like teeth. Walking legs slender, smooth, those of first pair reaching to the middle of palm; fourth joint as long as the thrce terminal joints.

RANGE.-Montserrat, Dominica, Barbados.

\section{Myropsis.}

Mj'ropsis . . . Stimpson.

The carapace has five posterior spines. There is no median hepatic ridge. Basal joint of external antenne indurated and crested. The anterior extremity of the pterygostomian channels do not reach beyond the orbits. The fingers of the first pair of legs open in a horizontal plane. The outer margin of the external appendage of the external maxillipedes straight. The abdomen of the male is seven-jointed, and all seven segments may be soldered together (Stimpson); or only the third to the sixth segments, all included, may be joined together-(A. Milne Edwards.)

RANGE.-West Indian Sea ; in deep water.

\section{Synopsis of tile Species.}

A. Carapace subglobular.-( $M$. quinquespinosa.)

$B$. Carapace contracted in front.-( $M$. constricta. $)$

\section{Myropsis quinquespinosa.}

Myropsis quinquespinosa. . . Stimpson.

Body and first pair of legs granulated above and below. Carapace subglobular, regularly convex; in- 
testinal and cardiac regions only defined; hepatic region not swollen; cervical sulcus obsolete. Lateral margins regularly arched. Of five posterior spines, the median one is on intestinal region, the outer ones are about the same size and are on a lower level; the outermost ones, placed on the branchial regions over the insertion of the posterior feet, are small. There is a spine at the middle of the lateral margin, and one on the hepatic region. The frontal teeth are obtuse and not very prominent.

First pair of legs cylindrical; fourth joint more than two-thirds as long as the carapace; fingers, longer than palm, have acute teeth varying in size. Walking feet naked (except terminal joint) cylindrical ; first pair onesixth longer than the carapace.

RanGE.-Martinique, Grenada.

\section{Myropsis constricta.}

Myropsis constricta. A. Milne Edwards.

The carapace, instead of being globose, is restricted in front; and the granulations, in place of being regular, are very small upon the middle and posterior part, and short.

RANGE.-Barbados.

\section{Section II.}

Ebaliince (part). . . Stimpson.

The carapace is not produced so as to cover in great part the walking legs. The first pair of legs robust, not slender; the palms and fingers compressed, not slender and elongated. 


\section{Ebalia.}

Ebalia . . . Leach, H. Milne Edwards, Dana, Bell, Desmarest, Latreille.

Phlyitia. . Bell.

Bellidilia . Kinahan.

Cancer. . . Pennant.

Carapace transverse and often rather longer than broad, suborbiculate or subrhomboidal, with the dorsal surface moderately convex or depressed, uneven, tuberculated or obscurely carinated the front emarginated or subtruncated or quadridentated; the hepatic regions are usually concave; the lateral margins are entire or more or less distinctly tuberculated or toothed, but the tubercles are very rarely spiniform. The orbits are very small, circular, with two or three closed marginal fissures and an interior hiatus; the eyes very small. Antennulary fossx oblique, or nearly transverse. The external antenne are very small, and their basal joint enters the interior orbital hiatus. The buccal cavity is not separated from the antemulary fosse by any distinct epistoma, and the endostomian ridges are very strongly defined. The external maxillipedes cover the whole of the buccal cavity; their fourth joint is triangulate, and the external appendage, broad, has a somewhat curved exterior margin. The first pair of legs, in the male, is subequal and of moderate length, or more rarely considerably elongated, with the fourth joint subcylindrical or somewhat trigonous; palm and fingers usually compressed. Walking legs slender, small, with the joints usually smooth; last joint styliform.

Abdomen, in the male, narrow, four or five-jointed, with several of the intermediate segments coalescent; 
it covers the sternum at the base between bases of last pair of legs.

RANGE.-Atlantic and Indo-Pacific regions; in dccp watcr.

\section{Ebalia stimpsonii.}

Ebalic stimpsonii . A. Milne Edwards.

Carapace hexagonal, covered with flat and very close granulations, larger on the posterior part; front notched. Posterior cardiac lobe prominent and surrounded by a deep groove. The latero-posterior borders have a lobiform dilatation on a level with the antcrior cardiac groove. The posterior border terminates laterally in lobiform and round angles. First pair of legs very long, entirely covered with granulations like those on the carapace. Walking legs small, with finer granulations. Under surface granular.

RANGE.-Barbados.

\section{Persephona.}

Persephona . . Leach, H. Milne Edwards, Dana, Bell, Miers.

Guaia . . . H. Milne Edwards.

Resembles $M y y^{\prime} a$, except the carapace is more depressed and orbiculate, the internal antennæe are more transversely plicated, and the legs are morc robust. The external appendage of the external maxillipedes is narrow, and has a straight external border, not arcuated and slightly dilated at the base. MIyra (Leach). -Carapace dorsally very convex, and more or less distinctly granulated, with the lateral margins regularly arcuated; it has three posterior spines (the median one 
being more elevated, and situated on the posterior margin), and there is usually a more or less distinct protuberance on the pterygostomian region. The front is concave, and does not project beyond the anterior margin of the buccal cavity. The orbits are very small and circular, with usually three deep marginal fissures, and with a rather large inferior hiatus. Eyes very small. Internal antennæe somewhat obliquely plicated. External antenna with a slender basal joint, which scarcely reaches the front. The external maxillipedes cover the buccal cavity, and the fourth joint is triangulate and acute; the external appendage is rather broad, about as broad as the endognath, and its external border is slightly arcuated. The first pair of legs is subequal in the male, and sometimes considerably elongated; the fourth joint subcylindrical and sometimes exceeding the carapace in length; palm subcylindrical or compressed, not dilated; fingers rather robust, compressed, and distally acute; walking legs are relatively small, with the last joint styliform. The abdomen, in the male, is usually fourjointed, with all the segments except the first, second, and last coalescent.

\section{Synopsis of the Species.}

A. Three spines on the posterior part of the carapace.

«. Carapace covered with granulations.

$a^{1}$. Carapace regularly curved.- ( P. punctato.

${ }^{2}$. Carapace gradually and obtusely dilated anteriorly. -(P. latreillii. $)$

$c^{1}$. Carapace almost angular anteriorly.-(I'. lamarckii.)

$B$. Three spines upon the external border of the carapace.-(P. lichtenstenii.) 


\section{Persephona punctata.}

Persephona punctatar. . . . . Stimpson, Kingsley, Miers.

Perscthona gratia. . . . . . Bell.

Cancer punctatus . . . . . . Brown, Linné.

Gucria punctata . . . . . . H. Milne Edwards.

Carapace regularly curved, and covered with small granulations, somewhat separated from each other; front bi-lobed; lateral borders of the carapace ornamented with small points; a strong conical and horizontal spine upon the inferior part of the intestinal region, and two others a little above, at the extremity of the posterior border, which is granular. Pterygostomian regions swollen, with a small tubercle directed outwards. First pair of legs strong; about of a size in both scxes; fourth joint granular, hand slightly granular on the superior border. Remaining legs smooth, with the last joint styliform and grooved.

Colour yellow, with red spots.

RANGE.-West Indian Sea, Bahia; in shallow water.

\section{Persephona latreillii.}

Persephona latreillii . . H. Milne Edwards, Leach, Desmarest.

Anterior part of the carapace gradually and obtusely dilated; covered with granulations; three equal curved spines posteriorly. Fourth joint of first pair of legs tuberculous.

RAnge.-West Indian Sea. 


\section{Persephona lamarckii.}

Persephona lamarckii . . II. Milne Edwards, Leach, Desmarest.

Anterior part of the carapace almost angular, with scattered granules; three equal curved spines on the posterior border. Fourth joint of first pair of legs granular.

RANGE.-West Indian Sea.

\section{Persephona lichtenstenii.}

Persephona lichtenstenii . H. Mihne Edwards, Leach, Desmarest.

Carapace flat, covcred with scattered granulations; armed with a tubercle at each lateral angle, and with three slightly curved spines, of which the middle one is the longest, upon the external border.

RANGE.-West Indian Sea.

\section{Family IV. Dorippidæ.}

Dorippide . . . Dana, Miers.

Dorippiens . . . H. Milne Edwards.

The afferent channels to the branchixe open (normally) behind the pterygostomian region and in front of the first pair of legs; the fifth and following joints of the external maxillipedes are not conccaled by the fourth joint. The two to four posterior legs are short and feeble, and are raised on the dorsal surface of the carapace. The sexual appendages in the male are exserted from the sternum. 


\section{Synopsis of the Genera.}

I. Buccal cavity more or less triangular.

i. Carapace narrow in front.-(Cyclodorifte. $)$

B. Carapace with a rostrum.

a. Ocular peduncles are developed, but there is no cornea.-(Cymonomus.)

b. Eyes normally developed-(Cy'mofolns.

II. Buccal cavity nearly quadrate.

C. Carapace broadly transverse, with dentated, not spinous front.

c. Genital orifice of female is on the second sternal segment.-( $C_{y}$ mmopolia. $)$

I. Buccal carity more or less triangular:--

\section{Cyclodorippe.}

Cyclodorifte. . . . A. Milne Edwards.

The carapace is narrow in front and behind, its lateral borders are reguarly rounded; the greatest width is about the middle. The cres are short and retractile; the partition of the orbit not notched. The buccal cavity is prolonged into a canal that reaches the leve! of the front, but it is valved almost to its cxtrenity below by the external maxillipedes, of which the fourth joint is very long. There is no pterys stomian notch for the entrance of water to the gills above the insertion of the first pair of legs. The abdomen of the male is very small, six-jointed, and received into a leep groove in the sternum, it does not reach the surend stema? joint; of the female, it is large, also of six feces, with parallel edges; its last segment is large, and reache the base of the first pair of legs. 
The genital orifice of the female is in the basal joint of the third pair of legs.

RANGE.-IVest Indian Sca; in deep water.

\section{Symorsis or the SPECIES.}

$A$. Internal antenne are short, can be folded under the front. The fourth joint of the first pair of legs exceed much the lateral border of the carapace.-( $C$. nitida.)

$B$. Internal antennæ are long and cannot be folded under the front. The fourth joint of the first pair of legs scarcely excecd the lateral border of the carapace. - (C. antennaria.)

\section{Cyclodorippe nitida.}

Cyclodorippe nitidar. . A. Milne Edwards.

The carapace is smooth, thick, and not curved; it is slightly depressed transversely behind the front. The branchio-cephalic groove only is distinct; the front is depressed and notched in the middle; the lateral angles are on a level with the dorsal surface of the carapace, and are in the form of two small rostral teeth. The internal antenne are short and folded under the front. There is a spiniform tubercle on each side above and in front of the branchial region. The first pair of legs of the male is large; the fourth joint exceeds much the carapace, it is smooth; the fifth has a small tooth inside. The hand is flat above and very thick; fingers shorter than palm, with some hairs on inner face; second and third pair of walking legs are long, smooth, and terminate in a slightly bowed, styliform finger. The pincers of the female are short.

RANGE.-Grenada. 


\section{Cyclodorippe antennaria.}

Cyclodorippe antemariar . . A. Milne Edwards.

The carapace is oval, and fincly granular on the sides. The front, advanced much beyond the orbital angles, is round and scarcely depressed in the middle line; its edge has fine teeth. The postorbital angle is spiniform; there is a small spine within and in front of the branchial region. The gastric region has three projections, one middle, the others lateral; cardiac region is prominent. The interıal antwure are long and thin, and cannot be folded completely under the front. The orbital wall is slightly advanced. The fourth joint of the external maxillipedes is wide and rounded in front. The first pair of legs of the male is short and granular; the fourth joint scarcely exceeds the carapace; the fingers are very high, and are as long as the palms. The walking legs are long and compressed towards the ends. The two last pairs of legs are very thin. The middle part of the abdomen is elevated into a kind of pad.

RANGE.-Barbados, St. Vincent, Martinique, Dominica, Havana.

\section{Cymonomus.}

\section{Cymonomus. . . A. Milne Edwards.}

The carapace is narrow and terminates in front in a pointed rostrum, on each side of which is inserted the thin ocular peduncles, of equal size but without cornea. The internal antenna, large, cannot be folded under the front. The external arise below and inside the internal, and are shorter than they. The auditory tubercle is developed in a spiniform ridge. The buccal 
cavity has in front, in the middle line, a large notch; it is hid by the external maxillipedes, which are advanced much in such a way as to hide the base of the internal antennx. The third joint of the external maxillipedes is long; the fourth is narrow. The first pair of legs is short, and has pointed fingers. The second and third pair resemble those of Cyclodoriffe; the fourth and fifth are small, folded on the back, and end in a small hooked nail, but they are not cheliform.

The abdomen of the male is short. The last scrment of the abdomen of the female is triangular, with a rounded cnd. The eggs are very laige aid fow in number. The genital orifice of the female opens on the basal joint of the third pair of legs.

\section{Cymonomus quadratus.}

\section{Cymonomus quadratus . . A. Milne Edwards.}

The carapace is subquadrilateral, the antero-lateral edres being placed almost on the same transverse line as the facial region, which is very straight, the surface is little curved and fincly granular; the rostrum is thin and pointed; the antero-lateral edges are armed with some small spines, the postero-lateral are unarmed; the posterior border is wide. The legs of the first pair are feeble and granular; their fingers are as long as the palm. The walking legs are long and smooth.

RAxcie.-Grenada, Dominica, Guadeloupc, Santa Cruz, Havana; in decp water.

\section{Cymopolus.}

Cymopolus . . . A. Milne Edwards.

The eyes are normally developed. The fourth joint of the external maxillipedes do not conceal the fifth and 
following joints. The internal antenne are small, and can be folded under the front.

The legs are short and strong.

\section{Cymopolus asper.}

Cy'mopolus asper . . . H. Milne Edwards.

The carapace thick, larger in front than behind, and having; as well as the legs, many elevated tubercles and truncate spines. The rostrum is large; it is sloping, and notched upon the edges. The legs of the first pair are equal, large and spiny. The walking legs are short and strong; they are entirely covered with spines, as also the cxternal maxillipedes, the sternum, and the abdomen.

RANGE.-Montserrat; in deep water.

II. Bucial carity nearly quadrate:-

\section{Cymopolia.}

Cymopolic . . Roux, Milne Edwards.

Carapace broadly transverse, with dentated (not spinose) front, and dentated antero-lateral margins. Buccal cavity nearly quadrate, not triangulate. The afferent channel to the branchixe opens immediately at the bases of the first pair of legs. The genital orifice of the female, instead of being placed in the third sternal segment, is on the second near the suture of the first.

RAxGF.-West Indian Sea ; in deep water.

\section{STMUTSIS OF TIE SIECIES.}

A. The lateral edges of the carapace have three teeth.

a. Orbits very little adranced.-(C. sice.)

b. Orbits advanced so that middle lobe of wall hides peduncle when it is retracted.- $(C$. dilatater. 
$B$. The lateral edges of the carapace have two teeth.

c. The last lateral tooth is the most projecting.(C.obess $r$.)

d. The first lateral tooth is triangular and flat; the last is rounded at the base.- $(C$. dentatir. $)$

$C$. The lateral edges of the carapace have one tooth.

$\varepsilon$. The front is very advanced.-(C.gracilifes.)

$D$. The lateral edges of the carapace have no teeth.

$f$. The front is slightly advanced.-(C. cursor.)

\section{Cymopolia sica.}

Cymopolia sica . . . A. Milne Edwards.

The fifth segment of the sternum is prolonged backwards and forms a sharp point which exceeds the carapace, and extends between the base of the corresponding legs and the abdomen; the second and third segments carry a fine and transverse keel which is seen behind the carapace. The front is weakly notched. The latero-anterior edges have three pointed and spiniform tubercles. The dorsal surface is covered with granulations arranged in small groups. The wall of the orbit is very little advanced, and the internal orbital angle is truncated in front. The legs of the first pair are very frail in both sexes. The walking legs are of moderate length ; their fourth joint is granular; the two last joints are very flat and wide.

RAnge.-Barbados, Grenada, Dominica, Santa Cruz.

\section{Cymopolia dilatata.}

Cymopolia dilatata . . . A. Milne Edwards.

Carapace has few knobs, which are more in the form of tubercles. The orbits have projections, of which the 
middle lobe advances in such a way as to exeeed the ocular peduncle when it is retracted. The postorbital angle is short. The lateral edges have three teeth. The first sternal segment is broad, and has a transverse ridge uniting the bases of the sccond pair of legs. There is a prominence behind each external maxillipede and the first pair of legs.

RANGE.-St. Kitts.

\section{Cymopolia obessa.}

Cymopolia obessa . . . A. Milne Edwards.

The carapace is thick, enlarged behind and embossed; the prominences are round and finely granular. Behind they are arranged in a transverse line slightly bowed, about four on each metabranchial lobe and two on the anterior cardiac; these last are the largest. The posterior cardiac lobe has a protuberance, and the posterior edge has six. The front is advanced and divided into four small obtuse teeth; the central is longest. The internal orbital angle is rounded. The superciliary edge has two triangular teeth. The postorbital angle projects, pointed and directed forwards. The suborbital border has two notches, and its internal angle is advanced and rounded at its end. The lateral edges are armed with two teeth separated the one from the other, the last more projecting than the first. The legs of the first pair are very feeble in both sexes. The walking legs are of moderate size; the third and fourth pair are about the same length. The fourth joint is rough and has a tooth above at its extremity; the fifth pair is very weak.

RANGE.-West Indian Sea. 


\section{Cymopolia dentata.}

\section{Cy'mopolic denterta . . . A. Milne Edwards.}

The carapace is narrow, and has knobs and granulartubercles. The front is advanced, and the two median teeth are separated by a deep notch. The postorbital angle is large and sharp. The lateral edge has two teeth hardly separated the first is triangular and flat, the second is rounded at its base. The wall of the orbit is slightly advanced, its middle lobe is truncated in front; the internal suborbital angle is obtuse and short. The legs of the first pair of the male are of unequal size, and large. The largest pincer is swollen, granular above, and the fingers are strong and recurved. The walking legs are of modcrate length; the fourth joint, granular, terminates above in a spiniform angle; the fifth joint has a crest armed with two teeth; the last joint is keeled. The abdomen of the male is long, and the serenth segment advances between the base of the external maxillipedes; it is contracted in the middle of the sixth segment.

RANGE,-Barbados, Santa Cruz.

\section{Cymopolia gracilipes.}

\section{Cy'mopolic sracilites . . . A. Milne Edwards.}

The carapacc, wide, has a strong lateral tooth. The front is very advanced. The fourth joint of the walking legs of the third pair is not very granular. The abdomen of the male has two teeth upon the third segment, and a median spine on the fourth.

RANGE.-Grenada, Montserrat. 


\section{Cymopolia cursor.}

Cymopolic cursor . . . A. Milne Edwards.

The third pair of legs is much longer than the fourth, and is three times the breadth of the carapace. The carapace is large and oval, with the front slightly advanced. The lateral edge has no tooth; in front of the posthepatic groove the branchial region has large tubercles upon their edge. The posterior border has granulations. The wall of the orbit is advanced, with its median lobe rounded. The suborbital internal angle is wide and large. The legs of the first pair are very frail in both sexes. The fourth joint of the walking legs is swollen at the base, and has large tubercles.

Range.-Barbados, Dominica, St. Kitts, Havana.

\section{Suborder II. Anomoura.}

Anomoura . . Dana, Bell, Stimpson, Miers, Haswell. Anomura . Heller, Henderson.

Anomala . . De Haan.

Anomoures. . H. Milne Edwards.

The cephalothorax is more strongly developed than the abdomen. Carapace broad or elongate ; frontal region usually with a rostrum that is united below with the antennular sternum; orbits and antennular fosse selclom present. Antennules and antenne well dereloped, the latter usually situated externally to the eyes and with long flagella. External maxillipedes elongated and pediform. Last thoracic segment often free. Thoracic sterna usually broad in front, narrowed posteriorly. The three anterior pairs of legs well developed; the last pair 
(frequently the fourth pair) slender and small, prehensile, or folded in the branchial chamber.

The abdomen bent under the body or extended, with appendages. Genital openings of the females on the basal joint of the third pair of legs.

Gills nine or more in number on each side.

RANGE--In all seas, more abundantly in hot or warm climates; they may be found on dry land or they may be fluviatile, or range from the shore to extreme depths of the sea.

\section{Group I. Dromidea. \\ Group II. Raninidea \\ Group III. Hippidea. \\ Group IV. Paguridea. \\ Group V. Galatheidea.}

\section{SyNopsis OF THE GROUPS.}

$A$. Last pair of legs small and subdorsal in position.

a. Abdomen folded under the thorax, with, in the female, five appendages, the first pair rudimentary.

$a^{1}$. Carapace subglobose or subquadrate.-(Dromidea.)

b. Abdomen not folded under the thorax, with, in the female, four pairs of appendages.

b. Carapace ovato-oblong.-(Raninidca.)

$B$. The last pair of legs slender and filiform, folded under the penultimate pair.

c. Abdomen semi-extended, composed of six segments; the two terminal segments fused, the penultimate with prominent pair of biramous lamellar appendages.

$c^{1}$. Carapace ovate or subquadrate--(Hitpidec.)

$C$. The last pair of legs small and frequently chelate.

d. Abdomen usually asymmetrical. 
$d^{1}$. Antennal peduncles composed of five segments, the second segment furnished with a projecting spine.-(Pagurider.)

c. Abdomen symmetrical, of seven segments, terminating in a swimming organ.

$c^{1}$. Antennal peduncle composed of four segments.-(Golatheider.)

\section{Group I. Dromidea.}

Dromided . . Dana, Miers, Haswell Henderson.

Dromiaced. . De Haan.

Carapace subglobose or subquadrate, the frontal region narrow. The last pair of legs, sometimes the penultimate pair, subdorsal in position and of small size. Abdomen folded under the thorax, the penultimate segment usually without appendages; five pairs of appendages in the female, the first pair rudimentary. Lateral thoracic apodema united in a common centre, forming a sternal canal. External maxillipedes with the third and fourth joint subquadrangular.

\section{Family I. Dromidæ. Family II. Homolidæ.}

Synopsis of the FaMillies.

$A$. Carapace subglobular or flattened.

a. Fourth and fifth pair of legs subdorsal, usually prehensile.

$\alpha^{1}$. Eyes retractile, with well-defined orbits.

$a^{2}$. Antennules folded into special fossæ.

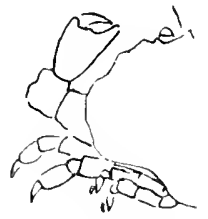

Dromitic. $-($ Dromide $)$ 
$B$. Carapace quadrangular, oval, or subtriangular.

b. Fifth pair of legs (sometimes the fourth pair) subdorsal and prehensile.

$b^{1}$. Eye-stalks very long and thin; orbits not well marked.

$6^{2}$. Antennules not capable of retraction into special fossie.--(Homolida.)

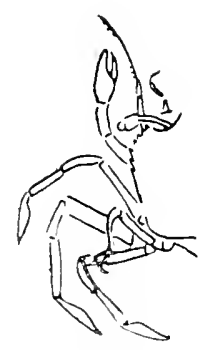

Homoliact.

\section{Family I. Dromidæ.}

Dromida. . . . Dana, Henderson.

Dromiens . . . H. Milne Edwards.

Carapace subglobular, rarely flattened. Legs of moderate size, cylindrical; the fourth and fifth pair (fifth only in Dynomene and Acanthodromid), short, subdorsal in position, usually prehensile. Eycs capable of retraction into well-defined orbits: internal antenna folded in special fosse. Males of many species, pcrhaps all, with the vasa deferentia protruded from the coxal joint of the last pair of legs, and forming tubular prolongations.

RANGE.- Wrarm and temperate seas, in shallow and moderately deep water. Many members of this family are protected more or less by some animal growing on them, or by shells.

\section{Syopeis OF THE GENERA.}

$A$. The fourth and fifth pair of legs have a subdorsal position.

a. The last two pairs of legs subchelate.

$a^{1}$. Sternal sulci in the female not approximated, only produced as far as the segment which bears the second pair of legs.-(Dromia.) 
$b^{1}$. Sternal sulci in the female produced as far as the segment which bears the first pair of legs, approximated towards their termination, and passing into a single tubercle.-(Dromidia.)

b. The last joint of the last two pairs of legs $Y$ shaped.-(Hypoconcha.)

$B$. Fifth pair of legs have a subdorsal position, and are chelate.-(Acanthodromia.)

\section{Dromia.}

Dromia . . . Fabricius, H. Milne Edwards,

De Haan, Dana, Stimpson, Henderson.

Carapace subglobose, usually pilose. Palate smooth. Sternal sulci in the female not approximated, only produced as far as the segment bearing the second pair of legs. Legs of moderate size; their fourth joint not dilated. First pair of legs with their apices calcareous.

Last two pairs of legs subchelate; the penultimate joint terminating in a spiniform process.

RANGE.-West Indies, Coast of Europe to South Coast of England, Canaries, Cape, East Indian Sea, Red Sea, Mediterranean Sea; in deep water.

\section{Dromia lator.}

Dromia lator . . . . . H. Milne Edwards.

Sponge crab (local name). Barbados.

The carapace without noticeable elevations; frontal teeth very prominent; suborbital tooth also prominent. Antero-lateral borders armed with five large teeth, of which the three first are almost of equal size; the 
fourth, not longer than the second and the third together, has at its base a prominent tubercle; the last is very large.

The hairs are short, stiff, and close. The colour is red-brown.

RANGE.-West Indies, Barbados.

\section{Dromidia.}

\section{Dromidir . . . Stimpson, Henderson.}

Carapace pilose; palate furnished with a slight elevation on each side. The sternal sulci in the female produced as far as the segment bearing the first pair of legs approximated towards their termination, and passing into a single tubercle. Appendages of the penultimate abdominal segment minute, concealed. Legs as in Dromia.

RANGE.-West Indies, Bahia, the Cape; in deep water.

\section{Dromidia antillensis.}

Dromidia antillensis . Stimpson, A. Milne Edwards, Henderson.

Body covered with hair, with longer hairs on the sides and feet. Carapace slightly longer than broad, convex, smooth, or may have slight inequalities on the posterior branchial and cardiac regions. Frontal region longitudinally grooved along the middle. Front strongly deflexed, and toothed with five projections, counting the supraocular teeth; teeth over the eyes short but acute. External angle of the orbit prominent but obtuse. Lateral margin of the carapace four-toothed, and deflexed anteriorly towards the corners of the buccal area, where 
there is a tubercle. First three teeth of lateral margin subspiniform; posterior one, situated at the lateral sulcus, as large as the others but less acute.

External maxillipedes elongated; fourth joint large, longer than the third, with its antero-exterior corner prominent, forming a sharp right angle.

First pair of legs rather short and stout, nearly smooth; inferior edges of the third and fourth joint granulated; fifth joint dentated at anterior angles with small teeth; hand short, smooth externally; palm shorter than finger, and armed with two or three small spiniform tubercles on basal half of its superior margin.

Walking legs rather slender, smooth. Last pair of legs much longer than penultimate pair.

Penultimate joint of abdomen in the male elongated and slender; terminal joint longer than broad; none of the joints soldered together.

RANGE.-St. Thomas, Grenada.

\section{Hypoconcha.}

Hypoconcha . Guérin-Ménéville, Stimpson.

Carapace flattened, membranous above; the anterior border arcuate and sharply defined, overhanging a triangular frontal region, the apex of which is directed downwards. External maxillipedes with the fourth joint large, and their external lateral angle somewhat produced; the external appendage (exognath) robust. The two last pairs of legs have their last joint terminating in a $\mathrm{Y}$-shaped end. Sternal sulci in the female widely separated, each terminating in a tubercle opposite the basal joint of the second walling leg.

RANGe.-West Indian Sea to Florida; in shallow water. 


\section{Hypoconcha sabulosa.}

Ifpyoconcha sabulosa . . Herbst, Guérin-Ménéville, Stimpson.

Cancer sabulosus . . . Herbst. Hypoconclar arcuata (?) . . Stimpson.

There are slight notches on the front margin of the carapace, but no notch at the middle, where there is a deep fissure; this margin may be spinulose and densely ciliated, or sparsely toothed. The lower surface of the facial region, maxillipedes, and first pair of legs granulated; but the granules on the latter are finer than those of the facial region. The fingers are toothed. The last two joints of the female abdomen are minutely granulated. It covers its back with the shell of a bivalve.

RANGE-St. Thomas, South Carolina.

\section{Acanthodromia.}

Acanthodromiar. . . A. Nilne Echwards.

The carapace is ovoid. The orbito-frontal region and the external maxillipedes are as in Dromic. The last pair of legs subdorsal in position, and cheliform.

RANGE.-West Indian Sea; in deep water.

\section{Acanthodromia erinacea.}

Acanthodromiar crinaced . . A. Milne Edwards.

The body and legs have many large and close spines. The front, in the form of a beak, projects and terminates in a median spine. The orbits are oblique. The basal 
joint of the external and internal antennæe has spines, and forms the orbit below. The first pair of legs terminates in excavated points, and the fingers have toothed margins. The abdomen of the female is slightly wide and spiny. The lateral pincers of the sixth segment are very small. The epistomian point joins the front.

RANGE.-St. Vincent.

\section{Family II. Homolida.}

Homolide. . Henderson.

Homoliens. . . H. Milne Edwards.

Carapace quadrangular or subtriangular. Legs flattened, or long, slender, and cylindrical; the last pair (sometimes the last two pairs) small and subdorsal in position, prehensile. Ocular peduncle usually slender, and of great length; orbits scarcely represented. Internal antenne not capable of retraction into special fossa.

RANGE.-West Indian Sea, East Coast of the United States, Mediterranean Sea, Pacific and Australian Seas; in moderately deep water.

SynOpsis OF THE GENERA.

A. Last two pairs of legs subdorsal in position, and prehensile.

a. The carapace is oval and elongated.-(Dicranodromia.)

b. The carapace wider behind than in front.-(Homolodromia.)

$B$. Last pair of legs subdorsal in position, and subcheliform. 
c. Carapace quadrilateral, longer than broad. (Homola.)

d. Carapace oval.-(Homolopsis.)

\section{Dicranodromia.}

Dicranodromia . . A. Milne Edwards.

The carapace is oval, elongated, and scarcely hairy. The facial region occupies almost the whole breadth of the carapace. There are no orbits or antennular fossæ. The epistomian point joins the front. The last two pairs of legs are subdorsal in position, and prehensile. The grooves of the sternal plastron of the female are scarcely marked, and do not exceed the level of the third pair of legs.

RANGE.-West Indian Sea.

\section{Dicranodromia ovata.}

Dicranodromia ozata. . . A. Milne Edwards.

The carapace is convex transversely; the lateral borders are almost parallel posteriorly; they diverge slightly behind, the carapace being wider there than in front. The front is formed of two large, triangular teeth, between which is seen a small median point. The superior orbital border has on the outside a straight linear fissure. There is a large notch outside the orbit. The suborbital angle is rounded and lobiform. There are small spines on the external orbital lobe, and on the anterior part of the lateral edges.

The first pair of legs, smooth, is clothed in short down.

RANGE.-Guadaloupe, Barbados, Havana. 


\section{Homolodromia.}

\section{Homolodromic . . . A. Milne Edwards.}

The carapace is narrow, wider behind than in front. The internal antenne cannot be folded in the subfrontal fossa. The external antennæ, very movable, are inserted below the ocular peduncles; they are longer than the carapace. The eyes are small. The buccal cavity is quadrilateral; the epistome is very distinct. The teeth of the extremity of the pincers are sharp. The legs of the second and third pair are very long and frail ; those of the fourth and fifth are folded on the back, small and cheliform.

The abdomen of the male has seven joints, which are in contact only in their median portion, their lateral part being narrow and free.

RANGE.-West Indian Sea.

\section{x. Homolodromia paradoxa.}

Homolodromia paradora . A. Mihne Edwards.

The carapace is thick, very curved transversely, and clothed in down which does not hide the test; its surface is smooth. The front has two strong and triangular rostral horns, which extend as far as the end of the second joint of the external antenne ; there is a large postorbital spine directed outwards, and a little in front. The lateral borders are unarmed and almost parallel. The lateroinferior regions are unarmed.

The anterior legs of the male are feeble, of the same size, covered with hairs, but smooth. The point of the immovable finger is divided to receive the point of the movable. 
The legs of the second and third pair are smooth, cylindrical ; their last joint is very long and curved; their fourth joint has above at its extremity a small spine. The pincer of the fourth and fifth pair is formed by a small hooked finger opposing a dilatation of the preceding articulation, omamented with many spines.

RANGE.-Nevis.

\section{Homola.}

Homola . . . Leach, H. Milne Edwards, De Haan, Dana, Heller, Henderson.

Carapace quadrilateral, longer than broad, terminating in front in a bi- or uni-dentate rostrum; sides vertical. Orbits only affording protection to the base of the eyestalks. Ocular peduncles composed of a long, slender basal part, and a shorter but dilated corneal portion. Internal antenne have the proximal joint of the peduncles swollen, the second and third joint slender. Antennal peduncle slender. First pair of legs of moderate size, with slender fingers. Walking legs long and compressed; the last pair subdorsal in position, and subcheliform. Abdomen composed of seven segments.

RANGE.-West Indies to East Coast of United States, Mediterranean Sea.

I. Homola vigil.

Homola aigil . . . A. Milne Edwards.

The rostral point not bifid; the spines on the body feeble. The legs are large at their extremities.

The pincers of the male are short; the walking legs with the fourth joint armed above with a row of sharp spines. The last joint but one of the legs of the last pair is long.

Range--Guadeloupe, Martinique. 


\section{Homolopsis.}

Homolopsis . . A. Milne Edwards.

Resembles Homola, only the carapace is oval, the rostrum is large, the eyes are small, and the legs are very thin and feeble.

RANGE.-West Indian Sea.

\section{Homolopsis rostratus.}

\section{Homolopsis rostratus . . A. Milne Edwards.}

The carapace, much contracted in front, terminates in a sharp rostrum, directed forwards and clownwards, and surmounted laterally with two strong spines; its point reaches as far as the base of the flagellum of the external antennee At the base of the rostrum there are two large suborbital spines directed upwards and outwards. The hepatic region has a very long spine having the same direction. The branchial lobe has a small spine, as well as the mesogastric lobe. There are two spines on the subhepatic region.

The legss are unarmed and almost cylindrical.

RANGE.-St. Thomas, Santa Cruz.

\section{Group II. Raninidea.}

Raninider . . . Dana, Menderson.

Raminiens . . . H. Milne Edwards.

Raninoidea. . . De Haan.

Carapace ovato-oblong, smooth, the regions not defined; frontal margin of variable width. Walking legs have broad flattened terminal joints; the last pair of small size, and subdorsal in position. Abdomen short, semi- 
extended, not folded under the thorax, with four pairs of appendages in the female. Sterna of the thoracic legs fused to form a ventral shield, which is wide anteriorly.

External maxillipedes moderately elongate. Eyes placed in orbits; internal antenne not furnished with special fosse, and placed to a certain extent behind the external antenne. Vasa deferentia protruded in the males.

RANGE.-IVest Indian Sea, Bahia, Australia, Amboia, Ki Island, Fiji Island, Borneo, Japan; in rock-pools, or deep water. Some may be found in the sand near tidemark.

Only one family.

\section{Family Raninidæ.}

Rerminide. . . . Dana, Henderson.

Characters the same as the group.

Syxopsis OF THE GeNerA.

A. External maxillipedes with third joint longer than the fourth.

a. Fronto-orbital border slightly narrower than the carapace at its middle, with a triangular rostrum.

$a^{1}$. Orbits well defined-(Rominoides.)

b. Fronto-orbital borders less than half the width of the carapace.

$b^{1}$. Orbits ill defined.-(Zandif $r$.)

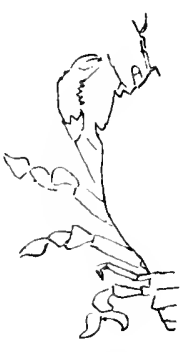

Raninoides.

\section{Raninoides.}

Raninoides. . II. Miine Edwards, Dana, Itenderson.

Carapace convex from side to side. Fronto-orbital border horizontal, slightly narrower than the carapace at 
its middle, with a triangular rostrum. Ocular peduncles capable of retraction into well-defined orbits, with the terminal joint basally dilated; the cornea small. Antennal peduncle of large size (especially the second joint), the flagellum minute. Internal antennæ well developed. External maxillipedes elongate, the fourth joint shorter than the third, of small size; the three terminal joints inserted near the apex of the fourth joint.

Sternal shield broad anteriorly, widely separating the legs of the first two pairs, and becoming narrower between those of the third pair. Last pair of legs situated above and in front of the fourth pair.

RANGE. - West Indian Sea, Pacific Ocean; in deep water.

\section{Raninoides nitidus.}

Raninoides nitidus. . . A. Milne Edwards.

The carapace is contracted in front, and has two spines behind the postorbital angle. The rostral point is straight. The postorbital spine is long, thin, and slightly diverging. The lateral edge of the carapace is slightly bowed.

RANGE.-Grenada.

\section{Zanclifer.}

\section{Zanclifer. . . Henderson.}

Carapace convex from side to side, and from before backwards; its surface partly tmeven. The fronto-orbital border very narrow, considerably less than half the width of the carapace; the frontal region trilobate, produced anteriorly. Eyes rudimentary, placed in ill-defined orbits; the peduncles short, and the cornea of small size 
though pigmented. Antennal peduncle massive, the first segment fused with the carapace, the second with a very prominent external prolongation; the flagellum short. Internal antenne of small size, completely concealed by the antennal peduncles, which meet together in the middle line. External maxillipedes moderately broad, with the third joint twice the length of the fourth. Sternal thoracic shield narrow, becoming linear betwcen the legs of the second pair, but slightly dilating again between the second and third pair.

First pair of legs of considerable length; the palm swollen laterally, the fingers long. Walking legs with hooked terminal joint; the fourth pair of small size, but not filiform. Male generative appendages like those of Raninoides, but shorter.

RANGE.-West Indies, Brazil.

\section{Zanclifer caribensis.}

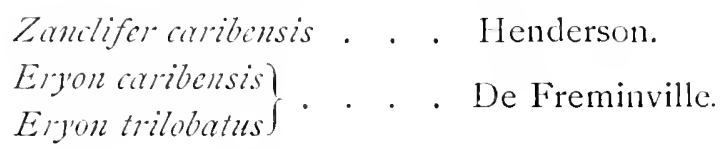

Surface finely granulated. The length of the carapace is one and a half times as great as its breadth. The median lobe of the front is the largest; the orbital portion, short, is marked externally by a rounded tooth. The peduncles of the internal antenne are hirsute. The antennal peduncle is composed of three joints; the external prolongation of the second joint exceeds the remainder of the peduncle; the third joint is of small size; the flagellum is minute, and ciliated on both sides.

The third joint of the external maxillipedes is slightly convex; the fourth joint has a longitudinal sulcus on its outer surface. The pterygostomian region is moderately 
convex, and separated from the carapace proper by a deep groove which becomes continuous with the line on the postero-lateral border. The anterior part of the thoracic sternum has a sulcus on each side, the posterior has a single median groove.

The first pair of legs with the surface finely granular; the fourth joint is slightly hollowed out on its inner aspect. The two fingers slender, excceding the hand in length, their opposed edges with numerous teeth; the apex of the fixed finger is bent over that of the movable one. The walking legs are granulated and fringed with long hairs; the fourth pair flattened from above downwards, with the terminal joint less strongly curved than that of the others.

The abdominal segments are moderately convex, gradually tapering towards the extremity, and fringed with long hairs; the apex of the telson is rounded. The vasa deferentia are protruded as short tubular outgrowths.

RANGE.-West Indies, Brazil; in moderately deep water.

\section{Group III. Hippidea.}

Hippider . De Haan, Dana, Stimpson, Miers, Haswell, Henderson.

Hippiens . . H. Milne Edwards.

Hifpes . . Latreille.

Carapace ovate or subquadrate, comparatively smooth, the regions ill-defined; the frontal margin broad. Walking limbs with flattened terminal joint; the last pair slender and filiform, folded under the penultimate pair. Abdomen semi-extended, composed of six segments (the fifth and sixth fused), the penultimate with a prominent 
pair of biramous lamellar appendages, the last of large size, its length exceeding the breadth. Thoracic sterna linear, not forming a shield.

External maxillipedes moderately broad, suboperculiform. Eyes not provided with distinct orbits; the cornea of small size. Internal antennæ strongly developed, without special fossæ; one of the flagella greatly elongated, the other of moderate size or absent. Antennæ with a massive peduncle composed of four or five joints, with or without a movable projecting spine (acicle); the flagellum short. Males destitute of copulatory organs, and with only a simple pair of abdominal appendages on the penultimate segment.

RANGe. - West Indian Sea, Azores, Brazil, Cape Verde Islands, Seas of Asia, lhilippines, Celebes, New Holland; in shallow water. They may bury themselves in the sand.

\section{Family I. Hippidæ.}

\section{Family II. Albuneidæ.}

\section{SyNopsis of THE FAMILIES.}

A. First pair of legs nonchelate, subcylindrical.

a. Terminal segment of abdomen elongated, lanceolate.-(Hippida.)

B. First pair of legs chelate, flattened.

b. Terminal segment of abdomen ovate-(Albuneida.)

\section{Family I. Hippidæ.}

Hippide . Dana, Stimpson, Miers, Henderson.

First pair of legs nonchelate, subcylindrical. Terminal segment of abdomen elongated, lanceolate. External maxillipedes suboperculiform, the fourth joint broad; 
external appendage (exognath) absent. Antenna with the accessory joint minute or obsolete.

\section{Synopsis of the Genera.}

A. Internal antennæ of moderate length.

a. Antennæe very short.

$a^{1}$. Last joint of external maxillipedes unguiculate.(Remipes.)

b. Antennæ very long.

$b^{1}$. Last joint of external maxillipedes laminate and compressed.-(Hippa.)

\section{Remipes.}

Remipis. . . . Latreille, H. Milne Edwards, Stimpson, Miers, Henderson, Latreille, Lamarck.

Squilla. . . . Petiver.

Cancer . . . . Herbst

Hippa. . . . . . Fabricius.

Carapace ovate, the fronto-orbital border sinuous. Ocular peduncles slender. Antennular peduncle moderatcly stout, one of the flagella strongly developed. Second joint of the antennal peduncle of large size, with a slight external prolongation; the flagellum short.

External maxillipedes with the fourth joint dilated, the third rudimentary, and the last joint unguiculate. Last thoracic segment free. Terminal segment exceeding the remainder of the abdomen in length. Female with three pairs of abdominal appendages in addition to the penultimate pair.

RANGE.-West Indies, Florida, West Coast of Africa, Cape Verde Islands, Asccnsion Island, Pacific. 


\section{r. Remipes scutellatus.}

Remipes scutellatus . . . . . Fabricius, White, Miers, Studer, Henderson.

Remites cubensis . . . . . . . Saussure.

Remipes barbadensis. . . . . . Stimpson.

Hippa scutellata . . . . . . . Fabricius.

Squilla barbadcnsis owalis . . . Petiver.

Sca cockroach (local name) . . Barbados.

Body depressed, broad. Front very broad. Anterior margin sinuated on either side of the very slightly prominent median frontal lobe. Eye-peduncles short.

First pair of legs of moderate length; terminal joint slightly compressed, with two strong, oblique; $3 \cdot$ setose ridges on the inferior surface. Terminal joint of the second and third pair of legs falcate, with the distal as long as and more slender than the proximal half.

Length about an inch; colour white, with light purple marks.

Range-_Barbados, Bermuda, St. Kitts, St. Vincent, Cuba, Florida, Ascension Island, IVest Africa, Cape Verde Islands.

\section{Hippa.}

Hiffa . Fabricius, II. Milne Edwards, Stimpson, Miers.

Internal antemne of moderate length; external antemne with a very long, robust, multiarticulate and strongly ciliated flagellum. Extcrnal maxillipedes with the last joint narrow, laminate, and compressed. First pair of legs with the terminal joint lamellate, oval. 
RANGE.-East Coast of America, from Cape Cod to Brazil.

\section{Hippa emerita.}

Hitpa emerita . . Latreille, Lamarck, Desmarest, H. Milne Edwards, Gibbes, Dana, Miers.

Hippa talpoidea. . Say. $\left.\begin{array}{l}\text { Hitpa emerita } \\ \text { Astacus eneritus }\end{array}\right\}$. Fabricius.

Cancer emeritus . Linné.

Body very convex. Median lobe of the front very triangular, subacute, separated from the lateral lobes by a distance usually greater than its own breadth at base; the lateral frontal lobes are narrow, acute, and much more prominent than the median lobe. Carapace marked with irregular, crenulated, transverse lines, which are nearly obliterated on the sides and towards the posterior margin, and with a distinctly marked postfrontal and postgastric incised line. Eyes very long and slender Internal antennæ densely hairy. Second joint of the external antennæ with three spines on its distal extremity, of which the median is much the longest, and directed slightly outwards. Fourth joint of external maxillipedes with the lobe at its antero-internal angle triangular and subacute. Terminal joint of the second and third pair of legs falcate, very broad at base, narrow and subacute in their terminal halves.

Rami of the appendages of the penultimate abdominal segment short, the outer shorter and broader oval than the inner.

RANGE.-Brazil, Venezuela, Mexico, Martiniquc, Cuba, United States. 


\section{Family II. Albuneidæ.}

Albuncida . . Miers, Henderson.

Albunide . . Stimpson.

First pair of legs terminating in a more or less perfectly subchelate hand. External maxillipedes subpediform ; the fourth joint not greatly enlarged, furnished with an external appendage (cxognath). Last tail segment not greatly elongated, ovato-lamellate,

\section{Synorsis of the Genera.}

$A$. Cornea very small. Fourth joint of external maxillipedes but shortly produced at its antero-external angle.-(Albunca.)

$B$. Cornea not visible. - Fourth joint of external maxillipedes produced at its antero-external angle into a lobe that reaches to or beyond the distal extremity of the penultimate joint.-(Lepidops.)

\section{Albunea.}

Albuncer . . Fabricius, H. Milne Edwards, Miers, Henderson.

Albunca . . Stimpson.

Cancer . . Herbst.

Carapace subquadrate, the fronto-orbital border serrated, with a median notch. Ocular peduncles lamellar, the cornea very small. Antennular peduncle of large size, with a single long ciliated flagellum which exceeds the whole body in length. Antennæ with a welldeveloped peduncle of five joints, the second with a movable acicle; the flagellum short and stout. External maxillipedes moderately slender; the fourth joint oblong, not much longer than the third, with its antero-external 
angle shortly produced. The terminal joint of the second, third, and fourth pair of legs uncinate. Last thoracic segment free. Female with four pairs of abdominal appendages in addition to the penultimate pair.

RANGE.-South Coast of United States to Brazil, Celebes; shallow or deep water.

\section{SyNOPSIS OF TIE SPECIES.}

$A$. The anterior margin of the carapace has six to eight teeth.-(A.gibbesii.)

$B$. The anterior margin of the carapace has ten to twelve teeth.-(A. oryophthalma.)

\section{Albunea gibbesii.}

Albunea gibbesii . . . Miers, Stimpson.

Albuner sy'mmitic. . . Gibbes.

Carapace is broad in proportion to its length; there are but six to eight teeth on the anterior margin. The ocular peduncles are narrow in proportion to their length, and their outer margin is straight. The last joint of the second pair of legs has a broadly triangular but narrow and prominent lobe near its proximal end. The inner ramus of the penultimate pair of abdominal appendages is much broader and nearly as long as the outer; its terminal joint in the male is somewhat oblong, with a narrow prolongation at its distal extremity.

RANGE.-Florida.

\section{Albunea oxyophthalma.}

Albunea oryophthalma . . Leach, White, Miers.

There are ten to twelve teeth on the anterior margin of the carapace, on each side of the median notch. Eyepeduncles are very long, narrow, more than three times 
as long as broad at base, with their outer margin straight. The lobe at the proximal end of the last joint of the third pair of legs is prominent, triangular, and acute, but not narrow at base.

The terminal segment of abdomen in the male is scarcely longer than broad; broadest in the middle, nearly straight at its proximal extremity; that of the female is longer than broad, oblong-ovate.

Length about one and one-third inches.

RAngE.-West Indies, St. Kitts, Cayenne, Brazil.

\section{Lepidops.}

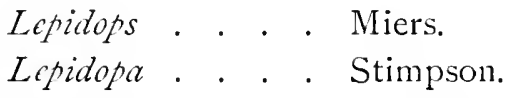

Eye-peduncles lamellate, compressed, almost squamiform; cornea not visible. Internal antennæe long. External antennxe with a very small accessory joint; flagellum very short. The external maxillipedes have their fourth joint produced at its antero-external angle into a lobe that reaches beyond the distal extremity of the penultimate joint.

\section{Synopsis OF THE SPECIES.}

$A$. No noteworthy teeth or spines on anterior margin of carapace.-( L. scutcllata.)

$B$. Anterior margin of carapace tridentate. $-(L$. venusta.)

\section{Lepidops scutellata.}

Lepidops scutellata. . . Miers.

Lepidopa scutellata. . . Stimpson.

Albunca scutellata . . . Desmarest, Gibbes, Dana.

Carapace scarcely emarginate, and without any noteworthy teeth or spines on its anterior margin. 
Eye-peduncles much broader than long, truncate anteriorly.

RANGe.-St. Thomas, Peru.

\section{Lepidops venusta.}

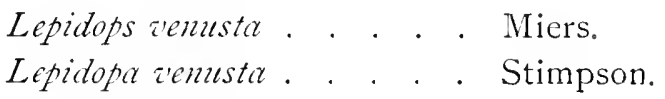

Carapace glabrous, shining; marlings not prominent; transverse sulcus nearly straight. Front tridentate; lateral teeth situated at about half-way between the medium one and the lateral angles. Eye-peduncles large, oval, diverging, and a little thickened below the middle, the minute eye being situated on the inferior surface near the extremity.

Internal antennæ slender, with flagella more than five times the length of carapace. Terminal joint of second pair of legs is sharply excised ; that of the following pairs slender.

RANGE,-St. Thomas.

\section{Group IV. Paguridea.}

Paguridea . . . Henderson.
Paguroide. . . Boas.

Frontal region of carapace usually prolonged in the form of a rostrum. Eyes not provided with distinct orbits; the peduncles cylindrical or subcylindrical. Antennal peduncle composed of five segments, the second segments furnished with a projecting spine (acicle). External maxillipedes subpediform, the third and fourth joint elongate. The first pair of legs well developed, and in most cases of unequal size; the last pair of legs always small, and frequently chelate. 
Abdomen generally asymmetrical, the number of appendages variable.

\section{Section A. Lithodea. \\ Section B. Pagurodea.}

Sinotsis of the Sections.

A. Carapace broadly ovate, uneven; rostrum prominent.

a. First four pairs of legs well developed, cylindrical or subcylindrical; last pair chelate, slender, folded in either branchial chamber.

$a^{2}$. Abdomen bent under thorax. Sternum broad.-( Lithodea.)

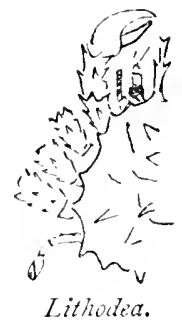

B. Carapace elongate, more or less membranous.

b. First three pairs of legs well developed; two last pairs of small size, one or both chelate.

b. Abdomen spirally twisted or extended, usually membranous. Sternum linear:-(Pagurodea.)

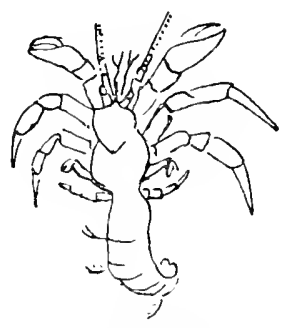

Paguivalia.

\section{Section A. Lithodea.}

Eithodea . . Dana, Henderson.

Lithodeacea . . De Haan.

Lithodided. . Stimpson.

Homoliens . . H. Milne Edwards.

Carapace broadly ovate, uneven, with a prominent median rostrum in front; the regions well defined. The first four pairs of legs well developed, cylindrical or sub- 
cylindrical; the posterior pair slender, chelate, folded in either branchial chamber; abdominal appendages only present in the female, consisting of a rudimentary pair on the first segment, and a single uniramous appendage on each of the four following segments (in Hapalogaster, Stimpson, the first of these is biramous). These last appendages are situated on the left side of the abdomen, which is more or less enlarged at the expense of the other side. Thoracic sterna broad. Antennular peduncles cylindrical and of moderate size, with short flagella.

They live in shallow or deep water in temperate and cold regions. They have been found at the Azores, but I have not come across any mention of them from the Vest Indies; however, as they may be found there, or about Bermuda, I mention them. At first inspection they resemble crabs of the subtribe Orymynch, but are easily distinguished by the last pair of less being much reduced in size.

One family.

\section{Family Lithodidæ.}

\section{Lithodide . . Dana, Henderson.}

The same as the Section.

\section{Genus Lithodes.}

Rostrum long, and spinulous. Abdomen with the third, fourth, and fifth segment provided with paired calcified plates, which in the female are very large on the left side; the median portion membranous, with scattered calcareous particles.

Lithodes agassizii (Smith) has very large spines on the carapace and rostrum.

RANGE.-Azores, East Coast of the United States. 


\section{Section B. Pagurodea.}

Pagurodea . . Henderson.

Paguriens . . H. Milne Edwards.

Paguroidea. . De Haan.

Paguridea . . Dana, Stimpson, Miers, Haswell.

Carapace elongate, the posterior portion to the cervical groove membranous, or less firm than the anterior portion. First three pairs of legs well developed, the last two pairs small, and one or both chelate. Thoracic sterna linear. Abdomen spirally twisted or extended, and usually membranous; abdominal appendages present in both sexes, consisting of a pair always present on the sixth (penultimate) segment, and of usually a single biramous limb present only on the left side of the second to the fifth segments inclusive, the first three of these well developed and ovigerous in the female.

They are usually called Hermit crabs, and are found in all seas in shallow and very deep water; in hot countries some of them live on dry land; they protect their soft abdomen usually by taking possession of an empty shell.

Professor Henderson divides this section into two branches according as to whether their gills are in the form of flat plates (Laminibranchiata) or in the form of round threads (Fibribranchiata).

Family I. Cœnobitidæ.
Family II. Paguridæ.
Family III. Parapaguridæ.

Synopsis of the Branches and Families.

I. Gills in the form of flat plates.-(Branch I., Laminibranchiata.) 
A. Antennular peduncle greatly elongated; the first joint deflexed, and as long as or exceeding the eye-stalls ; one of the flagella enlarged.

a. Antennal peduncle compressed; terminal joint long. $-($ Canobitidle. $)$

B. Antennular peduncle of moderate size, the first joint short and stout; flagella small.

b. Antennal peduncle subcylindrical.-(Pagurida.)

II. Gills in the form of round threads.-(Branch II., Fibribranchiatcr.)

C. Antennular peduncle elongated or of moderate size, first joint short and stout; flagella small.

c. Antennal peduncle subcylindrical. - (Parapag $z$ rida.)

\section{Branch I. Laminibranchiata.}

Gills in the form of flat plates.

\section{Family I. Cœnobitidæ.}

Conobitide. . . . . Dana, Stimpson, Haswell, Henderson.

Antennular peduncle greatly clongated; the first joint deflexed, and as long as or exceeding the eye-stalks, the second and third joint narrow and cylindrical; one of the flagella enlarged. Antennal peduncle compressed; the terminal joint long.

Found on land near the sea or on the seashore in hot countries. To this family belongs the genus Bergus, found in the Pacific, who is said to be able to open a cocoanut with his claw. They are of large size. 


\section{Cœnobita.}

Canobita . Ilenderson, Hilgendorf, Latreille.

Cenobita . H. Milne Edwards, De Haan, Dana, Stimpson, Haswell.

Carapace elongated; the rostrum but slightly marked. Ocular peduncles compressed. The first pair of legs of unequal size, the left the largest. Abdomen soft and membranous, twisted on itself. Firśt five abdominal segments with narrow tergal plates, the sixth with a welldeveloped pair of appendages (of which the left is larger), followed by a well-marked telson.

RANGe.-West Indies, Admiralty Islands, East Coast of Africa, Islands of the Pacific.

\section{Cœnobita diogenes.}

Canobita diogenes . . H. Milne Edwards, Catesby. Pagurus diogencs. . . Latreille.

The gastric region is scarcely convex. Ocular peduncles as long as the anterior border of the carapace, rounded on their superior border, and terminating in hemispherical cornea; their basal scale of moderate size, oval. A sharp and very prominent ridge upon the inferior border of the two last joints of the third left leg.

In the Barbados species the left hand is disc-shaped; with it the animal cloes the shell in which it lives. The colour is a light brick-red with patches of purple on the carapace, ccntre of eye-peduncles, centre of each joint of three first pairs of legs, except the terminal joint of walking legs. The left hand and fingers are almost all purple. These patches of purple have a margin of brick-red round 
them. The terminal appendages of the last abdominal ring are brick-red.

They are found among the trees under the Fort, near the sea.

\section{Family II. Paguridæ.}

Paguride . Dana, Stimpson, Henderson.

Antennular peduncle of moderate size, the first joint short and stout, the second and third slender, cylindrical; both flagella of small size. Antennal peduncle subcylindrical.

RANGE-Most seas; in shallow and deep water.

\section{Synopsis of THE GeNeKA.}

I. Abdomen spirally twisted or bent abruptly, soft and membranous, the segmentation imperfect.-(Pagzrince, Dana).

A. First and second abdominal segment without genital appendages.

a. Fourth pair of legs chelate or subchelate. Nales without a protruded vas deferens.

$a^{1}$. A rostrum present. Flagellum of external antenne naked.

$a^{2}$. Eye-stalks thin and long; basal scales close together.

$a^{3}$. Fingers move in a vertical plane--(Calcinus.)

$b^{3}$. Fingers move in a horizontal plane. - Clibonarius.)

b1. Rostrum distinct or slightly marked. Eye-stalls stout; basal scales wide apart.

$b^{2}$. Abdomen well developed.

$c^{3}$. Fingers move in a vertical plane. Flagellum of external antennæ long and naked.-(Pugumus.) 
$d^{3}$. Fingers move in a horizontal plane. Right hand in the form of an operculum.-(Pylopagums.

$c^{2}$. Abdomen atrophied.

$c^{3}$. Two last pairs of legs monodactyle--(Ostraconotus.)

b. Fourth pairs of legs subchelate. Males with a protruded vas deferens. Branchial lamine have a bifid extremity.

$d^{2}$. Vas deferens opens on the left side.

$f^{3}$. Vas deferens spiral.-(Stiropagums.)

$g^{n}$. Vas deferens curved.-(Anapagrims.)

$\epsilon^{2}$. Vas deferens opens on right side.

$h^{3}$. Vas deferens curved.-(Catapagurus.)

$B$. First and second abdominal segments provided with genital appendages (first segment only in the female).

c. Eye-stalks slender; basal scales far apart. Antennules long.

$i^{3}$. Flagellum of external antennæe usually short and hairy; chelipedes subequal, or equal; fingers move in a horizontal plane. Penultimate pair of legs not chelate.(Paguristes.)

$j^{3}$. Flagellum of external antenne long and naked. Chelipedes unequal, right largest; fingers move in an oblique plane. Penultimate pair of legss subchelate.(Sympagurus.)

C. First abdominal segment only, in the male, provided with genital appendages.

$k^{3}$. Rostrum wide and obtuse. Eyc-stalks strong, with dilated extremity, shorter than antennulary peduncle. Penultimate pair of legs subchelate, last pair chelate.(Tomopagurus.)

II. Abdomen not spirally twisted, composed of distinct movable segments that are usually calcified.-(Cancellina, Dana.) 
l3. Eye-staiks short and stout. Antennæ short and thin. Penultimate pair of legs subchelate, last pair chelate. The penultimate ring of the abdomen has an oval calcified plate.-(Iylopugumus.)

I. Abdomen spirally troisted or bent abruptly, soft and membranous, the segmentation imperfect.

A. First and second abdominal segment without genital appendages:-

\section{Calcinus.}

Colcimus . . . . Dana, Stimpson, Haswell, I Ienderson.

Pagurus . . . . . H. Milne Edwards.

Front with a distinct rostral projection. Ocular peduncles usually slender, the basal scales of moderate size, and situated close together. Antennal acicle short; the flagellum naked. First pair of legs unequal, the left larger; the fingers moving in a vertical plane, excavated internally, and calcarcous at the tips. Second and third pair of legs with short terminal joints. Fourth pair of legs chclate. Males without protruded vas deferens. Surface comparatively smooth, and often highly coloured.

RANGE.-West Indies, Pacific.

\section{Synopsis of tile Spectes.}

A. First pair of legs granular.

$\alpha$. The succeding legs are shightly hairy.- (C. tuberculosus.)

B. First pair of legs smooth.

b. Penultimate joint of third right leg cylindrical.(C. tibicen.)

c. Penultimate joint of third right leg compressed.-(C. sulcatus.) 


\section{Calcinus tuberculosus.}

Pagums tuberculosus . . H. Milne Edwards.

The first pair of legs grantular, the next legs slightly hairy. Length about three inches. Colour, red streaked with yellow:

RANGE-IVest Indies.

\section{Calcinus tibicen.}

Calcims tibicen . . Dana, Stimpson, Heller, Hilsgendorf, Miers, Henderson.

l'agumstibicen . . H. Milne Edwards, Latreille, Olivier, Ilerbst.

Pagurus leimanus. Randall.

Rostrum rudimentary. Eye-stalks longer than the anterior border of the carapace, exceeding the third joint of the internal antennæ; basal scales triangular. Legs entirely smooth; the left hand swollen; pincers obtuse, without terminal nail. The penultimate joint of right third leg cylindrical. The abdomen of the male has four false feet with two terminal laminx. Ovi-bearing false feet of the female large, biramous. Last joint of the abdomen almost symmetrical. Colour yellow red, with large white blotches on the extremities of the legs.

RANGE.-West Indics, Sruth Sea, Tahiti.

\section{Calcinus sulcatus.}

Pagurus sulcatus . . . H. Milne Edwards.

Resembles Calcinus tibicen, except that the penultimate joint of the right leg is compressed, and has outside, 
below its superior border, a wide longitudinal groove. Length about ten lines; colour whitish.

RANGE.-West Indies.

\section{Clibanarius.}

Clibanarius . Dana, Stimpson, Heller, Miers, Haswell, Henderson, A. Milne Edwards and Bouvier.

Carapace dilated posteriorly. Rostrum weak, sharp or obtuse, with the ophthalmic scales close together. The eye-stalks are more or less thin and long, not, or slightly, dilated anteriorly; the peduncles of the antennules and of the antennx are usually short; the acicles are little developed. The gills are in two rows and undivided. The first pair of legs subequal; the fingers, moving in a horizontal plane, are excavated and have horny tips. The penultimate pair of legs subcheliform; the last pair chelate, with long fingers. Males without protruded vas deferens.

RANGE.-West Indies, Bass Strait, Tasmania.

\section{Clibanarius anomalus.}

Clibanarius anomalus. . . A. Milne Edwards and Bouvier.

The carapace, long, deeply notched behind, is smooth, and naked except for a few hairs on the sides and the middle of the front. The rostrum is obtuse. The ophthalmic scales, with a wide base, terminate in a bidentated, lanceolate lamina. The eye-stalks are a little shorter than the brearlth of the frontal border. The cornea have depressions in which are implanted short microscopic hairs. The flagellum is naked, strong, and formed of very short joints; it exceeds the extremity of 
the pincers. Of the first pair of legs the right is slightly the larger; the fourth joint is as long as the fifth and pincers together. The external face of the fifth joint and the hand have large granules. The penultimate pair of legs slightly hairy. The last pair of legs has the pincers longer than the fifth joint, and is rough behind; there are hairs on the edges.

They live in empty shells at great depths.

RANGE.-Barbados, St. Vincent, Cariacou.

\section{Pagurus.}

Pagurus . Fabricius, H. Milne Edwards, A. Milne Edwards, De Haan, Dana, Stimpson, Heller, Miers, Haswell, Henderson, A. Milne Edwards and Bouvier.

Front with a distinct rostral projection, which may be very small. Eye-stallis stout, frequently constricted towards the middle; the basal scales of moderate size, and usually separated by a considerable interval. Antennal acicle short and robust; the flagellum long and naked. The first pair of legs subequal, the left usually the larger ; fingers moving in a vertical plane, slightly excavated internally, and horny at the tips. Penultimate pair of legs chelate. Abdomen well developed; males without protruded ras deferens.

They live in shells, and are found in very deep water.

RAvre.-West Indian Sea, Madeira, Canaries, Cape Verde Islands, West African Coast, Mediterranean Sea, Pacific, Seas of Australia and Japan.

\section{Synotsis of the Silecies.}

A. There is a long, deep, and hairy depression on the superior face of the right movable finger of the pincers, 
and granulations on the longitudinal lines of the walking legs.-(P. striatus.)

$B$. The legs are spiny, and the lateral borders of the cephalo-thorax have spines in front.--(P. insignis.)

$C$. The hands have above a row of strong spines, and are covered in the rest of their extent with tubercles which have each a semicircle of short hairs. $-(P$. gramulatus.)

\section{Pagurus striatus.}

Pagurus striatus. Latreille, Olivier, Risso, Desmarest, Roux, H. Milne Edwards, Costa, Lucas, De Haan, Stimpson, Henderson, Heller, Miers, A. Milne Edwards and Bouvier.

Pagumsstriatus, var. petersii

A. Milne Edwards. Aniculus petersii)

Pagurusstrigosus. Bosc.

Cancer arrosor. . Herbst.

Pagmus incisus. Latreille, Lamarck.

The left pincer, the strongest, is covered on the outside with transverse grooves, and has short hairs and granulations. These granulations become spines on the superior part of the hand; the fingers are very massive, enlarged at their base, terminating in a horny, black extremity, are ornamented in the same way as the hand; the movable finger has above near its joint a deep longitudinal depression. The forearm has piliferous grooves and small spines. The legs of the second and third pair are strong; they are longer than the pincers; numbers of grooves surmounted with granulations exist on the legs. The finger has above many longitudinal ranges of large tubercles separated by hairy surfaces, 
those of the third pair are wider, more trenchant below, and have numerous grooves arranged obliquely.

RANGE. - Barbados, Philippines, Mediterranean Sea, North-West Coast of Africa.

\section{Pagurus insignis.}

\section{Pagurus insignis . . . Saussure.}

The ophthalmic scales are large, directed inwards, and armed the length of their anterior border with four or five sharp spines. Peduncles of the external antenne have their first joint large, armed with two teeth; the external large, the internal small. The acicle has a row of spiniform teeth. The lateral borders of the carapace have hairs and spines. The first pair of legs rough; the fourth joint is stout and short, with its edges omamented with large points; the inferior and internal edge has a row of large spines. The fifth joint and hands are very rough. The fingers terminate in black nails; that of the fixed finger is sharp, and exceeds that of the movable finger. The second and third lcg of the left side, scaly above on their fifth joint, have spines on their superior border. The colour red and yellow, with the ocular peduncles ringed with the same colours.

RANGE-Guadaloupe.

\section{Pagurus granulatus.}

Pagurus gramulatus. . Olivier, Lamarek, H. Milne Edwards, Dana, Henderson.

Cancellus maximus

\section{bahamensi Catesby.}

Petrochirus gramulatus. Stimpson, Heller.

Eye-stalks longer than the anterior border of the carapace, exceeding the peduncles of the external 
antennæ; cornea very small, and occupying only about a sixth of the length of the terminal joint of the peduncle. The carapace has tufts of hair. First pair of legs very large, that of the right slightly the largest, both armed above with a row of strong spines, and covered in the rest of their extent with tubercles, of which the base is surrounded in front with a row of short hairs which describe a semicircle, and in their arrangement resembling scales. The next two pairs of legs are large, almost cylindrical, and covered with hairy ridges arranged somewhat like those of the first pair. The pincers of the last two pairs of legs are well-formed.

RANGE.-West Indian Sea.

\section{Pylopagurus.}

Pylopagurus

A. Milne Edwards and Bouvier.

The right pincer is well developed, and forms an operculum, filling more or less exactly, as a door, the chamber in which the animal lives. This pincer is folded at a right angle upon the forearm; and cannot be completely cxtended. Its external face is more or less oval, the internal regularly convex. The left pincer is much swollen, and can also be placed at a right angle with its forearm. The fingers are wide, compressed, and move in a horizontal plane; those of the left hand have horny tips. The front has three projections, obtuse, but usually little developed. The internal antennæ are of moderate length, and the eye-stalks are wider at their extremity than at the base; the basal scales are wide apart. The walking legs are laterally compressed, and never exceed the large hand. The penultimate pair are subchelate, and the last pair chelate. Abdomen well developed; no protruded vas deferens. 
RANGE.-They live in deep water from the IVest Indian Sea to the Cape of Good Hope. They occupy cmpty shells.

Synopsis of tile SPeCies.

I. "Border of large pincer finely notched; its external surface smooth.-(P. discoidalis. $)$

2. "Border of large pincer armed with unequal tricuspid teeth; its external surface with mushroom-like warts with round and granular heads. $-(P$. boletifer. $)$

3. "Border of large pincer with conical teeth; its cxternal surface with mushroom-like warts with conical heads, isolated, very irregular upon their borders, and having a projection above.-(P. erosus.)

4. "Border of large pincer armed with multicuspid tecth; its external face with mushroom-like warts with conical heads, more or less rounded upon the edges, which are granular and more or less in contact.-( $P$. bartletti.)

5. "Border of large pincer armed with conical teeth; its external surface with mushroom-like warts with conical heads, rounded on the edges, which are tangental and cut into rosettes.-( $P$. rosaceus.)

6. "Border of large pincer armed with obtuse teeth; its external surface with polygonous mushroom-like warts with wavy edge, which lie close together- $(P$. gibbosimanus.)"-A. Milne Edwards and Bouvier.

\section{Pylopagurus discoidalis.}

$\left.\begin{array}{l}\text { Pylopagums discoidalis } \\ \text { Eupagurus discoidalis }\end{array}\right\}$ A. Milne Edwards and Bouvier.

The border of the large pincer is finely notched; its external surface is smooth. The fingers are wide, compressed, and their contour is a continuation of that of the 
palm. The forearm is short, and has granulations arranged in irregular lines continued into the part of the hand not forming the operculum. The small pincer is weak. Walking legs terminate in fingers with a well developed nail.

RangE.-Barbados, St. Vincent, St. Lucia, Guadaloupe, Montserrat, Santa Cruz.

\section{Pylopagurus boletifer.}

Pylopagums boletifir. A. Milne Edwards and Bouvier.

Border of large pincer armed with unequal tricuspid teeth; its external surface with mushroom-like warts with round and granular heads. The carapace is naked. The ophthalmic scales are very broad at the base, with thin extremity; eye-stalks contracted in the centre, longer than the frontal border, exceed the antennal peduncle. The cornea is large. The acicle is short. The walking legs are smooth, and have hairs.

RANGE.-St. Vincent.

\section{Pylopagurus erosus.}

$\left.\begin{array}{l}\text { Pylopagums erosus } \\ \text { Eupaguns cresus }\end{array}\right\}$ A. Milne Edwards and Bouvier.

Border of large pincer with conical teeth; its external surface with mushroom-like warts with conical heads, isolated, very irregular upon the borders, and with a projection above. The ophthalmic scales are lanceolate and end in a narrow spinule. The eye-stalks are as long as the breadth of the frontal border of the carapace. The flagellum has hairs. The last two joints of the walking legs have teeth on their superior border.

Range.-Barbados, Grenada, St. Vincent. 


\section{Pylopagurus bartletti.}

Pylopaguris bartletti) Eupagumes bartletti A. Milne Edwards and Bouvier.

Border of the large pincer armed with multicuspid teeth; its external surface with mushroom-like warts with conical heads, more or less rounded upon the edges, which are granular and more or less in contact. The ocular peduncles are shorter than the subantennary spine. The basal scales are large, slightly dilated at the base, lanceolate at the extremities. The acicle is hairy on the inner side. The walking legs are unarmed.

RANGE--Barbados, Grenada, St. Vincent.

\section{Pylopagurus rosaceus.}

Pylopagurus rosaceus . . . A. Milne Edwards and Bouvier.

Border of large pincer armed with conical teeth; its external surface with mushroom-like warts with conical heads, rounded on the edges, which are tangental and cut into rosettes. The eye-stalks are long and have hairs; the centre is slightly contracted.

RANGE-Grenada.

\section{Pylopagurus gibbosimanus.}

Pylopagurus gibbosimanus A. Milne Edwards and Euparums gibbosimanus $\}$ Bouvier.

Border of large pincer armed with obtuse teeth; its external surface with polygonous mushroom-like warts with wavy edge, which lie close together. The carapace is wider behind than in front. The ophthalmic scales 
are triangular, and terminate in a spinule. The ocular peduncles are shorter than the frontal border. The walking legs are smooth.

RANGE.-St. Vincent, Martinique.

\section{Ostraconotus.}

Ostraconotus. A. Milne Edwards, A Milne Edwards and Bouvier.

The carapace is short, its lateral edges are slightly rounded; it is wide behind. The eye-stalks are large and short; cornea well developed; basal scales apart. The external antenna have an acicle; the internal antennxe are long and thin. The branchial laminæ, in two rows, are undivided. The first pair of legs subequal, the right the strongest; the fingers move in a horizontal plane, and terminate in calcareous tips with traces of a rudimentary nail. The walking legs have flat terminal joints; the penultimate pair is monodactyle, as is also the last pair.

The abdomen is atrophied.

RANGE.--West Indian Sea.

\section{Ostraconotus spatulipes.}

Ostraconotus spatulipes.

A. Milne Edwards and Bouvier, A. Agassiz.

The basal ophthalmic scales are separated by a moderate space. The eye-stalks are compressed on their inner face. The first pair of legs unarmed. The pincers are a long oval. The walking legs have their fourth joint long and strong. The penultimate pair is much larger than the fifth pair; its penultimate joint is flat and dilated.

RANGE.-Barbados; in deep water. 


\section{Spiropagurus.}

Spiropagurus . . . Stimpson, Henderson, A. Milne Edwards and Bouvier.

Anterior portion of the carapace depressed, the cervical groove deep; front with the rostral projection but slightly marked. Ocular peduncles short and stout, with the cornea dilated; the basal scales, of moderate size, are separated by a considerable interval. Antennal acicle slender; the flagellum naked. First pair. of legs, subequal, of small size, the right slightly larger; the fingers, moving in a horizontal plane, are calcareous at the tips. Second and third pairs of legs with long, flattened, and ciliated terminal joints. First joint of the fifth left leg in the male with a long, spirally coiled membranous organ (formed by a protrusion of the vas deferens), strengthened along its outer surface by a corneous band; the vas deferens of the right side scarcely produced. They live in empty shells.

RANGE.-West Indian Sea, Seas of India and Japan; at moderate depths and in very deep water.

\section{Spiropagurus iris.}

Spiropagurus iris. . . A. Milne Edwards, A. Milne Edwards and Bouvier.

The carapace is smooth and naked. The rostrum, rounded, projects slightly; the ophthalmic ring is exposed. The eyes do not reach the level of the point of the subantennary spinc. The first pair of legs, of about equal size, terminates in pointed fingers; there are small spines that form below a regular border; the fine hairs between the spines and the teeth present iridescent re- 
flections. The walking legs are strong; the fourth joint of the second pair has below some spines.

Branchial laminæe bifid.

RANGE.--Barbados, Grenada.

\section{Anapagurus.}

Anapagurus . . Henderson, A. Milne Edwards and Bouvier.

The anterior portion of the carapace depressed, the cervical groove deep; front with the rostral projection but slightly marked. Eye-stalks usually short and stout, with the cornea dilated; the basal scales of moderate size, and separated by a considerable interval. Antennal acicle slender; the flagellum usually ciliated. First pair of legs unequal, the right larger; the fingers move in a horizontal plane, and are calcareous at the tips. Walling legs long and slender, the last joint but one slightly ciliated. First joint of the fifth left leg in the male with a short, curved, membranous organ (formed by the protruded external portion of the vas deferens). Branchial lamina have a bifid extremity.

RANGE.-Most seas, Scandinavia and European Seas, Azores, West Indies, Canaries, Cape of Good Hopc Mediterranean Sea, New South Wales.

\section{Anapagurus marginatus.}

Anafagurus marginatus . . A Milne Edwards and Bouvier.

The eye-stalks are slightly depressed upon their superior face; the basal scales are wide at their base, lanceolate towards their extrcmity; and armed with a spinule which is inserted on the inner side below and 
behind the joint. The antennal acicle is thin, and curved outwards; the flagellum is long, thin, and naked.

The first pair of legs are very dissimilar. The right is larger. The left is much thinner, the hand forming a long oval; it and the fifth joint have no spines upon their superior and external face.

RANGE.-Barbados; in deep water.

\section{Catapagurus.}

Catapagurus. A. Milne Edwards, Smith, Henderson, A. Milne Edwards and Bouvier.

Hemipagums. Smith.

Front with the rostral projection but slightly marked. Eye-staiks short and stout, with a dilated cornea; basal scales well developed, and separated by a wide space. Antennal acicle slender: the flagellum not distinctly ciliated. First pair of less slender and unequal, the right longer and stouter; fingers moving in a horizontal plane. Walking legs long and slender, the terminal joint ciliated. First joint of the fifth right leg in the male with a membranous protrusion of the vas deferens, which is curved over the right side of the abdomen. Branchial laminæe have a bifid extremity.

They live in a very small shell that contrasts with the exposed legs and carapace.

RANGE.-West Indian Sea, Fiji Islands; in not very deep water.

Synopsis of the Species.

$A$. The ophthalmic scales do not reach the middle of the eye-stalk.-(C. shameri.)

$B$. The ophthalmic scales exceed the middle of the ey'e-stalk. - (C. gracilis.) 


\section{Catapagurus sharreri.}

Catapagums shameri

\section{Catapagurus socialis} Hemipagurus socialis.

A. Milne Edwards and Bouvier, S. J. Smith, Agassiz.

The gastric region of the carapace is marked by two prominent lobes. The front has three slightly marked prominences, the middle is wide and the most prominent ; the lateral parts of the front are oblique. The ophthalmic rings are completely exposed; the scales are scarccly widened at their base, thin, sharp, long, and terminating a little behind the posterior border of the cornea and the centre of the cye-stalk; these last are short, being about haif the breadth of the front. They are compressed in an oblique plane. The antennulary peduncles are thin; their last joint is about as long as the superior flagellum, and about once and a half the breadth of the penultimate joint. The antennal acicle is longer than the eyes, reaching almost to the centre of the last joint. The flagellum is long.

The first pair of legs smooth on the external face. The right leg slightly shorter than the left; its pincer is almost three times as long as broad, being broadest on a level with the articulation of the movable finger; it is slightly convex on both sides. The walking legs are slightly longer than the large pincer, compressed towards the end, and terminating in a wide and flat finger capable of being folded on preceding joint. The penultimate pair are slightly hairy and monodactyle, the last pair is very small.

RANGE.-Barbados, St. Kitts. 


\section{Catapagurus gracilis.}

Catapagurus gracilis. A. Milne Edwards and Bouvier, S. J. Smith.

Hemipagurus gracilis. S. J. Smith.

Carapace smooth, almost naked. Ophthalmic ring exposed; basal scales slightly wide at the base, narrow, and in length reaching beyond the middle eyestalk, which is short and stout. The antennal acicle is pointed, reaching to almost the extremity of the peduncle.

RANGE.-Barbados, Dominica.

B. First and second abdominal segments provided with sental appendages (first segment only in the female):-

\section{Paguristes.}

Paguristes . . . Dana, Stimpson, Heller, Henderson, A. Milne Edwards and Bouvier.

Rostrum prominent, often acute. Eye-stalks long and slender; basal scales of moderate size, and some distance apart. Antennules long. Antennal acicle robust, the flagellum usually ciliated. First pair of legs subequal or of equal size, the fingers moving in a horizontal plane, with calcareous or corncous tips. Penultimate pair of legs not chelate. On the second, third, and fourth segment of the abdomen of the female, on the left side, there is a membranous oviferous sac.

RANGE.-Shallow and deep water in warm seas, living in shells. West Indian Sea, Pernambuco, Manila, New Zcaland. 


\section{Sinopsis of the Species.}

A. Rostrum well marked.

a. Eye-stalks longer than breadth of frontal border.

$a^{1}$. Eye-stalk is longer than antennal peduncles by about one-third of its length.-( $P$. spinipes. $)$

b. Eye-stalks not so long as breadth of frontal border.

$b^{1}$. Eye-stalks reach to middle of last joint of antennal peduncle.-( $P$. triangulatus. $)$

$c^{1}$. Eye-stalks reach to about the extremity of last joint of antennal peduncle.-(P. sayi.)

$B$. Rostrum not well marked.

c. Eye-stalks not so long as breadth of frontal border.

$d^{2}$. Eye-stalks slightly longer than antennal peduncle. $-(P$. plonatus. $)$

$\epsilon^{1}$. Eye-stalks excecd antennal peduncle by about onesixth of their length.-(P. lymani.)

\section{Paguristes spinipes.}

Paguristes spinipes. A. Milne Edwards, A. Milne Edwards and Bouvier.

Paguristes risor . . Henderson.

Rostrum well marked and slightly depressed; the posterior portion of the carapace is semicalcareous towards the centre. The eye-stalks are curved laterally, exceeding the antennal peduncle by one-third of their length, with a few hairs on their upper surface; the basal scales are obscurely bidentate. Antennal acicle extends to the middle of the last joint of the peduncle; its surface is hairy, and has two spines on the outer border and one or two on the inner; the external prolongation of the second joint is short and its apex bidentate; the flagellum is nearly as long as the body, slightly ciliated. The first pair of legs 
similar in appearance and subequal in size, with the terminal joint slightly hairy.

RANGE-Grenada, Martinique, St. Vincent, Barbados, Pernambuco; in deep water.

\section{Paguristes triangulatus.}

Paguristes triangulatus. . . A. Milne Edwards and Bouvier.

Carapace with a notch in front, in the centre of which is placed a long and pointed rostrum, slightly depressed, and reaching the anterior border of the ophthalmic ring. Eye-stalks reach the level of the middle of the last joint of the antennal peduncle, being shorter than the breadth of the front. The basal scales are slightly rough on their inner border. The ocular peduncles have some hairs on their upper surface. The antennal acicle has three or four spines on the inner side, one or two externally. WValking legs have few hairs.

RANGE.-Bardados; in deep water.

\section{Paguristes sayi.}

Paguristes sayi . . . . . A. Milne Edwards and Bouvier.

The rostrum scarcely exceeds the base of the ophthalmic scales, which are short and are notched anteriorly. The eye-stalks are shorter than the breadth of the front, reaching about the extremity of the last joint of the antennal peduncle. Antennal acicle hairy, strong, with a wide base and sharp extremity; it has four or five obtuse spines on the inside, and some teeth on the external border.

RANGE-Barbados; in deep water. 


\section{Paguristes planatus.}

Paguristes planatus. A. Milne Edwards and Bouvier.

Rostrum not well marked. Eye-stalks not as long as the breadth of the front of the carapace, reaching a little beyond the antennal peduncle; scales unequally bidentate at their extremity. Antennal acicle bifurcate; it has five or six spinules on the internal, and three or four on the external border.

RANGE-Barbados; in decp water.

\section{Paguristes lymani.}

Paguristes lymoni. A. Milne Edwards and Bouvier

The rostrum is short and has hairs; it does not reach as far as the level of the lateral tecth. Eye-stalks exceed the antennal peduncle by about one-sixth of its length; they are cylindrical; the basal scales have two unequal spines at their extremity; they have hairs on their inner edge. The antennal acicle has three or four spines on the external and internal borders, and terminates in a forked end.

Range,-Grenada, Guadaloupe, Barbados, Sand Key; in deep water.

\section{Io. Sympagurus.}

Sympergurus. S. J. Smith, A. Milne Edwards and Bouvicr.

This genus is like Parapagurus, except that the gills are in the form of plates and not in the form of threads, like those of the latter genus. They live in shells.

RANGE.-New York to Barbados; in deep water. 


\section{Synorsis of tIE Species.}

A. The rasp on the penultimate joint of the fourth pair of legs is composed of a single row of scales.- $-(S$. arcuatus.)

$B$. The rasp of the penultimate joint of the fourth pair of legs is composed of two rows of scales.-(S. pictus.)

$C$. The rasp on the penultimate joint of the fourth pair of legs is composed of four rows of scales.- $(S$. pilimams.)

\section{Sympagurus arcuatus.}

Sympagmms aroutus. A. Milne Edwards and Bouvier.

The carapace is feebly calcified, almost smooth, and naked. Rostrum almost wanting. Latero-frontal teeth scarcely indicated. Ophthalmic scales narrow and acuminate in front. Eye-stalks have dilated extremities, compressed and hairy above. They scarcely exceed the end of the acicle, reaching the extremity of the peduncles of the external antenna, but not the extremity of the penultimate joint of the peduncles of the internal antenne. The internal antenna have many hairs on the last peduncular joint; their superior terminal flagellum is long, thin, and exceeds the inferior. The basal joint of the external antennx is visible from above; the flagellum is long and naked; the acicle has a row of sharp teeth upon its internal border.

The legs of the first pair are very unlike, the right is longer and stronger; the hand is short, high, and slightly hairy.

The fingers move in an oblique plane. The fourth pair of legs has a rasp composed of a single row of scales; the last pair is subchelate.

RANGE.-St. Lucia, Dominica, Martinique. 


\section{Sympagurus pictus.}

Sympagrums pictus. . Smith, A. Milne Edwards and Bouvier.

The ophthalmic ring is almost hid by the rostrum: scales reduced. Ocular peduncles slightly compressed, shorter than the frontal border, and scarcely reaching the extremity of the antennal peduncles; cornea dilated. leduncles of the internal antenne are scarcely longer than the breadth of the front; the superior flagellum is longer than the inferior. The antennal acicle is slightly hairy and bowed. The flagellum is long and almost naked. The legs of the first pair, covered with hair, are of unequal size. The fourth pair of legs has a rasp composed of two rows of scales; the fifth pair is chelate.

RANGE.-Barbados.

\section{Sympagurus pilimanus.}

Sympagurus pilimumus) A. Milne Edwards, A. Milne Eupagunus pilimanus $f$ Edwards and Bouvier.

The oplithalmic ring is completely exposed; the scales large, acuminate in front, are separated in the middle line by a groove curved from above downwards.

The eye-stalks are stout, with swollen extremities. They reach almost to the end of the acicle and of the antennal peduncle, and exceed a little the penultimate joint of the antennulary peduncle. The antennal acicle reaches the extremity of the peduncle, and has long hairs on the inside and three spinules. The legs of the first pair are of unequal size; the right, the largest, 
has a broad pincer. Each finger has large and small teeth. The fourth pair of legs subchelate; the rasp is composed of four rows of scales. The last pair of legs chelate.

RANGE.-Guadaloupe, St. Kitts.

C. First abdominal segment only in the male provided with genital appendages:-

\section{Tomopagurus.}

Tomopagmms . . . . . A. Milne Edwards and Bouvier.

The rostrum, wide and obtuse, leaves exposed the ophthalmic rings, of which the scales are wide apart. The ocular peduncles are strong, dilated at the extremities, moderately long, shorter than the antennal and antennulary peduncles; the acicle and the external prolongation of the second joint of the antennal peduncles are well developed. The first pair of legs short, strong, and terminates in fingers slishtly or not nailed that move in a horizontal plane; the legs are very unlike, the right the largest and strongest; the next two pairs of legs are longer than the first pair, and are laterally compressed. The fourth pair subchelate, the last pair chelate.

RANGE.-Barbados; in deep water.

\section{Tomopagurus rubropunctatus.}

Tomopagurus mbropunctatus . A. Milne Edwards and Bouvier.

Characters as in the genus. 
II. Abdomen not spirally twisted, composed of distinct movable segments which are usually calcificd (Cancellina, Dana) :-

\section{I2. Xylopagurus.}

Iylopagumas. A. Milne Edwards, A. Milne Edwards and Bouvier.

Carapace narrow, bounded by parallel edges; it terminates in front in a small rostral point. The ophthalmic ring is represented by two small scales some distance apart. Eye-peduncles are short and stout; the antenne are short and thin ; the antennules are large and shortened. The pincers are of unequal size and unlike in shape; the fingers move in a horizontal plane; the right is the largest and has sharp fingers; the next two pairs of legs are thin and long; the fourth pair is subchelate; the firth chelate.

The abdomen terminates in a special armature in the form of a plate on the penultimate ring, which is much developed, widely oval, and strongly calcified. The lateral appendages are inserted below and are symmetrical; they are folded in a hollow depression on the under side of the joint that carrics them.

On each of the two first segments the male has, on the ventral side, a pair of sexual feet. The female has on the left side three unequally biramous appendages, but not in pairs.

They live in holes in wood, the holes being open at both ends; they can close the posterior door by the oval plate on their abdomen, and the front door by their hand.

Range.-West Indian Sea; in deep water. 


\section{Xylopagurus rectus.}

Xylopagurus rectus . A. Milne Edwards, Agassiz, Filhol, A. Milne Edwards and Bouvier.

The pincers scarcely exceed the extremity of the walking legs; the articulation of the large hand is transverse in such a way that the movable finger is inside and opens laterally, not vertically; it has a strong, long spine on its basc. The palm is swollen and has outside granulations and some hairs; the fingers are equally granular and hairy; the arm and forcarm are rough and hairy. The small pincer is very frail. The legs of the second and third pair are laterally compressed, and terminate in styliform fingers, and have some hairs; they are unarmed. The ocular scales are rounded in front, and toothed on the edges. The antennal flagellum is thin, moderately' hairy, and scarcely exceeds the base of the larger hand.

RANGE.-St. Vincent, Dominica.

\section{Branch II. Fibribranchiata.}

Gills in the form of round threads.

\section{Family III. Parapagurida.}

Parapaguride. . . . . S. J. Smith, Henderson.

Antennular peduncle elongated or of moderate size: the first joint short and stout, the sccond and third joint slender and cylindrical; both flagella of small size. Antennal peduncle subcylindrical. 


\section{SyNopsis of the Genera.}

A. Terminal appendage on last abdominal segment is in one piece with notched margin.

a. The covering of the abdomen is membranous; the central segments of the abdomen have no paired appendages.-(Parapugurus.)

b. The covering of the abdomen is calcified above, membranous below, except for slight calcified zones on the first to sixth segment; the six first segments of the abdomen have each a pair of appendages. - (Mirtopagurus.)

$B$. Terminal appendages on last abdominal segment has a transverse joint, and terminates in two hinged flat lobes.

c. The covering of the abdomen is calcified above, the first to sixth segment calcified below, and membranous at the sides; paired appendages on each first six segments.-(Pylocheles.)

\section{Parapagurus.}

Parapagurus . S. J. Smith, Henderson, A. Milne Edwards and Bouvier.

Rostrum is slightly marked. Ocular peduncles of moderate size, rarely dilated at their extremity, and their ophthalmic scales are separated by a considerable interval. The two pairs of antenne are well developed; the peduncles of the internal antenne exceed the eyes and that of the external antenne by more than the length of the carapacc. The first pair of legs of unequal size. The legs are long, and terminate in long fingers. Legs of the fourth pair almost cheliform.

The abdomen is spiral and membranous. The two 
first segments of the male have a pair of sexual legs; the same segments of the female have only one appendage on the second joint. The third, fourth, and fifth segment in both sexes have one appendage. The last segment terminates in a flat piece with notched margin, but no transverse joint.

They live in very deep water, in shells.

RANGE.-Atlantic and Pacific Oceans.

\section{Parapagurus pilosimanus.}

Parapagurus pilosimamus . . S. J. Smith, Pocock, A. Milne Edwards and Bouvier.

Eupagurus jacobii . . . . A. Milne Edwards.

Parapagurus abyssomm . . Henderson.

The body is small compared with the legs. The anterior part of the carapace is calcareous, and terminates in a very small pointed rostrum; the cardiac region is small and crustaceous. The ocular peduncles are not near as long as the subantennary spine. Of the first pair of legs, the right is largest, and is covered with fine granulations; it is unarmed above. The fingers are sharp, with trenchant edges, and in contact along their whole length when closed. The walking legs of the second and third pair are very long, compressed, smooth and shining; those of the third pair exceed the others. The finger is elongated, and is more than once and a half the length of the carapace.

RANGE.-Martinique, St. Lucia, Guadaloupe, Havana; if Parapagums abyssom (Henderson) is identical with this species, we must add Bermuda, Azores, West Africa, Philippines, Papua, Yokohama, Valparaiso, and Patagonia. 


\section{Mixtopagurus.}

Mixtopagunus . . . . . A. Milne Edwards, A. Milne Edwards and Bouvier.

Pylocheles. . . . . . . Henderson.

The carapace is that of Pagums; the gastric region is hard, and the branchial regions are membranous. The abdomen is curved, and more developed on the right side than the left; it is divided into seven very distinct segments, articulated and mobile. The skin of the five first are incompletely calcified; the sixth is large and less hard; the last has a lamina, without transverse joint. The appendages of the penultimate joint are large and symmetrical. The first six segments have each a pair of appendages.

RANGE.-West Indian Sea; in deep water.

I. Mixtopagurus paradoxus.

Mixtopagurus parcdorus . . . A. Milne Edwards and Bouvier, A. Agassiz.

The carapace has some bunches of flexible and very long hairs arranged along the cdges and sutures. The rostral point is very short, exposing the ophthalmic rings. The eyes are as long as the two first joints of the internal antennæ; the subantennary spine has some hairs and spines. The first pair of $\operatorname{lggs}$ small, thick, and equal. The hand is very swollen, and covered, as well as the movable fingers, with short and conical spines, between which are fine, long yellow hairs. The extremities of the fingers are brown and horny. The forearm has spines 
like those on the hand. The legs of the second and third pair are very hairy; their short terminal joint has some short spines on their superior border. The legs of the fourth pair are monodactyle. Some long hairs ornament the last joints of the abdomen.

RANGE.-Barbados, Guadaloupe.

\section{Pylocheles.}

Pylocheles. . A. Milne Edwards, A. Milne Edwards and Bouvier.

Cheiroplated. Sp. Bate.

There is no rostrum on the frontal border; the ophthalmic scales are widely separated, and the antennular peduncles, well developed, exceed the eyes, and are almost as long as the carapace. The external antenne have on the second joint a prolongation in the form of a toothed spine; the flagellum is not as long as the first pair of legs. The legs of the first pair are of equal size, and the hands can be placed at a right angle with the carpus; their inner edge is more or less straight, so that when placed alongside its companion they form a closed door; the fingers move in a horizontal plane. The abdominal rings are calcified above and below, but are membranous along the side; the first six rings have each a pair of appendages, and the terminal ring ends in a flat process divided in two by a transverse hinge, its terminal part being two hinged lobes. The biramous legs of the sixth segment have a rasp-like arrangement on the external face of the two branches.

The one specimen found lived in a hole in a stony substance, and was able to close the entrance by its two hands placed side by side.

RANGE.-West Indian Sea; in deep water. 


\title{
I. Pylocheles agassizii.
}

\begin{abstract}
Pylocheles agassizii . . A. Milne Edwards, Agassiz, A. Milne Edwards and Bouvier.
\end{abstract}

The carapace is calcified dorsally, becoming less so on the sides, and is membranous below. The gastric region is limited anteriorly by a groove bowed in front. The eyes are broad and flattened antcriorly. The abdomen has short hairs. The external face and edges of the hands have hairs and fine granulations; the fingers are large and flat; the legs of the second and third pair are compressed, smooth, and hairy; the two last pairs are not cheliform.

RANGE.-Barbados, Santa Cruz.

\section{Group V. Galatheidea.}

Galatheidea . . . . Henderson.

Galathide . . . Boas.

Carapace well developed; the frontal region prominent, provided with a median rostrum, and frequently lateral processes. Eye-stalks short and stout. Antennal peduncle composed of four segments (the second and third having fused); the flagellum long and slender. First pair of legs elongated, and not markedly asymmetrical; the first three pairs of walking limbs well developed, the ultimate pair slender and inflexed, frequently chelate. Thoracic sterna broad. Abdomen symmetrical, composed of seven segments, of which the first is usually concealed by the carapace; the penultimate segment with a pair of lamellar appendages, which form with 
the telson a broad swimming fin; the second segment in the male nearly always provided with genital appendages.

\section{Section A. Porcellanodea. \\ Section B. Galathodea.}

Synopsis of the Sections and Families.

I. Carapace ovate; regions not well marked.

A. Front trilobed; lobes short.

a. First pair of legs broad; walking legs robust and of moderate length.

$a^{1}$. Antennules concealed; antennal peduncle directed backwards.

$a^{2}$. Abdomen applied closely to thorax.-(Sect. Porcillanodea, Family Porcellanida.)

II. Carapace elongate; regions well marked.

$B$. Front produced into a prominent and acute rostrum.

b. First pair of legs elongated; walking legs long.

$b^{1}$. Antennules exposed; antennal peduncle directed forwards.

$b^{2}$. Abdomen not applied closely to thorax.-(Sect. Galathodea, Family Galatheida.)

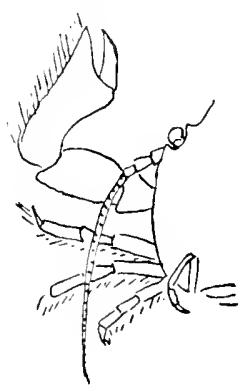

Family Porcellanide. 


\section{Section A. Porcellanodea.}

Porcellanoded . . Henderson.

Porcellaniens . . H. Milne Edwards.

Porcellanider . . De Haan, Dana, Stimpson, Miers, Haswell.

Carapace broadly ovate, smooth, with the regions not well marked; the front usually trilobed, lobes never of great length. First pair of legs broad and often flattened; the walking legs robust and of moderate length. Antennules concealed; the antennal peduncle directed backwards. Eyes always pigmented, and partially concealed in orbits. External maxillipedes with the third joint broad, and the fourth joint provided with a prominent internal lobe. Abdomen bent under the thorax; females with two (or three) pairs of slender uniramous appendages on the fourth, fifth (and third) segment; males with a single genital pair on the second segment.

RANGE.-All seas between tide marks. As they are usually found under stones, they may live also at great depths, where they would be picked up with difficulty.

One family.

\section{Family I. Porcellanidæ.}

\section{Porcellanida . . Henderson.}

Characters the same as the Section.

\section{Synopsis of the Genera.}

I. First joint of antennal peduncle short, not reaching the superior margin of the carapace.

a. Carapace subovate; frontal region triangular, with more or less undulating margin.-(Pctrolisthes.) 
b. Carapace rounded. Frontal region has two margins; upper straight, lower projecting into a small triangular tooth.-(Pisosoma.)

II. First joint of the antennal peduncle more or less produced, and joined to the margin of the carapace; the second joint placed at a distance from the orbit.

c. Carapace suborbicular or subovate.

c. First pair of legs flattened; fifth joint short, and usually has a single projecting lobe near the proximal end of internal margin.-(Porcellana.)

$d^{1}$. First pair of legs large; fifth joint longer than broad, with entire margins; front margin not dilated, posterior margin arcuated.--(Megalobranchinm.)

\section{Petrolisthes.}

Petrolisthes . . . . Stimpson, Miers, Haswell, Henderson.

Carapace subovate, depressed, the length usually slightly greater than the breadth. Frontal region triangular, usually depressed, with the margin more or less undulating. Eyes rather large. First joint of antennal peduncle remarkably short. First pair of legs broad and flattened; the fifth joint of moderate length, and often provided with teeth on the inner margin. Walking legs with the last joint short and robust, terminating in a single claw.

RANGE.-IVarm seas, under stones; in shallow and deep water.

Symopsis of the Species.

$A$. Spines or teeth on inner border of fifth joint of first pair of legs. 
a. Colour brick-red. The surface when magnified shows many punctures.-(I'. magnifica.)

b. Teeth on inner margin of fifth joint of both legs... (P. armatus.)

c. Teeth on inner margin of fifth joint of left anterior leg.-(P. marginatus.)

$B$. Inner border of fifth joint of first pair of legs without spines or teeth...-(P. tridentatus.

\section{Petrolisthes magnifica.}

Petrolisthes magnifica . . Gibbes, Benedict.

Petrolisthes politus . . . Stimpson.

Porcellana polita . . . . Gray.

Porcellana magnifica. . Gibbes.

When the surface is magnified many punctures are secn, the position of each puncture being marked by a very small light coloured spot. The fourth joint of the walking legs is coloured the same as the carapace. The fifth joint is daricr. The sixth joint is a deep red, darkest near the distal cnd, which is abruptly light. The terminal joint is light, each with a deep red ring in the middle. First pair of legs, a deeper red than the carapace, has spines on inner border of fifth joint. The tips of the finger are crimson, with subterminal portion black. Carapace brick-red.

Range.-Barbados, St. Thomas; found under stones on the shore.

\section{Petrolisthes armatus.}

Petrolisthes amatus . Gibbs, Stimpson, Henderson. Porcellana armata. . Gibbs.

The inner border of the fifth joint of the first pair of legs has three or four spines. The outer edge of the hand 
is serrated. The spine on the anterior edge and distal end of the fourth joint is present on the second and third pair of legs, but not on the fourth pair.

Range.-St. Thomas, Bermuda, Aspinal, Florida.

\section{Petrolisthes marginatus.}

Petrolisthes marginatus . . . Stimpson.

Resembles Petrolisthes armatus, but the median lobe of the front is smaller and more prominent, and the fifth joint shorter. There are four teeth, equal in size and very sharp, on the anterior margin of the carpus of the left first leg. The surface is smooth and pubescent. The hands are granulated, and covered above with a very short but dense pubescence. From the inner base of the finger to the exterior angle of the fifth joint there extends a moderately prominent ridge. The anterior margin of the hand is regularly crenulated, the tubercles being of a lighter colour than the rest of the hand; beneath these are two rows of marginal granules. The fourth joint of the walking legs is spinulose above, and one-spined below, near extremity. Colour a purple-crimson.

RANGE.-Barbados.

\section{Petrolisthes tridentatus.}

Petrolisthes tridentatus . . . Stimpson.

Carapace smooth and unarmed. Front deflexed and tridentate, with the median tooth or lobe triangular; margins smooth. The teeth of the front are most distinctly seen in a front view. Feet nearly naked. First pair of legs scaly; fifth joint about twice as long as broad, with the anterior margin nearly straight, not toothed, very slightly projecting at the inner angle. The 
carapace is generally minutely spotted with red, and streaked down the middle with white. First pair of legs red. Walking legs annulated.

RANGE.-Barbados, St. Thomas.

\section{Pisosoma.}

Pisosoma . . . . Stimpson.

Carapace rounded. Front bimarginate; the upper margin of crest straight, the lower margin projecting into a small triangular tooth. First joint of antennal peduncle short, not reaching the superior margin of the carapace. Walking legs terminate in a joint with single claw.

\section{Pisosoma reisei.}

Pisosoma reisei . . . Stimpson.

Carapace smooth and shining, faintly punctuate and obsoletely striated transversely. Triangular tooth of lower frontal margin nearly vertical. Last three joints of walking legs hairy; fourth joint not dilated, with smooth margins. Colour, crimson, with a large white spot on either side of the front; walking legs crimson, banded with white.

RANGE.-St. Thomas.

\section{Porcellana.}

Porcellana . Lamarck, Latreille, Desmarest, $\mathrm{H}$. Milne Edwards, De Haan, Dana, Bell, Stimpson, Heller, Haswell, Henderson.

Pisidia . . Leach.

Carapace suborbicular or subovate; the length usually greater than the breadth. Frontal region prominent and 
dentate; teeth usually well developed. Eyes of moderate size, the orbits deep. First pair of legs moderately flattened; the fifth joint short, and usually provided with a single projecting lobe near the proximal end of the internal margin; the fingers frequently contorted. Walking legs with the last joint short and robust, terminating in a single claw. First joint of the antennal peduncle more or less produced and joined to the margin of the carapace; the second joint placed at a distance from the orbit.

RANGE--Temperate and tropical seas; in shallow and deep water.

\section{Porcellana robertsoni.}

\section{Porcellana robertsoni. . Henderson.}

Carapace smooth, though minutely punctate; numerous transverse lines on the posterior branchial areas, and a few hairs on gastric region. Front tridentate, median tooth broadest and most prominent, slightly deflexed and with a shallow median groove on upper surface. First joint of antennal peduncle forms a flattened process below the orbit; its flagellum is of moderate length. First pair of legs of moderate size, upper surface densely pubescent; fourth joint has a flattened lobe on inner and distal margin which overlaps the fifth joint; fifth and sixth joint have their upper surface crossed by numerous short and ill-defined lines; the inner margin of the fifth has a single acute tooth of large size near its proximal end. The inner border of the sixth is short and strongly curved. Walling legs are short and strongly pubescent; terminal joint short and moderately curved, with yellow tip.

RANGE.-West Indies; in deep water. 


\section{Megalobranchium.}

Megalobranchinm . . . Stimpson.

Carapace subovate; frontal region depressed, tridentate. First joint of antennal peduncle more or less produced, and joined to the margin of the carapace; the second joint placed at a distance from the orbit. First pair of legs large; fifth joint longer than broad, with entire margins; hand short. Walking legs terminate in joints with single claw.

RANGE.-West Indies.

\section{Megalobranchium granuliferum.}

Megalobranchium sranuliformm . . . Stimpson.

Sides of body densely hairy above and below the bases of the feet. Feet hairy. Colour white, with scarlet patches on the margins of the median region of the carapace, and on the upper sides of the hands. Carapace smooth, but uneven and rugate towards the sides. Teeth of front not very prominent. First pair of legs granulated above, and longitudinally bisulcated, dividing the surface into three equal obtuse ridges; fourth joint very large, not dilated at anterior angle. Front margin of fifth joint not dilated, posterior margin arcuated; hand triangular, much narrowed behind, summit at juncture of finger very prominent; surface of hand more deeply sulcated than the fifth joint; outer margin hairy; fingers gaping, hairy above, crossing each other at their tips; finger longer than the palm.

RANGE.---Barbados, St. Thomas. 


\section{Section B. Galathodea.}

Galathodea . . Henderson.

Galatheide. . . Leach.

Galatheides . . H. Milne Edwards.

Galatheidea. . . De Haan, Dana, Stimpson, Miers, Haswell.

Carapace elongate, the regions well defined and usually rugose, with the front produced into a prominent and acute rostrum. First pair of legs and walking legs elongated and frequently slender. Abdomen broad and well developed, simply bent or folded on itself, never closely applied to the surface of the thorax, terminating in a powerful swimming fan formed by the telson and the appendages of the sixth segment. Females with four pairs of simple and slender ovigerous appendages on the second, third, fourth, and fifth segment (those of the second and fourth segment may be rudimentary); males furnished with two pairs of well-developed accessory genital organs on the first and second segment (those of the first segment may be rudimentary or absent), and three pairs of short, usually flattened appendages on the third, fourth, and fifth segment, all of which may, however, be rudimentary. Antennules exposed; the antennal peduncle directed forwards. External maxillipedes subpediform, with the third and fourth joint narrow and frequently spinose internally. Eyes placed in very incomplete orbits.

One family.

\section{Family II. Galatheidæ.}

Galatheidce . . . Dana, Henderson.

Characters the same as the Section. 


\section{Synopsis of the Genera.}

I. Abdomen simply bent.

A. Eyes normal.

a. Rostrum flattened, of moderate breadth. Carapace with pubescent transverse stria; cardiac area not prominent. Abdominal segments unarmed.-(Galathea.)

b. Rostrum slender, styliform, with well-developed supraorbital spines. Carapace usually with spines; cardiac area usually distinctly circumscribed. One or more of the abdominal segments with spines on anterior dorsal margin.-(Munida.)

$B$. Eyes nonpigmented.

c. Eye-peduncles usually prolonged beyond cornea.

$c^{1}$. Rostrum spinulose, usually more or less triangular ; margins rarely dentate or spinose. Carapace rugose, spinose, or glabrous. Antennal peduncle usually stout.(Munidopsis.)

$d^{1}$. Rostrum flattened or triangular. Carapace unarmed. Antennal peduncle of moderate width.(Elasmonotus.)

d. Eye-peduncles not prolonged beyond cornea; cornea terminal. Rostrum long, spinulose. Carapace broad, convex from side to side, armed with four spines on dorsal surface. Antennal peduncle usually stout. (Galacantha.)

II. Abdomen folded on itself.

$\boldsymbol{e}$. Rostrum slender and spiniform, usually upturned. Eye-stalks with dilated cornea. No acicle on antennal peduncle.-(Ptychogaster.)

f. Rostrum flattened and acute. Cornea scarcely dilated. Acicle present on antennal peduncle.(Uroptychus.) 
I. Abdomen simply' bint.

A. Ejes normal:--

\section{Galathea.}

Galathea. . . . Fabricius, Latreille, H. Milne Edwards, De Haan, Dana, Bell, Stimpson, Heller, Haswell, Henderson, A. Milne Edwards and Bouvier, Desmarest.

Galatea . . . . Leach.

Rostrum flattened and of moderate breadth, with the margins usually spinous. Carapace with pubescent transverse strix; the surface usually unarmed, with the exception of the anterior gastric area; the cardiac area not prominent. Abdominal segments unarmed.

RANGE.-Tropical and cool seas; in shallow and deep water.

\section{Galathea agassizii.}

Galathea agassizii . A. Milne Edwards, A. Milne Edwards and Bouvier.

The transversal strix of the carapace are few, finely granular, and hairy. The rostrum exceeds by about a fourth of its length the ocular peduncles; it is triangular, and its edges are unarmed; there is a very small spine on each side at its base. The sides have about six small spines. The first pair of legs, strong, has some long hairs. The fourth and fifth joint spiny; the hand slightly so upon its superior and inferior border; that of the left side is generally stronger than the other, and the fixed finger is slightly bowed in such a way that the fingers only touch at their tips when closed. The walking legs are 
thin, compressed, and armed with small spines upon the fourth and fifth joint.

RANGE.--Barbados, St. Lucia, St. Vincent, east side of Atlantic.

\section{Munida.}

Munida . . Leach, Desmarest, Dana, Bell, Stimpson, Heller, Miers, Henderson, A. Milne Edwards and Bouvier.

Rostrum slender and styliform, with a well-developed supraorbital spine on either side of its base. Carapace with the surface usually spinulose; the cardiac area as a rule distinctly circumscribed. First pair and walking legs elongated and slender. One or more of the abdominal segments usually with a series of spinules on the anterior dorsal margin.

RANGE.-Tropical and temperate seas; in shallow and deep water.

\section{Synopsis OF tHE SPECIES.}

I. Eyes large.

A. No spines on dorsal surface of abdomen.

a. Lateral spines of rostrum exceed the eyes.(M. iris.)

b. Lateral spines of rostrum do not exceed the eyes.(MI. caribar.)

$B$. Dorsal surface of abdomen has spines.

c. Second and third abdominal segments have small spines. Lateral spines of rostrum nearly as long as eyes.-( $M$. miles.)

d. Second and third abdominal segment have spines, and the first segment has four spines. Lateral spmes of rostrum exceed the eye.-- $(M$. constrictar $)$ 
e. Second and third abdominal segment have two pairs of spines; fourth segment has one pair. Lateral spines of rostrum are as large as the rostrum.(M. longipes.)

$f$. Second, third, and fourth abdominal segments have small spines; the last spine is median. Lateral rostral spines do not exceed the eye.-(M. stimpsonii.)

\section{Eyes small.}

$g$. Second abdominal segment has four spines. Lateral spines of rostrum exceed the eye.-( $I$ I. microphthalma.)

I. Eyes large:-

\section{Munida iris.}

Munida iris . . . . A. Milne Edwards, A. Milne Edwards and Bouvier.

Munida cariber . . . S. J. Smith.

The hairs which garnish the transverse strix of the carapace have a remarkable iridescent reflection. The gastric region has some small spines in front; there are none behind. The lateral borders have seven spines; the first the longest. The lateral points of the rostrum exceed the eyes slightly. The first pair of legs very large; the hand is almost cylindrical, rough, and has very small spines on its superior border; the fingers are long, frail, and applied the one against the other. The abdomen has no spines. The basal joint of the internal antennx exceeds the eyes; they have three spines upon their external border, and a fourth, much longer, upon the internal border.

They grow to a large size.

RANGE.-Barbados. 


\section{Munida caribæa.}

Mnnida caribur . . . Stimpson, A. Milne Edwards, A. Milne Edwards and Bouvier.

\section{Munida irrasa . . . A. Milne Edwards.}

The lateral frontal spines are very short, and scarcely reach a fraction of the length of the ocular peduncles. Otherwise resembling Munida iris.

RANGE.-Barbados, Grenada, Grenadines, St. Vincent, Dominica, St. Lucia, Cariacou.

\section{Munida miles.}

Munida miles . . A. Milne Edwards, Henderson, A. Milne Edwards and Bouvier.

The body and the legs are slightly hairy. The carapace has very marked strix. The gastric region has small short spines upon the transverse line behind the front; the other regions are unarmed. The rostral points are strong, slightly erect, and do not exceed the eyes. The lateral edges have six spines, the first large, the others small. The legs of the first pair are strons, and in adult males they do not resemble each other. One pincer is the strongest; the fixed finger is notched at its base in such a way as not to be in contact at this part with the opposing finger when closed. The extremity of the finger is sharp and hooked; that of the movable finger passes on the outside that of the fixed finger. The hand is compressed laterally and has some spines. The fourth and fifth joint are spiny. The fingers of the pincers of the other side are in contact along their whole length when closed. The walking legs are short, strong, 
very compressed, and carinated above. The second and third joint of the abdomen have a transverse row of small spines.

RANGE.-Barbados, Martinique, Pernambuco.

\section{Munida constricta.}

Munida constricta . . A. Milne Edwards, A. Milne Edwards and Bouvier.

The body and legs are almost smóth. The carapace is narrow, and the gastric region has two spines situated behind the lateral points of the rostrum. Lateral spines of rostrum exceed the eyes. The first abdominal segment has four spines. The pincers are symmetrical.

RANGe--Grenada, St. Lucia, Dominica, Nevis, St. Kitts, Cariacou.

\section{Munida longipes.}

Munida longipes . . . A. Milne Edwards, A. Milne Edwards and Bouvier.

The carapace has a pair of gastric spines situated behind the lateral points of the rostrum, a small cardiac spine, and two pairs of internal branchial spines, and a pair on the posterior edge; there are a few small spines on the lateral borders. The front has three spines of about the same length, and do not exceed the eyes; the lateral spines diverge slightly. The legs of the first pair are of moderate length, spiny, and of equal size; the second pair exceed slightly the others, and all exceed the first pair. The second and third segment of the abdomen have two pairs of spines; there is but one pair on the fourth ring.

Range.-Barbados, St. Kitts, St. Lucia. 


\section{Munida stimpsonii.}

Munida stimpsonii . A. Milne Edwards, Henderson,
A. Milne Edwards and
Bouvier.

The carapace has very marked granular transverse lines. The gastric region has five small spines; two are in pairs in front, the fifth is in the middle line behind. The cardiac region has a median spine; the posterior border of the carapace has a median pair. The branchial regions have a spine placed almost at a level with the gastro-cardiac groove. The lateral edges, commencing in a strong spine, has three or four small spines behind it. The rostral points are long, thin, and do not exceed the eyes. The legs of the first pair are spiny. The second, third, and fourth segment of the abdomen have small spines arranged symmetrically; the last spine only in median.

Range.-Barbados, Grenada, Grenadines, St. Vincent, St. Lucia, Martinique. Dominica, Guadaloupe, St. Kitts, Santa Cruz, Pernambuco.

\section{Eyes small:-}

\section{Munida microphthalma.}

MInida microphthalma. A. Milne Edwards, Henderson, Faxon, A. Milne Edwards and Bouvier.

The cornea of the eyes are scarcely dilated. The median rostral point is long. Its lateral spines exceed the eyes. The spines on the gastric region are numcrous. The second abdominal segment has four spines. The pincers are symmetrical; the fingers of both hands are 
in contact along their entire length when closed. The external antennx are very long.

RANGE.-St. Vincent, Martinique, Kermadec Islands, Ascension Island.

B. Eyes non-pigmented.

c. Ey'e-peduncle usually prolonged beyond cornea:-

\section{Munidopsis.}

Munidopsis. . . Whiteeaves, Henderson, A. Milne Edwards and Bouvier.

$\left.\begin{array}{l}\text { Galathodes . . . } \\ \text { Orophorhynchus (part) }\end{array}\right\}$ A. Milne Edwards.

Rostrum spinulose; usually more or less triangular, with its margins rarely dentate or spinose. Carapace rugose or spinose, but in most cases glabrous. First pair of legs and walking legs of variable length, and frequently spinose; the terminal joint of the walking legs with their posterior margin often dentate. Eyes devoid of pigment, with the peduncle frequently prolonged beyond the cornea in the form of a spine or spines. Antennal peduncle usually stout. Eggs few in number and of large size.

RANGE.-In deep water (IOO to 2000 fathoms).

\section{Sinopsis of the SPECIES}

A. Rostrum a simple spine.

a. Abdominal segments almost smooth.-( $($ I. sigsbei.)

b. Second and third abdominal segment have a small median spine.-( MI. simpler.)

$B$. Rostrum triangular.

c. No spines on dorsum of abdomen.

$c^{1}$. Rostrum keeled above. 
$c^{2}$. Eye-stalks produced into two slender lateral spines. -(M. nitidu. $)$

$d^{2}$. Eye-stalks produced into one long spine--(MT. spinoculata.)

d. Spines on dorsum of abdomen.

$d^{1}$. Second, third, and fourth abdominal segment have a median spine directed forwards.-( M. abbreviata.)

$e^{1}$. Second and third abdominal segment have a median spine and lateral spines.-(M. serratifrons.)

$f^{1}$. Second, third, and fourth abdominal segment have a median keel terminating in front in a spine.- $(M I$. robusta.)

C. Rostrum composed of three spines.

$\epsilon$. Second and third segment of abdomen have four or six spines arranged transversely, these are slightly marked on fourth segment.-(H. erinccerr.)

$f$. Second and third abdominal segment have three spines; the fourth has none.-(MI. spinifer.)

$g$. The abdomen is smooth.

$g^{-1}$. Carapace has no spines on dorsum.-( MI. latifrons.)

$h^{1}$. Carapace has two spines on gastric region.-( $M$. tridens.)

A. Rostrum a single spine:-

\section{Munidopsis sigsbei.}

Munidofsis siosbei. . A. Milne Edwards, Henderson, A. Milne Edwards and Bouvier.

Galathodes sigsbei . A. Milne Edwards.

The carapace has no spines and no ridges arranged transversely; it is much curved from side to side. The 
transverse cardiac depression is not deep. The anterior edge is more oblique, starting from this frontal point, The posterior edge has in its middle portion three small spines arranged transversely. The rostrum is straight, and slightly keeled above. The abdominal segments are almost smooth. The legs of the first pair are long, with fourth and fifth joint spiny; the hand has sharp points. The walking legs are short and strong; there are some hairs.

RANGE-Martinique, Guadaloupe.

2. Munidopsis simplex.

Munidopsis simpler . . . . A. Milne Edwards and Bouvier.

Galathodes simplex . . . . A. Milne Edwards.

The carapace has no spines, only some pointed tubercles on the gastric region; it has some transverse, line-like rugositics. There is a deep transverse depression between the anterior and posterior cardiac lobes. The lateral angle is sharp and spiniform. The lateral edges are rounded and unarmed. The rostrum is slightly elevated. The second and third abdominal segment have a small median spine. The legs of the first pair are weak in both sexes. The fourth and fifth joint have spines inside. The hand is smooth, and the fingers are in contact along their entire length when closed. The fourth joint of the walking legs is rough.

RANGE.-St. Vincent, Martinique, Dominica, Guadaloupe. 
B. Rostrum triangular:--

\section{Munidopsis nitida.}

Munidopsis nitidd . . . A. Milne Edwards, A. Milne Edwards and Bouvier.

Munidopsis brevimana. . Henderson.

$\left.\begin{array}{l}\text { Orophortynchus nitidus } \\ \text { Orophorhynchus spinosus }\end{array}\right\}$. A. Milne Edwards.

The rostrum is straight and sharp, with its lateral edges spiny; a keel above. The eye-stalks are produced into two slender lateral spines. There are two small spines placed symmetrically upon the gastric region. The fourth and fifth joint of the walking legs and of the pincers have spines. Abdominal segments are comparatively smooth; a few granulations on the posterior ones. The second, third, and fourth each bear a curved transverse sulcis, the convexity of which is directed forwards.

RANGE.-Dominica, Guadaloupe.

\section{Munidopsis spinoculata.}

Munidopsis spinoculata . . A. Milne Edwards and Bouvier.

Orophorhinchus spinoculatus. A. Milne Edwards.

The carapace is rough, with a subantennary spine on each side in front. The antero-lateral angle is sharp. There is a short spine on the hepatic region. The dorsal surface has two rough lines. The rostrum is keeled above. The eyes do not move. The cyc-peduncle is prolonged into a large and sharp spine that reaches half of the length of the rostrum. The abdomen has no spines. The pincers are very short; they have a spine on the inside, towards the extremity of the arm.

RANGE.-Dominica. 


\section{Munidopsis abbreviata.}

Munidopsis abbreviatcr. A. Milne Edwards, A. Milne Edwards and Bouvier.

Galathodes abbreviata. A. Milne Edwards.

The carapace wide, and covered with granulations in a transverse serics, becoming short spines on the gastric region. The lateral edges have two spines, one hepatic, the other smaller and epibranchial, behind which is a tubercle on the branchial edge. The rostrum is horizontal, with its point slightly raised. The legs of the first pair are short and strong; fourth and fifth joint have short spines at their extremities; they are rough. The legs of the second pair reach about the level of the articulation of the movable finger of the pincers. The second, third, and fourth abdominal segments have, in the middle line, a spine directed forwards. The body and legs are hairy, with long hairs on the pincers.

RANGE.-Guadaloupe, Martinique.

\section{Munidopsis serratifrons.}

Munidopsis serratifrons.

A. Milne Edwards, Henderson, A. Milne Edwards and Bouvier.

Galathodes serratifions . A. Milne Edwards.

The carapace is rough and unequal. The gastric region has three small spines arranged transversely, one median, the others lateral. There are two median spines on the cardiac region. The latero-anterior angle of the carapace spiniform. The lateral edge has granulations in front, but behind the branchial regions it has three spines. The lateral edge has on each side of the middle line a spine in the form of a hook. The rostrum is keeled 
above and finely serrated. The second and third abdominal segment has a median spine and lateral spines. The legs of the first pair are long and thin. The fourth and fifth joint have large spines and granulations. The hand is granular. The walking legs carry spines on their fourth joint; the other joints are rough.

RANGE.-Dominica.

\section{Munidopsis robusta.}

Munidopsis robusta . . A. Milne Edwards, A. Milne Edwards and Bouvier.

Galathodes robustus . . A. Milne Edwards.

The carapace is larger behind than in front; it is thick and covered, as well as the rest of the body, with short hairs. Its surface is covered with tubercles of unequal size arranged regularly and symmetrically. The latero-anterior angle is pointed. The lateral edges are unarmed. The rostrum, short, large at base, raised towards its extremity, is keeled below and finely granular upon its edges. The second, third, and fourth abdominal segments have a median keel terminating in front in a spine. The first pair of legs weak; the fourth joint spiny. The walking legs short, robust, not spinous; the fingers have fine teeth.

RANGE.-Grenada.

\section{Rostmm composed of three spines:-}

\section{Munidopsis erinacea.}

Munidopsis crinacer. A. Milne Edwards and Bouvicr, Henderson.

Galathodes erinacens. A. Milne Edwards.

The carapace is very curved transversely; the posterior gastric groove is well marked. The gastric region has 
four spines arranged in pairs, the one before the other; the cardiac region has four spines, one pair, large, in front; the other, small, behind. The sides posteriorly have in front three strong spines; there is a short spine between the first and second. The branchial regions have laterally three spines, shorter and arranged longitudinally. The rostrum is almost as long as the internal antennx; towards the middle of its length it gives origin on each side to a small point in such a way as to appear trifurcate, the middle point being longest. The second and third segment of the abdomen carry four or six spines arranged transversely. These points exist, but slightly marked, on the fourth segment. The first pair of legs long; the fourth and fifth joint have spines; the hand is unarmed. In the female the fingers are in contact in their whole length when closed; in the males, only at their extremities. The walking legs are spinous.

RANGE.-St. Vincent, St. Lucia, Nevis.

\section{Munidopsis spinifer.}

Munidopsis spinifer. . . . A. Milne Edwards and Bouvier.

Galathodes spinifor . . . . A. Milne Edwards.

The spines of the carapace are short and numerous; the gastric region has three pairs, the cardiac four. The lateral edges have a series of five equal spines, within which on the branchial regions is another series of three spines. There are six short symmetrically arranged spines on the posterior edge. The rostrum is straight, and the two lateral points are very small and directed forwards. The second and third abdominal segment have three spines; the fourth has none.

RANGE.-Barbados, St. Kitts. 


\section{I0. Munidopsis latifrons.}

Galathodes latifrons. . A. Milne Edwards, A. Milne Edwards and Bouvier.

The carapace, smooth above, is narrow, and has short hairs. The lateral edges have in front four or five small spines. The rostrum is flat at its base; the middle point is the longest. The abdomen has no spines. The legs of the first pair are frail, and have long hairs. The arm and forearm have some spines. The hand is smooth.

RANGE.-Barbados.

\section{Munidopsis tridens.}

Galathodes tridens . . A. Milne Edwards, A. Milne Edwards and Bouvier.

The carapace is large, entirely smooth, except for a pair of spines on the gastric region. The lateral edges have four spines. The legs are short, strong, and almost smooth. The abdomen is smooth.

RANGE.-St. Kitts.

\section{Elasmonotus.}

Elasmonotus . . . A. Milne Edwards, Henderson, A. Milne Edwards and Bouvier.

Galathopsis . . . . . Henderson.

Orophorhy'nclus (part). A. Milne Edwards.

Rostrum flattened and triangular, usually of moderate length. Carapace unarmed, with the lateral margins parallel and entire. Orbito-antennal border short and transverse. First pair of legs and walking legs frequently 
robust, with or without spines. Eyes devoid of pigment, with the peduncle in some cases prolonged beyond the cornea. Antennal peduncle of moderate width. Anterior abdominal segments, as a rule, transversely carinated. Eggs few in number and of large size.

RANGE.-Deep seas.

\section{Synopsis of the Species.}

A. No transverse keels on abdominal segments.

a. Rostrum short. The projection on the inside of the cornea resembles a second cornea.-(E. squamosus.)

$B$. Transverse keels on abdominal segments.

$b$. Second and third segment keeled.

$b^{1}$. The rostrum is wide, with parallel sides for a great part of its length, long, and terminates in a sharp point.(E. abdominalis.)

$c^{1}$. The rostrum is contracted at its base, wide in the middle, and terminates in a long spine.-(E. armatus.)

c. Second, third, and fourth abdominal segments keeled.

$d^{1}$. Rostrum wide, partly hiding the eyes; upper surface granular; extremity obtuse.-(E. longimanus.)

\section{Elasmonotus squamosus.}

Elasmonotus squamosus . . A. Milne Edwards and Bouvier.

Orophorhynchus squamosus . A. Milne Edwards.

The carapace is short, massive, and covered with groups of granulations resembling prominent and thick scales. The lateral edges are unarmed. The rostrum is short. The eyes are immovable. The projection on the inside of the cornea resembles a lateral cornea. The first pair of legs are short; the hand is compressed, and rough; the arm and forearm have spines and tubercles. The walking legs are 
compressed, and covered on the first joints with spine-like tubercles. The segments of the abdomen have no transverse keels.

RANGE.-Martinique, St. Lucia.

\section{Elasmonotus abdominalis.}

Elasmonotus abdominalis . . A. Milne Edwards, A. Milne Edwards and Bouvier.

The carapace is almost as wide in front as behind, and its antero-lateral angle terminates in a short and sharp point. The rostrum is wide, and its borders are parallel for a great part of its length ; it reaches almost to the end of the internal antenne and terminates in a sharp point; it has a slight keel below. The eye-peduncles are mobile; their corneal surface is slightly developed. The peduncles of internal antenne tcrminate in two large spines, of which the lowest is the longest. The basal antennal joint has a spine upon each of its angles. The legs of the first pair are of unequal size; they and the walking legs, which are short and strong, have spines. The abdomen is smooth; upon its second and third segment there is a feeble tranverse keel.

RANGE.-Barbados.

\section{Elasmonotus armatus.}

Elasmonotus armatus. . A. Milne Edwards, Henderson, A. Milne Edwards and Bouvier.

The carapace widens gradually from before backwards. The antero-lateral angle terminates in a subacute point. The rostrum, keeled below, rounded on its dorsal surface, 
is retracted at its base, widened in the centre, and terminates in a long spine. The eye-peduncles are slightly dilated at the base; they reach the terminal joint of the antennal peduncles and end in a reduced corneal surface. The first pair of legs are long and slender; there are a few spinules on the distal end of fourth and fifth joint; fourth joint has a few spines on inner border. Walking legs thin; a spinule on distal end of fourth joint; terminal joint large, with horny spines on posterior margin. Abdomen has an elevated keel on second and third segment.

RANGE.-West Indian Sea.

\section{Elasmonotus longimanus.}

Elasmonotus longimanus. A. Milne Edwards, A. Milne Edwards and Bouvier.

The carapace is a little wider in front than behind; its lateral borders are almost parallel. The rostrum is wide, very obtuse at its extremity, slightly depressed dorsally, especially posteriorly; it partly hides the eyes. The eyepeduncles are compressed and retracted at the base, rounded distally. The corneal surface is large. The first pair of legs long and strong; the fingers of the pincers of the male project slightly at their base; their edges are finely and regularly toothed. The fourth and fifth joint are granular. The walking legs are short and feeble; the superior border of the fourth joint is trenchant. The fifth joint has a toothed border or two longitudinal ridges. All the joints are granular.

The second, third, and fourth abdominal segment are carinated, and the middle portion is raised up to form a strong, compressed tooth, curved in front.

Range.-St. Lucia, Martinique, Dominica. 
d. Eye-peduncle not prolonged byond cornea :-

\section{Galacantha.}

Galacantha . A. Milne Edwards, Henderson, Faxon, A. Milne Edwards and Bouvier.

Rostrum long and spinulose, the proximal part horizontal, the apical portion upturned. Carapace broad, convex from side to side, armed with a median spine of large size, placed near the posterior limit of the gastric area, and with an anterior gastric pair of spines and a cardiac spine of smaller size. Lateral margin of the carapace provided with two prominent flattened spines in front. First pair of legs rather stout, and exceeded in length by the walking legs. Eyes devoid of pigment, with the cornea terminal in position. Antennal peduncle stout; the flagellum of moderate length. Second, third, and fourth abdominal segment strongly bicarinate transversely, and armed each with a prominent median spine. Male reproductive appendages of large size. Eggs few and large.

RANGE.-Very deep seas.

\section{Galacantha spinosa.}

Galacantha spinosa. A. Milne Edwards, A. Milne Edwards and Bouvier.

Rostrum without spines at its base. The carapace is covered with spiny tubercles in place of granulations; the first lateral spine is larger than the second; the mesogastric point is large and compressed. The segments of the abdomen are covered with pointed tubercles. The pincers are smooth.

RANGE.-Dominica. 
II. Abdomen folded on itself:-

\section{Ptychogaster.}

Ptychogaster. . A. Milne Edwards, IIenderson, Bouvier.

Chirostylus. . . Ortmann. Gastroptychus . . . Caullery.

Rostrum slender and spiniform, usually upturned. Carapace narrow and somewhat ovate in shape, with its surface glabrous and usually spinose. First pair of legs and walking legs slender and greatly elongated; the basal joints of the latter not hid by the sides of the carapace. Eye-staiks with the cornea dilated. Antennal peduncle slender without basal scale; the flagellum short. External maxillipedes narrow; the terminal joints elongated. Abdomen folded on itself; the telson (which is transversely segmented) and the last pair of appendages bent under the preceding segments, and applied to the thoracic stema; males with the first two pairs of appendages (genital) well developed, those of the third, fourth, and fifth segments rudimentary. Eggs few in number and of large size.

RAXGE.-Deep sea.

\section{r. Ptychogaster spinifer.}

Ptychogister spinifer. A. Milne Edwards, A. Milne Edwards and Bouvier.

The carapace is long, curved transversely, flat from before backwards, contracted in front and covered with small spines. There is a row of larger spines in the middle line; there are four gastric and four cardiac spines. On each side on the branchial region on the sutures there is a range of spines. The rostrum is in 
the form of a needle, exceeding slightly the ocular peduncles.

The legs of the first pair are about five times the length of the carapace; they are cylindrical and covered with small serrated spines, directed forwards, arranged longitudinally. There are some scattered hairs. The fingers are frail, long, with very fine and pointed denticulations. The succeeding legs are very large, feeble, and spinous. The second pair is the most developed, and extend to the joint of the pincers.

The abdomen is wide and smooth.

The sternal plastron has a deep median groove.

Range. - Barbados, Grenadines, St. Lucia, Guadaloupe, Cariacou.

\section{Uroptychus.}

Uroptychus . Henderson.

Diptychus . A. Milne Edwards, A. Milne Edwards and Bouvier.

Rostrum flattened and acute. Carapace somewhat ovate in shape, with its surface glabrous and usually devoid of spines. First pair of legs elongated and of varying width; walking legs slender. Eye-stallis short and stout; cornea scarcely dilated. Antennal peduncle slender, the first free joint provided with a flattened and acute acicle or movable spine; the flagellum never of great length, and in some cases remarkably short. External maxillipedes comparatively smooth, with the terminal joints elongated, more especially the last joint but one, which is considerably longer than any of the other joints. Abdomen smooth and glabrous externally; the telson (which is transversely segmented and of small size), as well as the last pair of appendages, bent under 
the preceding segments and applied to the thoracic sterna; males with the first two pairs of appendages (copulatory organs) fairly well developed, those of the third and fourth segment rudimentary, those of the fifth absent; females with two pairs of ovigerous appendages on the third and fourth segment, those of the other segments (with the exception of the penultinuate) absent. Eggs few and of large size.

RANGE.-Moderately deep and deep seas.

\section{Synopsis of the Species.}

A. Dorsal surface of carapace smooth.

a. No spines on lateral edges of carapace except at antero-lateral angle.

$a^{\mathbf{1}}$. Rostrum twice as long as eye.-(U. nitidus.)

$b^{1}$. Rostrum about as long as eye.-(U. uncifer.)

$B$. Dorsal surface of carapace (and rostrum) covered with small spine-like tubercles.-( $U$. mgosus.

\section{Uroptychus nitidus.}

Uroptychus nitidus. Henderson.

Diptychus nitidus. . A. Milne Edwards, A. Milne Edwards and Bouvier.

The carapace is smooth, shining, without spines (except at each antero-lateral angle) or transverse strie; it is transversely curved, almost flat from before backwards, and straighter in front than behind. The regions are scarcely marked. The rostrum is spiniform and flattened above; it is about twice as long as the eyes. The lateral edges are unarmed.

The legs of the first pair are very long, smooth, and shining. The fourth joint is very frail at its base. The fifth is longer than the fourth, slightly compressed 
laterally, and rounded above and below. The palm is as long as the fifth joint; the fingers are slightly shorter than the palm, hairy towards their extremity, which is sharp and excavated within. The movable finger has at its base a long fine tooth with a toothed edge. The walking legs are smooth, slightly compressed; the second pair longest, the fifth shortest.

The sternal plastron has on the middle line a groove; it is curved from before backwards, and notched in front.

RANGE-Barbados, Grenada, St. Vincent, Martinique, Dominica, St. Lucia, Guadaloupe, St. Kitts, Santa Cruz; in deep water.

\section{Uroptychus uncifer.}

Diptychus uncifer . . . . A. Milne Edwards, A. Milne Edwards and Bouvier.

The carapace is smooth, except a spine at cach antero-lateral angle. The rostrum is prominent, and terminates in a sharp point; its edges are unarmed. In length it reaches about the anterior margin of the cornes. The first pair of legs short and strong.

RANGE.-Barbados, St. Vincent.

\section{Uroptychus rugosus.}

Diptychus rugosus . . . . A. Milne Edwards, A. Milne Edwards and Bouvier.

The carapace is very short, narrow in front, and terminates in a very long rostrum, which, like the upper surface of the carapace, is covered with small spine-like tubercles. The fourth joint of the first pair of legs has spines. The fifth joint is rough; the hand is almost 
smooth. The walking legs have upon the fourth and fifth joint small spines.

RANGE.-Barbados, St. Vincent, Grenadines, Dominica.

\section{Suborder III. Macroura.}

Macroura (part) . . . Latreille.

Macroures (part) . . . H. Milne Edwards.

Macroura. . . . . Dana, Miers.

Macrura (part). . . . Spence Bate.

The external antenna very greatly developed; the internal antenne, usually terminating in two flagella, have no fossettes. The external maxillipedes nearly always pediform. Buccal cavity not distinctly defined in front. Abdomen well developed, extending backwards, with lamellar appendages beneath. Appendages to the last segment but one large, laterally expanded, and constituting, with the tcrminal segment, an expanded swimming organ (telson.)

\section{Division I. Trichobranchiata. \\ Division II. Dendrobranchiata. Division III. Phyilobranchiata.}

Syropsis of the Divisions.

A. Gills in the form of threads.-(Trichobranchata.)

$B$. Gills in the form of branching plumes.-(Dcndrobranchiata.)

C. Gills in the form of broad, thin plates.-(Phyllobranchiata.)

Division I. Trichobranchiata. Trichobranchiata . . . Spence Bate.

Gills more or less in the form of rounded threads. 


\section{Group I. Aberrantia. Group II. Normalia.}

\section{Synopsis of the Groups.}

I. The abdomen is very large in proportion to the rest of the body; its segments do not overlap.-(Group Aberrantia.)

II. The abdomen is in proportion with the rest of the body, both being equally developed; its segments more or less overlap.-(Group Normalia.)

\section{Group I. Aberrantia (Spence Bate).}

Carapace short and compressed, with little or no rostrum. Last thoracic segment articulated with the preceding segment. The segments of the abdomen are long, and do not overlap each other. Eyes small. Antennæ have long peduncles. The legs are more or less armed with pincers; first pair the longest, the posterior pair more or less directed backwards. The abdominal appendages are long and have two branches. The swimming organ is strong.

\section{Family I. Callianassidæ.}

Family II. Thaumastochelidæ.

$$
\text { STNOPSIS OF TIIE FAMILIES. }
$$

A. There is no scale on the base of the external antenna.-(Callianassida.)

$B$. There is a scalc on the base of the external antenna.-(Tharmastochelida.) 


\section{Family I. Callianassidæ.}

Callianasside . . . . . Spence Bate.

The internal antenne have long flagella. The external antennx have no scale at base. The first pair of legs asymmetrical; the right usually the largest, and less perfectly chelate than the left; the fifth joint on the right side is formed, usually, as if it were a continuation backwards of the hand-the sixth joint. The segments of the abdomen increase in size backwards, and terminate in a foliaceous swimming organ; second pair of appendages is like the third and following pairs.

\section{Symorsis of the GenerA.}

$A$. The external maxillipedes have their third and fourth joint very broad. No spines on posterior margin of swimming organ.-(Callianassa.)

$B$. The external maxillipedes have their joints more or less rounded, pediform. There are strong spines on the posterior margin of swimming organ.-(Cheramus.)

\section{Callianassa.}

Callianassa . . Leach, H. Milne Edwards, Bell, Spence Bate.

Cancer (Astacus) . Montague.

Carapace ovate. The external maxillipedes have their third and fourth joint rery broad, constituting, when in contact, a broad oval disc terminating in a small seta formed of the last three joints. The posterior pair of legs is minutely chelate.

There are no spines on the posterior margin of the swimming organ. The second pair of abdominal ap- 
pendages is slender and filamentous; the three following pairs are broad, and are fringed with ciliated hairs.

The gills spring from the membranous articulation between the body and the first joint of the legs-ten pairs. There is a branchial plate on first maxillipede.

RANGE.-Atlantic and Pacific Oceans.

Synopsis of the Species.

$A$. The lower margin of the fourth joint of the large leg is compressed into a thin convex plate serrated posteriorly.-(C. occidentalis.)

$B$. The fourth joint of the large leg is armed with a strong tooth.-(C. major: $)$

\section{Callianassa occidentalis.}

Callianassa occidentalis . . Spence Bate.

The large hand is smooth, longer than broad, and broader than the fifth joint, which is also longer than the palm. The fourth joint is as long as the fifth; the lower margin is compressed to a thin convex plate, which is serrated posteriorly.

RANGE.--IVest Indies; in deep water.

\section{Callianassa major.}

Callianusse major . . Say, H. Milne Edwards.

The fifth joint of the large leg has granulations. The fourth joint is armed with a strong tooth.

RANGE.-IVest Indies, Florida.

\section{Cheramus.}

Cheramus . . . Spence Bate.

Resembles Calliancrsact, only the external maxillipedes have their joints more or less rounded and are pediform. 
There are strong spines, more or less curved, on the posterior margin of the swimming organ. Gills are attached to the membranous joints of the first four pair of legs, and to the first joint of the external maxillipede.

RANGE. - West Indies, Arafura Sea; in deep water.

\section{Cheramus occidentalis.}

Cheramus ocidintalis . . . Spence Bate.

Carapace smooth, with a sharp rostrum reaching nearly to the extremity of the legs. Branchial region defined from the gastric. The telson is long, quadrate; the posterior margin, rather narrower than the anterior, is fringed with long ciliated hairs, and has in the middle line a strong sharp tooth, and two short sharp spines on the posterior half of the lateral margin.

RANGE.-West Indies.

\section{Family II. Thaumastochelidæ.}

Thaumastochelide . . . . Spence Bate.

The carapace, ovate and smooth, projects to an anteriorly flattened point or rostrum. The internal antennæe have two long flagella; the external antenne have a scale at the base. The first pair of legs chelate, large; the hand, terminating in long slender fingers, subequal, somewhat unsymmetrical. Second pair chelate, symmetrical, subequal, small. The abdomen has the basal joint of appendages well defined. The swimming organ has the outer plate much larger than the iliner.

RANGE.-West Indies. 


\section{Thaumastocheles.}

Thanmastocheles . Spence Bate, Wood-Mason. Astacus. . . . . Suhn.

Carapace less than half the length of the animal, dorsally flattened, divided by a moderately deep cervical sulcus; near the centre the lateral walls are depressed, and the posterior margin is secured in its position by a strong blunt process attached to the lateral portion of the first joint of the abdomen. The abdomen is longer than the carapace, and each segment increases in width posteriorly to the fifth, then decreases.

The eyes are absent or obsolete.

Gills are attached to the body wall, to the membrane between body and first joint of external maxillipede and anterior four pair of legs, and to their first joint. There are six branchial plates.

\section{Thaumastocheles zaleuca.}

Thaumastocheles zaleuca. Spence Bate, Wood-Mason. Astacus saleucus . . . Sulnn.

Animal long and slender, sides subparallel and compressed, dorsal surface smooth except on the antennal and postocular regions of the carapace, on each side of the rostrum, and the third and fourth segment of the abdomen, where there are numerous short, thick tufts of hair. Rostrum dorsally flat. The external antenne are about as long as the animal; basal scale with serrated edges. The first pair of legs asymmetrical. The right being the larger, and furnished with slender, rod-like fingers which are nearly as long as the animal; their extremity is curved, and they are armed on their prehensile 
margin with many long, spine-like teeth that interlock when closed. The swimming organ has the outcr plate large and strong and the inner small; the central plate is quadrate.

RANGE.-West Indies; in deep water.

\section{Group II. Normalia (Spence Bate).}

The gills are well developed. The abdomen is not out of proportion with the rest of the body, cephalo-thorax and abdomen being well developed. The segments more or less overlap.

\section{Tribe I. Synaxidea. \\ Tribe II. Astacidea. Tribe III. Stenopidea.}

SyNopsis of the Tribes.

A. The anterior pairs of legs have no pincers; the less are six-jointed. The external antennz have no scale on basal joint.-(Symaridea.)

$B$. The anterior pairs of legs have pincers, the first pair the largest; the legs are seven-jointed. The basal scale of external antenne is small or large.-(Astacider.)

$C$. The anterior pairs of legs have pincers, the third pair the largest; the legs are seven-jointed. There is a basal scale on external antenne.-(Stenopider.)

\section{Tribe I. Synaxidea.}

Syncrider. . . . . Spence Bate.

The external antennix have no basal scale. The in ternal antennx terminate in two flagella. The legs have six joints, and have no pincers, except the last pair sometimes in the female. The ova are very small. 


\section{Family I. Scyllaridæ. Family II. Palinuridæ.}

Synorsis of tile Families.

$A$. The external antemne are short, and in the form of flat plates.-(Soyldrida.)

$B$. The external antenne are long, and in the form of long, stiff, multiarticulate flagella.-(Polinmide.)

\section{Family I. Scyllaridæ.}

Scyllaride. . . . Spence Bate, Dana.

Carapace horizontally depressed. Eyes implanted in orbits excavated in the dorsal surface of the carapace The external antenna short, in the form of flat plates. The mandibles have an unarticulate palp. The legs of the posterior pair of the female are minutely chelate.

Synopsis of THE Genera.

$A$. The carapace is wider than long; the orbits are situated at some little distance from its anterior angles.-(Ibacus.)

$B$. The carapace is longer than wide; the orbits are situated at a short distance from its anterior angles.

$a$. The external antenne are close. The gills are twenty-one in number. There is

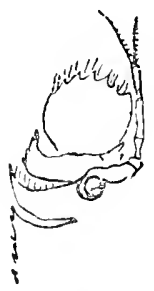

Ibacius.
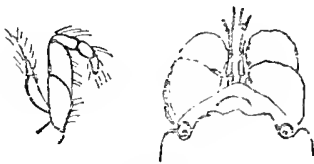

Soyllarus.
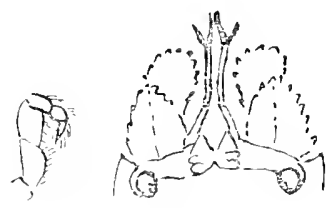

Arclus.

an external appendage to the external maxillipede.(Scyllarus.) 
b. The external antenne are some distance apart. The gills are nineteen in number. The external maxillipedes have no external appendage.-(Arctus.)

\section{Ibaccus.}

Ibaccus . . . Spence Bate.

Ibacus. . . . H. Milne Edwards.

Ibachus . . . Leach, Desmarest.

Scyllarus. . . Fabricius, Latreille.

The carapace, wider than long, has on each side a flat prolongation which hides the greater portion of the legs. These prolongations are more extensive in front than behind, consequently it is broader in front than posteriorly. These expansions are divided on each side by a wide and deep fissure. The orbits are situated at some distance from the anterior angles of the carapace. The abdomen is very short, and contracts from before backwards. Gills are attached to the body wall, to the membranous articulation, and to the first joint of all the limbs except the last pair, which have also branchial plates.

RANGE.- West Indies, Atlantic, New Holland, Japan, Hong Kong, New Guinea, New Zealand; in deep water.

\section{Ibaccus parræ.}

Ibacus pare. . . . . . . H. Milne Edwards.

Horscshoe crab (local name) . Barbados.

The carapace and the external antennx are covered with rough rounded elevations, each elevation being fringed in front with a row of short hairs. The margin is cut into numerous large teeth separated from each other by deep and wide notches. There are two teeth 
on the margin in front of the deep lateral notch. The external antenne are wider than long, with their margin cut into sharp teeth; the first joint is toothed anteriorly. There is no spine upon the base of the posterior legs, and their third joints are grooved on the under side. The colour is yellow-brown, each tooth having a purple tip, with a light purple spot.

RANGE.-West Indies, Barbados.

\section{Scyllarus.}

Scyllarus . Fabricius, Latreille, Lamarck, Leach, Desmarest, H. Milne Edwards.

Cancer . . Linné, Herbst.

The carapace is longer than wide, with the lateral edges parallel. The orbits are situated at some distance from the middle line near the external angles of the carapace. They are circular, and are directed upwards. The sternum is of moderate size. The abdomen is very thick, and is longer than the anterior portion of the body.

The external antennæ are close together; the gills are twenty-one in number, and there is an external appendage to the external maxillipedes.

RANGE.-Atlantic Ocean, West Indies, Mediterranean Sea.

\section{Sinopsis of the Species.}

$A$. The tubercles on the surface of the carapace are fringed with hairs. The third and fourth joint of the legs are cut into grooves.-(S. squamosus.)

$B$. The tubercles on the surface of the carapace are scarcely hairy. The third and fourth joint of the legs are not cut into grooves.-(S. aquinoxialis.) 


\section{Scyllarus squamosus.}

Scyllarus squamosus . . H. Milne Edwards.

The tubercles on the upper surface, broad, are only fringed with hairs, and are scale-like. There are no points upon the gastric region. The third and fourth joint of the legs, in place of having a simple crest upon their upper surface as usual, are cut into longitudinal grooves. The tubercles upon the sternum are scarcely visible. Colour red-brown.

RANGE.--West Indies, Isle of France.

\section{Scyllarus æquinoxialis.}

Scyllams aquinorialis . . Fabricius, Bosc, Latreille, H. Milne Edwards.

The tubercles upon the upper surface are scarcely hairy. There are no conical teeth upon the gastric region. The lateral edges of the carapace have obtuse tecth. The external antenne are short; their penultimate and antipenultimate joint are wider than long, and their teeth are not very prominent. The third and fourth joint of the legs are crested above, and are not cut into longitudinal grooves. Colour brown, with orange-red marks.

RANGE.-West Indies, Barbados.

\section{Arctus.}

Arctus . . . . . Dana, A. Milne Edwards, Spence Bate.

Scyllarus (part) . Fabricius, De Haan, Spence Bate.

The carapace is longer than wide, with the lateral edges parallel. The orbits are situated at some distance 
from the middle line, near the cxternal angles of the carapace. They are circular and are directed upwards. The sternum is of moderate size. The abdomen is very thick, and is longer than the anterior portion of the body. The cxternal antenne are some distance apart. The gills are nineteen in number. There is no external appendage to the external maxillipedes.

RANGE.-West Indian Sea, South Coast of England, Mediterranean Sea, Canary and Cape Verde Islands, Philippine Sea, West Coast of North America, Fiji, Japan.

\section{Arctus americanus.}

Artus americanns . A. Milne Edwards, Smith.

RANGE-Guadaloupe, in decp water; West Coast of Nortin America.

\section{Family II. Palinuridæ.}

Palinuride . . Dana, Spence Bate, Miers.

Langonsticns. . . H. Milne Edwards.

Carapace longitudinally subcylindrical. Orbits only partially excavated in the carapace. External antenne terminating in a long rigid multiarticulate flagellum.

\section{Synopsis of THE Genera.}

A. There is a small central tooth or tubercle over-

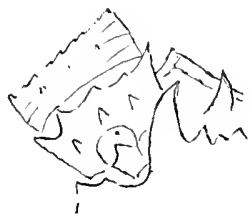

Palinurus.

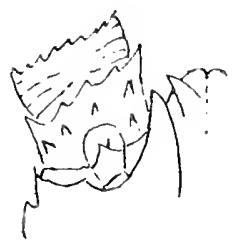

Panuliras.

hanging the ophthalmic segment of the carapace, situated in the middle line between the frontal horns.-(Falinums.) 
$B$. There is no central tooth in the middle line between the frontal horns (there may be a spine in this locality).(Panulims.)

\section{Palinurus.}

Palimurus . . . . . . Spence Bate, Miers, Dana, Heller.

Palimus (part) . . . . H. Milne Edwards, Fabricius.

Palinurus (subgenus) . . . Gray.

Langoustes ordinaires . . . H. Milne Edwards.

There is a small central tooth (not a spine) in the middle line between the frontal horns, overhanging the ophthalmic segment. The antennary segment very narrow above. External antenne nearly in contact with one another at their base, and concealing the base of the internal antenna, the flagella of which are very short. Gills attached as in Ibaccus, with the same number of branchial plates.

RANGE. - West Indies, shores of Europe, Mediterranean Sea, Japan, New Zealand, the Cape.

\section{Palinurus longimanus.}

Palinurus longimame . . H. Milne Edwards.

The lateral horns of the front are armed with two or three spines upon their superior border, and with many small spines between their base and the central rostral tooth, which is simple, acute, and spiniform. There is a single large spine on each side of the anterior border of the carapace. There are seven rows of spines on the anterior portion of the carapace, but not so many on the postcrior portion. The whole surface of the carapace is 
cut into small semicircular grooves that have hairs and resemble imbricated scales. The first pair of legs the longest. The abdomen has upon each segment four or five transverse grooves.

RANGE.-IVest Indies.

\section{Panulirus.}

Panulirus . . . . . . Spence Bate.

Palinurus (part) . . . . . H. Milne Edwards, Fabricius.

Panulirus (subgenus) . . Gray.

Langoustes longicornes . . . H. Milne Edwards.

There is no central tooth in the middle line between the frontal horns. The ophthalmic segment is exposed and membranous. The antennary segment is greatly produced in front of the frontal margin, which is generally armed with strong teeth. The terminal filaments of the internal antenne are long and slender. Gills as in Palinumus.

R.ANGE.-West Indies, Pacific Ocean; in warm seas.

\section{Synopsis of the Species.}

I. The abdomen is grooved transversely.

$A$. The first antennary segment is armed with two teeth.- $(P$. guttatus. $)$

$B$. The first antennary segment is armed with four teeth.

$a$. The four conical teeth remote.

$a^{1}$. Teeth large, equidistant, and forming a quadrangle.

$a^{2}$. Carapace spinose all over.-(P. americanus.)

$b^{1}$. Teeth minute, scarcely approximate on the median line, anterior and posterior much more distant.- $(P$. argus.) 


\section{Panulirus guttatus.}

Panulinus guttatus. . Latreille, Spence Bate.

Palimurus guttatus. . Latreille, H. Milne Edwards, Olivier, Lamarck, Desmarest.

\section{$\left.\begin{array}{c}\text { Guinea bird lobster } \\ \text { (local name) }\end{array}\right\}$. Barbados.}

Antennary segment is armed with two very large conical teeth, sometimes preceded by two rudimentary spines. Carapace very spinous; two spines upon the median line of the gastric region, near the base of the frontal horns, and on each side of these last, upon the anterior border of the carapace, are two teeth nearly as large. Anterior border of the epistome is armed with three subequal conical teeth, separated by a series of small teeth. Peduncle of the external antenne very spinous below. The second pair of legs the longest, the first pair the thickest. Abdomen smooth, presenting near the middle of each segment a transverse piliferous groove that is not interrupted upon the median line in the three first segments. The lateral horns of the abdomen are produced to a single tooth.

The colour is green spotted with yellow; the two last joints of legs are striped longitudinally with orange and green. The large spines are tipped with vermilion. The base of the legs, the anterior margin of each abdominal segment, the swimming organ, and the abdominal appendage are marked with orangered.

RANGE.-West Indies, Barbados, Isle of France, New Holland, St. Paul's Rocks. 


\section{Panulirus americanus.}

Panulirus americanus . Spence Bate, Streets.

P'alimurus americanns . H. Milne Edwards, Lamarck.

The antennary segment is armed with four large conical equidistant teeth forming a quadrangle. The carapace is spinous all over. The posterior border of the lateral horns of the abdominal segments armed with a single tooth; these segments have transverse grooves. The basal joint of the internal antennæ is very long, reaching the middle of the last peduncular joint of the external antennæ.

The colour is green, mixed with yellow-brown; nut brown on the sides, shading off to yellow below. There are two orange bands and four yellow spots on each abdominal segment. The frontal horns are marbled with yellow and black. All the legs have longitudinal stripes, on every joint, of nut brown and yellow.

RANGe. - West Indies, Barbados, where they are common, grow to a large size, and are good for food; Florida, Key West, Panama.

\section{Panulirus argus.}

Panulirus argus. . Spence Bate.

Palinurus argus. . H. Milne Edwards, Latreille,

Olivier, Lamarck, Desmarest.

Antennary segment armed with four small conical teeth scercely approximate on the median line, but the two anterior are very distant from the two posterior. Frontal horns very long. Carapace spinous; the lateral spines of the anterior border of moderate size; a service of small spines on the middle line of the gastric region. Abdomen smooth, and presenting on each segment a 
piliferous groove interrupted in the middle line. The second pair of legs slightly longer than the third pair.

The colour is green-violet, spotted irregularly with yellow on the thorax, fasciated with yellow on the legs. Each abdominal segment near its posterior border has a yellow band and some circular spots, of which two on the second segment and two upon the sixth segment are rery large and are bordered with green.

RANGE.-West Indies.

\section{Tribe II. Astacidea.}

Astacidea . . . . Dana, Miers, Spence, Bate.

Macroura astacina . De Haan.

Carapace often marked with a dorsal transverse suture, with the longitudinal sutures obsolete. Basal scale of external antenne small, obsolete, or large and well developed. First pair of legs stout, didactyl or monodactyl.

\section{Family I. Eryonidæ. \\ Family II. Homaridæ. \\ Family III. Astacidæ.}

Symorsis OF THE FAMILIES.

I. No rostrum present.

$A$. The first three pairs, sometimes the first four pairs, or all the legs, have pincers; the posterior pair of legs directed backwards.-(Eryonida.)

II. A rostrum present.

b. First three pairs of legs have pincers; the first pair the largest.

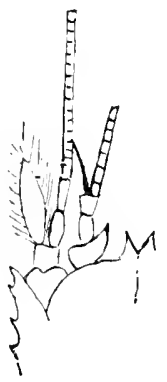

Eryonidie. 
a. Rostrum narrow, armed with many teeth.(Honaride.)

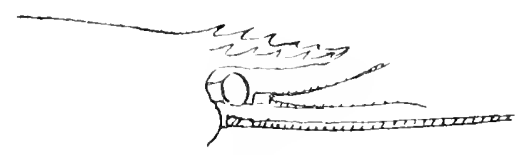

Homaridte.

b. Rostrum depressed, armed with few teeth.(Astacida.)

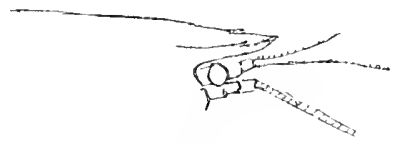

Astacidie.

Family I. Eryonidæ.

Eryonide . . . Spence Bate.

Carapace depressed, with the lateral margin serrate, and broader than the abdomen. No rostrum. Eyes wanting or abnormal. The internal antenna have two multiarticulate flagella. The external antenne have a basal scale and a long multiarticulate flagellum. The maxillipedes are pediform. Legs seven-jointed; first three pair, sometimes the fourth pair, or all the legs, chelate; posterior pair reversed. Abdominal appendages, except the first and sixth pair, have a small process attached to the inner branch; no division in the outer branch of sixth pair. Telson tapering.

\section{Sycopsis of tile Genera.}

$A$. First four pair of legs with pincers; first pair the largest.-(Polycheles.)

$B$. All the legs more or less armed with pincers.(Pentacheles.) 


\section{Polycheles.}

\section{Polycheles . . . Heller, Spence Bate.}

Dorsal surface of carapace flattened. Antero-lateral angles projecting beyond the anterior margin. Abdomen not longer than the carapace. Eyes obscure, immovably lodged in an orbit excavated in the dorso-frontal margin of the carapace, more or less covered by its antero-lateral margin. Internal antenne have the outer flagellum the shortest. The external antenne terminate in a long slender flagellum. The first four pairs of legs are armed with pincers; the first pair is the largest; the fifth pair in the male terminates in a simple style-like joint. The first pair of abdominal appendages in the male has a long and slender two-jointed stalk terminating in a broad spoon-like extremity; in the female it is two-jointed, but slender and feeble throughout. The second and four posterior pairs are two-branched, the branches are fringed with long eiliated hairs; the inner branch, in the male, supports two subequal processes; in the female, one. The swimming organ is symmetrical and well developed, its outer branch is broad. Gills attached to body wall, to membranous articulation, and first joint of anterior four pair of legs. There are branchial plates on these and on the external maxillipedes.

RANGE.-West Indies, Nova Scotia, Mediterranean. Sea, Fiji, Celebes; in deep water.

\section{Polycheles crucifera.}

Polycheles crucifere

Willemasia crucifera $\}$. Suhn, Spence Bate.

Carapace ovate; lateral margins fringed with large teeth; frontal margin armed with a single rostriform 
tooth, and two sharp teeth on the inner angle of the orbital notch; dorsal median ridge without teeth. On the posterior part of the carapace a median and a transverse nodulated ridge form a cross. The abdomen has a spinous keel traversing the middle line, cach segment being armed with two strong teeth. The eye is an obtuse point.

RANGE.-West Indies.

\section{Pentacheles.}

Pcntacheles. Spence Bate, A. Milne Edwards.

All the legs are more or less perfectly chelate in both. sexes. The eyes are immovably lodged in a notch in the anterior dorsal surface of the carapace, and the anterior portion projects beneath the antero-lateral angle of the carapace, which is produced anteriorly to a level with the central rostral tooth. Gills as in Polycheles.

RANGE.-Atlantic and Pacific Oceans; in deep water.

\section{SyMopsis OF THE SPECIES.}

A. A single rostral spine.

a. The carapace is hairy, and contracted in front.(P. agossiaii.)

B. Two rostral spines.

b. The lateral borders of the carapace have strong spines.-(P. spinosus.)

$c$. The lateral borders of the carapace are finely denticulated.-(P. validus. $)$

\section{Pentacheles agassizii.}

Pentacheles agressizii . A. Milne Edwards.

The carapace is hairy and contracted in front; the lateral edges are parallel in a great part of their extent; 
the frontal border carries in front a single small spine. The orbital notch is straight and deep; its external borders is very broad and has fine spines. The median keel is very elevated, and there is another keel on each side. The posterior border of the carapace is notched and has some spines.

The basal joint of the internal antennxe is very pointed, but it is slightly dilated inside, so the borders are not in contact in the middle line; there is a wide space in front of the rostrum.

The abdomen is very rough, and the second, third, fourth, and fifth segments have above a projecting keel terminating in front in a strong rccurved spine.

There is no difference between male and female.

RANGE.-Barbados, Grenada, Grenadines, St. Lucia, Nevis.

\section{Pentacheles spinosus.}

Pentacheles spinosus . . A. Milne Edwards.
Polycheles helleri . . . Spence Bate.

The carapace is smooth and wide in front. There are two sharp points forming the rostrum. The orbital notch is very wide and the eye is large; the borders of this notch are unarmed.

The lateral borders of the carapace have strong spines. The median keel, instead of being granular, has spines arranged singly or in pairs; three pairs on the cardiac region, one pair in the middle of the gastric region, while in front and behind this region there is but one spine. The branchial keels have about five spines. There is a wide space in front of the rostrum at the base of the internal antenna, of which the basal articulation is slightly enlarged and is not in contact in its whole extent with the one on the opposite side. 
The first segment of the abdomen has three spines, one median, two lateral; the second, third, fourth, and fifth segments have strong median spines.

RANGE-Guadaloupe, Dominica.

\section{Pentacheles validus.}

\section{Pentacheles ralidus . A. Milne Edwards.}

The carapace is flat, and wider in the branchial than in the gastric region. The frontal border has in the middle line two small rostral spines, another spine at the internal orbital angle, and some spines on its edge. The ocular notches are triangular, very narrow and deep; the external orbital angle is spinous. The lateral edges are finely toothed; the middle line of the carapace is projecting and granular, as well as the line behind the gastric region, and which forms a notch of the lateral edge.

The basal articulations of the internal antennæ are lamellar, much dilated within, and in contact along their whole length along inner border; they terminate in a sharp point, and have a small spine at their external angle; the external flagellum is very small. The internal antenne is longer than the external.

The eye is armed in front with a spine. The five first segments of the abdomen have an obtuse keel above terminating in front in a point; from this point on each side a deep groove is directed backwards and outwards.

The anterior legs are long. The fourth joint has four spines below; the fingers of the pincers are crooked and unarmed. There is a small spine on the seventh joint.

RANGE--Martinique, Dominica. 


\section{Family II. Homaridæ.}

Homaride. . Spence Bate, Dana, Bell.

Cephalon subcylindrical. Carapace anteriorly rostrated, posteriorly produced over the anterior half of the first abdominal segnent, but not kept down by a tubercle. Rostrum narrow, armed with many teeth. The abdominal segments overlap each other. The legs are seven-jointed; the anterior three pairs have pincers, the first pair the largest. Swimming organ well developed; outer branch has no division.

SYNorsis OF TIIE GENERA.

A. A basal scale on external antennæ.-(Phoberns.)

B. No basal scale on external antennre-(Nephropsis.)

\section{Phoberus.}

Phoberzs . A. Milne Edwards, Spence Bate.

Carapace slightly compressed laterally, armed anteriorly with a long and narrow rostrum furnished with lateral teeth. Abdomen laterally compressed; swimming organ well developed, outer branch of the posterior pair of appendages having a well-marked division. Terminal segment quadrate, with terminal angles slightly rounded. Eyes small, close together, implanted on short rudimentary stalks. The internal antenne short, terminating in two long, slender, subequal flagella. The external antenne have a large basal scale, of which the outer margin is produced to an acute point.

The first pair of legs long, slender; the second and third pair are slightly shorter and much more slender; fourth pair simple; the fifth pair has the inner distal angle of the sixth joint produced. Gills attached as in 
Ibaccus, excepting the membranous articulation of first maxillipede. Branchial plates as in Ibacuss.

Ravge.-West Indies, Papuan Sea.

\section{Phoberus cæcus.}

Phoberus cacus . . A. Milne Edwards.

RANGE.-Grenada; in deep water.

\section{Nephropsis.}

\section{Nephropsis . . . Spence Bate, Wood-Mason.}

Carapace, not including the rostrum, rather more than half the length of the abdomen, bisected by a deep cervical sulcus. Abdomen dorsally smooth. Telson quadrate. Eyes small, situated close together beneath the rostrum. Internal antenne terminate in two slender flagella; the first joint has a large spine. The external antennx have no basal scale. Mandibles robust, and furnished with a three-jointed termination. First pair of maxillipedes subpediform, seven-jointed, having a twojointed external appendage; the external maxillipedes long, slender, and pediform. The first pair of legs large, the second and third pair slender; the last two pairs slender and simple. The first pair of abdominal appendages has one branch, almost rudimentary; the others are long, slender, and two-branched.

RANGE.-Bermuda, Papuan Sea; in deep water.

\section{Nephropsis rosea.}

Nephropsis rosea . . Suhn, Spence Bate. Astacus rosed . . . Suhn.

Nepluropsis agassizii (?) A. Milne Edwards.

Carapace slightly granular. Rostrum about half the length of the carapace, armed with a strong tooth on each 
side near the middle, another at the base just above the eye, and a smaller one in a line behind the last mentioned. First pair of legs armed with a small tooth on the lower distal angle of the fourth joint, and another on the upper distal angle of the fifth joint. Coxal plates of the abdomen terminate behind in a sharp point, the anterior edge of the first plate being slightly toothed, the other smooth.

RANGE.-Bernuda.

\section{Family III. Astacidæ. .}

Astacide . . Dana, Miers, Spence Bate.

Body elongated, subcylindrical; carapace rostrate. Rostrum depressed, armed with few teeth. External antenne long, with a basal scale. First pair of legs large, with a well developed pincer; second and third pair slender, with a small pincer; fourth and fifth pair nearly always simple. Abdomen of nearly the same width as the body throughout. Fresh water forms.

RANGE.-Lakes and rivers of Europe, Asia, North and South America, West Indies, Madagascar, Australia, Tasmania, New Zealand.

SrNorsis of the Genera.

$A$. The first pair of abdominal appendages, in the male, modified for sexual purposes. The movable finger of the large hand has its outer margin straight or inflexed. There is no gill attached to the body wall.

RANGE.-North America-(Cambarus.)

$B$. The first pair of abdominal appendages wanting. The movable finger of the large hand has its outer margin convex. There is always one or

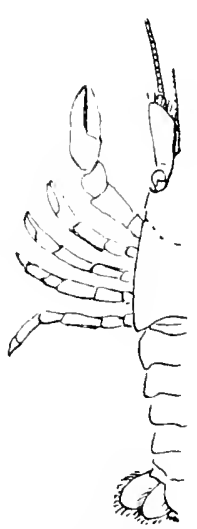

Cambarus. 
more gill plumes attached to the body wall on each side.

RANGE.--South America.-(Parastacus.)

This family and their genera are mentioned as they may be found in the fresh water of the countries under consideration.

\section{Tribe III. Stenopidea.}

Stenopidea . . . Spence Bate.

A laterally compressed rostrum. First three pair of legs armed with pincers, of which the third pair is the largest and longest.

One family.

\section{Family Stenopidæ.}

Stenopide . . . Spence Bate.

Gills attached to the first joint of the first maxillipede. Of the gills attached to the body wall, the posterior plume is the largest. The external appendage of the external maxillipedes is small, slender, and almost rudimentary.

\section{Stenopus.}

Stenopus . Latrille, Desmarest, H. Milne Edwards, Dana, Spence Bate.

The internal antenne have two flagella. The external antenne have a long, flat, and obtusely pointed basal scale, the apex being continuous with the external margin. Flagellum long and slender. Mandible furnished with a three-jointed palp, of which the last joint is the longest. The third maxilla terminates in a sharp finger. The first pair of maxillipedes is short, six-jointed, furnished 
with a long external appendage; the first joint has a branchial plate, carrying a well-formed gill plume. The external maxillipedes are long, slender, and seven-jointed ; their first joint carries a rudimentary gill plate without a gill plume. The first two pairs of legs have the fifth joint longer than the sixth; in the third pair it is not quite so long. The last two pairs are slender, having the fifth joint very much longer than the sixth; both joints are multiarticulate, and terminate in a double pointed finger. The basal joint of all these limbs carries a rudimentary gill plate without any gill plumes.

The first pair of abdominal appendages in the female, two-jointed, has only one branch; the second pair has two branches, but has no internal process. The outer plate of the swimming organ has no division. The terminal joint is long and tapering.

RANGE.-Atlantic and Pacific Oceans; in warm and cold seas.

\section{Stenopus hispidus.}

Stcnopus hispidus . Olivier, Latreille, Desmarest, $\mathrm{H}$. Milne Edwards, Dana, Spence Bate.

The cntire animal is covered with small, sharp, strong spines, verti.... on the carapace and dorsal surface of the first three segments of the abdomen; almost horizontal and directed posteriorly on the three posterior segments, and on the telson. The peduncle of the external antenne is furnished with spines, so is the third pair of legs, and the basal joint of the abdominal appendages; all the other appendages are smooth.

The third pair of legs is very long, and freely covered with teeth that run in several longitudinal rows, those of 
the upper and lower margins being laterally compressed and closely implanted. The end of the fixed finger has two cusps with a cleft between, into which fits a broad sharp cusp attached to the movable finger.

R.NAE.-Bermuda, Fiji; in shallow water.

\section{Division II. Dendrobranchiata.}

Dendrobranchicata . . . . Spence Bate.

Gills in the form of branching plumes.

\section{Group Normalia (Spence Bate).}

The first three pairs of legs, or the second and third, or the third only, may be armed with pincers. The gills may be well developed, few, or wanting.

\section{Family Penæidæ.}

\section{Penceide . . . . Spence Bate.}

The body is laterally compressed. The carapace is well developed, and is laterally produced so that its posterior lower border is covered by the first abdominal segment. The dorsal median line is keeled. The rostrum is laterally compressed, and may be strengthened on the sides by a longitudinal ridge. There is a longitudinal ridge over the branchial region.

The segments of the abdomen, especially the first three, are divided into an anterior and aposterior portion by a deep groove; the posterior portion carries the lateral (coxal) plate. That of the first segment is large and broad; it overlaps the carapace in front, and that of the second segment postcriorly. The first three segments are never keeled, but the others are. The last segment may have spines and hairs. The cye-stalls are two-jointed. 
The internal antennæe may be in the form of a flattened cylinder, depressed where the eye rests. There are two flagella of equal or unequal length. The external antennxe have a large basal scale and a very long flagellum. The maxillipedes are pediform. The first three pairs of legs increase in length from before backwards, and also in thickness; they are armed with pincers.

\section{Synotsis of tile Genera.}

A. Rostrum long
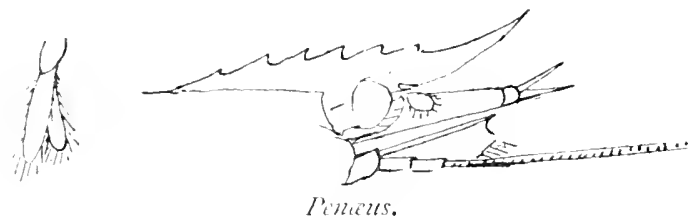

a. The abdominal appendages, except the first pair, are two-branched, large.-(Pencus.)

B. Rostrum short.

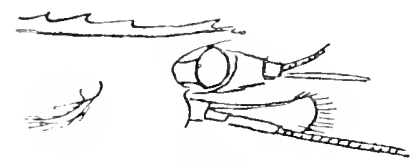

Sicyonia.

6. The abdominal appendages are one-branched, short.-(Sicjonicr.)

c. Rostrum only a crest.

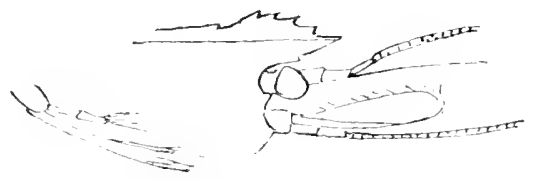

Benthesicymus,

The abdominal appendages, except the first pair, are two-branched, long.-(Benthesicymus.) 


\section{Penæus.}

Pencus . . . Spence Bate, Fabricius, Latreille, Lamarck, Leach, Desmarest, Roux, H. Milne Edwards.

Palcmon . . . Olivier.

Body compressed, especially posteriorly. Carapace with rostrum, which is more or less dorsally serrated. The eyes are large and longitudinally ovate. The internal antennæe have the first joint deeply excavated on the upper surface, and furnished on the inside with a flat process that has a hairy margin, and on the outside with a spine. Each terminates in two flagella that are never longer than the carapace. The basal scale of the external antennæe terminates in a sharp tooth on its outer margin; the inner margin is thin, and is fringed with long hairs. The first basal joint has a tubercle on the inner side, and the third has a hook on the upper surface.

The first maxillipede is seven-jointed, short, and subpediform; the last three joints are reflexed, and flattened on the inner margin. The external appendage has two joints; the first round, the second flat and margined with hairs. The external maxillipedes are seven-jointed, pediform, and long.

The first three pairs of legs are chelate, increasing in size from before backwards, and each of them has an external appendage from the basal second joint.

The last two pairs of legs are not longer than the preceding; they are slender, and terminate in a simple finger.

The abdominal appendages are large and twobranched, except the first pair, which, in the male, has 
attached to the base a large membranous appendage; and, in the female, is small and rudimentary The swimming organ is large and strong; the lateral plates are broad and foliaccous, and strengthened by a longitudinal ridge that traverses the external margin of the outer plate and terminates in a sharp tooth. The telson is tapering.

The gills are attached to the body wall, to the membrane between the first joint of the two maxillipedes, and all the legs except the last pair, and the body; there is a branchial process on all these limbs except the posterior two pairs, but no gills are attached to the first joint of any of these limbs.

RANGE.-Atlantic and Pacific Occans.

\section{Penæus brasiliensis.}

Pencus brasiliensis . . . . . Latreille, H. Milne Edwards.

The flagella of the internal antennæe are short, not as iong as the rostrum, and flat. The rostrum has nine tecth above and three below. There is a median groove which extends from the base of the rostrum to the posterior border of the carapace.

RANGE. - Berbice River, British Guiana, Brazil, Florida, South Carolina, West African Coast.

\section{Sicyonia.}

Sicyonia . Spence Bate, Milne Edwards.

Body hard; anterior portion of the carapace and posterior portion of the abdomen more compressed than the central region. The rostrum is short, usually toothed above. Eye-stalk short. Eye reniform. 
The internal antennæe have on the outside a spine, and on the inside an appendage which is rudimentary and terminates in two subequally short flagella. The external antennæ have a basal scale, broad at the base, narrow at the apex, strong and rigid on the outside, and terminates in a strong sharp tooth. The flagella are moderately long.

The abdominal appendages are one-branched and very short; the first and second pair, in the male, have membranous appendages.

The gills are attached to the body wall, except the last segment, to the membrane between the first joint of the two maxillipedes, and all the legs except the last pair, and the body of the animal. There is a branchial lash attached to all these limbs, except the two posterior pairs of legs.

RiNGE.-West Indies, South America, Cape Verde Islands, Mediterranean Sea, China, Japan, Indian Ocean, New Guinea.

\section{Sicyonia carinata.}

Sicyonia carinata . . Olivier, Milne Edwards; Dana. Spence Bate.

Palamon carinatus. . Olivier.

The dorsal surface is carinated in the median line from the rostrum to the posterior segnent of the abdomen. The rostrum, directed obliquely upwards, is armed with two small teeth, with indications of a third at the extremity, and with two larger tectls posterior to the gastric region; a short tooth on the anterior margin of the carapace, corresponding with the external orbital angle, and onc posterior on the hepatic region. The dorsal keel on the first segment of the abdomen is produced into an anteriorly 
directed tooth, and on the sixth with a posteriorly directed one. Telson tapering, dorsally depressed, and nearly equalling the lateral branch of the swimming organ in length.

RANGE.-St. Thomas, Bahia.

\section{Benthesicymus.}

Benthcsicymus . . . . Spence Bate.

Body smooth. Rostrum short, eleratéd into a crest. Cervical fossa deeply marlied; a strong calcified ridge separates the lateral cardiac from the branchial region. Posterior segments of the abdomen, laterally compressed, are shorter than the branches of the swimming organ. The tclson is narrow, pointed, and laterally compressed. The abdominal appendages are long, and, except the first pair, two-branched. In the male the basal joint of the first pair has a membranous appendage.

The internal antenne have outside a spinc, but inside there is no appendage. There are two long flagella. The external antennæ have a long slender flagellum. The third basal joint has a hook-like process which is lodged in a depression on the under surface of the internal antenne. The epistome is produced to a point. The maxillipedes have external appendages.

Each leg has a basal appendage which diminishes posteriorly. All the first joints of the two maxillipedes and the four first legs have branchial plates that increase in size, each with a branchial plume. There are gills from the chest wall, and from all the membrane between the body and the first joint of all the limbs, except the last pair.

RANGe.-Atlantic and Pacific Oceans; in deep water. 


\section{Benthesicymus pleocanthus.}

Benthesicymus pleocanthus . . . Spence Bate.

Surface membranous. Rostrum pointed. Crest armed with two teeth, the anterior of which is the smaller. Cervical fossa clearly defined, but not deep. Abdomen with the posterior segments laterally compressed, and the dorsal surface of the fifth segment posteriorly produced in the median line to a laterally compressed tooth that nearly equals the segment in length. The sixth segment is deep, and carries a distinct but not a high ridge in the median dorsal line. The telson tapers to a point, is smooth at the sides, and quite half the length of the lateral wing of the swimming organ.

Range.-West Indies, Philippine Isles, North Pacific.

\section{Division III. Phyllobranchiata,}

Phyllobranchiatir . . . . Spence Bate.

The gill plumes are dereloped in the form of broad foliaceous plates attached to a central stalk.

\section{Group Normalia (Spence Bate).}

The three posterior pairs of legs are never armed with pincers.

\section{Tribe I. Polycarpidea. \\ Tribe II. Monocarpidea. \\ Symorsis of the Tribes.}

A. The second pair of legs slender; the fifth joint is divided into a number of small joints.(Polycarpidea.)

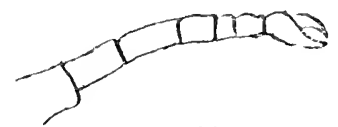

Polycarficia. 
B. The sccond pair of legs has usually a large hand; fifth joint is composed of one picce. -(Honocarpider.)

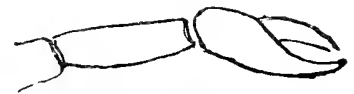

Monocartidea.

\section{Tribe I. Polycarpidea.} Polycarpidea . . . . Spence Bate.

The second pair of legs is slender; their fifth joint, carpus, is divided into many joints.

Family I. Nikidæ.

Family II. Alpheidæ.

Family III. Hippolytidæ.

Family IV. Pandalidæ.

Sinopsis of the FaMilies.

A. The first pair of legs simple or armed with pincers, the second pair minutely so.

๙. Rostrum horizontal with dorsal surface-(Nikide.)

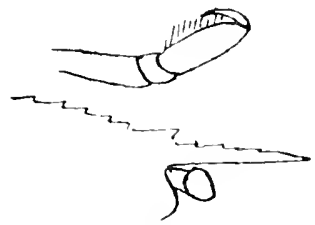

Nikidi.

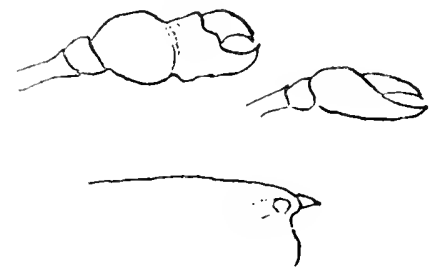

Alpheide.

$B$. Of the first pair of legs, the pincers on one side are of normal form; on the other side, of irregular form. The sccond pair of legs has pincers.

b. Rostrum short or wanting. Eycs covered by the carapace.-(Alphicide.) 
$C$. The two first pairs of legs with pincers.

c. Rostrum large.-(Hipfolytide.)
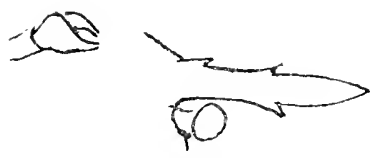

Hitholytidu.

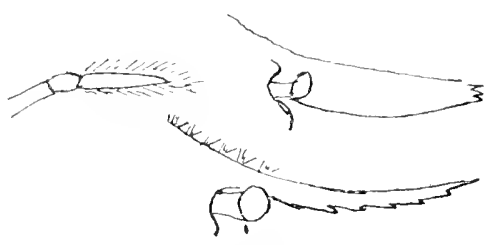

Pandalidie.

$D$. The first pair of legs has no pincers, the second pair has.

d. Rostrum long and slender--(Pandalide.)

\section{Family I. Nikidæ.}

\section{Nikide . . . Spence Bate.}

The rostrum horizontal with the dorsal surface of the carapace. The mandibles have no cutting margin or palp.

The first pair of legs simple or chelate, stronger than the second pair, which is minutely chelate.

\section{Glyphocrangon.}

Glyphocrangon . . Spence Bate, A. Milne Edwards, Smith.

The carapace, about a third the length of the animal, is ornamented on the sides with longitudinal rows of simple ridges or of tecth. The rostrum is large, pointed, and depressed in the middle line, its cdges being upturned and armed with tecth. The segments of the abdomen are rough and spiny. The telson is long and bayonetshaped. The eyes are well developed. The internal 
antenne, short, terminate in two short flagella; the basal joint is hollowed to receive the eye; it has no external spine. The external antenna have a disc-like basal scale; the flagellum is about half the length of the animal.

The first pair of legs large, the third and fourth joint fused together, the sixth joint is long and ovate; there is a strong and simple seventh joint. The second pair of legs is long and slender, and the pincer is feeble.

The gills are attached to the body wall and to the membrane between the body and the first joint of the external maxillipede, and of the first three pairs of legs.

RAxGe.-West Indies, North and South Atlantic, Indian Ocean, Japan, Fiji.

\section{SYNOPSIS OF THE SPECIFS.}

A. The rostrum has no median lieel.

a. The hepatic region is almost smooth. The seventh segment of the abdomen is straight.-(G. spinianda.)

B. The rostrum has a median keel.

b. The hepatic region is rough. The seventh segment of the abdomen is curved upwards.-( $G$. nobilis.)

C. The rostrum is straight.

c. The carapace has in front and below a strong spine directed outwards and forwards.--(G. aculeata. $)$

\section{Glyphocrangon spinicauda.}

Glyphocrangon spinicander . . A. Milne Edwards.

The carapace, very resistant, is covered with large rough tubercles arranged in bands more or less clevated, forming prominent ridges on each side. The gastrocardiac groove is deep, and the smooth hepatic region is bounded behind by a deep grove. There is a strong curved spine above and inside upon the anterior edge 
between the eye and the antenne, another straighter spine forms the latero-anterior angle; there are two lateral spines on the side of the carapace in front of the cervical groove. The rostrum is large, and exceeds the subantennary lamina; it is wide at its base, flat and depressed above, and curved upwards towards its extremity; it has two spines on each side, one behind the other in front of the eye ; it is unarmed below. The external maxillipedes are large. The legs of the first pair are short, strong, and compressed; their basal joint is prolonged outwards in the form of a spine or tooth; the mobile finger is very hooked and pointed, it folds upon the superior border of the next joint, and not as in Crangon, on its anterior border. The legs of the second pair are very long and thin, the other legs are feeble and monodactyl.

The abdomen is covered with rough prominences, arranged longitudinally, resembling keels; one is median. The second, third, fourth, fifth, and sixth segment terminates below and laterally in a strong spine. The seventh segment is straight.

RANGE.-St. Kitts; in deep water.

\section{Glyphocrangon nobilis.}

Glyphocrangon nobilis . . . A. Milne Edwards.

Distinguished from $G$. spinicanda by its form being more thin, and by its rostrum being straight at its base, more elongated, and being provided above with a small median keel.

The rough prominences of the carapace and of the abdomen are more numerous; they are on the hepatic region, which is almost smooth in the other.

The seventh segment of the abdomen, instead of being straight, is curved upwards.

RANGE.-Dominica; in deep water. 


\section{Glyphocrangon aculeata.}

Glyphocrangon aculeata . A. Milne Edwards, Spence Bate.

The rostrum is straight like $G$. nobilis, but the carapace is wider in front, where it terminates on each side in a very strong spine directed a little outwards and forwards; another smaller spine limits the orbital cavity, and there is another outside the articulation of the external antennæ. The lateral border has also a spine behind the cervical groove. The carapace has above four toothed lieels; the space between them is smooth. The two lateral keels are smooth.

The abdomen is more strongly carinated in the middle line than the other, and it is very sculptured.

RANGE.-St. Vincent; in deep water.

\section{Family II. Alpheidæ.} Alpheide . . . . Spence Bate.

Rostrum short or wanting. Eyes short and covered by the carapace. The mandible has a cutting edge and a two-jointed palp. The first pair of legs asymmetrical, on one sicle having the fifth joint short and the hand large and normal in form, and on the other side a hand very large and of irregular shape. The hand of the second pair is very small. The terminal segment of the abdomen is broad and rounded.

\section{Alpheus.}

Ilphess. H. Milne Edwards, Fabricius, Risso, Spence Bate, Miers.

Alpheus . . Desmarest.

The body is dorsally rounded and laterally compressed. The eyes are small, and are covered by the carapace, 
through which the eyes can be seen. The rostrum is short and pointed. The internal antenna have the peduncle short; the first joint, flattened, has a spine on the outside, and terminates in two flagella, the inner of which has a tendency to bifurcate. The external antenne have a long flagellum, and a strong basal scale that has a subapical point or sharp tooth.

The first maxillipede is short and five-jointed. The external maxillipede, pediform, five-jointed, has a short slender external appendage. The first pair of legs armed with pincers; the sixth joint is large, the right, being usually larger than the left, is of a more or less abnormal form, especially in the male. The second pair, slender, has minute pincers. The other legs are simple, and terminate in short robust joints. The last abdominal segment is broad and rounded; the outer plates of the swimming organ have a well marked division.

The gills are attached to the body wall, and to the membrane between the body and the first joint of the external maxillipede.

RANGE.-In shallow and deep water of most seas; one has been found in fresh water in South-IVest ColoradoAlphous minus.

\section{SyNOPSIS OF THE SPlCIES.}

A. A rostrum present, but no spines on front margin of the carapace.

$a$. The basal scale of the external antennx is as long as the peduncle of the internal antennat- $-(A$. armillatus.)

b. The basal scale of the external antenne is longer than the peduncle of the internal antenne.-(A. bcrmudensis.) 


\section{Alpheus armillatus.}

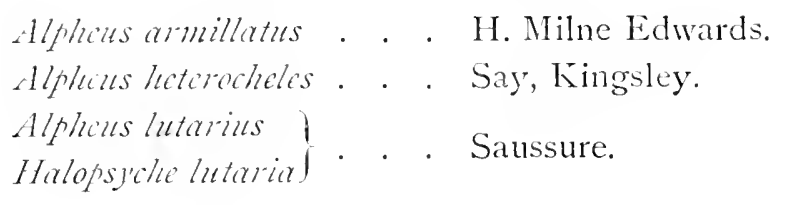

Carapace smooth. Rostrum short, acute, depressed; ocular arches without spines. Basal spine of internal antenne stout, short, not reaching base of second joint; second joint more than twice as long as third. Outer flagellum half as long as inner. Antennal scale as long as peduncle of the internal antenne; the spine on the anterior lateral margin large, stout, acute; inner margin arcuate, widening towards the base; flagellum somewhat longer than the body. Legs of the first pair unequal; fourth joint triangular; fifth as broad as long; larger hand one and a half times as long as carapace, compressed, margins rounded; a constriction of the upper and under margins at about the middle. Fixed finger three-fourths as long as palmar portion; a strong rectangular tooth on inner portion of occludent margin; apex acute. Movable finger with a process on the inner margin which shuts into a cavity in the opposing finger; points of fingers overlapping. The smaller hand cylindrical, the constrictions but faintly indicated; fingers three-fourths as long as palm. Movable finger flattened; occludent margin with a longitudinal carina, shutting into a groove in the fixed finger; the fingers with a fringe of hair. Legs of the second pair slender, filiform; third and fourth joint equal; fifth joint five-jointed; first joint as long as second and third, second as fourth and fifth, third and fourth equal, fifth a half longer than preceding. Telson subquadrate; extremity arcuate. 
Range.-West Indies, Bahamas, Cuba. This species is very common under stones on the shore betwcen high and low water-marks, Barbados.

\section{Alpheus bermudensis.}

\section{Alpheus bermudensis . . . Spence Bate.}

Rostrum short, slightly depressed anteriorly, forming a carina that extends posteriorly as far as the orbital lobes, and separated from them by a small groove. Fronto-orbital margin produced to a blunt point that reaches nearly to the extremity of the rostrum.

Internal antenne having the first joint of the peduncle not longer than the extremity of the rostrum; the second joint about the same length as the first, and the third shorter than the second. The spine on outer side is flat and pointed, reaching nearly as far as the end of the first joint. The flagella are equal, the upper branch being about the same length as the peduncle, the lower being about two-thirds that of the whole animal. External antenne having a basal scale that is a little longer than the peduncle of the internal antenne. First pair of legs having the larger hand broad and long, obliquely attached and laterally compressed, the upper margin indented a little behind the finger hinge, from which indentation a longitudinal groove runs back on the inner and outer sides and gradually dies out towards the posterior or carpal extremity. The telson is short, broad, and ovate at its posterior extremity, which is fringed with hairs.

RANGE.-Atlantic, Bermuda. 


\section{Family III. Hippolytidæ.}

Hippolytide . . Spence Bate.

Rostrum large. The first and second pairs of legs armed with pincers; the first pair moderately robust. The posterior three pairs of legs are simple.

\section{Syrotsis of the Genera.}

I. First and second pair of legs with pincers.

A. Rostrum compressed, decp.-(Latreutcs.)

B. Rostrum slender, toothed.-(Hippolyte.)

\section{Latreutes.}

\section{Latreutes . . Stimpson, Spence Bate.}

Rostrum elongate, being more than half the length of the carapace, laterally compressed and deep. Internal antenne subequal in length to the rostrum. The external antenna have an acutely pointed basal scale. The mandible has only a molar process, no palp. The first maxillipede is seven-jointed, has a branchial plate and an external appendage. The external maxillipedes, five-jointed, robust and rigid, have a small gill plume from the first joint and a short external appendage.

The first pair of legs is short, robust, and terminates in a strong pincer; the sixth joint articulates at the inferior angle of the fifth joint, the upper portion falling into an excavation in the distal margin of the fifth joint. The fifth articulates at the inferior extremity of the fourth joint, which is excavated in such a way as to receive the fifth joint when extended. The second pair of legs is slender, and has pincers. The three last pairs of legs are slender, and terminate in simple joints. 
The abdominal appendages are two-branched, the branches subequal. The telson tapers to a point. The gills spring from the body wall and from the first joint of the external maxillipede.

RANGE.--Atlantic, Gulf weed, West Indies, Japan, in deep water; Philippine Islands, near the surface.

\section{Latreutes ensiferus.}

Latreutes cusiferus . . . Stimpson, Spence Bate. Hippolyte cusiferus . . . H. Milne Edwards.

Body slender. Carapace dorsally rounded, with a small tooth on the gastric region. Rostrum nearly as long as the carapace, slightly curved upwards towards the apex; extremity serrate, lower margin smooth and curved. Five or six small teeth on antero-lateral angle of carapace. The two last joints of the external maxillipedes have spines. The abdomen is smooth.

RANGE.-West Indies, Gulf weed, in the open sea near Azores.

\section{Hippolyte.}

Hippolyte . Spence Bate, Leach, H. Milne Edwards. Kinahan.

Trorbius . . Stimpson, Heller, Miers, Kingsley, Sars.

Carapace anteriorly carinated. Rostrum slender, laterally compressed, the upper margin of which is parallel with the dorsal surface of the carapace, and armed with teeth; the under margin is excavated at the base, and scrrate towards the extremity. There is a supraorbital and an antennal tooth in front. The abdomen is smootli; the third segment is produced posteriorly in the middle line, and somewhat arcuate. The telson is dorsally flat, 
laterally compressed, tapering, and has two spines on each side. The eyes are short. The internal antennx have the first joint of the peduncle excavate, and armed with a sharp spine that is subequal with its length. The second and third joint smaller and subcylindrical. There are two flagella, of which the outer is the shorter and more robust. The external antenne have an oval basal scale that has a tooth on the outer margin, and a flagellum which is subequal with the length of the animal. The external maxillipede has an external appendage.

The first pair of legs is short, stout, and chelate; the fifth joint is triangulate, and excavated to receive the extremity of the sixth joint. The second pair of legs, slender, slightly longer than the first pair, chelate, has the fifth joint triangulate. The other three pairs of legs short, slightly decrease in length posteriorly, and have their terminal joint spinulose within.

The gills are attached to the body wall and to the branchial plate of the first maxillipede.

\section{Hippolyte bidentatus.}

\section{Hippolyte bidentatus. . . Spence Bate.}

Rostrum half the length of the carapace; a small tooth upon its upper margin, half-way between the orbital margin and apex; the lower margin has a similar tooth a little in advance of the one above. Supraorbital tooth well developed. The fifth abdominal segment has two sharp teeth on the posterior margin. The telson has its extremity truncate and is furnished with a spine at each angle, and it has a large spine on its inner side. The eyes are about half the length of the rostrum. The internal antenne are slightly longer than the rostrum. The basal scale of the external antenne is subequal in 
length with the rostrum. The three posterior pairs of legs, longer than the two front pairs, have their last joint armed with numerous spinules.

RANGE.-Atlantic, Gulf weed.

\section{Family IV. Pandalidæ.} Pandalida . . Spence Bate.

Carapace about one-third the total length of animal. Rostrum long and slender, armed with tecth or spines. Eyes well developed. The internal antenne terminate in two flagella. The external antenne have a large basal scale. The external maxillipedes are pediform. The first pair of legs not provided with pincers; the second pair has pincers; the other three pairs simple. The abdominal appendages are two-branched. The swimming organ is well developed and strong.

\section{Synopsis of the GenerA.}

A. Carapace laterally and dorsally keeled. Rostrum armed with teeth above and below.-(Hetcrocarpus.)

B. Carapace smooth. Rostrum armed above with movable spines, below with teeth.-(Pandalus).

\section{Heterocarpus.}

Heterocarpus . . . A. Milne Edwards, Spence Bate.

The carapace is keeled at the sides and above, which terminates in a rostrum, that is generally armed with tecth above and below. The abdomen has on some of its segments a modian keel tcrminating behind in a point. The telson, long, laterally compressed, is generally armed with small spines. Eyes short. The internal antenne have a short peduncle armed with a spine; flagclla long, 
slender, the outer one usually having a thick base and a thin extremity. The first maxillipede has six joints; it has a branchial plate. The external maxillipede is long. The first pair of legs resembles the external maxillipede. Of the second pair of legs, the right is the larger. The three last pairs of legs are not very long; the posterior margin is usually fringed with sharp spine-like teeth. The abdominal appendages have long basal joints. The gills spring from the body wall, the nembrane between the body and the first joint of all the limbs, except the first and last pair, and from the base of the first maxillipede.

RANGe.-West Indies, Philippine Islands, Japan; in deep water.

\section{Srnolsis OF THE SPECIES.}

A. The median kecl and rostrum have seventeen teeth above and eight teeth below. The flagella of the internal antenna are longer than the rostrum.-( H. cnsifer.)

$B$. The median keel and rostrum have fourteen teeth above and nine below. The flagella of the internal antenne are not as long as the rostrum.-(

\section{Heterocarpus ensifer.}

Heterocarpus ensifer. . . A. Milne Edwards. Pandalus carinatus. . . Smith.

The carapace is thick; it has on each side two licels which extend from the base of the external antennx to the external border, and arise in front from a small spine; a third parallel keel, but much less marked, is seen above the preceding. There is a projecting median kecl along the whole length of the carapace, which is continued in front into a long and upcurved rostrum; 
this keel and rostrum has above about seventeen and below eight teeth.

The eyes are small. The flagella of the internal antenne are longer than the rostrum. The abdomen is wide; the fourth and fifth segment only are kecled. The legs of the third pair are spinous above on the fourth and fifth joint.

RANGE.-Barbados, Philippine Islands.

\section{Heterocarpus oryx.}

\section{Hetcrocarpus ory.x. . . A. Milne Edwards.}

Like $H$. cusifer, except the form of the carapace is thinner; there is no third keel or latero-superior keel. The rostrum is strongly toothed above. There are teeth on the median keel of the carapace up to a small distance from the posterior edge (about fourteen above and nine below). The abdominal keel is prolonged into a short point upon the third, fourth, and fifth segment. The flagella of the internal antenna do not reach the extremity of the rostrum.

RANGE.-IVest Indies.

\section{Pandalus.}

Pandalus . Leach, H. Milne Edwards, Spence Bate.

The anterior portion of the carapace is keeled, and produced to a long rostrum that is armed abov? with movable spines and with hairs, below with rigid fixed teeth. In front there is an antennal tooth, and a second tooth on the antero-lateral angle of the carapace. Abdomen is smooth; third segment more compressed than the preceding segment, posteriorly produced to a point. Sixth segment longer than the fifth. Telson longer than sixth segment; narrow, tapering, dorsally flat, laterally 
compressed, and armed with some spinules. Appendages two-branched and foliaccous. Internal antennx longer than the rostrum, with two flagella and a spine at the base half the length of the joint which carries it. External antennæ longer than the animal, with a basal scale nearly as long as the carapace. The first maxillipede has an external appendage, as also the external maxillipede, which is pediform. First pair of legs long and simple; second pair unequally long, slender, and provided with pincers; remaining legs robust.

The gills are attached to the body wall, to the membrane between the body and the first joint of all the legs except the last pair, and of the external maxillipede, and to the first joint of the first maxillipede, which is provided with a branchial scale.

RANGE.-European Seas, Madeira, Australia, West Indies.

\section{Pandalus longipes.}

Pandalus longifes. . . A. Milne Edwards.

The rostrum is straight; it is about twice as long as the carapace. The spines at the base are fine, above the eye they are strong, and they again diminish towards the tip; below the teeth are very numerous and very fine. The legs of the third, fourth, and fifth pair cxceed the rostrum; their fourth joint is spiny.

RANGE.-Barbados; in deep water.

\section{Tribe II. Monocarpidea.}

Monocarpidea. . . Spence Bate.

The fifth joint of the second pair of legs is composed of one piece, and usually the hands of this pair are longer than those of the first pair of legs, when they are present. 
Family I. Atyidæ.

Family II. Acanthephyrida.

Family III. Palæmonidæ.

Family IV. Nematocarcinidæ.

Family V. Tropiocaridæ.

Family VI. Stylodactylidæ.

Family VII. Pasiphæidæ.

Synopsis of the FAMILIES.

I. The two first pairs of lcgs armed with pincers.

$A$. The three posterior pairs of legs are not very short nor imperfectly formed.

a. Finger and thumb of
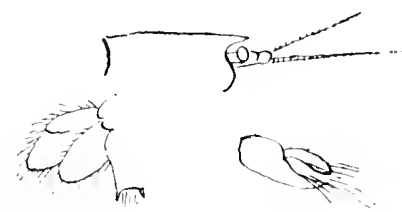

Alytide. pincers spoon-shaped. Telson truncate.-(tyide).

b. Carapace dorsally carinated. Internal antenne have two flagella. First two pairs of legs subequal.-(Acanthe-

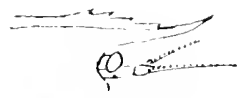

Acanthifhyrida. phyride.)

c. Carapace dorsally rounded. Rostrum compressed. Usually three flagella on internal antenna. Second pair of legs usually the largest.-(Palcmonide).

d. Body smooth. Two long slender flagella on internal an-

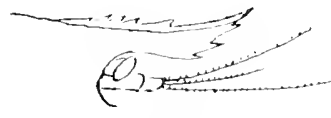

Patumonide. tenna. The fifth joint of the legs are much longer than the sixth joint. First two pairs of legs long and slender. - Nematocarcinide.

$c$. Carapace dorsally compressed. Rostrum short. Two flagella on internal antennx.

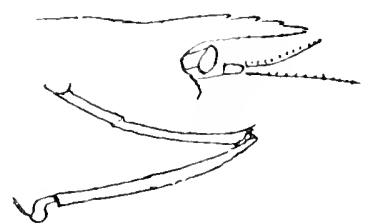

Nematocarinidi. 
First two pairs of legs subequal, small. - (Tropiocrride).

$f$. The first pair of maxillipedes two-branched. 'The finger and thumb of the two anterior pairs of legs are very long and fceble.-(Stylodactylide).

B. The three posterior pairs of Jegs are very short and some-

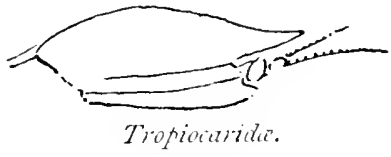
times imperfectly developed.--(I'asiphaida.)

\section{Family I. Atyidæ.}

Atyide. . . Spence Bate.

Carapace dorsally smooth, rounded, and produced to a flattened rostrum, not laterally compressed. Abdomen short and robust. Internal antenne with a spine on outer side; external antenne with a short basal scale. Mandibles with a molar process and cutting margin, but no palp. External maxillipedes four-jointed and pediform. First and second pairs of legs with pincers; finger and thumb spoon-shaped. Three last pairs of legs simple. Abdominal appendages two-branched. Swimming organ well developed. 'Telson flattened, truncate.

\section{r. Atya.}

Atya . . . Leach, Latreille, Desmarest, Roux, Wiegmann, H. Milne Edwards,

A. Milne Edwards, Spence Bate.

Atys . . . . Leach.

Atyoida. . . Randall.

Animal laterally compressed, dorsally smooth. Rostrum in a line with the carapace, flat and broad at the 
base, tapers to the apex. First and second pair of legs short; pincers fringed with hairs. Third pair large and long; fourth and fifth pair robust, shorter than the third. Abdominal appendages short, broad, and foliaceous. Swimming organ short, robust, and well dereloped. The telson is shorter than the lateral plates. The internal antenne have two flagella; the external have a basal scale and a long flagellum.

RANGE.-Fresh-water rivers and ponds of West Indies, Mexico, Cape Verde Islands, New Caledonia, Ncw Zcaland, and Fiji.

\section{Atya scabra.}

Atya scabra . . Leach, Desmarest, Roux, H. Milne Edwards.

Rostrum triangular, armed with three small parallel ridges, of which the middle one is the longest. The gastric region is a little rough. The two first pairs of legs do not exceed the peduncles of the external antenna. Those of the last three pairs are rough, with small points. There are two series of small spines upon the telson.

RANGE.-West Indies, Mexico.

\section{Family II. Acanthephyridæ.} Acanthephyride. . . Spence Bate.

Animal smooth, laterally compressed, and dorsally carinated. Internal antenne with two long flagella. External antennæ with a sharp and rigid basal scale. Mandibles with a palp. First two pairs of legs slender, subequal, and armed with pincers.

Telson long, narrow, and tapering to a truncated point. 


\section{Srnopsis of tile Genera.}

I. The first abdominal segment overlaps the posterior lateral margins of the carapace.

$A$. The projection in the median line on the posterior border of the abdominal segments are short. Outer margin of basal antennal scale is smooth.-(Acanthephyra).

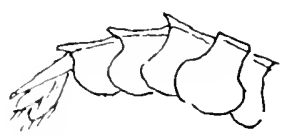

tianthiplyor.

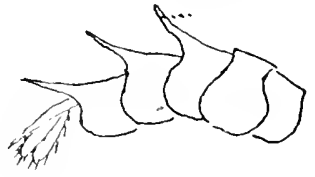

Oplophorus.

B. The projections in the middle line on the posterior border of the abdominal segments very long. Outer margin of basal antennal scale has teeth.-(Oplophorus).

C. The posterior border of the abdominal segments has a subequal small tooth on each side of the median line. Outer margin of basal antennal scale smooth, anterior margin rounded.-(Gonatonotus).

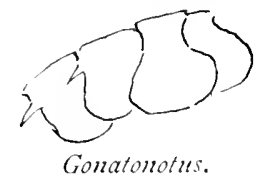

\section{Acanthephyra.}

Acanthepluyra . A. Milne Edwards, Smith, Spence Bate.

The dorsal crest extends from rostrum to telson. Carapace anteriorly produced into a long, slender rostrum having a number of teeth above and below. Frontal margin depressed, and excavated to form an orbit, the outer canthus being defined by a rounded angle, external to which stands the internal antemnal tooth, then a second excavation is formed to receive the external antenna, at the lower angle of which the second antennal tooth projects. The first segment of the abdomen is as deep 
as the carapace, the posterior surface of which it overlaps. The telson is long, slender, and tapering. The appendages are two-branched, narrow, and subfoliaccous.

The eycs are short, and carry a small ocellus. The peduncle of the internal antenne is short; the first joint is excavated on the upper surface, and has a stout spine; the second and third joint cylindrical. The external antennx are long and slender, and the basal scale articulates between two strong teeth.

The cutting edge of the mandible is serrate, and has a two-jointed palp. The first pair of maxillipedes is subpediform, seven-jointed, with a large external appendage. The external maxillipede is long, pediform, and five-jointed, with a long external appendage; its first joint carries a lunate calcified plate that articulates with a rudimentary branchial plate, with no gill plume attached.

The first two pairs of legs are short; there is an external appendage from their second joint.

The gills are attached to the chest wall, to the membrane between the first joint of the two maxillipedes and the four first pairs of legs, and the body of the animal. All these appendages, except the last two pairs of legs, have branchial plates, of which the one of the first maxillipede has a branchial plume.

RANGE.-Atlantic, Australian and New Zealand Sea; ill deep water.

\section{SyNOPSIS OF TIIE SPECIES.}

I. Rostrum long, thin, and upturned.

a. Rostrum has four spines above and more than fortyfive below.-(A. chsis.)

b. Rostrum has five spines above and one below, near tip.-(A. armata.)

c. Rostrum has above three or four spines over base, 
and about twelve scattered spines; below there are nine. -(A. ablitis.)

\section{Acanthephyra ensis.}

Acanthephy'a ensis. A. Milne Edwards.

The rostrum is long, thin, and sliarply turned upwards towards its posterior third; it has four small spines above near its base; its inferior border is cut into more than forty-five small serrated denticulations. The abdomen is rounded above; its third segment alone carrics bchind a small median point.

RANGE.-Barbados, Bahamas.

\section{Acanthephyra armata.}

Acanthephyra armater. A. Milne Edwards.

The rostrum is thin, long, and much curved upwards ; it springs from the carapace from a slightly projecting keel. Its superior border has above the eyes five smail spines; it is smooth in the rest of its extent. Its lower border has only one spine at a level with the antennal basal scale, giving the rostrum a forlicd appearance. The superior flagellum of internal antenne is broad at its base, and has below a kind of down. The abdomen is large. The second, third, fourth, fifth, and sixth segments have, except the second, a postero-median point; the sixth has, at its extremity, three or five small spines.

RANGE.-St. Lucia, Sea of Bancla.

\section{Acanthephyra debilis.}

Acanthephyra debilis . . A. Milne Edwards. Systillaspis debilis. . . Spence Bate.

The rostrum is almost twice as long as the antennal basal scale; it is slightly curved upwards; the superior 
border is toothed in its free portion; there are four small teeth on the edge above the eyes, to this group follow about twelve teeth. The inferior edge has nine teeth. The lieel and spines on the abdomen are not well marlied. R.NGE.-Barbados, Bahamas.

\section{Oplophorus.}

Oplophorus . . H. Milne Edwards, Spence Bate.

Carapace about one third the length of the body, supported on each side by a subcarina, and anteriorly produced to a long and slender rostrum that is serrate on upper and lower margins. Outer angle of the orbit defined by the first antennal tooth, which is curved inwards between the eye-stallis and the external antenna. The second antennal tooth is directed forwards, and the fronto-lateral angle is produced to a tooth that is directed forwards and outwards. The posterior margin of the carapace is overlapped by the first abdominal segment laterally. The third and following segments of the abdomen are posteriorly produced in the middle line to long teeth, so, when the animal is extended, they form a strong keel. Telson ends in a sharp point.

The eyes are short, with a circular ocellus on the corneal margin. The internal antennce have a short peduncle. The external have a longs, strong basal scale that tapers to a sharp point and has a serrated outer edge. The mandibles have a three-jointed palp. The first maxillipede is subpediform, and has the terminal joints reflexed. The external maxillipede is five-jointed ; the third and fourth joint are flattened, and have a long and flat external appendage.

The first two pairs of legs are short, subequal, and robust. The following three pairs, short, terminate in a 
styliform finger, of which that of the posterior pair is the shortest.

The gills are attached to the body wall, to the membrane between the body and the first joint of all the appendages, except the first maxillipede and the last pair of legs, and to the first joint of the first maxillipede. Except the last pair of legs, all are provided with branchial plates.

RANGE--West Indies, New Guinea, Fiji, Philippine Islands; in deep water.

\section{Oplophorus gracilirostris.}

\section{Oplophorus gracilirostris . . A. Milne Edwards.}

The carapace is elevated and deeply notched behind for the insertion of the abdomen; there is a prolongation in the form of a point on the posterior edge, outside the articulation with first ring of the abdomen. A triangular point forms the latero-posterior angle. There is a very small spine below and another above the articulation of the antennae. There is a keel above in the middle line along its whole length. This keel is continued into the rostrum, which is thin, and has above six or eight small teeth and seven below. Upon the gastric regrion the median keel has on each side a small smooth keel.

RANGE.-Dominica.

\section{Gonatonotus.}

Gonatonotus . . A. Milne Edwards.

The carapace is thick, strongly keeled above; this keel is continued into the rostrum, which is very elevated and laterally compressed. Its superior border and that of the keel is divided into many teeth (above twenty-two). Its inferior border has eight teeth, and laterally there is a ridge which, starting from the orbital border, extends as 
far as the rostral point. There are two keels upon the sides of the carapace, each terminating in front in a spine. The eyes are large, and lodged at the base of the rostrum in a fossa of the basal articulation of the internal antennx. The basal scale of the external antennx, instead of being straight and spiniform as that of Oplophorus, is broad and rounded in front; the flagellum is fine and slightly elongated. The legs of the first pair are the shortest of all, but they are more stout; those of the second pair are more thin. All the legs have at their base an appendage.

The abdomen is strongly curved at the third segment; it has a very prominent median keel that only commences a short distance from its anterior edge; it has towards its posterior third a small tooth, and it terminates behind, not in a large spine as Oplophorus and Heterocarpus, but in two small symmetrical teeth. The fourth ring is feebly keeled, and has three small teeth behind, one median, two lateral. The fifth has but the two lateral. The other segments are rounded above.

\section{Gonatonotus crassus,}

Gonatonotus crassus . . A. Milne Edwards.

The same as the genus.

RANGE.-Grenada; in deep water.

\section{Family III. Palæmonidæ.}

Palcmonide . . . Spence Bate, Miers. Palemonide (part). Dana. $\left.\begin{array}{l}\text { Palemonicns } \\ \text { Alphéns }\end{array}\right\}$ (part). H. Milne Edwards.

Carapace dorsally rounded and laterally compressed. Rostrum long, laterally compressed, and usually armed with teeth. Abdomen laterally compressed; the sides of 
the second segment cover the first and third. Telson long, and gradually narrowing to a truncated extrenity. Eyes well developed and pyriform. Antenne long and slender; internal pair having the first joint of the peduncle hollowed on the upper surface, carrying a well-developed spine on the outer side, and terminating in two flagella, of which one is frequently branched; external pair has a long, narrow, foliaceous basal scale, the outer margin of which is rigid and armed with a small tooth. Mandible has a molar process, a cutting edge, and a palp. - The external maxillipedes are pediform. First and second pair of legs have pincers. Abdominal appendages two-branched. Swimming organ well developed.

\section{Sinopsis of tIIE GENERA.}

I. Rostrum deep, serrate above and below. Three flagella on internal antemne. The second segment of the abdomen overlaps the firstand third with its expanded lower margin.

$A$. The fifth joint of the second pair of legs is long.

a. There are two spines on the frontal margin of the carapace, one

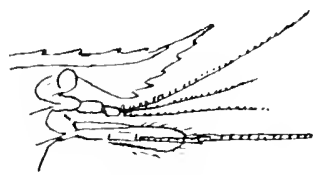

I'alemon. above the other.-(Palamon.)

b. There is one spinc on the frontal margin of the carapace, and behind it, but a little lower down, is a sccond spine.-(Bithynis.)

$B$. The fifth joint of the second

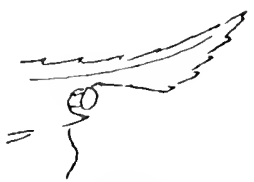

Bithynis. pair of legs is short.

c. There is one spine on the frontal margin of the carapace, and a second spine behind it, but on a lower level. -(Brachycarpus.)

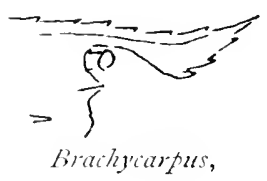




\section{Palæmon.}

Palcmon . . . . Fabricius, Leach, Spence Bate.

Polemon . . . . . H. Milne Edwards.

Leandor . . . . . . Desmarest, Stimpson.

Carapace less than a third the length of the animal posteriorly smooth, slightly compressed anteriorly, elevated into a crest over the frontal region, and produced to a long rostrum that is armed above and below with teeth. The orbital notch is well defined, but has no tooth. At the outer canthus a strong first antennal tooth projects below it, and still farther down a second tooth stands within the margin on a level with the external antennæ, and above the line of the fronto-lateral angle. There is no tooth on the hepatic region, but a depression or fissure. The abdomen is smooth, dorsally rounded; the appendages are robust and two-branched; the telson tapers to a central tooth, and has dorso-lateral spines; the lateral wing of the swimming organ has a division.

The eyes are short, broad, unarticulate, and supported on a slender pedicle; the cornea is hemispherical, and has an ocellus that is sometimes distinct. The internal antennæ have the first joint compressed above and below, and armed on the outer margin with a sharp spine, and at the anterior distal angle with a flattened tooth; the second joint is thicker than the first, shorter on the upper surface than on the lower, and articulates obliquely with the third joint, that supports two long flagella, of which the upper and outer sends off a third that is shorter than the others. The external antenna are armed with a tooth at the outer and lower distal angle of the first joint 
of the peduncle, have a basal scale that is about twothirds the length of the carapace, and terminate in a long flagellum.

The external maxillipedes have only three joints exposed, of which the terminal is the shortest and ends in an obtuse point; there is a rather slender external appendage.

The first pair of legs is slender. The second pair resembles the first, but is longer and larger. The three other pairs of legs resemble each other, and approach in length that of the second pair; the terminal joint is simple, the next joint (the sixth) long and cylindrical, the next joint (the fifth) has the anterior distal angle produced beyond the carpal articulation of the sixth joint.

The gills are attached to the body wall, to the membrane between the body and the first joint of the external maxillipede, and to the first joint of the internal maxillipede. There are no branchial plates.

RANGE.-America Rivers, Gulf weed, European Seas, East Indies.

\section{Palæmon natator.}

Palemon natator . . . H. Milne Edwards, Spence Bate.

Leander craticus. . . Desmarest.

The rostrum is as long as the basal scale of the external antennæ, narrow at the base, but very wide towards the tip, having slightly the form of an arrowhead armed with eleven or twelve teeth above and scarcely toothed below. The legs of the second pair are of moderate length, very thin at the base, but narrowing towards their extremity; hand oval; fingers longer than the palm, 
which is subcylindrical, and subequal in length with the fifth joint. The first pair of legs extend to about the level of the tip of the rostrum; the fingers are as long as the palm, and the fifth joint is as long as the palm and fingers. The last segment of the abdomen has three spines.

RANGE.-Floating weed, Atlantic and Pacific, Guadaloupe.

\section{Bithynis.}

Bithynis . . . . . Philippi, Spence Bate.

Macrobrachimm . . . . Spence Bate.

Palcmon (part) . . . . Dana, H. Milne Edwards. Palamon. . . . . . Stimpson.

Resembles Palamon. There is one tooth on the anterior margin of the carapace. There is a second tooth behind it, but a little lower down. The second pair of legs is long, cylindrical, and developed, in the male, to a greater length than that of the animal, and more or less unequal. The abdomen is short in proportion to the length of the carapace.

RANGE.-Fresh water streams of tropical Asia, Africa and America, or in adjacent scas.

\section{Synopsis OF the SPECIEs.}

I. No space between fingers of large hand when closed.

$A$. Of the largest leg the fifth joint is shorter than the palm.

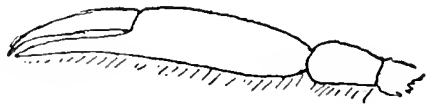

a. Rostrum has six to twelve teeth above and three 
or four below. The second pair of legs is very long and strong.-(B.jamaicensis.)

b. Rostrum has thirteen teeth above and three or four below. Second pair of legs is of moderate length.-( $B$. astecus.)

c. Rostrum has ten to twelve teeth above and three or four below. Second pair of legs short and thin.-( $B$. montcaumce)

d. Rostrum has eleven teeth above and four below.

$d^{1}$. There are no tecth on inner margin of fingers of large hand. Sides of carapace below hepatic spine smootl. -(B. brasiliensis.)

$\epsilon^{1}$. There are some large teeth on inner margin of fingers of large hand. Sides of carapace below hepatic spine rough.-(B. nattercri.)

$B$. Of the largest leg the fifth joint is longer than the palm.

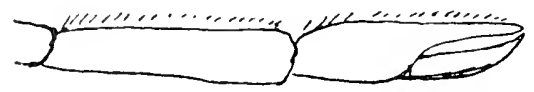

$\varepsilon$. Rostrum armed with six or seven teeth above, upon the posterior two-thirds, and with the same number below. -(B. lamarri.)

$f$. Rostrum armed with eight to ten teeth above and five or six below.-(B. forcess.)

$g$. Rostrum armed with nine to twelve teeth above and cight to twelve tecth below.-(B. ensiculus.)

h. Rostrum armed with six or seven teeth toward the base and three at apex above, and with seven tecth below.-(B. jelskii.)

II. A wide space between fingers of large hand when closed.

$i$. Rostrum armed with thirteen or fourteen teeth above and three or four below.-(B. spinimams.) 
I. No space between fingers of large hand when closed. A. Fifth joint of largest leg shorter than palm:-

\section{Bithynis jamaicensis.}

Bithynis jamaicensis . Kingsley, A. Milne Edwards.

Palcmon jamaticunsis . . H. Milne Edwards, Seba, Olivier, Lamarck, Leach, i)esmarest, Smith, Saussure.

Palemon carcinns . . . Latreille, Fabricius.

Astacus fluriatilis . . Sloan.

Camaron de agna dulce. Parra.

Cancer astacus jamaicensis Herbst.

Body stout. Rostrum short, not exceeding the peduncle of the internal antennæ, slightly sharp, and armed with six to twelve serrated teeth above and with three or four below. External maxillipedes very long, exceeding much the peduncle of the external antennx, and reaching almost to the end of their basal scale. Legs of the second pair very long, strong, almost cylindrical, and finely granular; hands slightly swollen; pincers almost cylindrical. In large specimens the limbs become spiny, and develop large teeth on the cutting edge of the fingers. The last three pairs of legs are short and stout. Last segment of the abdomen is wide, and terminates in a semicircular border ornamented with hairs and with two lateral spines.

Range.-West Indics, Jamaica, Barbados, British Guiana, Gulf of Mexico, Rio San Francisco, West African Coast. 


\section{Bithynis aztecus.}

\section{Palamon astecus . . . . Saussure.}

Rostrum short, elevated, its superior border bowed, its apex sharp, its inferior border convex, being as long as the peduncle of the internal antennx; there are thirteen tecth above and three or four below. The legs of the second pair are of moderate length, fifth joint short; hand three times as long as it, almost cylindrical; fingers cylindrical, about as long as the palm. Swimming organ of moderate size, rounded, and having on each side a large spine preceded by a small one.

RANGE-Gulf of Mexico.

\section{Bithynis montezumæ.}

\section{Palamon montesume. . . . Saussure.}

Rostrum long and narrow, ending in two teeth one above the other, as long or longer than the peduncle of the internal antenne, armed above with ten to twelve teeth and with three or four teeth below. Legs of the second pair short, thin, cylindrical, fifth joint short; hand three times as long as it. Swimming organ terminates in a tooth which is armed with two teeth on each side.

RANGE.-Gulf of Mexico.

\section{Bithynis brasiliensis.}

Palamon brasiliensis. . . . . Heller, Miers, Von Martens.

The second pair of legs about of a size; the palm is but little longer than the fifth joint; no tecth on inner margin of fingers; sides of carapace below hepatic spines 
almost smooth. The rostrum has eleven teeth above and four below.

RANGE.-Guiana, Brazil.

\section{Bithynis nattereri.}

Palamon nattereri . Heller, Miers, Von Martens.

The second pair of legs long, strong, closely spinulose, and of unequal length; the palm is longer than the fifth joint; the movable finger has two and the fixed finger has one strong tooth on the inner margin. The sides of the carapace are rough below the hepatic spine. The rostrum has eleven teeth above and four below.

RANGE.-Guiana, Rio Negro, Brazil.

B. Fifth joint of largest leg longer than palm:-

\section{Bithynis lamarrei.}

Palemon lamarei . . . H. Milne Edwards.

Rostrum large, longer than the basal scale of the external antennæ, turned up, armed above with six or seven teeth which are placed upon the posterior twothirds, and below with six or seven small teeth. Legs of the second pair filiform in their entire length ; hand very short and scarcely swollen ; fifth joint about twice as long as the hand. Last abdominal segment has three spines.

RANGE.-Indian Ocean.

\section{Bithynis forceps.}

Bithynis forceps . . . Kingsley.

Palemon forcots . . . H. Milne Edwards, Saussure, Smith.

Body thickset. Rostrum straight, as long as the basal scale of the external antennx; cight to ton tceth 
above and five or six below. Legs of the second pair very long, thin, cylindrical, and armed with many longitudinal rows of small points; pincers large, cylindrical, as long as the palmar portion of the hand, and surrounded with a close down. Following legs short and almost smooth. The last segment of the abdomen terminates in three spines, of which the central one is very strong.

RANGE.--Rio Para, Gulf of Mexico, West Indies.

\section{Bithynis ensiculus.}

Palemon cusiculus . . . . Smith.

The rostrum is rery long, strongly curved downwards for the basal half of its length; the terminal half very slencler, nearly straight, but strongly inclined upwards; it has nine to twelve teeth above, of which seven or eight are on the basal portion, and eight to twelve teeth below. The flagella of the internal antenne are very long; the basal scale of the external antennx is not as long as the rostrum, and has a rounded extremity; the peduncle has a spine on the outside and the basal scale another on the extremity of the outer margin; the flagellum is very long.

The first pair of legs, slender, reach beyond the extremity of the basal antennal scale, smooth and naked except for a few tufts of hair on the hands. The second pair of legs is very long and slender; the fifth joint is longer than the palm of the hand; all the limbs have spinules. The three posterior pairs increase in length backwards. The telson tapers to a point

RANGE.-Para. 


\section{Bithynis jelskii.}

\section{Palamon jolskii . . . . Miers.}

Body smooth. Rostrum long and slender, reaching beyond the end of the basal antennal scale, at base rising considerably above the dorsal surface of the carapace; apex slightly directed upwards, upper margin armed with six or seven teeth towards the base, and three at apex, below with seven teeth.

The longest flagellum from the internal antennx about as long as the body, that from the external antennx very long. Second pair of legs filiform, no thicker than the rest, and not much longer than the carapace and rostrum ; fifth joint about twice as long as the hand, which has the palm and fingers equal.

RANGE.-Guiana.

II. A wide space between fingers of large hand whon closed:-

\section{Io. Bithynis spinimanus.}

Bithynis spinimanus. . Kingsley.

Palcmon spinimanus . . . H. Milne Edwards.

Palamon faustinus . . . Saussure.

Rostrum almost straight, not as long as the peduncle of the internal antennæ, and armed with thirteen or fourteen small teeth above and three or four below. Legs of the seeond pair stout, of unequal size, and very spiny; a row of large curved spines close together upon the superior border of the hand, and numerous long flexible hairs upon its intcrnal face; pincers short, large, and bowed, leaving a space betwecn them ornamented with 
hairs. The colour is rod, with the tips of the fingers green.

RANGE.-West Indies, Barbados, Hayti, Brazil.

\section{Brachycarpus.}

Brachycarpus . . . . Spence Bate.

Resembles Palcmon; the outer canthus of the orbit is defined, the first antennal tooth being distinct from it; there is no second antennal tooth, but there is one on the hepatic region which, instead of being a little under the same horizontal line with the first, is some distance below this line and posterior to it. The external maxillipedes are unguiculate. The first pair of legs has the fifth joint long and cylindrical, and the hand short. The second pair has the fifth joint shorter than the fourth, triangulate, with the hand long and cylindrical.

RANGE.-North Atlantic and South Pacific Oceans.

\section{Brachycarpus savignyi.}

Brachycarpus savignii . . . Spence Bate.

Rostrum horizontal; seven tecth above and three below. Except for the tooth on the lateral margin and the one behind and below it on the hepatic region, the carapace is smooth. The fingers of the large hands have a thick fringe of stout hairs on their inner margin. The fixed finger has two strong teeth; the movable finger is a little longer than its companion, and both end in a sharp point. The three posterior pairs of legs are robust, and not very long. The fourth joint is longer than the third, and the fifth is one-third shorter than the third, and overlaps the sixth on the anterior surface. The sixth joint is a third longer than the fifth, and furnished with two or 
three solitary spines on the posterior margin. The seventh joint is short, curved, and terminates in a curved bifid nail, both points being sharp.

The telson is shorter than the lateral wing of the swimming organ; it has two spines on the upper surface, and a long and a shorter one on the margin on each side of the terminal extremity.

RANGE.-Bermuda; shallow water.

\section{Family IV. Nematocarcinidæ.}

Nematocarcinide . . . . Spence Bate.

Animal smooth and slender. Internal antennæ with two long slender flagclla. External antenna have a long and narrow basal scale, and a long slender flagellum. Mandibles have a palp. The legs have a fifth joint much longer than the sixth. The first two pairs, long and slender, have pincers. Telson slender and tapering.

\section{Nematocarcinus.}

Nematocarinus . A. Milne Edwards, Spence Bate.

Rostrum laterally compressed, toothed above, smooth below, or at most armed with very small teeth. Frontal margin of the carapace has one tooth on a level with the internal antenne, and a second tooth at the fronto-lateral angle. Eye-stalk short; eyes globular. The internal antennæ have the first joint deeply excavate, and furnished with an external spine; the second and third joint short and robust; outer flagellum is stout near the base. The mandibles have a cutting edge and a molar process, and carry a two-jointed palp. The first maxillipede has the terminal joints reflexed, and carries a long external appendage. The external maxillipede terminates 
in a flattened joint, and is furnished with a long external appendage. The first two pairs of legs are slender, the second being much longer than the first, and having the fifth joint about four times the length of the sixth. The three following pairs of legs are very long, articulation between the third and fourth joint overlap, the fifth joint is many times longer than the sixth, and the seventh is short and sharp. The telson is subequal with the inner branch of the swimning organ. The ventral surface of the three posterior segments under the carapace carry a flat anteriorly projecting plate, in the male, on each side of the middle line; in the female it is only on the fourth segment.

The gills are attached to the five last segments of the body wall, to the membrane between the body and the first joint of all the limbs except the first maxillipede and the last pair of legs, and to the first joint of the first maxillipede. The two maxillipedes have branchial plates. RANGE.-Atlantic and Pacific Oceans; in deep water.

\section{Nematocarcinus cursor.}

Nematocarimus cursor . . . A. Milne Edwards.

RANGE.-West Indies.

\section{Family V. Tropiocaridæ.}

Tropiocaride. . . . Spence Bate.

Carapace not laterally but dorsally compressed. Frontal regions projecting above the eyes, and produced to a short pointed rostrum. Internal antenna have two flagella. The external antenne have a basal scale which is long and narrow. First two pairs of legs subequal, small, with pincers. Telson long and tapering. 


\section{Notostomus.}

Notostomus . . A. Milne Edwards, Spence Bate, Smith.

The dorsum is elevated into a keel extending from the rostrum, which is toothed above and below, to the telson. From the apex of the rostrum, corresponding with its infero-lateral margin, a second keel traverses the carapace along the upper line of the branchial region to its posterior margin. The dorsal surface of the carapace is arched, especially over the frontal and gastric regions; the rostrum is horizontally straight. The eye-stalks are widely separated at their base, and carry a large cornea at their extremity.

The peduncle of the internal antenne is shorter than the rostrum; the first joint is long and excavated above to receive the eye, and carries a short, broad, and pointed external spine; the next two joints are short, and carry one stout and one slender flagellum, the former gradually tapering to a fine extremity. The external antenne have the peduncle robust, which carries a broad basal scale that is rounded at the extremity, and armed on the outer distal margin with a strong tooth. The mandibles have a large and broad cutting edge that is slightly serrate, and continuous with a small, smooth, lunate molar process, and carry a stout three-jointed palp, of which the terminal joint is short and spatuliform.

The first pair of legs is shorter than the second. The third and fourth pair are long, and have the sixth joint more slender than the preceding joints; the terminal joint is long, styliform, and slightly curred. The fifth pair resemble the two preceding, but terminates in a short, 
almost obsolete finger embedded in a thick brush of ciliated hairs.

The ridge on the dorsal surface of the segments of the abdomen is produced into a posterior tooth on the third and following segments. The telson is dorsally flat or grooved, and does not extend beyond the length of the inner plate of the swimming organ.

The gills are attached to the six posterior segments of the body wall, to the membrane between the body and the first joint of all the limbs except the first maxillipede and the last pair of legs, and to the first joint of the first maxillipede. The two maxillipedes and the first three pairs of legs carry each a branchial plate.

RanGE.-West Indies, South America, Tristan da Cunha, New Guinea, Celebes, Japan ; in deep water.

\section{Sinorsis of tile Siecies.}

$A$. The rostrum is not as long as the basal antennal scale.-( $N$. gibbosus. $)$

$B$. The rostrum is longer than the basal antennal scale.-(N. elegans.)

\section{Notostomus gibbosus.}

Notostomus gibbosus . . . A. Milne Edwards.

The rostrum, not as long as the basal antennal scale, has a dorsal crest which occupies about half its length and is situated on the basal portion; the terminal portion is slender, and toothed above and below. The ridges on the carapace are more or less parallel. The dorsal keel on the abdomen is well marked, and the posterior projections are well developed.

RANGE.-Grenada. 


\section{Notostomus elegans.}

Notostomus elegans . . . A. Milne Edwards.

Resembles $N$. gibbosus, only the carapace is not so elevated, the dorsal keel is less bowed, very finely toothed, and continued into the rostrum, which is thin and about twice as long as the basal antennal scale, and has above and below small spines, about thirty above and eighty below. The latero-inferior keel on the carapace arises in front in a strong postantennary spine.

RANGE.-West Indies.

\section{Family VI. Stylodactylidæ.}

Stylodactylida . . . . . Spence Bate.

The first pair of maxillipedes terminates in two branches subequal in size. The first two pairs of legs have pincers, of which the palm is short, and the fingers very long, slender, and feeble.

\section{Stylodactylus.}

\section{Stylodactylus . . A. Milne Edwards, Spence Bate.}

Carapace one-third the length of the body. The rostrum is long, laterally compressed, curved upwards, and has above and below a series of articulated and movable spines (about forty above and twenty below). The carapace has a spine on its anterior border, one above and one below the insertion of the external antenne. The eyes are small, and are in contact in the middle line. The internal antennæ have only two flagella; they have at their base and outside a small pointed scale. The basal antennal scale is slightly developed, and narrow. The 
basal point is swollen, and the flagellum is long, stout, and very strong. The external maxillipedes are thin and pediform. The legs of the first and second pair are about the same length. The palm is rudimentary. The third, fourth, and fifth pair equal; the fourth joint has below many spines; their finger is short and hooked. The abdomen is large and smooth; the second segment has above two rows of small articulated spines; it terminates behind in a point from each side of which there is a longer articulated spine.

RANGE.-West Indies, Pacific Ocean; in deep water.

\section{Stylodactylus serratus.}

Stylodactylus serratus . . . A. Mine Edwards.

The same as the genus.

RANGE.-Dominica.

Family VII. Pasiphæidæ. Pasiphaida. . . Spence Bate.

The first two pairs of legs are well developed, and have pincers. The remaining three pairs of legs are very much reduced in size, and sometimes imperfectly formed.

\section{Leptochela.}

Leptocheli. . . Stimpson, Spence Bate.

Carapace smooth, scarcely crested; rostrum very short, spiniform. The internal antennæ have two flagella. Mandibles inflexed, broad, and compressed. Palp short, ovate, and nonarticulate. First pair of maxillipedes not pediform, having the last joint armed with long spines. 
The external maxillipedes have an external appendage. The legs have external appendages; first and second pair compressed, slender, with long parallel fingers; three posterior pairs short. Abdomen has the fifth segment more or less abruptly curved; appendages two-branched; swimming organ well developed; telson long, narrow, and tapering.

The gills are attached to the chest wall of the five last segments, to the membrane between the body and the first joint of all the legs except the last pair. The branchial plates are only rudimentary, and on the first joint of the two maxillipedes.

Range.-West Indies, China Sea, Sea of Japan, Bass Strait; in moderately deep water.

\section{Leptochela serratorbita.}

Leptochela serratorbita. . . Spence Bate.

Orbital margin fringed with a series of small teeth. Dorsal surface of fifth and sixth segment of the abdomen smooth. External maxillipede furnished with a large and pointed tooth.

RANGE.-St. Thomas.

\section{Order II. Stomapoda.}

Stomapodir. . . Latreille, Miers, Dana.

Stomatopodir. Brooks.

Stomapodes. . H. Milne Edwards.

Anomobranchiata. Dana.

The gills (when present) are not covered by the carapace, but are exposed, attached to the base of the legs or to the abdominal appendages. The maxillipedes 
are usually pediform. The posterior legs may be absent. The abdominal appendages may be very small. The head and chest are more or less in segments.

\section{Family Squillidæ.}

Squillide. . . Dana, Miers, Brooks.
Squilliens. . . II. Milne Eclwards.

The abdomen is larger than the cephalo-thorax, the gills being attached to its under surface; its last joint and the appendages of the joint next it are greatly developed. The carapace is more or less quadrilateral, with two longitudinal grooves above, leaving exposed the two first segments of the head and several segments of the body. Frontal plate mobile, separated by a suture from the carapace. Internal antenne have three flagella. External antenne short, bearing a large oval scale. Second pair of maxillipedes large, prehensile, with the inferior margin of the last two joints usually armed with spines. Three first pairs of thoracic legs shorter, prehensile, applied to the buccal cavity, with their last joint but one expanded; the succeeding pairs slender.

RANGE.-Most seas.

Members of this family are found in shallow water, sometimes under stones and in holes in the sand when the tide is out. In shape they call to mind the insect called "Mantis" or "God Horse." The definition of the order and family is taken from Mr. Miers' "Crustacea of New Zealand," the symopsis of the genera from Mr. Brooks' "Challenger Report" on the Order. The latter naturalist states that the young are found on the surface of the sea. 


\section{Synopsis of the GenerA.}

I. Sixth abdominal segment distinct, not fused with last segment; rostrum without antero-lateral spines.

A. Hind body narrow and thick.

$\alpha$. Dactyle of raptorial claw dilated at base, and unarmed; primary marginal spine of telson very large, with one or two secondary spines on each side between the submedian and the intermediate.-(Gonodactylus.)

b. Dactyle of raptorial claw not dilated at base, usually armed with marginal spines; submedian spines of telson tipped with movable spinules; from one to three secondary spines between the submedian and intermediate.-(Pscudosquilla.)

$B$. Hind body depressed and wide.

c. Dactyle of raptorial claw not dilated at base, but usually armed with marginal spines.

c. Primary marginal spines of telson large, with more than four secondary spines between the intermediate and the submedian; dactyle of raptorial claw usually with no more than six marginal spines.--(Squilla.)

\section{Gonodactylus.}

Gonodactylus . . Latreille, Miers, Brooks, II. Milne Edwards, Dana.

Hind body narrow and thick, convex. The sixth abdominal segment separated from the telson by a movable joint. The dactyle of raptorial claw enlarged at base, without marginal spines. The rostrum has no antero-lateral spines. Primary marginal spines of telson very large, with one or two secondary spines on each side between the submedian and the intermediate.

RANGE--Atlantic and Pacific Occans. 


\section{Gonodactylus chiragra.}

Gonodactylus clivragra. . . Latreille, H. Milne Edwards, Brooks.

Mantis marina barbadensis. . Petiver.

Squilla chiragra. . . . . . Fabricius, Desmarest.

Cancer chiragrus . . . . . Herbst.

The rostral lamina has in the middle line a long spiniform tooth. The eyes are pyriform. -The tarsi of the three last pairs of legs flat, but narrow. Colour, green banded with darker green

RANGE--Seas of most warm countries. Found under stones at Barbados when the tide is out; St. Thomas, Bermuda, Mediterranean Sea, Pacific.

\section{Pseudosquilla.}

Pseudosquilla. . . Guérin, Broolss.

Hind body smooth, convex, and narrow. The sixth abdominal segment separated from the telson by a morable joint. The dactyle of the raptorial claw not dilated at base, with few marginal spines, or none. The submedian spine of the telson long, tipped with movable spinules with usually a single secondary spinule, sometimes two, three, or four, between the submedian and intermediate marginal spines; the terminal joint of the first abdominal appendage of the male imperfectly divided by a marginal notch into an inner and an outer lobe. The rostrum without lateral spines.

RAnGe-Warm seas, Atlantic and Pacific Oceans. 


\section{Pseudosquilla ciliata.}

Pseudosquilla cilicta . . . Miers, Brooks.

Pseudosquilla stylifera . . Von Martens.

The postero-lateral angles of the fourth, fifth, and sixth abdominal appendages end acutely in spines. The lateral lobes of the last thoracic segment are bidentate. They are found on the shore. The colour, red.

RaNGE.-St. Thomas, Cuba, Honolulu.

\section{Squilla.}

Squilld . . Fabricius, H. Milne Edwards, Brooks, Miers.

Rostrum without antero-lateral spines. Sixth abdominal segment distinct. Hind body depressed and widc. Dactyle of raptorial claw not dilated at base. but usually armed with marginal spines. Primary marginal spines of telson large, with more than four secondary spines between the intermediate and the submedian spincs.

RANGE.-Most seas.

\section{Synopsis of the Siecies.}

1. There are no ridges or large tubercles upon the upper surface of the abdomen; its last segment is one and a half times as wide as long, rounded, and scarcely toothed.

$A$. There are five or six tecth upon the raptorial claw.-(S. vitterta.)

$B$. The last two rings of the abdomen are finely granular. There are nine or ten teeth on raptorial claw--(S. scabricauder.) 


\section{Squilla vittata.}

Squilla vittata. . . H. Milne Edwards, Latreille.

The raptorial claw has five or six teeth. The abdomen has neither crests nor large tubercles upon its upper surface; its last segment is one and a half times as wide as long, rounded, and scarcely toothed. The bands upon the carapace and upon each joint of the abdominal segments are wide, and indistinctly divided into three portions, one median and two lateral.

RANGE.-West Indies.

\section{Squilla scabricauda.}

Squilla scabricauda. . H. Milne Edwards, Latreille, Lamarck.

The dorsal surface of the abdomen has no ridges or large tubercles; its last segment is one and a half times as wide as long, rounded, and scarcely toothed. The two last segments are finely granular. There is a row of small spines upon the posterior border of the antipenultimate segment, and a row of shorter points upon the posterior border of the last segment but one. The seventh segment has above a sort of shield, and on the lower part behind three large and obtuse teeth. Resembles $S$. maculata, which has nine or ten teeth on raptorial claw (H. Milne Edwards).

RANGE.-West Indies. 


\section{ALPHABETICAL INDEX}

abbreviata (Galathodes), 4 IO. abbreviata (Munidopsis), $4 \mathrm{IO}$. abbreviatus (Eurypanopens), I 37. abbreviatus (Panopeus), I 37 . abdominalis (Elasmonotus), 4I5. Aberrantia, 423 . abyssorum (I'arapagurus), 3 S6. acantha (Actiea), I 26. Acanthephyra, 474. Acanthephyride, 473 . Acanthocarpus, 304 . Acanthodromia, 336 . Acanthonychidie, $3 \mathrm{~S}$. Acanthonychine, 3 S. Acanthonyx, 43 . acanthophorus (Neleus), I7o. Acanthus, I 54. acanthus (Cancer), 126.

Achelous, 173, ISI, I95. Acrorhynchus, I 2.

Actra, 125 .

Actodes, 125 . aculeata (Glyphocrangon), 460. aculeata (Hyas), So. aculeata (Othonia), So. aculeatus (Cancer), go. aculeatus (Mithrax), 90. aculeatus (Pilumnus), I 56. adspersus (Carpilius), I 20. advena (Pachygrapsus), $2 S_{4}$. requinoxialis (Scyllarts), 432 . aflinis (Epialtus), 42.

affinis (Gelasimus), 272. affinis (Mithrax), 95 . affinis (1'seudothelphusa), 2 IS. agassizii (Amathia), 33. agassizii (Galathea), 400. agassizii (Lithodes), 355. agassizii (Lobopilummus), I64. agassizii (Nephropsis), 445. agassizii (Pentacheles), 4. I. agassizii (Pilumnus), I64. agassizii (Pseudothelphusa), 2 I 5. agassizii (Pylocheles), 3 S9. agonus (Lambrus), IO4. agrestis (I'seudothelphusa), 2 I 2. allicans (Ocypoda), 267.

Alluniea, 350 .

Allunea, 350.

Albuncidre, 350.

Allunirle, 350 .

alexandri (Acanthocarpus), 306.

Alphacus, 460.

Alpheéns, 479.

Alpheidie, 460.

Alphens, 460 .

altifrons (Grapsus), 2 So.

Amathia, 3 I.

americana (I'seudothelphusa), 207.

americana (Sesarma) 292.

americanus (Arcus), 433.

americanus (Chlorodius), I 47.

americanus (Euchyrograpsus), 287 .

americanus (Leptodius), 147.

americanus (Palinurus), 437.

americanus (I'anopeus), I32, I35.

americanus ('Tanulirus). 437 .

americanus (Santhodius), I47.

Amphitrite, 173, I 77.

Anamathia, $3 \mathrm{I}$.

Inapagurus, 373 .

- Inasimus, 23.

anceps (Achelous), I 77.

anceps (Lupa), 177.

anceps (Neptunus), 177.

angustata (Calappa), 303, $30 \mathrm{OS}$.

angustatus (Hepatus), 308 .

angustatus (Nautilograpsus), 2 S6.

angustipes (Sesarma), $29 \mathbf{I}$.

anisudon (Othonia), So.

Anisonotus, 20.

Anisopus, 198 .

Anomala, 329 .

Anomalopus, 39 .

Anomalothir, 39 .

anomalus (Clibnarius), $3^{6} 3$. 
Anomobranchiata, 497.

Anomoura, 329.

Anomoures, 329.

Anomura, 329.

ansoni (Leptograpsus), $2 S_{3}$.

antennaria (Cyclodorippe), 323 .

antillensis (Dromidia), 334 .

antilocapra (Pisa), 53.

Arachnopsis, 25.

Aratus, 293.

Arctus, 432.

Arcuata, I I 3 .

arcuata (IIypoconcha), 336.

arcuatus (Callinectes), is6, 190.

arcuatus (Sympagurus), $3 \mathrm{So}$.

Arenieus, 173 .

arenaria (Ocypoda), 267.

arenarius (Cincer), 267.

argus (P’alinurus), 437.

argus (I'anulirus), 437.

armata (Acanthephyra), 476.

armata (Epilolocera), 224.

armata (Nibilia), 35.

armata (I'orcellana), 393.

armatum (Cardiosoma), 246.

armatus (Elasmonotus), +15.

armatus ( ielasimus), 270.

armatus (1'etrolisthes), 393.

armatus (I'otamocarcinus), 222.

armillatus (Alphens), 462.

arroser (Cancer), 365.

Astacidie, 446.

Astacidea, $43 \mathrm{~S}$.

Astacus, 427 .

astacus jamaicensis (Cancer), $4 S_{5}$.

asper (Cymopolus), 325 .

Alya, 472.

Atyidie, 472.

Atyoida, 472 .

Aty's, 472.

aztecus (Bithynis), 486 .

aztecus (Paliemon), 486.

barladensis ovalis (Squilla), 34 S.

barbadensis (Remipes), $34 \mathrm{~S}$.

barlatus (Cardiosoma), 247 .

bartletti (Eupagurus), 370.

bartletti (Pylopagurus), 370.

Bathyplax, 262.

lelliana (I'seudothelphusa), 214.

bellicosa (Lupa), I90.

bellicosus (Callinectes), I\$6, I90.

Bellidilia, 316 .

Jenthesicymus, 454.

bermudensis (Alpheus), 463 .

bertheloti (Leptograpsus), $2 \$_{3}$.

bicoma (Pericera), 73.

bicorna (I'isa), 73 . bicornis (Pericera), 73.

licornuta (Milnia), 73 .

bicornuta (Pisa), 73.

bicornutus (Microphyrys), 73.

budentatus (I Iippolye), 466.

hidentatus (Xanthodes), I 30.

bispinosus (Acanthocarpus), 305.

bisuturalis (Iseudothelphusa), 2 I6.

Bithynis, $4 S_{3}$.

bituberculatus (Epialtus), 42.

Black crab. 239.

bocourti (Boscia), 220.

bocourti (Callinectes), 192.

bocourti (I'seudothelphusa), 220.

boletifer (Pylopagurus), 369 .

Boscia, 204, 206.

Bosciacrea, 20.4.

Bosciadie, 204.

bouvieri (P'seudothelphusa), 2 I 5 .

Brachycarpus, 490.

Brachyura, 3 .

Brachyures, 3 .

brasiliensis (Jithynis), 486 .

lrasiliensis (Epialtus), 42.

Lrasiliensis (l'alemon), 456 .

brasiliensis (Pentus), 452.

Lrevifrons (Gelasimus) 272.

brevimana (Nunidopsis), 409.

hrevipes (Grapsus), $2 \mathrm{~S} 2$.

linck crab. 250.

Bundory crab, 246 .

cæecus (Phoberus), 445.

Calappa, $302,3^{\circ} 7$.

Calappide, 301.

Calappiens, 301.

Calappine, 301.

Calcinus, $36 \mathrm{I}$.

Callianassa, 424.

Callianasside, 424 .

Callinectes, $\mathrm{I}_{5}$.

Cambarus, 446.

Camaron de agna dulce, $4 \$ 5$.

Cancellinee, $3 \mathrm{~S}_{3}$.

Cancer, 10, 36, 49, 51, 65, 67, 10\$, $119,125,12 \mathrm{~S}, 243,24 \mathrm{~S}, 254,265$, $268,289,295,3$ I I 3 I $6,347,35$, $43 \mathrm{I}$.

Cancer (Astacus), 42.4.

Cancer vocans major, $27 \mathrm{I}$.

Cancériens, i 15.

Cancériens arqués, I I 5.

Cancériens quadrilatéres, i 5.

Cancri Brachyuri, 3.

Cancride, I I 5 .

Cancrince, I 5.

Cancrinea, IIf.

Cancroidea, 113. 
Cancroidea typica, II4.

Carciniens, 196.

Carcinine, 196.

Carcinoplacinx, 255, 259.

carcinus (Palemon), $4 \mathrm{~S}_{5}$.

Cardiosoma, 243 .

caribrea (Munida), 402, 403.

caribreus (Chlorodius), 147.

caribaus (Leptodius), I 47.

caribrus (Pilumnus), I 5.'.

caribensis (Eryon), 344.

caribensis (Zanclifer), 344.

carinata (Sicyonia), 453.

carinatus (Palimon), 453 .

carinatus (I'andalus), 468.

carnifex (Cancer), $2+5$.

carnifex (Cardiosoma), $2+5$.

camifex (Gecarcinus), 245 .

carolinensis (Spencarcinus), $25 \mathrm{~S}$.

Carpilius, I I9, I4I.

Carpilodes, I 4 I.

Carupiens, I 7 I.

castelmani (Dilocarcinus), 233.

Catapagurus, 374.

Catometopa, 200.

Catometopes, 200.

cayennensis (Callinectes), I92.

Cenobita, $35 \mathrm{~S}$.

ceratopus (Heteractica), I66.

ceratopus (Pilumnus), i 66.

cerdata (Ocypoda), 245.

Chaliepus, 259.

Cheiroplatea, 388.

Cheramus, 425 .

chilensis (Potamia), 2 I 5.

chilensis (I'seudothelphusa), 2 I 5.

chiragra (Cancer), 65 .

chiragra (Gonodactylus), 500.

chiragra (Inachus), 65 .

chiragra (Lissa), 65.

chiragra (I'isa), 65 .

chiragra (Squilla), 500 .

chiragrus (Cancer), 500.

Chirostylus, $4 \mathrm{I} S$.

Chlorodius, I43, I44, I48.

Chorinus, 36 .

ciliata (Pseudosquilla), 500.

cinctimanus (Nithraculus), 95.

cinclimanus (Nithrax), 95.

cinerea (Sesarma), 20I.

cinereus (Grapsus), 286, 291.

Clibanarius, 363 .

clypeatus (I'lanes), 286.

ccelata (Pericera), 70.

Conobita, 358 .

Conobitidix, 357 .

colombiana (Pseudothelphusa), 2 I 9.

Common crab. 25 o. compressus (Sisyphus), 55.

concameratus (Acanthonyx), 44.

conradi (Pseudothelphusa), 2 r7.

constricta (Nunida), 404 .

comstricta (Myropsis), 3I 5 .

convexa (Pseudothelphusa), zis.

corallinus (Carpilius), I 20.

cordata (Ocypoda), 252.

corlata (Uca), 250.

cordatus (Cancer), $250,252$.

cormudo (Cancer), 6u).

cornuta (Pericera), 69.

comuta (Trachymaia), 29.

comutus (Nithrax), $8 S$.

coronatus (Cancer), $9 S$.

coronatus (Mithraculus), 94, 9S.

coronatus (Mithrax), $9 S$.

corrosus (Sphenocarcinus), 66.

Corvohynchus, I6.

Crabe blanc, 246 .

Cralse violet, 239.

crassir (Amathia), 33.

crassa (Anamathia), 33.

crassus (Esopus), 45.

crassus (Gonatonotus), 479.

crenulatus (Gelasimus), 272.

crenulatus (Lambrus), 105.

crenulatus (Platylambrus), I05.

cressum (Cardiosoma), 247.

cribraria (Lupa), 176.

cribrarius (Areneus), 176 .

cribrarius (Neptunus), I 76 .

cribrarius (l'ortunus), I76.

cristatipes (Nesorhoea), I I I.

Cronius, I95.

crucifera (I'olycheles), 440.

crucifera (Willemoesia), 440.

cruentatus (Grapsus), 278 .

cruentatus (Goniograpsus), 278 .

cruentatus (Goniopsis), 278.

cruentatus (Neptunus), ISo.

Crustacea, I.

Crustaces pediocles, I.

Cryptoporlia, I I 2.

cubensis (Epilobocera), 225.

cubensis (kemipes), 348 .

cursor (Cymopolia), 329.

cursor (Nematocarcinus), 492.

curvicorna (lericera), 77.

curvirostris (Anisonotus), 20.

cyaneus (J'lanes), 286.

Cycledorippe, $32 \mathrm{I}$.

Cyclograpsus, 294.

Cyclometopa, si 3 .

Cyclometopes, I I 3 .

Cymonomus, 323.

Cymopolia, 325 .

Cymopolus, 324 . 
danx (Callinectes), IS6.

debilis (Acanthephyra), +76 .

(le) ilis (Acanthonyx), 4 .

rebilis (systellaspis), +76 .

I ecapodli, 2.

Decipodes, 2.

declivifuns (Grapsus), $2 S_{4}$. deflexifrons (Poulochela), I6.

Dendrubranchiata, 44 ?.

dentata (Brscia), 209.

dentatia (Cmopolia), $32 S$.

dentata (I'senduthelphusa), 209.

dentata (Thelphusa), 209.

dentatus (D)ilucarcinus), 234.

(dentatus (Trichodactylus), 220.

denticulata (Boscia), 207.

denticulata (Peseluthelphusa), 207.

denticulatus (Xantho), 120.

depressa (1 Ierlstia), 50.

depressa (I Ierbstichia), 50.

depressa (1'lagusia), 296.

depressifrons (Achelons), $\mathbf{I} S_{3}$.

lepressifrons (Amphitrite), $\mathrm{IS}_{3}$.

depresifrons (Neptunus), $\mathbf{I}_{3}$.

depressus (Acrorbynchus), It.

depressus (Cancer), 296.

depressus (Geocarcinus), 2 . 0.

depressus (Grapsus), 296.

depressus (Mithrax), 91.

derillei (Syiriocarcinus), 230.

diacantha (Lupa), IS6.

diacanthus (Callinectes), IS6.

diacanthus (Neptunus), I S6.

diacanthus (Portunus), IS6.

I)icranorhomia, $33^{\mathrm{S}}$.

dilatata (Cymopisia), 326.

dilatata (1'seudothelphusa), 216.

dilatus (Epialtus), 42.

I) ilocarcinus, $23 \mathrm{I}$.

dimgenes (Comolita), 35 s.

dirgrenes (Pagurus), 358 .

diplacantha (Macrocieloma), 77 .

diplacantha (Pericera), 77 .

I)iptychus, 419.

discoidalis (Eupagurun). 368 .

discuidalis (Pylopagurus), 368 .

Discoplax, $2 \mathbf{S} \mathbf{I}$.

distincta (Libinia), 62.

diumum (Cardiosoma) 2,6 .

divis (Grapsus), $2 \$ 6$.

Domecia, I69.

Dorhynchus, 3 .

Durippidie, 320 .

1) orippiens, 320 .

Dromia, 333 .

I) romiacea, $33 \mathrm{I}$.

Dromide, 332 .

Dromidea, $33 \mathrm{I}$.
Dromidia, 334 .

Iromiens, 332 .

Dryope. 12.

diriba Callinectes), I91.

dubia (Libinia), 62.

dubius et miniatus (Metograpsus), $28+$.

duchassagui (Lupea), 177 .

dugesi (I'seudothelphusa), 207.

Ehalia, 316 .

Elsaliine, 315 .

ecuadorensis (Pseudothelphusa), 2 Io.

Leta crab, 23t.

Elasmonotus, 413.

elegans (Notostomus), 495.

emarginata (Tyche), 47.

cmarginatus (Acanthonys), 44.

emarginatus (Dilocarcinus), 232.

emerita (Hippa), $3+9$.

emeritus (Astacus), $3+9$.

eneritus (Cancer), $3+9$.

ensiculus (Bithynis), $48 S$.

ensiculus (I'alemon) 4 SS.

ensifer (Heterocarpus), 468.

ensiferus (Hippolyte), 465 .

ensiferus (Latreutes), 465 .

ensis (Acanthephyra), 476 .

Epialtus, 4 I.

Epilolocera, 223.

equatorialis (Pseudothelphusa), 2 I 3 .

erinacea (Acanthodromia), 336 .

erinacea (Munidopsis), $4 \mathrm{II}$.

erinacea (Nibilia), 35.

erinacea (I'isa), 54.

erinaceus (Galathodes), $4 \mathbf{I}$.

Eriphia, 167.

Eriphicle, I 5.

erosus (Eupagurus); 369.

crosus (I'ylopagurus), 369 .

erraticus (Leander), $4 \mathbf{S 2}$.

Lryonicle, 439.

Esopus, 45.

Eubranchiata, 2.

Euchirograpsus, 287 .

Encratopsinae, 256.

Euctenota, 173.

Eupilumnus, 154 .

Euprognatha, 26.

Eurypanopeus, I 36 .

Euryplacince, 256 .

Euryplax, 256.

Eurypodiide, 17 .

Eurytium, 149.

exaratus (Chlorodius), 146.

exilipes (I'seudothelphusa), 2 I I.

falcipoda (Dryope), I6. 
fasciatus (Hepatus), 308.

faustinus (Palitmon), 489 .

feste (Rathlumia), 226.

Fibribranchiata, $3 S_{4}$.

filipes (Arachnopsis), 25.

Fisheria, $7 \mathrm{I}$.

flammea (Calappa), 304.

flammea (Cancer), jo4.

floridanus (Chlorodius), I $46, \mathrm{I}+7$.

foridanus (Leptodius), $1+6$.

floridus (Carpilius), I 20.

flosculosus (Carpilius), I 20.

fluriatilis (Astacus), 485 .

fluviatilis (Cancer), 209.

fluviatilis (Trichodactylus), 229.

forceps (Bitlynis), 487.

forceps (Inachoides), 23.

forceps (Lupa), I93.

forceps (Mithraculus), 96 .

forceps (Nithrax), 96.

forceps (Palxmon), $4 S_{7}$.

forceps (Portunus), I93.

forficulatus (Metoporaphis), I 2.

fossor (Pseudothelphusa), 208.

Fountain crab, 30.4 .

fragosus (Pilumnus), $\mathbf{I}_{3}$.

Frevillea, 26r.

frontalis (Anomalopus), $4 \mathrm{I}$.

frontalis (Anomalothir), $4 \mathbf{r}$.

fujax (Anasinus), 24.

furcillatus (Anomalopus), 40.

furcillatus (Anomaluthir), 40.

furcillatus (Lispognathus), 30.

Galacantha, 4I7.

Galatea, too.

Galathea, 400

Galatheidx, 3 S9, 39 S.

Galatheider, 389,395 .

Galatheides, 395 .

Galathodea, 39 S.

Galathodes, 406.

Galathopsis, 4I3.

galibica (l'isa), 73 .

galloides (Calippa), 303.

Gallus, 302.

gallus (Calappa), $\mathbf{3} 3$.

gallus (Cancer), 303 .

gallus (Gallus), 303 .

garmani (l'seudothelphusa), 209.

Gastroptychus, $7 \mathrm{IS}$.

Gecarcinide, 235.

Gécarciniens, 235.

Gecarcinus, 243, 2.48.

Gecarcoidea, $2+2$.

Gelasimus, 268.

gemmatus (Pilumnus), I60.
Geocarcinidx, 235 .

Gencarcinus, 237.

Geograpsus, $28 \mathrm{I}$.

Gelyon, 259.

giblesii (Allunea), $35 \mathrm{I}$

gilingimantis (Eupaguns), 370.

gibloosmanus (l'ylopagurus), 370.

giblosus (Notustomus), 494.

gigantea (6)ypoda), 2.6.

gilmanii (Evilubocena), 224.

silmanii (Upisthocera), 22.7.

Glyphocrangon, 457.

gonigra (Cancer), I6S.

gonagra (Eriphia), IES.

Gomatonotus, 47 S.

Goniograpsus, 277.

Croniopsis, 277.

Gonodactylus, 499.

Gonoplaciens, 26.1.

Gonoplax, 268.

gracilipes (Boscia), 2 I 2.

gracilipes (Cymopolia), $32 S$.

gracilipes (Euprognatha), 28 .

gracilipes (f'ilumnus), I5s.

gracilipes (lodochela), I 5 .

gracilipes (Pseudothelphusa), 2 I 2.

gracilirostris (Oplophorns), $47 \mathrm{~S}$.

gracilis (Catapagurus), 376.

gracilis (1 temipagurus), 376 .

gracilis (Metograpsus), $2 \$ 5$.

gracilis (1'achygrapsus), $2 \$ 5$.

sracilis (I'lagusia), 297.

sramulata (Calappa), 304.

granulata (Cryptopodia), i I2.

granulata (Epilobocera), 225.

granulata (Heterocrypta), I I 2.

granulatus (P'agurus), 366 .

granulatus ('otrochirus), 366.

granuliferum (Negalobranchium), 397 .

granulosus (Temnonotus), 57 .

Grapsicte, 274 .

Grapsinx, 274, 275 .

Grapsini, 276 .

Grapsoirlea, 200.

Grapsoidiens, 274

Grapsus, 279, 289.

grapsus (Cancer), 2 So.

grosipes (I'odochela), I 4 .

Gradulpensis (Grapsus), $2 \$ 5$.

guadulpensis ('ortunus), Igs.

Guaia, 317 .

guaia (l'ersephona), 3 Ig.

granhuni (Cancer), $2+6$.

suanhumi (Cardiosoma), 246.

Guathochaimus, 294.

Guinea-lird lolster, 436 .

guttatus (Palinurus), $43^{6}$.

guttatus ('’anulirus), 436 . 
hastata (Lupa), IS6.

hastatus (Callinectes), IS6, I $\$ 7$.

haytensis (Epilolocera), 225.

Ilellenus, $173,1 \$_{4}$.

helleri (1'olycheles), $4+2$.

1 Ienipasturus, 374 .

henrici ('seudothelphusa), 2 ro.

Itepatinic, 3 o6.

I Lejatus, 307.

llerlstia, 34, 49 .

Herbstiella, 49 .

herhstii granulosus (l'anopeus), I 32,

I 34 .

herlstii obesus (l'anopeus), I32, I34.

herlsstii (Panopetis), 132.

heros (Chorinus), 37 .

heros (Maia), 37 .

heros (l'isa), 37 .

hertipes (Cardiosoma), 245.

hertipes (Gecarcinus), 245.

Ileteracheal, 165.

Heterncarpus, 467 .

hetcrochcles (Alpheus), 462.

heterocheles (Gelasimus), 271.

heterocheles (Ocypoda), 270,27 r.

1 eterocrypta, 1 I 2.

1lexapodince, 299.

hillii (Geograpsus), $2 S_{I}$.

hillii (Orthograpsus), $2 S 1$.

IIippa, $347,34^{\text {\% }}$.

1 lippes, $3+5$.

llippidie, $3+6$.

llipplea, 345 .

1lippiens, $3+5$.

llippolyte, 405.

Iippolitydx, 464 .

hirsuta (i)malacantha), 73 .

hispida (1)omecia), 170.

hispidus (Cancer), 90.

hispicus (Mithras), 90.

hispidus (Stenopus), 448 .

Holometopus, $2 S 9$.

Homariche, 444.

IIomula, 340 .

110 molidx, 337 .

Homoliens, 337, 354.

Ilomolodromia, 339 .

1 omolopsis, $3+\mathbf{I}$.

Horned crab. 69.

horridic (Maia), IoS.

horrida (Parthenope), roS.

horridus (Cancer), ios.

llorsesho crab, $43^{\circ}$.

humilis (Xantho), I 29.

hydromus (Cancer), 245.

IIymenosomina, 299.

1 Yypoconcha, 335.

llypolobocera, 206. hystrix (Anamathia), 32.

hystrix (Amathia), 32 .

llacens, 430 .

Ilnachus, 430 .

Ihacus, 430 .

Ilia, $31 \mathrm{I}$.

Iliacantha, 313 .

Hiince, $3 \mathbf{I O}, 3 \mathrm{I} \mathbf{I}$.

immaculata ('lagusia), 296.

Inachidie, 7 .

Inachina, 17 .

Inachoides, 2 I.

Inachus, io, 49, 5I, 65 .

incertus (Geryon), 260.

incisus (l'agurus), 365 .

inermis (Euprognatha), 28 .

inermis (Monolepis), 267 .

innotatus (Goniograpsus), $2 S_{4}$.

insignis (l'agurus), 366 .

integer (Cyclograpsus), 295.

integer (Grapsus), 295.

intermedius (Yachygrapsus), $2 S_{4}$.

iris (Munida), 402 .

iris (Spiropagurus), 372.

irrasa (Nuniclia), 403 .

jacolii (Eupagurus), $3 \$ 6$.

jamaicensis (Bithynis), $4 \mathrm{~S} 5$.

jamaicensis (J'atemon), 455 .

jelakii (Bithỵnis), 4 so.

jelskii (1'alimon), 4 So.

jouyi (1'seudothelphusi), 2 I 2.

Jumbi crab, 272.

Kingsleya, 22I.

Kilistygnatha, 3 .

lacteus (Pilumnus), 159.

lacustris (Panopeus), I 32.

licvigata (Macrocoloma), 77.

levigata (Othonia), SI.

levigata (l'ericera), 77 .

l.erimanus (Nithrax), 92.

levimanus (Pachygrapsus), $2 S_{4}$.

lievis (Uca), 25o, 253 .

lagostoma (Gecarcinus), $24 \mathrm{I}$.

lagostoma (Geocarcinus), $24 \mathbf{I}$.

Inlaudii (Gecarcoidea), 243.

lalandii (Pelocarcinus), 243 .

lamarckii (l'ersephona), 320.

lamarrei (Bithynis), 487 .

lamarrei (l'alienon), $4 S_{7}$.

Lambrus, IOI, IO2.

lamellifrons (l'seudothelphusa), 221.

Laminibranchiata, 357 .

Langoustes Inngicornes, 435 .

Langoustes ordinaires, 434 . 
Langoustiens, 433 .

larvatus (Callinectes), I $\$ 6$, I $\$ S$.

lateralis (Geocarcinus), 239.

latifrons (Galathodes), 4I 3 .

latifrons (Munidopsis), $4 \mathrm{I} 3$.

latifrons (Potamocarcinus), 222.

latimanus (Cardiosoma), 247.

latipes (Pisa), $\$_{3}$.

lator (Dromia), 333.

latreillii (I'ersephona), 3 I9.

Latrentes, 464.

Lazy crab, IoS.

Leacosoidea vel Oxystomata, 299.

Leander, $4 \mathrm{~S}$ I.

Lepilopa, 352 .

Lepidops, 352.

Leptochela, 496.

Leptodius, I 44, I 46.

Leptograpsus, $2 \mathrm{~S} 2$.

Leptopodia, Io.

Leptopodide, 9

Leptopodinee, 9.

lencomelas (Mithrax), 93.

Lencosia, 3 I I.

Lencosiens, 3 Io.

Leucosidx, 3 Io.

levimanus (Pagurus), 362.

therminieri (Nicrorhynchus), So.

lherminieri (Othonia), So.

Libinia, 60.

lichtenstenii (Persephona), 320.

limosum (Eurytium), I 49.

limosus (Cancer), I49.

limosus (Chlorodius), I 46 .

limosus (I'anopeus). I 49.

lindigiana (Pseudothelphusa), $2 \mathbf{I}$ I.

linneana (I'lanes), $2 S 6$.

Liocarcinus, 197.

Liomera, I4I.

Lispognathus, 30 .

Lissa, 65.

Lissocarciniens, 196.

Lithodea, 354.

Lithodeacea, 354 .

Lithodes, 355 .

Lithodidie, 355 .

Lithodidea, 354.

lividus (Geograpsus), $2 S 2$.

lividus (Grapsus), $2 \mathrm{~S} 2$.

lobata (Lophactara), I 22.

lobatus (Atergatis), 122.

lobatus (Cancer), I22.

lobifrons (Micropanope), I 40.

Lobopilumnus, I64.

longimana (Liomera), I 42.

longimanus (Carpilodes), I 42.

longimanus (Chlorodius), I 44 .

longimanus (Elasmonotus), 4 I 6 . longimanus (Palinurus), 434.

longipes (Grapsus), $27 \mathrm{~S}$.

longipes (Nunida), 404.

longipes (l'andalus), 470.

longirostris (Epialus) 42.

Lophactiea, I 2 I.

Liphos, 302.

Lupa, 193.

Lupea, IS5, 195.

Lupiens, I7I.

Lupine, I 7 I.

Lupocycliens, I 7 I.

lupoides (Lambrus), I05.

lutaria (Malopsyche), 462.

lutarius (Alpheus), 462.

lymani (l'aguristes), 379 .

Macrobrachium, $4 S_{3}$.

macrocera (Ocypora), 266.

macrochelos (Cancer), Io5.

Nacroceloma, 74 .

macrodera (Podochela), I5.

macropa (Boscia), zro.

macropa (Psendothelphusa), 2 Io.

Macrope, 10.

Macrophthalmide, 254.

Nacropodiens, 9, 17 .

Nacroura, 422.

Macroura astacina, $43 \mathrm{~S}$.

Nacroures, 422.

Nacrura, 422 .

maculatus (Carpilius), I20.

maculatus (Chlorodius), I48.

maculatus (Grapsus), 280.

maculatus (I'agurus), 2 So.

maculatus (l'hymodius), I 48.

magna (I'seudothelphusa), 2 I 7.

magnifica (I'etrolisthes), 393.

magnifica (Porcellana), 393.

Naia, 43, 49, 5I, IOS.

Maia I'isa, 67.

Maiens cryptophthalmes, $49,5 \mathrm{~S}$.

Maiens phanerophthalmes, 38 .

Maiidie, $4 \mathrm{~S}$.

Maiime, 49.

Maiinea, 6.

Mizioidea, 5.

majou (Callianassa), 425.

major (Nautilograpsus), 286.

Nango crab, 239.

Nantis marina larbadensis, 500 . maracuani (Gelasimus). 270, 271.

maraconni (Gonoplax), 270.

maracoani (Ocypoda), 270.

margaritifions (Dilocarcinus), $23 \mathrm{I}$.

marginatus (Anapagurus), 373.

marginatus (Grapsus), 283.

marginatus (F'ctrolisthes), 394. 
marinis scutiformis (Cancer), I79. mamoratia (Calappa), 304.

Matutidxe, 306. maxillipes (I'seudothelphusa), 2 IS. maximus bahamensi (Cancellus), 366 . Mechells, I23.

Ne.galobranchium, 397.

Menippe. I 52.

mercenaria (Menippe), I 53 .

mercenarius (Cancer), I 53 .

nercenarius (I'seuducarcinus), 153.

Mesortura, II I.

Metagrapsus, $2 S 9$.

Netoporhaphis, I I.

Metopuraphis, I I.

Micropanope, i 3 S.

Microphrys, $7 \mathrm{I}$.

microphthalma (.Imita), fo5.

Nicropisa, 49.

Microrhynchinte, $4 \frac{4}{4}$.

miersii (I'ilumnu-), I60.

miles (Nunida), 403.

Milnea, $7 \mathrm{I}$.

miniata (Fesarma), 292.

miniatus (Cancer), I24.

minutus (Cancer), 286.

mintutus (Mithrax), 94.

minutus (Nautilosrapsus), 286.

minutus (I'lanes), 256.

Mithracine, 8 I.

Nithraculus, $8_{3}, 8_{7}$.

Mithrax, 49, $S_{j}, 87$.

Mixtopagurus, $3 S_{7}$.

modesta (Amathia), 33 .

modesta (Anamathia), 33 .

Monocarpilea, 470 .

montana (l'seudothelphusa), 214.

montezume (1)ithynis), 456 .

montezume (l'alemon), 486.

mordax (Gelasimus), 272.

Mountain cral, 239.

multidentatus (Dilocarcinus), 234 .

Munida, 40I.

Munislopsis, 406.

muricatus compressum (Cancer), 44 .

Myctirin.e, 299.

Myropsis, 3 I 4 .

matator (Palimon), 482.

nattereri (Bithynis), 187.

nattereri (l'al:mon), 487 .

Ninutilograpsus, $2 S_{5}$.

Neleus, I69.

Nematocarcinide, 49 I.

Nematocarcinus. $49 \mathrm{I}$.

Nemausa, $\mathrm{S}_{3}, \mathrm{~S} 6$.

Nephropsis, 445 .

Neptunes anguliaites, 177.
Neptunes arpues, I75.

Neptunus, 173, I75, I $\$ 5$.

Nililia, 34 .

nicaraguensis (Potamucarcinus), 222.

nigerrimus (Cancer), 142.

Niliclite, 457 .

nitida (Cyclodorippe), 322.

ntiida (Mlunidopsis), 409.

nitidus (Callinectes), is6, I90.

nitidus (Diptychus), 420.

nitidus (Euryplax), 257.

nitidus (Lanbrus), IO7.

nitidus (Orophorhynchus), 409.

nitidus (I'isolambrus), ro7.

nitidus (Raninoides), $3+3$.

nitidus (Uroptychus), 420.

nobilii (I'seutothelphusa), 2 I 5.

nobilis (Glyphocrangon), 459.

nodosir (Actica), I 27.

Non uca una, 250.

Normalia, 42S, 449,455 .

Notostomus, 493.

nudifrons (I'ilumnus), Iб 6 .

nudipes (T'ericera), 75 .

nudus (Mitluraculus), 97.

nudus (Mithrax), 97.

obessar (Cymopolia), 327.

obessum (Cardiosoma), 245.

oltusus (Inachoides), 22.

occidentalis (Callianassa), 425.

occidentalis (Charimus), 426.

occirlentalis (Etisus), I 46.

occidentalis (Geosrapsus) 282 .

wccidentalis (Panupens), I32, I34.

ocellatus (I'latyonychus), I 99.

ocellatus (I'scudocarcinus). I 53 .

Ocypota, 243, 254, 265, 268 .

Ocyporliacere, 254 .

Ocypodide, 200, 254.

Ocyporlien<, 254, 264 .

Ocypodine, 264.

Opisthocera, 223 .

Oplophorus, 477.

Orbiculata, 299.

ordwayi (Neptunus), ISo.

ornatum (Callinecter), IS6, ISS.

ornates (Grapsus), 2 So.

(Jophoshychus, 406, 413 .

Grtherrapsus, 2SI.

oryx (Ileterocarpus), 469.

Osachela, 309 .

Ostraconotus, $37 \mathrm{I}$.

othonia, $7 \mathrm{~s}$.

()honine, $7 S$.

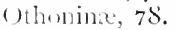

oratil (I)icranodronia), 338 .

oxyophthalma (Albunea) 35 I. 
Oxyrhinques, 5 .

Oxyrhyncha, 5 .

Oxyrhynchi, 5 .

Oxystomata, 299.

Oxystomes, 299.

Ozius, 15 I.

Pachygrapsus, $2 \mathrm{~S}_{3}$.

Pachysona, 289.

Paguridie, 359.

Paguridea, 353, 356 .

Paguriens, 356.

Pagurina, 359.

Paguristes, 376 .

Pagurodea, 356 .

Paguroilie, 353.

laguroidea, 356 .

Pagurus, 361, 364 .

Paliemon, $48 \mathrm{I}$.

Paliemonidie, 479.

Palemon, $45 \mathrm{I}, 4 S_{1}, 4 S_{3}$.

l'alemoniens, 479 .

Palinuride, +33 .

I'alinurus, 434,435 .

palustris (Gelasimus), 272.

Pandalidie, 467 .

landalus, 469 .

panope (Cancer), I 32.

Panopelts, 131, I 36, I 4 \%.

Panulirus, 435 .

Parapaguridie, $3 S_{4}$.

Parapagurus, $3 \$ 5$.

paraclosa (Homolodronia), 339.

pararloxus (Mixtopagurus), 387.

Parapilumnus, I5t.

Parastacus, 447.

parre (Ilaccus), 430 .

parre (Ibacus), 430.

Parthenope, ros.

Parthenopidit, 99.

Parthenopine, Ioo.

l'arthenopinea, 99.

parvula (Lipa), 186.

parvulus (Cancer), 137.

parrulus (Eurypanopets); 137.

parrulus (Xantho), 137.

P'asiphridie, 496.

pectinatum (Samatiun), 280.

pectinatus (Netagrapsus), 280 .

pelagica (Lupa), I 76.

pelagicus (Grapsus), 286.

pelagicus (Portunus), I 76 , ISz.

pelli (Grapsus), $27 \mathrm{~S}$.

Pelocarcints, 242.

l'encidie, 4.19.

Penielis, 45I.

Pentacheles, $44 \mathrm{I}$.

I'ericera, 67, 71, 74. l'ericeride, 5 s.

Pericerinu, 59.

I'erinea, 71.

Persephona, 3 I 7 .

peromatus (Grapsus), $2 S_{3}$.

peruviana (1'seudothelplusa), 220.

petersii (Aniculus), 365 .

petersii (l'agurus), 365 .

petiverii (Acanthonyx), 44.

Petrolisthes, 392.

pharaonis (Grapsus), zSo.

lhlyxia, 3 I 6 .

lhoberus, $44+$.

Phyllobranchiata, 455.

Phymodius, Its.

pictus (Dilocarcinus), 233.

pictus (Grapsus), $2 \mathrm{So}, 2 \mathrm{~S}_{3}$.

pictus (Sympagurus), jSr.

pilimanus (Eupagurus), $3 \mathrm{SI}$.

pilimanus (Sympagurus), 3 SI.

pilosimanus (T'arapagurus), 386 .

Pilummus, I 54 .

pinima (Arata), 294.

l'innotheridte, $29 S$.

J'innotheriens, $20 \mathrm{~S}$.

I'innotherine, 299.

l'isit, $36,51,65$.

Jisiclia, 395 .

l'isolambrus, 106.

pisoni (Aratus), 294.

pisoni (Sesarma), 294.

l'isonoma, 395 .

l'itho, $7 S$.

pittieri ('semolothelphusa), 2 I9.

I'logusia, 295 .

l'lagusiines, 295.

l'lagusine, 295.

plana (l'seudothelphusa), 2 I I.

planatus (Geocarcinus), $24 \mathrm{I}$.

planatus (J'aguristen), 379. .

Planes, $2 S_{5}$.

planifrons (Crapstis), $2 S_{3}$.

platydactylus (Gelasimus), $27 \mathrm{I}$.

Platylambrus, 102.

Platyonychidic, 170.

Platyonychus, IgS.

l'attyryonchus, 47 .

pleocanthus (benthesicymu), 455 .

pleuracanthus (Mithras), 92.

pleuriticus (Callinectes), IS6, I90.

l'odochela, I2, I4.

liedonema, I2, 16.

p'edepluthatmix, $\mathbf{I}$.

Porlophthalmata, I.

l'odophthalmix, I.

Ioctephthatmiens, $\mathbf{I}$.

polita (Porcellana), 393.

politus (l'ctrolisthes), 393. 
Polybiens, 196.

Polycarpidea, 456 .

Polycheles, 440 .

Pontus, 173.

Porcellana, 395 .

Porcellanirle, $39 \mathrm{I}$.

Porcellanidea, $39 \mathrm{I}$.

Porcellaniens, $39 \mathrm{I}$.

Porcellanodea, 39 I.

Portunicle, I7o.

Portuniens, I 70.

Portmiens normaux, I 70.

Portmine, 170.

l'ortunus, I 85 , I95. 197.

Potania, 206.

l'otamocarcinidx, 204 .

Potamocarcints, 206, 221.

Potamonidx, 202.

pourtalesii (Lambrus), IO3.

prxlonga (P'isa), 53 .

princeps (Cancer), 308.

princeps (Gelasimus), $27 \mathrm{I}$.

l'seudocarcinus, I52.

Pseudosquilla, 500.

Pseudothelplusisa, 206.

Psendothelphusidie, 204 .

Pseudothelphusine, 204.

Ptychogaster, $4 \mathrm{I} 8$.

pucillus (Grapsus), 2 S6.

pucillus (Ocypoda), 286.

puella (Thoe), $s_{3}$.

pugillator (Gelasimus). 272, 274 .

pugillator (Micropanope), I 40.

pugillator (Ocypoda), 274 .

pugnax (Gelasimus), 272.

punctata (Guaia), 319.

punctata (Llia), 312.

punctata (Leucosia), $3 \mathbf{I} 2$.

punctata (I'ersephona), 319.

punctatus (Cancer), 312, 319.

purpurea (Pisa), 73.

lylocheles, $387,3 S S$.

I'ylopagurus, 367 .

quadrata (Ocypoda), 267.

quadratus (Cancer), 267.

quadratus (Cymonomus), 324.

quadratus (Trichodactylus), 229.

quadratum (Cardiosona), 246.

Quachilatera, 200.

quinquedentatus(Trichodactylus), 22S. quinquespinosa (Nyropsis), 314.

quey:i (I'ilumnus), I 59.

Raninicle, 342.

kaninidea, 341 .

Raniniens, $3+\mathrm{I}$.

Raninoidea, $34 \mathrm{I}$.
Raninoides, 342.

rastellifere (Euprognatha), 27.

Rathlunia, 226.

rectus (Xylopagurus), $3 S_{4}$.

reflexifrons (P'seudothelphusa), 2 Io.

regulosus (Grapsus), $2 \mathrm{~S}_{5}$.

regulosus (Leptograpsus), $2 S_{4}$.

reisei (Coryrhynchus), I6.

reisei (I'isosoma), 395 .

reisei (Podochela), I6.

reisei (Podonema), I6.

Remipes, 347.

repax (Gelasimus), 272.

reticulata (Lagostoma), I 52.

reticulata (Sesarma), 291.

reticulatus (Grapsus), $29 \mathbf{I}$.

reticulatus (Ozius), I 52 .

reticulatus ('ilumnus), I62.

Rhinolambrns, 102.

Khodia, 49.

rhombea (Ocypoda), 267.

Rhombille, 269.

rhomboidea (Libinia), 63.

richmondi (Psendothelphusa), 2 IS.

robertsoni (Porcellana), 396.

robusta (Munidopsis), 4 I 1 .

robustus (Callinectes), IS6, IS9.

robustus (Galathorles), 4 Ir.

rosaceus (l'ylopagurus), 370.

rosica (Frevillea), 26I.

rosea (Astacus), 445 .

rosea (Nephropsis), 445.

rostrata (Mithrax), $S_{7}$.

rostrata (Nemausa), $\$ \mathbf{7}$.

rostratus (Iomolopsis), 34 I.

ruber (Achelous), 195.

ruber (Cronius), 195.

ruber (Lupea), 195.

ruber (Portunus), I95.

ruber (Nithraculus), $9 \mathrm{~S}$.

ruber (Mithrax), gS.

rubropunctatus (Tomopagurus), $3 \mathrm{~S} 2$.

rufopunctata (Actea), I27.

rugosus (Diptycluus), $42 \mathrm{I}$.

rugosus (U roptychus), $42 \mathrm{I}$.

ruricola (Cancer), 239.

ruricola (Geocarcinus), 239.

ruricola (Goniopsis), $27 \mathrm{~S}$.

ruricola (Ocypoda), $239,246$.

sabulosa (Hypoconcha), 336 .

sabulosus (Cancer), 336 .

sagittaria (Leptopodia), I I.

sagittarius (Inachus), II.

sapidus acutidens (Callinectes), I9I.

sapidus (Callinectes), I $\$ 7$.

Sarmatium, 289.

savignyi (Brachycarpus), 490. 
sayi (Lupa), г76.

sayi (Neptunus), I 76.

sayi (Paguristes), 378.

scabra (Atya), 473.

ecabricanda (Squilla), 502.

Schizophrysinæ, 56 .

schomburgkii (Potamocarcinus), 222.

Scissor crab, 270.

sculpta (Maia), 94.

sculptipes (Micropanope), I 39.

sculptus (Mithraculus), 94.

sculptus (Mithrax), 94, 98 .

scutellata (Albunea), $35^{2}$.

scutellata (Hippa), 348.

scutellata (Lepidopa), 352.

scutellata (Lepidops) 352.

scutellatus (Remipes), 348 .

Scyllaridæe, 429.

Scyllarus, 430, 43r, 432.

Scyra, 64 .

Sea cockroach, 348 .

sebæ (Lupa), I 79.

sebæ (Neptunus), I79.

serrata (Thelphusa), 209.

serratifrons (Galathodes), 4 IO.

serratifrons (Munidopsis), 410.

serratorbita (Leptochela), 497.

serratus (Lambrus), 105.

serratus (Panopeus), I32, 135.

serratus (Platylambrus), I05.

serratus (Stylodactylus), 496.

Sesarma, 289, 293.

Sesarmine, 275, 288.

Sesarmini, 288.

seticornis (Cancer), I I .

setiger (Actrea), $\mathbf{2} 26$.

setiger (Xantho), I26.

setigera (Actrea), I 26 .

sexdentata (Othonia), So.

sharreri (Catapagurus), 375.

Sherigo crab, I 85.

sica (Cymopolia), 326.

Sicyonia. 452.

sigsbei (Frevillea), 262.

sigsbei (Galathodes), 407

sigsbei (Munidopsis), 407.

simplex (Galathodes), 408.

simplex (Munidopsis), 4o8.

simplex (Temnonotus), 58 .

sinuatifrons (Epilobocera), 226.

Sisyphus, 54.

smithii (Nautilograpsus), 286.

socialis (Catapagurus), 375.

socialis (Hemipagurus), 375.

socius (Pachygrapsus), 284.

Solenolambrus, Iog.

spatulifrons (Podochela), I7.

spatulipes (Ostraconotus), 37 I.
Speocarcinus, 257.

Sphenocarcinus, 66.

spinicarpus (Achelous), I S4.

spinicarpus (Neptunus), I 84.

spinicauda (Glyphocrangon), 458.

spinicincta (Maia), 90.

spinicinctus (Mithrax), 90.

spinifer (Dilocarcinus), 234.

spinifer (Galathodes), $4 \mathbf{I} \mathbf{2}$.

spinifer (Munidopsis), 4I 2.

spinifer (Ptychogaster), 4I 8 .

spinifrons (Dilocarcinus), 232.

spinimana (Lupa), I 82 .

spinimanus (Achelous), I82.

spinimanus (Bithynis), 489.

spinimanus (Cancer), I 24.

spinimanus (Medæus), I24.

spinimanus (Neptunus), I 82.

spinimanus (Palemon), 489.

spinimanus (Portunus), I82.

spinipes (Paguristes), 377.

spinoculata (Munidopsis), 409.

spinoculatus (Orophorhynchus), 409.

spinosa (Galacantha), 4 I 7 .

spinosissima (Maia), 88.

spinosissima(Pericera), 70.

spinosissimus (Mithrax), 88.

spinosus (Cancer), ro\&.

spinosus (Orophorhynchus), 409.

spinosus (Pentacheles), 442.

Spiropagurus, 372.

Sponge crab, 333 .

squamosus (Cancer), 296.

squamosus (Elasmonotus), 414.

squamosus (Scyllarus) 432.

squamosus (Orophorhynchus), 4I4.

Squilla, 347, 501 .

Squillad $x, 498$.

Squilliens, 498.

Stenocionopinx, $4^{6}$.

Stenopidx, 447.

Stenopidea, 447

Stenopus, $4+7$.

Stemorynque, Io.

stimpsonii (Ebalia), j I 7 .

stimpsonii (Munida), 405

Stomapoila, 497.

Stomapodes, 497.

Stomatopoda, 497.

striatus (Pagurus), 365.

strigillatus (Grapsus), $28_{3}$.

strigosus (Grapsus), 280.

strigosus (Pagurus), 365 .

stylifera (I'seudosquilla), 500.

Stylodactylidie, 495 .

Stylodactylus, 495.

subglobosa (Iliacantha), 3 I 3 .

subparalleta (Macrocoloma), 76 . 
subparallela (I'ericera), 76 . sulcatus (Calcinus), 362. salcatus (Neptunus), I79. sulcatus (Pagurus), 362. sulcifrons (P'seudothelphusa), 2 I 6. Sylviocarcinus, 230. symmita (Albunea), 35I.

Sympagurus, 379.

Synaxidea, 428.

talpoidea (Hippa), 349.

taurus (Maia), 69.

Teleophrys, $8_{3}, 87$.

Temnonotus, 56 .

tenuipes (Pseudothelphusa), 209.

terrestris (Cancer), 239.

terrestris (Pseudothelphusa), 2 I 3 .

testudineum (Grapsus), 296.

Tetrogonostoma, 3 .

Thaumastocheles, 427 .

Thammastochelidxe, 426.

Thelphuside, 202.

Thelphusiens, 202.

Thoe, $8 \mathbf{2}$.

tibicen (Calcinus), 362.

tibicen (Pagurus), 362.

Tomopagurus, $3 \mathbf{S 2}$.

toxotes (Callinectes), I 86, I 89.

Trachymaia, 29.

transversus (Pachygrapsus), 283.

triangulatus (Paguristes), 378 .

Trichobranchiata, 422.

Trichodactylinx, 227.

Trichodactylus, 227, 228 .

tridens (Galathodes), 413 .

tridens (Munidopsis), $4 \mathrm{I} 3$.

tridentata (Frevillea), 262.

tridentatus (Petrolisthes), 394.

Trigonostoma, 3 .

trilobatus (Eryon), 344.

trispinosa (Macrocreloma), 75.

trispinosa (Pericera). 75.

trispinosa (Pisa), 75.

tristani (Pseudothelphusa), 2 I 4.

trituberculatus (Platyrhynchus), 47.

Tropiocaride, 492.

tuberculata (Plagusia), 296.

tuberculata (Pseudothelphusa), 2 I 7.

tuberculatus (Hepatus), 308.

tuberculosus (Calcinus). 362 .

tuberculosus (Pagurus), 362.

tuberosa (Osachela), 309.

tumidus (Callinectes), I\$6, I\$9. tumimanus (I'seudothelphusa), 2 I4.

Tyche, 47.

typhlus (Bathyplax), 263.

typicus (Solenolambrus), I Io.

Uca, 248, 268.

uca (Cancer), 250, 252.

uca (Gecarcinus), $25^{2}$.

uca (Una), 252.

uka (Cancer). 27I.

umbonata (Scyra), 64.

uncifer (Diptychus), $42 \mathrm{I}$.

uncifer (Uroptychus), $42 \mathrm{I}$.

Uroptychus, 4 I 9.

urvillei (Cardiosoma), 245.

validus (Pentacheles), 443.

variegatus (Cancer), 283.

variegatus (Grapsus), 283 .

variegatus (Leptograpsus), 283 .

ventralis (Neptunus), 178.

venusta (Lepidopa), 353.

venusta (Lepidops), 353 .

venustus (Cancer), I22.

Verbius, 465 .

verreauxi (Leptograpsus), $28_{3}$.

verrucosus (Mithrax), 93 .

verticalis (Pseudothelphusa) 213.

vigil (Homola), 340.

vilpini (Pericera). 76 .

vinaceus (Pilumnus), 157.

visor (Paguristes), 377 .

vittata (Squilla), 501.

vocans (Gelasimus), 272, 274.

vocator (Gelasimus), 272.

webbi (Grapsus), 280 .

websteri (Eupilumnus), I 7 O.

weddellii (Microphrys), 72.

White crab, 246.

xanthiformis (Panopeus), I 35 .

Xantho, I25, I28, I29.

Xanthodes, I 29.

Nanthodius, I 44, 147.

xantusi (Pseudothelphusa) 208.

Xiphus, 2 I.

Xylopagurus, 383 .

zaleucus (Astacus), 427.

zalenca (Thaumastocheles), 427.

Zanclifer, 343.

Zosymus, 125, I4I. 



